\title{
Caracterización molecular y funcional del gen Pathogen and Circadian Controlled 1 (PCC1) en Arabidopsis thaliana
}

Memoria realizada por

Ricardo Mir Moreno

Dirigida por

Dr. José León Ramos

UNIVERSIDAD POLITÉCNICA DE VALENCIA

Departamento de Biotecnología

Valencia, abril 2013 

El Dr. José León Ramos, doctor en Ciencias Biológicas y Científico Titular del Consejo Superior de Investigaciones científicas (CSIC).

\section{CERTIFICA:}

Que la presente memoria titulada “Caracterización molecular y funcional del gen Pathogen and Circadian Controlled 1 (PCC1) en Arabidopsis thaliana”, ha sido realizada por Ricardo Mir Moreno bajo mi dirección y constituye su Memoria de Tesis para optar al grado de Doctor en Biotecnología.

Para que así conste a todos los efectos oportunos, firma el presente certificado en Valencia, abril del 2013

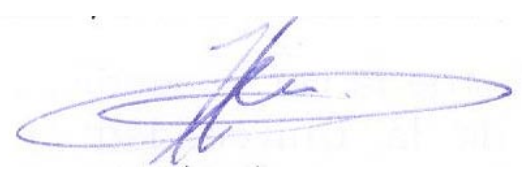

Dr. José León Ramos 

$A$ mis padres 

Resumen 

Las plantas son capaces de modificar los patrones de desarrollo tras percibir ciertos tipos de estrés. En Arabidopsis, se identificó PCC1 como un regulador positivo de la transición floral en respuesta al estrés generado por irradiación con luz UV-C. El análisis de plantas transgénicas $p P C C 1:: G U S$ muestra que $P C C 1$ se expresa durante los primeros días de desarrollo en estomas y haces vasculares de cotiledones. En hojas verdaderas en formación se detecta tinción GUS en su parte basal, incluyendo los haces vasculares, y se va extendiendo completamente a toda la superficie de hojas completamente formadas. Líneas que expresan construcciones de RNAi para PCC1 (iPCC1) presentan reducidos niveles de $F T$ y, consecuentemente, una floración más tardía. El mecanismo por el cual PCC1 podría regular la transición floral parece estar relacionado con alteraciones en la transmisión de la señal por luz. Concomitantemente, las plantas iPCC1 muestran fenotipos parcialmente escotomorfogénicos en los distintos tipos de luz ensayados de forma independiente de la acumulación y señalización de GAs. El transcriptoma diferencial de plantas iPCC1 versus plantas silvestres muestra una clara implicación de PCC1 en procesos relacionados con defensa. De acuerdo con este hecho, hemos observado que las plantas iPCC1 son más susceptibles a la infección con el oomiceto hemi-biotrofo Phytophtora brassicae y más resistentes al hongo necrotrofo Botrytis cinerea. Además, las líneas iPCC1 presentan una regulación al alza de genes de respuesta a ABA, y una mayor sensibilidad a esta fitohormona para los distintos fenotipos analizados. Finalmente, entre los genes alterados en las líneas iPCC1 se observa una sobrerepresentación de genes implicados en el metabolismo y en el transporte de lípidos. La pérdida de función de $P C C 1$ conlleva una reducción del 70\% en los niveles de fosfatidilinositol, y en menor medida de otros tipos de lípidos polares como la fosfatidilserina o la fosfatidilcolina. Además, el análisis de la composición de ácidos grasos de cada tipo de lípidos polares revela un mayor grado de insaturación de sus cadenas laterales, fundamentalmente en la fosfatidilserina y el fosfatidilinositol. PCC1 es una proteína asociada a la membrana plasmática por su extremo carboxiterminal, el cual es responsable además de la formación de homodímeros. Aunque queda por dilucidiar los mecanismos por los cuales PCC1 puede regular procesos tan dispares molecularmente como la respuesta a patógenos y la transición floral, hemos observado que PCC1 interacciona con la subunidad CSN5 del signalosoma (CSN), lo que sugiere que PCC1 podría actuar como un regulador de la función de CSN, y en última instancia, de la degradación de proteínas por ubiquitinación. 

Les plantes poden modificar els patrons de desenvolupament després de percebre certs tipus d'estrés. En Arabidopsis, es va identificar PCC1 com a un regulador positiu de la transició floral en resposta a l'estrés generat per irradiació amb llum UV-C. L'anàlisi de plantes transgèniques $p P C C 1:: G U S$ mostra que $P C C 1$ s'expressa durant els primers dies de desenvolupament a estomes $\mathrm{i}$ als feixos vasculars de cotiledons. En fulles veritables en formació es detecta tinció GUS a la seua part basal, inclossos els fiexos vasculars, i es va estenent completament a tota la superficie de les fulles completament formades. Plantes que sobreexpressen construccions de RNAi per a PCC1 (iPCC1) presenten reduïts nivells de $F T$ i, conseqüentment, una floració més tardana. El mecanisme pel qual PCC1 pot regular la transició floral pareix estar relacionat amb alteracions en la transmisió de la senyal per llum. Concomitantment, les plantes iPCC1 mostren fenotipus parcialment escotomorfogènics sota els diferents tipus de llum assajats de forma independent de la acumulació i senyalització de GAs. El transcriptoma diferencial de plantes iPCC1 versus plantes silvestres mostra una clara implicació de PCC1 en processos relacionats amb defensa. D'acord amb aquest fet, hem observat que les plantes iPCC1 són més susceptibles a la infecció amb l'oomicet hemibiotròfic Phytophtora brassicae i més resistents al fong necrotròfic Botrytis cinerea. A més, les plantes iPCC1 presenten una regulació a l'alça de gens de resposta a ABA, i una major sensibilitat a aquesta fitohormona per als diferents fenotipus analitzats. Finalment, entre els gens alterats a les plantes iPCC1 s'observa una sobrerepresentació de gens implicats en el metabolisme i el transport de lípids. La pèrdua de funció de PCC1 implica una reducció del 70\% dels nivells de fosfatidilinositol, i en menor mesura d'altres lípids polars com ara la fosfatidilserina o la fosfatidilcolina. A més, l'anàlisi de la composició d'àcids greixossos de cada tipus de lípids polars revela un major grau d'insaturació de les seues cadenes laterals, fonamentalment en la fosfatidilserina i el fosfatidilinositol. PCC1 és una proteïna associada a la membrana plasmàtica pel seu extrem carboxi-terminal, el qual és a més responsable de la formació d'homodímers. Encara que queda per elucidar els mecanismes mijançant els quals PCC1 pot regular processos tan dispars molecularment com ara la resposta a patògens i la trancisió floral, hem observat que PCC1 interacciona amb la subunitat CSN5 del signalosoma (CSN), el que sugereix que PCC1 podria actuar com un regulador de la funció de CSN, i en última instància, de la degradació de proteïnes per ubiquitinació. 

Plants are able to modify their development patterns in response to some kinds of stress. In Arabidopsis, PCC1 has been identify as a positive regulator of floral transition in response to the strees generated by UV-C irradiation. The analysis of transgenic $p P C C 1:: G U S$ plants show that $P C C 1$ is expressed during the very early development in stomata and the vasculature of cotiledons. In true leaves under formation GUS staining can be detected in their basal region, including vasculature, and it can be detected on the complete surface of true completely formed leaves. Arabidopsis lines expressing RNAi contructions specific for PCC1 (iPCC1) show reduced levels of FT and, consequently, a delayed flowering time. The mechanism by which PCC1 could regulate flowering transition seems to be related to light signal transmition. Concomitantly, iPCC1 plants show partial scotomorphogenic phenotypes under the different qualities of light assayed, in a GA accumulation and signaling independent way. The diferential transcriptome of iPCC1 plants versus wild type plants show a clear role of PCC1 in defense-related proceses. Accordingly, we have observed that iPCC1 plants are more susceptible to the hemi-biotrof oomycete Phytophtora brassicae and more resistant to the necrotrof fungus Botrytis cinerea. Moreover, iPCC1 lines showed an upregulation of ABA-responsive genes, and a hypersensitivity to this phytohormone for the different phenotypes analyzed. Finally, among the altered genes in iPCC1 lines we have observed an overrepresentation of genes implied in lipid metabolism and transport. Lose of function of $P C C 1$ entail a reduction of $70 \%$ in the levels of phosphatidylinositol, and, in a lesser extent, of some other class of polar lipids such as phosphatidylserine and phosphatidylcoline. Moreover, the analysis of fatty acid composition of each type of polar lipids shows a higher insaturation degree of their lateral chains, mostly in phosphatidylserine and phosphatidyinositol. PCC1 associates the the plasma membrane by its carboxi-terminal region, which is as well responsible of the homodimer formation. Although it is still unclear the mechanisms by which PCC1 regulates so molecularly different proceses such as pathogen responses and flowering transition, we have observed that PCC1 interacts with CSN5 subunit of the signalosome complex (CSN), what suggest that PCC1 could act as a CSN regulator, and ultimately as a regulator of protein ubiquitination. 

Índice 

Introducción

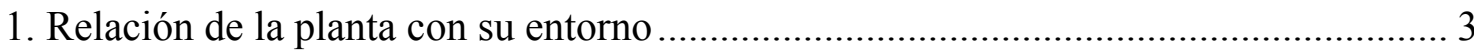

2. Identificación de Pathogen and Circadian Controlled 1 ............................................ 4

3. La transición floral en Arabidopsis thaliana ........................................................... 5

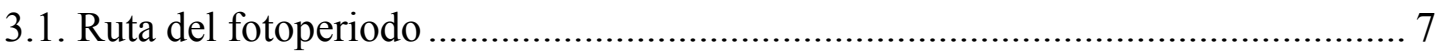

3.1.1. Percepción y transmisión del fotoperiodo en Arabidopsis .............................. 7

3.1.2. Función de CONSTANS-FLOWERING LOCUS T en la regulación de la transición floral por la ruta del fotoperiodo........................................................... 9

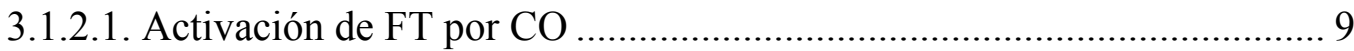

3.1.2.2. Función de FT en la activación de la transición floral .......................... 12

3.2. Otras rutas para la activación de la transición floral en Arabidopsis .................. 13

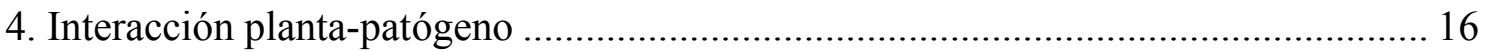

4.1. Respuesta de las plantas frente a patógenos ...................................................... 16

4.2. Señalización por SA en la defensa frente a patógenos ...................................... 19

4.3. Señalización lipídica en la respuesta frente a patógenos ................................... 21

4.3.1. Tipos y función de los lípidos en plantas ................................................ 21

4.3.2. Ácidos grasos y compuestos derivados ...................................................... 22

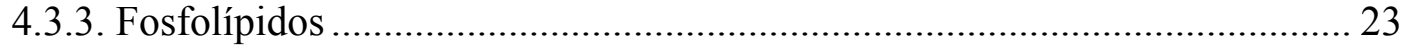

4.3.4. Señalización por el ácido jasmónico ……….............................................. 24

5. El signalosoma COP9 en Arabidopsis thaliana .......................................................... 25

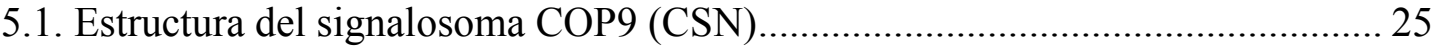

5.2. Función de CSN en la regulación de la degradación de proteínas ...................... 26

5.3. Función de CSN en la regulación transcripcional ............................................. 30

5.4. Función fisiológica de CSN en Arabidopsis ...................................................... 30

5.4.1. Función de CSN en el desarrollo de Arabidopsis......................................... 30

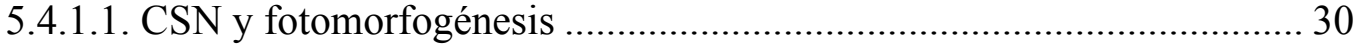

5.4.1.2. Otras alteraciones del desarrollo en plantas csn ................................ 31

5.4.2. Función relacionada con la respuesta a estrés biótico ............................... 32

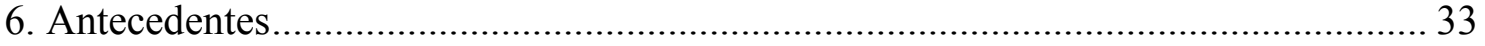

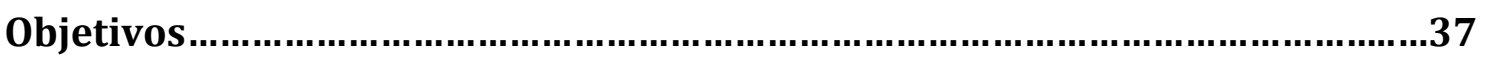


1. Análisis in silico de la proteína PCC1 y sus homólogos en Arabidopsis..... 43

1.1. Características generales de PCC1 43

1.2. Análisis de secuencia de genes homólogos a PCC1 en Arabidopsis 49

2. Patrón de expresión de $P C C 1$ 51

3. Localización celular de PCC1 55

3.1. Localización celular de PCC1 fusionada a GFP en plantas de Nicotiana transformadas transitoriamente y en plantas transgénicas de Arabidopsis. 55

3.2. La aplicación de SA altera la localización de PCC1 de Arabidopsis 61

3.3. Homodimerización de PCC1

3.4. El dominio CYSTM de PCC1 es el responsable de la homodimerización y del anclaje a la membrana plasmática 65

4. Función de PCC1 en la transición floral en Arabidopsis. 68

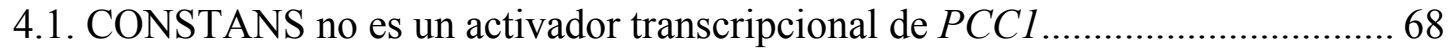

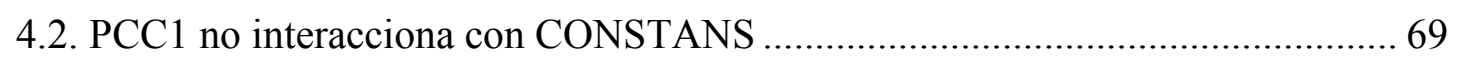

4.3. PCC1 no es necesario para la activación de FT por CO..................................... 70

4.4. La expresión de $P C C 1$ no depende de $\mathrm{CO}$...................................................... 71

4.5. Implicación de PCC1 en la transición floral dependiente de vernalización y de giberelinas.

4.6. El fenotipo de floración tardía en plantas iPCC1 podría estar relacionado con alteraciones en la señalización por luz........................................ 74

5. Interacción de PCC1 con otras proteínas de Arabidopsis.......................................... 77

5.1. Escrutinio de posibles interactores de PCC1 mediante doble híbrido en levadura

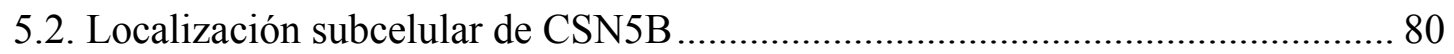

5.3. Confirmación de las interacciones PCC1 con CSN5A y CSN5B in planta ........ 80

5.4. Detección de formas rubiladas de CUL1 en líneas iPCC1 …............................. 82

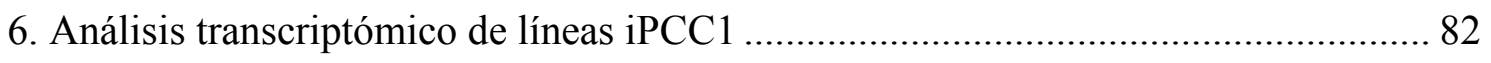

6.1. Categorías funcionales sobrerepresentadas en el análisis transcriptómico ..........83

6.2. Comprobación por RT-qPCR de los datos del análisis transcriptómico .............. 84

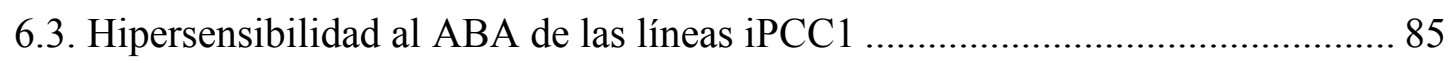


6.4. Alteración de la composición lipídica en líneas iPCC1

6.5. Fenotipos de defensa de líneas iPCC1 frente a distintos tipos de patógenos ...... 96

Discusión.....................................................................101

Conclusiones.........................................................................123

Materiales y métodos...........................................................127

1. Material biológico y condiciones de cultivo.......................................................... 129

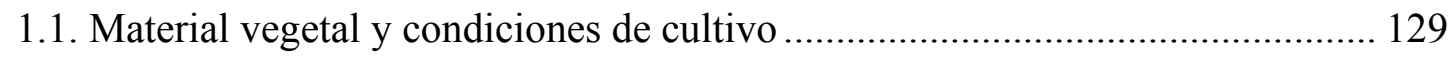

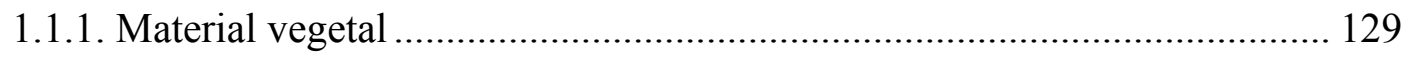

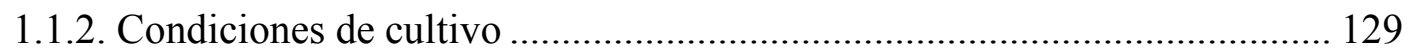

1.2. Material microbiológico: cepas utilizadas y condiciones de cultivo................. 130

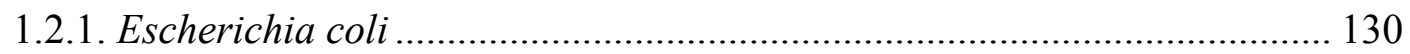

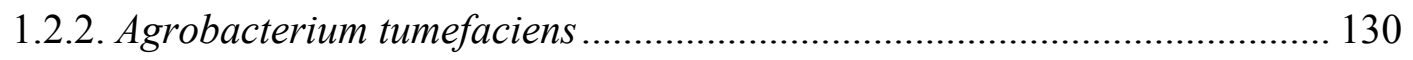

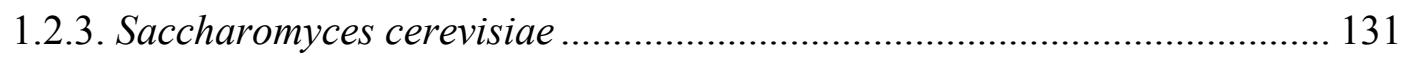

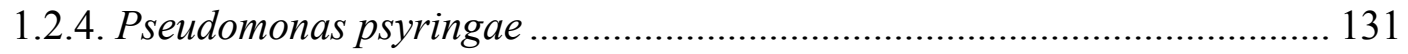

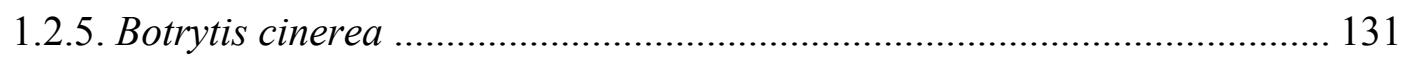

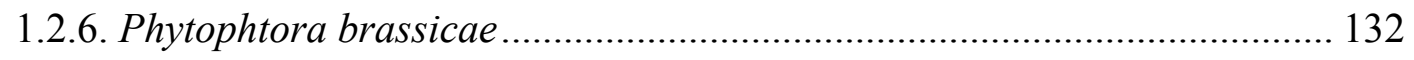

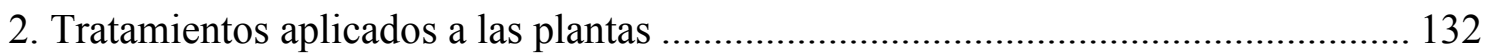

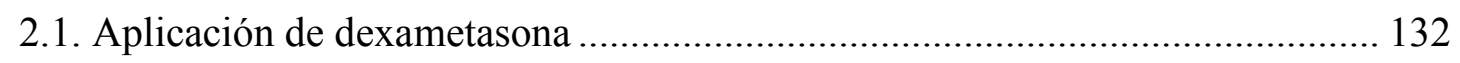

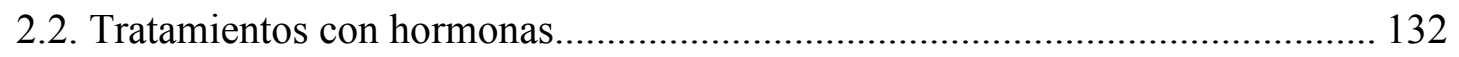

2.3. Infección con microorganismos patógenos …….............................................. 133

2.3.1. Infección con Pseudomonas syringae ................................................... 133

2.3.2. Infección con Botrytis cinerea .............................................................. 134

2.3.3. Infección con Phytophtora brassicae ..................................................... 134

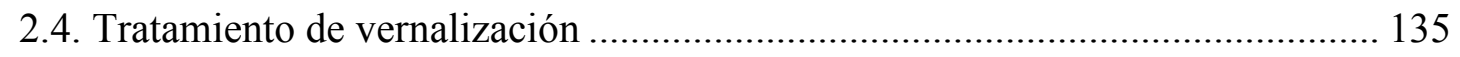

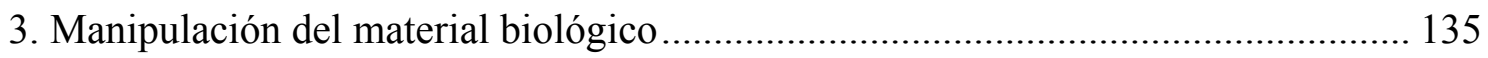

3.1. Generación de electro-competencia en células de $E$. coli y transformación

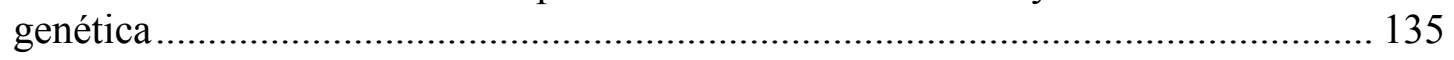

3.2. Generación de termo-competencia en células de A. tumefaciens y transformación

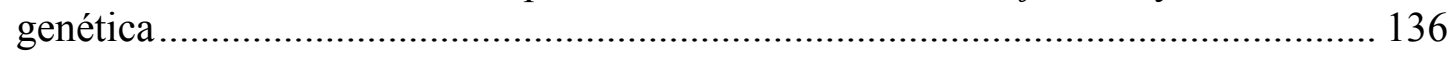

3.3. Generación de termo-competencia en células de $S$. cerivisiae y transformación genética. 
3.4. Transformación estable de plantas de Arabidopsis thaliana...

3.5. Transformación transitoria en plantas de Nicotiana benthamiana .................... 138

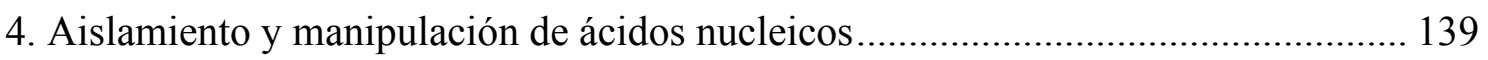

4.1. Extracción y purificación de ácidos nucleicos ................................................. 139

4.1.1. Extracción de ADN genómico de Arabidopsis ........................................ 139

4.1.2. Extracción de ARN de Arabidopsis............................................................ 139

4.1.3. Extracción de ARN para el análisis transcriptómico................................ 140

4.1.4. Extracción de ADN de bacteria ............................................................ 140

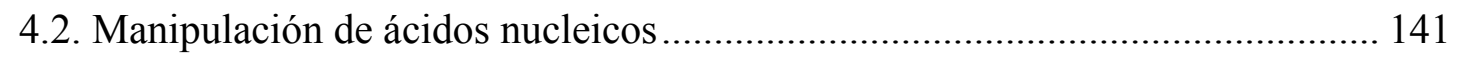

4.2.1. Amplificación de fragmentos específicos de ADN por PCR .................... 141

4.2.2. Purificación de bandas de ADN ................................................................ 143

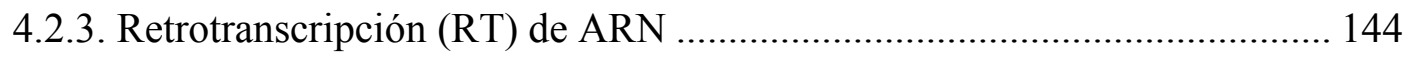

4.2.4. Cuantificación de transcritos por RT-qPCR ........................................... 144

4.2.5. Digestión de ADN con enzimas de restricción........................................ 145

4.2.6. Reacciones de fosforilación y defosforilación de fragmentos de ADN y

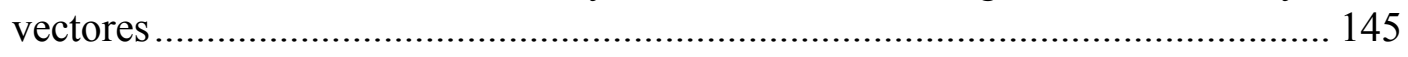

4.2.7. Ligación de fragmentos de PCR y plásmidos........................................... 146

4.2.7.1. Ligaciones convencionales .............................................................. 146

4.2.7.2. Ligaciones mediante el uso de tecnología Gateway ${ }^{\circledR}$........................ 147

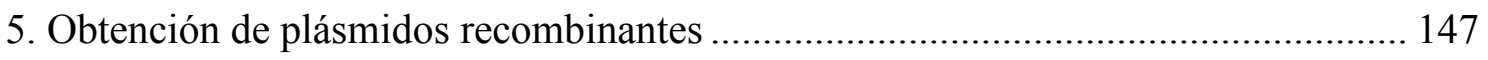

5.1. Generación de fusiones pPCC1::GUS ......................................................... 147

5.2. Generación de fusiones traduccionales de proteínas con distintas etiquetas para

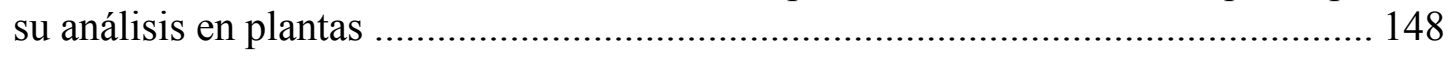

5.3. Generación de fusiones traduccionales de proteínas con distintas etiquetas para

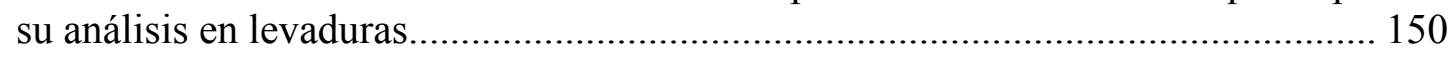

6. Analisis cuantitativo de ácidos grasos y lípidos polares ........................................ 150

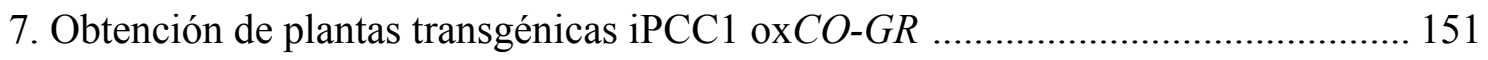

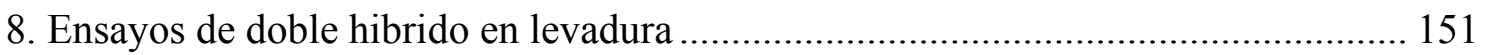

8.1. Comprobación directa de interacciones por doble híbrido en levadura ............ 151

8.2. Escrutinio por doble híbrido en levadura para la búsqueda de proteínas interactoras. 


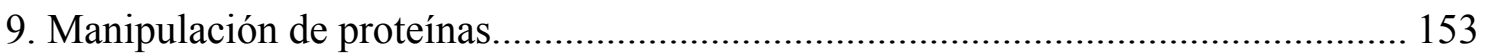

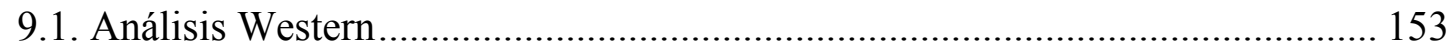

9.2. Inmunoprecipitación de proteínas con anticuerpos específicos ........................ 154

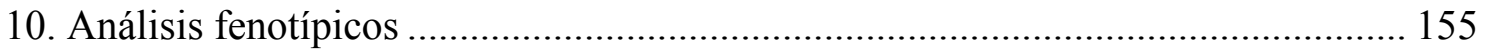

10.1. Medida de la longitud de hipocotilos ......................................................... 155

10.2. Ensayos de germinación y establecimiento de plántula .................................. 155

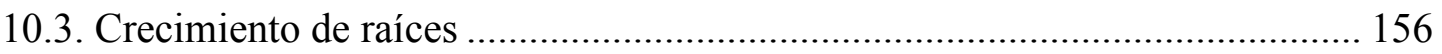

10.4. Medida del cierre estomático..................................................................... 156

10.5. Estimación de la pérdida de agua .............................................................. 156

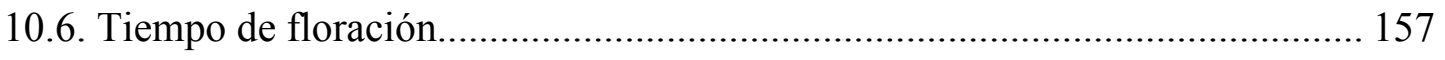

11. Obtención de protoplastos a partir de hojas de Nicotiana benthamiana ................. 157

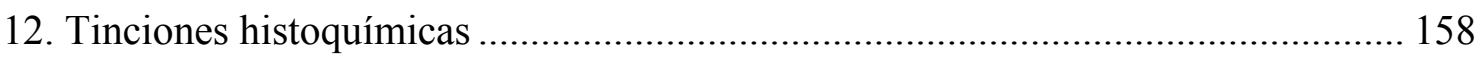

12.1. Tinción de actividad b-glucuronidasa (GUS) ............................................. 158

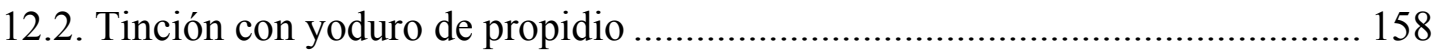

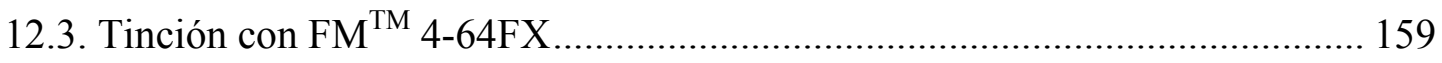

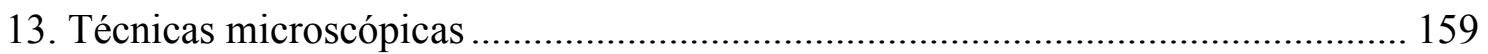

13.1. Toma de imágenes de plantas pPCC1 1180::GUS....................................... 159

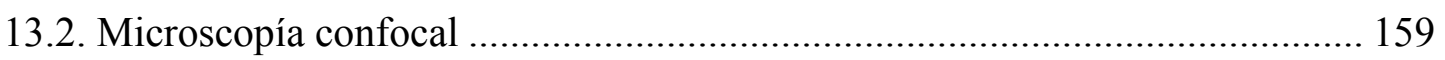

14. Aplicaciones bioinformáticas y bases de datos .................................................. 160

14.1. Herramientas básicas para el manejo de secuencias...................................... 160

14.2. Predicción de modificaciones secundarias de proteínas.................................. 161

14.3. Predicción de localización subcelular........................................................... 161

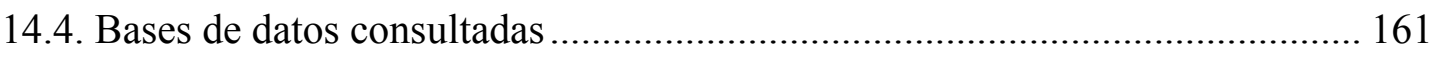

14.5. Herramientas utilizadas para el análisis de datos transcriptómicos................. 162

Bibliografía.....................................................................163

Agradecimientos................................................................193 

Introducción 

1. Relación de la planta con su entorno

El desarrollo de los organismos vivos engloba el conjunto de procesos relacionados con el crecimiento, consistente en procesos de división y elongación celular, así como con la diferenciación, que implica la especialización funcional de las células en el organismo en cuestión. Ambos procesos están finamente programados a nivel genético, si bien, factores relacionados con el ambiente en el que se desenvuelven los organismos vivos van a condicionar su desarrollo final. La plasticidad en el desarrollo tiene una importancia especial en los organismos vegetales por su incapacidad de desplazamiento, y supone una ventaja adaptativa para cada especie (Novoplanrky, 2002). La plasticidad de desarrollo o plasticidad fenotípica explica por qué un determinado genotipo puede manifestar distintos patrones de desarrollo o fenotipos en diferentes ambientes. En el caso concreto de las plantas, esta plasticidad fenotípica está marcada por factores de naturaleza abiótica, como luz, temperatura, disponibilidad de nutrientes o salinidad, entre otros, y factores de naturaleza biótica, como la interacción con microorganismos, el ataque de insectos, o heridas causadas por animales herbívoros. Estos factores ambientales, que en algunas ocasiones podrían considerarse factores de estrés, son percibidos por las plantas y traducidos ocasionalmente en una serie de modificaciones de los patrones de desarrollo como la elongación del tallo, la regulación del gravitropismo radicular, el momento de germinación, el tiempo de floración o el cese en la producción de biomasa (Palmer et al., 2012).

El desarrollo de organismos vegetales es un proceso continuo durante su ciclo vital, si bien en algunas especies puede verse ralentizado o incluso detenido bajo determinadas condiciones ambientales, como pueden ser las bajas temperaturas de invierno en especies de hoja caduca. El ciclo vital de las plantas comprende el período de tiempo desde la embriogénesis hasta la formación de semillas de la siguiente generación. En el caso de Arabidopsis thaliana, tras la germinación inicial de las semillas maduras, se generan plántulas con características de juvenilidad que se desarrollan de modo vegetativo hasta formar plantas adultas. En esta fase de desarrollo vegetativo las plantas de Arabidopsis producen hojas de roseta primaria y un sistema radicular, que formarán respectivamente las estructuras fotosintéticas de captación de energía e intercambio gaseoso, y el sistema de captación de nutrientes y de anclaje al suelo. En un momento dado, determinado por factores ambientales y endógenos de la planta, se producen señales moleculares que, al ser percibidas y transmitidas al meristemo apical del tallo (SAM; Shoot Apical Meristem), 
implican el cese de la formación de órganos vegetativos u hojas y la producción de órganos reproductivos o flores. A este proceso se le denomina transición floral, y a la fase de desarrollo en cuestión se la denomina fase reproductiva. Finalmente, y en el caso concreto de Arabidopsis, las flores se autopolinizarán y producirán semillas fértiles que darán lugar a plantas de la siguiente generación (Huijser y Schmid, 2011).

El proceso de transición floral está finamente regulado a nivel molecular e integra señales ambientales y endógenas. Esta regulación puede verse alterada por ciertos factores de estrés, tanto de tipo abiótico y biótico. La percepción por parte de la planta de estos factores de estrés provoca por lo general un adelanto del proceso de transición floral en detrimento de su biomasa y de su tasa reproductiva. Las semillas son estructuras vegetales más resistentes a las condiciones ambientales adversas, por lo que con esta producción prematura de semillas se asegura un mayor éxito para la perpetuación de la especie en el medio (Sultan, 2000). Las semillas, además, son capaces de percibir las condiciones ambientales y permanecer en estado latente hasta que éstas sean más propicias, tanto para se germinación como para el desarrollo de la futura planta (Daszkowska-Golec, 2011; Rajjou et al., 2012).

\section{Identificación de Pathogen and Circadian Controlled 1}

El estudio del estrés generado en plantas por irradiación con luz UV-C ha sido de especial interés por su estrecha relación con el estrés generado por la infección con determinados tipos de patógenos. Así, la infección por ciertos tipos de patógenos, al igual que sucede con la irradiación con luz UV-C, provoca en Arabidopsis una rápida síntesis de ácido salicílico (SA) y la activación de una ruta de señalización con numerosos intermediarios en común (Yalpani et al., 1994; Nawrath et al., 2002). Se ha descrito que la irradiación de plantas de Arabidopsis con luz UV-C provoca un adelanto del tiempo de floración dependiente de la síntesis y acumulación de SA (Martínez et al., 2004). Además, mutantes de síntesis de SA, así como plantas transgénicas portadoras del gen bacteriano $n a h G$, las cuales no acumulan SA por su degradación a catecol (Delaney et al., 1994), presentan fenotipos de floración más tardía que plantas silvestres (Martínez et al., 2004), por lo que se ha descrito al SA como un activador de la transición floral. 
Con el fin de identificar genes de Arabidopsis que puedan estar implicados en el adelanto de la floración por irradiación con luz UV-C de forma dependiente de SA, Segarra y colaboradores (2010) utilizaron una aproximación transcriptómica en la que compararon plantas deficientes en la biosíntesis, acumulación y señalización de SA con plantas silvestres durante la ventana temporal en la que ocurre la transición floral. De los genes alterados transcripcionalmente, se seleccionaron aquellos que respondían a la irradiación con luz UV-C en fondos silvestres y no en plantas $n a h G$ deficientes en la acumulación de SA. Así se identificó Pathogen and Circadian Controlled 1 (PCCl) como un gen regulado a la baja en plantas deficientes en SA que se activaba fuertemente en plantas silvestres irradiadas con luz UV-C pero no en plantas transgéncias nahG (Segarra et al., 2010). En este trabajo se generaron líneas de interferencia de ARN específicas para PCC1 (iPCC1) que presentaban fenotipos de floración tardía en ausencia de estrés, y que eran deficientes en el adelanto de la floración tras irradiarlas con luz UV-C (Segarra et al., 2010). Por esta razón $P C C 1$ se consideró un gen candidato a codificar un regulador de la floración tanto en condiciones control como en condiciones de estrés generado por la irradiación con luz UV-C. Por lo tanto, PCC1 se puede considerar como un potencial nodo de conexión entre procesos de desarrollo y respuestas a estrés en Arabidopsis.

\section{La transición floral en Arabidopsis thaliana}

El éxito reproductivo de las plantas depende directamente del momento en el que se produce la transición floral, es decir el momento en el que el meristemo apical del tallo deja de producir órganos vegetativos en favor de la producción de órganos reproductivos. Las plantas han desarrollado sistemas de percepción de estímulos ambientales que promueven la formación de órganos florales en el momento más apropiado para su establecimiento y posterior formación de semillas. Por otro lado, el estado endógeno de la planta también es importante para que se produzca la floración, ya que para ello la planta debe poseer, entre otras cosas, un sistema de captación energética apropiado. El proceso de transición floral ha sido bien estudiado a nivel molecular en Arabidopsis durante las últimas dos décadas, conociéndose actualmente un gran número de genes responsables así como el mecanismo de acción de muchas de las proteínas que codifican.

Se han descrito en Arabidopsis distintas rutas de floración dependientes del ambiente, como la ruta del fotoperiodo y la ruta de vernalización, y rutas dependientes del 
estado endógeno de la planta, como la ruta autónoma y la ruta de las giberelinas (Komeda, 2004) (Figura 1 a-e). Se ha descrito además una ruta termosensorial que depende de la temperatura ambiental y comparte genes con la ruta autónoma (Blázquez et al., 2003). Todas estas vías o rutas moleculares regulan la expresión de los llamados genes integradores de floración, como $\underline{F L O W E R I N G ~ L O C U S ~} \underline{T}$ (FT), $\underline{S} U P R E S S O R \underline{O F}$ $\underline{C O N S T A N S} 1$ (SOC1) y $\underline{F R U I T F U \underline{L}}$ (FUL) (Figura 1f), los cuales van a activar los genes de identidad de meristemo floral. La expresión de los genes de identidad de meristemo floral en los flancos del meristemo apical confieren identidad de flor al primordio lateral, es decir, el meristemo apical detendrá la formación de hojas en favor de la formación de órganos florales. Los principales genes de identidad de meristemo floral descritos son APETALA1 (AP1), LEAFY (LFY), CAULIFLOWER (CAL) y TERMINAL FLOWER 1 (TFL1) (Figura 1g). Mutaciones múltiples en genes centrales de las distintas rutas de floración provocan en Arabidopsis la incapacidad de florecer (Reeves y Coupland, 2001), mientras que mutaciones simples pueden retrasar la floración, pero ésta culmina finalmente por la actividad de las rutas de floración no alteradas (Koornneef et al., 1998, Simpson et al., 1999; Mouradov et al., 2002).

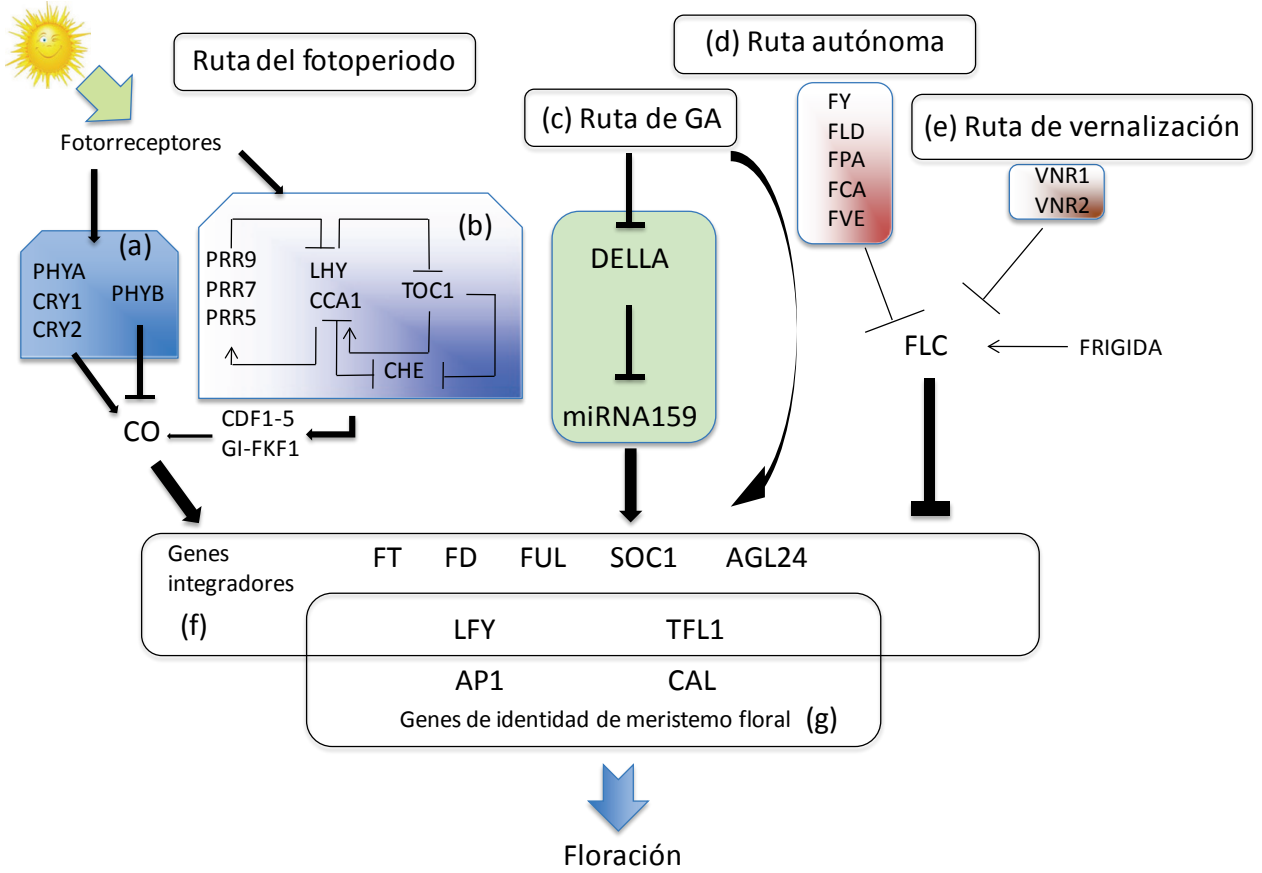

Figura 1. Rutas de activación de la transición floral en Arabidopsis thaliana. La transición floral está regulada por distintas rutas moleculares dependientes del ambiente, como la ruta del fotoperiodo regulada por la percepción de la luz (a) y por el reloj circadiano (b), y la ruta de vernalización (e), y dependientes del estado endógenos de la planta, como la ruta de las giberelinas (c) y la ruta autónoma (d). Las distintas rutas regulan la actividad de los genes integradores (f), los cuales activan finalmente los genes de identidad de meristemo floral (g), que darán lugar a la formación de las flores. Adaptado de Komeda, 2004 y actualizado con datos recientes. 


\subsection{Ruta del fotoperiodo}

La primera evidencia científica de la importancia del número de horas de luz en el proceso de floración en plantas se atribuye a los científicos Garner y Allard, los cuales observaron una floración más temprana en plantas de soja y de tabaco cuando se las exponía a un número de horas de luz por debajo de cierto umbral (Garner y Allard, 1922). La regulación de la transición floral mediada por el fotoperiodo garantiza a las plantas la formación de los órganos florales en las condiciones más apropiadas para cada especie. Así, las plantas que florecen en primavera son capaces de percibir un alargamiento paulatino del día, momento a partir del cual activan la formación de flores (plantas de día largo), mientras que en las plantas cuya floración tiene lugar en otoño, la transición floral se produce cuando el número de horas de luz en el ciclo diario se reduce (plantas de día corto). Un tercer grupo de plantas atendiendo a los requerimientos de fotoperiodo para la floración son las plantas de día neutro, las cuales florecen independientemente del número de horas de luz diarias (Simpson et al., 1999; Franklin et al., 2005).

Arabidopsis es una planta facultativa de días largos, es decir, florece en condiciones normales cuando el número de horas de luz a lo largo del día supera un determinado umbral (Días Largos; DL), pero es capaz de florecer si el número de horas de luz está por debajo de dicho umbral (Días Cortos; DC), si bien lo hace más tardíamente. El uso de esta especie modelo ha permitido elucidar en gran parte los mecanismos moleculares por medio de los cuales la planta percibe el fotoperiodo, así como la direccionalidad y la calidad de la luz ambiental, y cómo esta información es transmitida a genes relacionados con la activación de la transición floral.

\subsubsection{Percepción y transmisión del fotoperiodo en Arabidopsis.}

El reloj circadiano se puede definir como un mecanismo endógeno por medio del cual los organismos vivos son capaces de medir el tiempo en intervalos de aproximadamente 24 horas, que les permite anticiparse y predecir las condiciones ambientales venideras (Mas, 2008; Imaizumi, 2010). El reloj circadiano controla la expresión de un elevado número de genes con funciones variadas. Concretamente en Arabidopsis thaliana se ha descrito que un 6\% de sus genes presentan un patrón de expresión circadiano. Entre los genes de expresión circadiana se encuentran genes relacionados con procesos celulares tan dispares como la fotosíntesis, la percepción de la luz, el metabolismo secundario, la respuesta al frío y a la sequía, la floración, la elongación 
de los hipocotilos, el movimiento de hojas y cotiledones, la expansión celular, y el metabolismo del carbono-nitrógeno-azufre (Harmer et al., 2000). Conceptualmente se consideran tres componentes generales para la definición de sistemas circadianos. La percepción de estímulos ambientales que supone la entrada o input al reloj, el oscilador central del reloj que integra estímulos de distinta naturaleza, y una serie de rutas de salida $u$ output reguladas por el oscilador central, que regularán a su vez distintas rutas moleculares dependientes de la variación circadiana (Dunlap, 1999).

La percepción de la luz en plantas está mediada por fotorreceptores que de forma específica son capaces de percibir luz de distintas longitudes de onda. Funcionalmente los fotorreceptores se dividen en dos subgrupos, los pigmentos fotosintéticos que captan energía luminosa para la obtención de energía química por fotosíntesis, y los receptores fotosensoriales o fotorreceptores propiamente dichos, los cuales son capaces de percibir la calidad, cantidad, direccionalidad y duración de la luz en un momento dado y un ambiente determinado ( $\mathrm{Yu}$ et al., 2010). Este segundo tipo de fotorreceptores transmite la información lumínica percibida al oscilador central del reloj y son importantes para el control de un amplio abanico de procesos de desarrollo en plantas, desde la germinación hasta la transición floral (Figura 1a) (Fankhauser y Staiger, 2002; Quail, 2002). En Arabidopsis, la percepción de luz azul y UV-A está mediada por dos fototropinas (PHOT1 y PHOT2; Briggs et al., 2001) y por dos criptocromos (CRY1 y CRY2; Ahmad y Cashmore, 1993; Lin et al., 1998; Cashmore et al., 1999). Además, se han identificado miembros de la familia LOV, KELCH REPEAT, F-BOX con actividad E3 ligasa de ubiquitina que también participan en la percepción y señalización de luz azul, como ZEITLUPE (ZTL; Somers et al., 2000), FLAVIN BINDING, KEALCH REPEAT, F-BOX (FKF1, Nelson et al, 2000), y LOV KELCH PROTEIN 2 (LKP2, Schultz et al., 2001). Por otro lado, la luz roja y roja lejana es percibida en Arabidopsis por una familia de cinco fitocromos (PHYA-E), siendo PHYB el más activo en la percepción de luz roja y PHYA en la de luz roja lejana (Somers et al., 1998; Khanna et al., 2003; Tepperman et al., 2006). Recientemente ha sido elucidado el sistema de percepción de luz UV-B en Arabidopsis, el cual implica la monomerización de UVR8 tras la irradiación por UV-B, y la transmisión de la señal mediada por la interacción de monómeros de UVR8 con COP1 (Rizzini et al., 2011). Los distintos tipos de fotorreceptores van a percibir las distintas calidades de luz en un momento concreto, y van a transmitir la información generada al oscilador central del reloj circadiano. 
El oscilador central del reloj circadiano consta de varios bucles interrelacionados entre sí (Figura 1b). Alabadí y colaboradores establecieron la interrelación entre los factores de transcripción de tipo MYB denominados CIRCADIAN CLLOCK

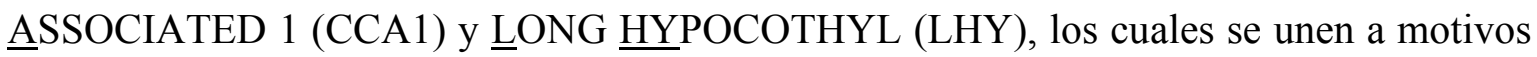
(evening elements) del promotor de $\underline{T} I M I N G \underline{O F} \underline{C A B}$ EXPRESSION 1 (TOC1), y reprimen su transcripción durante las primeras horas del día (Alabadí et al., 2001) (Figura 1b). Por otro lado, durante el periodo de oscuridad la interacción de TOC1 con el factor de transcripción de tipo TCP, $\underline{C} C A 1 \underline{H I C K I N G} \underline{E X P E D I T I O N ~(C H E ; ~ P r u n e d a-P a z ~ e t ~ a l ., ~}$ 2009), favorece la activación de $C C A 1$ y de $L H Y$, que se traducirán y volverán a reprimir TOC1 en las primeras horas del día (Alabadí et al., 2001). Además del bucle central del reloj circadiano que componen las proteínas CCA1/LHY/TOC1, se han descrito otros bucles adicionales e interrelacionados entre sí para el mantenimiento de la periodicidad del reloj circadiano, que implican a las proteínas PRR7 y PRR9 de la familia de TOC1 (Farré et al., 2005; Nakamichi et al., 2005), y a CCA1/LHY/CHE, que actúan de forma independiente de TOC1 (Pruneda-Paz et al., 2009) (Figura 1b).

Tanto los fotorreceptores de forma independiente como el oscilador central del reloj, regulan finalmente la transcripción y acumlación de CONSTANS (CO) para el control de la transición floral regulada por el fotoperiodo (Figura 1 a y b).

3.1.2. Función de CONSTANS-FLOWERING LOCUS $T$ en la regulación de la transición floral por la ruta del fotoperiodo

\subsubsection{Activación de $F T$ por $\mathrm{CO}$}

CONSTANS (CO) y $\underline{F L O W E R I N G ~ L O C U S ~} \underline{T}(F T)$ constituyen el núcleo central de la activación de la floración por la ruta del fotoperiodo. $\mathrm{CO}$ es un factor de transcripción de tipo dedos de zinc que activa la expresión del gen integrador FT. Tanto la acumulación del transcrito como de la proteína $\mathrm{CO}$ están reguladas por el reloj circadiano. En plantas de Arabidopsis cultivadas en condiciones de días largos los niveles de transcrito de $C O$ empiezan a aumentar a partir de las 8 horas de luz alcanzando dos picos de expresión, un primer pico de expresión en la fase luminosa a las 14 horas y un segundo pico de mayor intensidad en la fase de oscuridad a las 20 horas (Figura 2). El patrón de expresión en días cortos, sin embargo, presenta un único pico de expresión a las 14 horas, coincidente con el periodo de oscuridad (Suárez-López et al., 2001; Hayama y Coupland, 2004). El control de

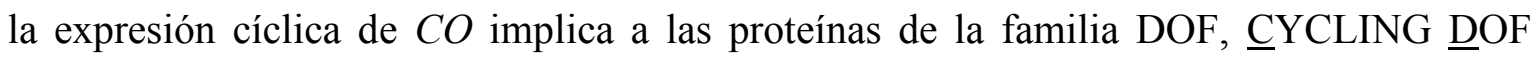
FACTOR (CDF1-5) (Imaizumi et al., 2005; Fornara et al., 2009), cuya acumulación 
depende a su vez de las proteínas del reloj circadiano PRR5, PRR7 y PRR9 (Nakamichi et al., 2007), y de su degradación por ubiquitinación dependiente de GIGANTEA (GI) y del fotorreceptor FKF1 (Imaizumi et al., 2005; Fornara et al., 2009).

Por otro lado, el aspecto crítico de la activación de $F T$ es la acumulación de la proteína CO. Los mecanismos de control de la acumulación de CO dependen directa o indirectamente del tipo de luz e implican a los distintos fotorreceptores, siendo PHYB un regulador negativo de su acumulación durante las primeras horas del día, mientras que CRY1, CRY2 y PHYA favorecen la acumulación de CO a partir de las 12 horas de luz (Figura 1a) (Valverde et al., 2004). Este hecho explica los fenotipos de floración tardía observados en los mutantes cryl, cry2, y phya, y el adelanto de la floración que experimenta el mutante phyb (Johnson et al., 1994; Guo et al., 1998; Reed et al., 1993; Lin, 2000). Los niveles de acumulación de proteína CO se ven reducidos en oscuridad por su degradación por ubiquitinación en los que participa las E3 ligasa de ubiquitina COP1 (Jang et al., 2008; Liu et al., 2008b). Bajo las condiciones de luz en las primeras horas del día, la degradación de CO depende de PHYB (Jang et al., 2008), y presumiblemente está mediada por la E3 ligasa de ubiquitina HOS1/ESD6 (Lázaro et al., 2012). Por el contrario, la luz azul ejerce un papel favorable en la acumulación de CO por la degradación de COP1 dependiente de CRY2 (Liu et al., 2008b). Este mecanismo de regulación conlleva una acumulación cíclica de la proteína $\mathrm{CO}$ en condiciones de días largos y la consecuente activación transcripcional de $F T$ (Figura 2). En fotoperiodos de días cortos, sin embargo, no se produce acumulación de CO (Valverde et al., 2004), por lo que los niveles de FT permanecen bajos, y no se activa por tanto la transición floral por esta ruta (Figura 2). La transición floral regulada por el fotoperiodo se ha explicado con el modelo de coincidencia externa, según el cual, para la consecución de un determinado proceso deben coincidir temporalmente niveles endógenos de un estimulador y condiciones ambientales adecuadas. En este caso, la coincidencia de los niveles elevados de $C O$ con la fase luminosa del día es indispensable para la acumulación del estimulador $\mathrm{CO}$, y la consecuente activación de $F T$, y, en última instancia, de la floración (Figura 2).

La activación de $F T$ por $\mathrm{CO}$ está controlada a distintos niveles, que implican la formación de complejos multiproteicos, o bien la acción de $\mathrm{CO}$ de forma independiente. Se ha descrito la formación de complejos proteicos HAP (Heme Activation Protein ) entre CO y las proteínas AtHAP3 y AtHAP5 (Wenkel et al., 2006; Kumimoto et al., 2010), que favorecen la unión de $\mathrm{CO}$ a las cajas CCAAT del promotor de FT. Además, CO 
interacciona con otros factores de transcripción, como TGA4 (Song et al., 2008) y ASYMMETRIC LEAVES 1 (AS1, Song et al., 2012) para la activación de FT. Todos estos resultados apuntan a que $\mathrm{CO}$ es realmente un coactivador de $F T$ cuya función está regulada por el fotoperiodo. Sin embargo, se ha demostrado recientemente la capacidad de CO para unirse por su dominio CTT a motivos específicos del ADN distintos de los dominios CCAAT, y su capacidad de activar la transcripción de $F T$ de forma autónoma (Figura 2) (Tiwari et al., 2010).

Días Largos
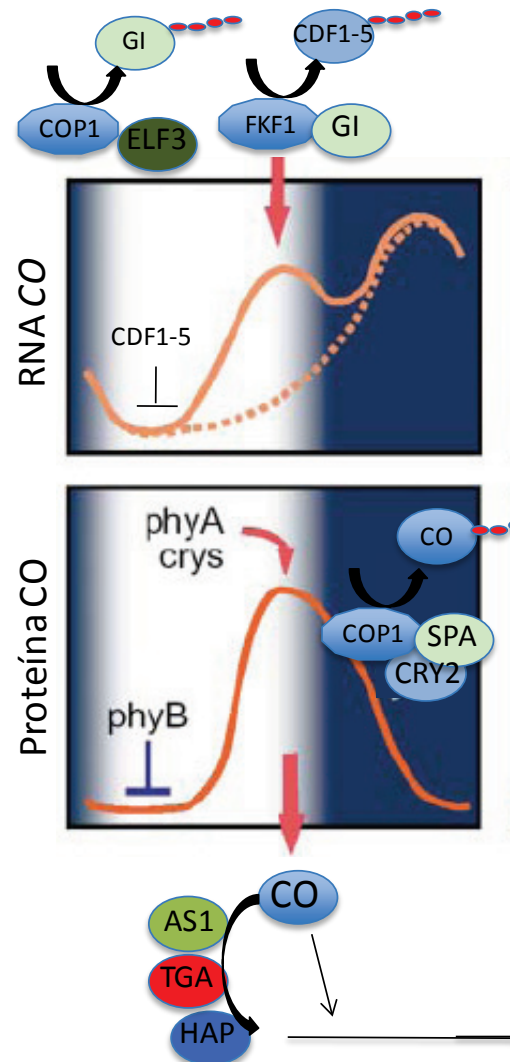

Días Cortos
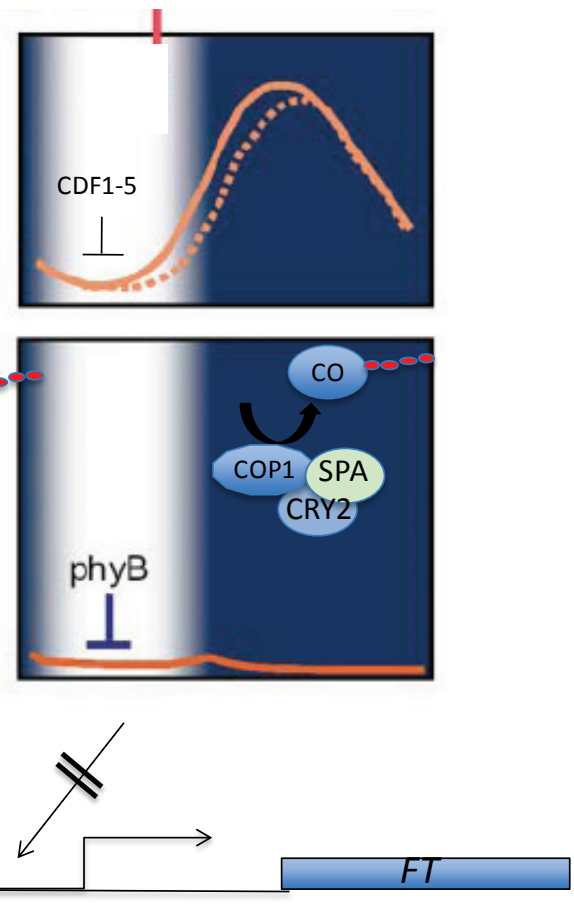

Figura 2. Representación esquemática del modelo de coincidencia externa. Representación de los niveles de transcrito y de la acumulación de proteína $\mathrm{CO}$ en condiciones de fotoperiodo inductoras de floración (días largos), y condiciones no inductoras (días cortos). Adaptado de Hayama y Coupland, 2004.

El mecanismo de control de la transcripción de FLOWERING LOCUS T por CONSTANS ha sido ampliamente estudiado y en gran parte elucidado. El control de la transcripción de $F T$, sin embargo, no depende exclusivamente del factor de transcripción $\mathrm{CO}$. Se han descrito otras proteínas que pueden regular la expresión de FT. La expresión 
dirigida de GIGANTEA (GI) en células del mesófilo o en los haces vasculares es capaz de activar FT independientemente de $\mathrm{CO}$ en condiciones de días cortos. Ensayos de inmunoprecipitación de cromatina muestran que GI es capaz de unirse a motivos del promotor de $F T$, por lo que la activación parece ser directa (Sawa y Kay, 2011). Además, GI regula la acumulación de miR172 el cual está implicado en la activación de $F T$ por la degradación de represores independientes de CO como $\underline{T} A R G E T \underline{O F} \underline{E} A T 1$ (TOE1) (Jung et al., 2007) y $\underline{S} C H L A F \underline{M} U T \underline{Z} E(S M Z)$ (Mathieu et al., 2009). Se han descrito también reguladores negativos de la transcripción de FT dependientes de la ruta del fotoperiodo e independientes de CONSTANS como los factores de transcripción de tipo RAV, TEMPRANILLO (TEM1 y TEM2), y se ha propuesto que la activación de FT por el fotoperiodo depende del balance entre la acumulación de la proteína activadora $\mathrm{CO}$ y los represores TEM (Castillejo y Pelaz, 2008).

\subsubsection{Función de $F T$ en la activación de la transición floral}

La percepción del fotoperiodo se produce mayoritariamente en las hojas, mientras que la transición floral se produce por cambios moleculares en el SAM. Por lo tanto es necesaria una señal, denominada tradicionalmente florígeno, que transporte la información generada en las hojas hasta el SAM donde se percibe. FT es una proteína de $20 \mathrm{kDa}$ que pertenece a la familia CENTRORADIALIS (CEN), TERMINAL FLOWER 1 (TFL1), FLOWERING LOCUS T (FT), y presenta una elevada homología a proteínas de unión a fosfatidiletanolamina o proteínas inhibidoras de Raf quinasas (Kobayashi et al., 1999). Tanto $C O$ como $F T$ se expresan en las células acompañantes del floema (Takada y Goto, 2003), lugar donde tiene lugar la activación transcripcional de FT por CO. La proteína FT traducida en los haces vasculares de las hojas es transportada pasivamente por el floema hasta el SAM (Figura 3) (Lifschitz et al., 2006, Corbesier et al., 2007; Jaeger y Wigge, 2007; Mathieu et al., 2007). Una vez en el SAM, FT forma heterodímeros con el factor de transcripción de tipo bZip FLOWERING LOCUS D (FD; Abe et al., 2005; Wigge et al., 2005). FD se expresa fundamentalmente en el SAM, y, a diferencia de $F T$, su expresión es independiente del fotoperiodo (Abe et al., 2005). El dímero FT-FD regula la expresión en el SAM de otros genes integradores, como SOC1 y FUL (Borner et al., 2000), y finalmente genes de identidad de meristemo floral, como APl (Wigge et al., 2005) y LFY (Lee et al., 2008). Además, el fenotipo de floración temprana de líneas sobreexpresoras de FT se ve suprimido en mutantes $s o c 1$ y $f u l$, lo cual indica que $S O C 1$ y $F U L$ son importantes para la activación de la transición floral mediada por FT (Melzer et al., 2008). Por lo tanto, los 
cambios genéticos producidos en el SAM constituyen una serie de bucles de activación, controlados fundamentalmente por FT-FD, SOC1 y FUL, los cuales regulan directamente la activación de genes de identidad de meristemo floral.

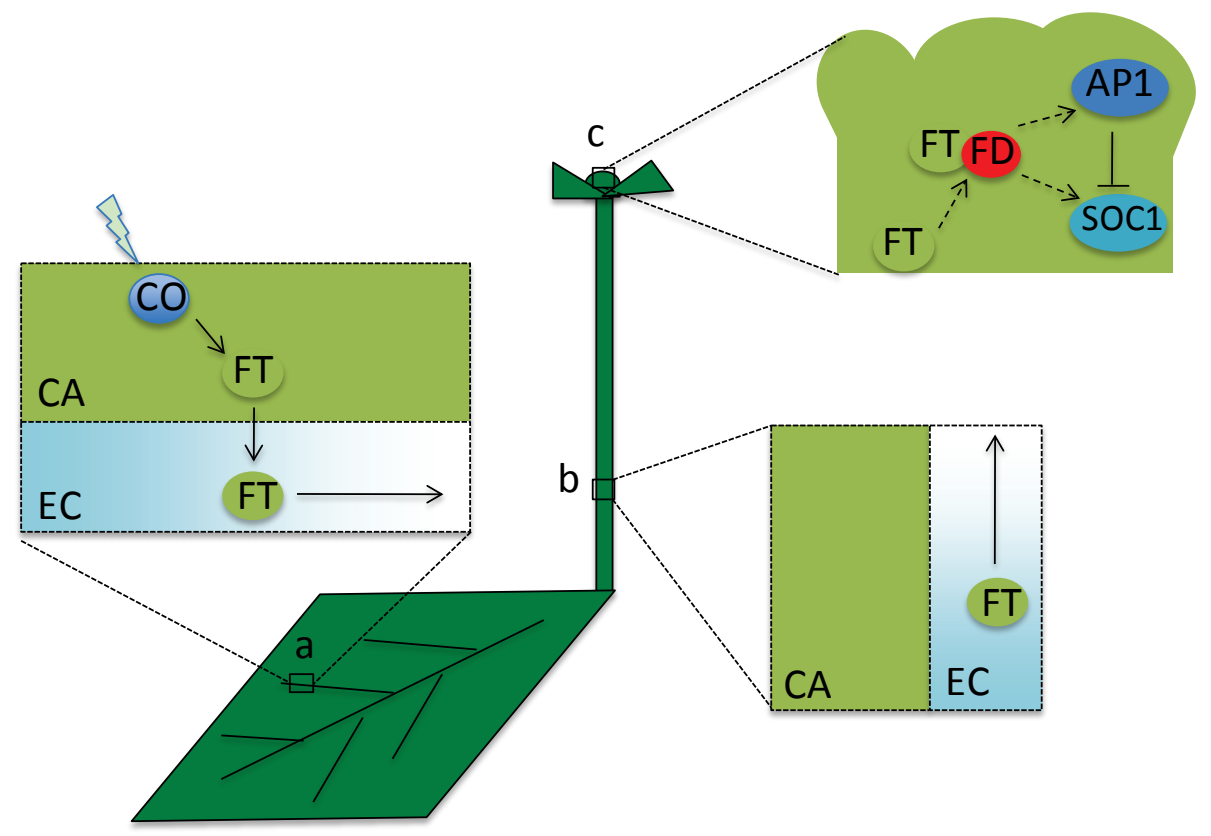

Figura 3. Movimiento de FT en Arabidopsis. a. Bajo condiciones de días largos CO se acumula y activa la expresión de $F T$ en las células acompañantes (CA) del floema. b. La proteína FT se transporta por los elementod cribosos (EC) del floema hasta el meristemo apical del tallo. c. En el meristemo apical del tallo FT forma heterodímeros con FLOWERING LOCUS D y activan la transcripción de AP1.

3.2. Otras rutas para la activación de la transición floral en Arabidopsis

$\underline{F L O W E R I N G} \underline{L} O C U S \underline{C}(F L C)$ ha sido descrito como un regulador negativo central de la transición floral. FLC codifica un factor de transcripción de tipo caja MADS que regula además otros aspectos del desarrollo, como la formación de los órganos florales, y está implicado potencialmente en la respuesta a estrés por frío y por luz, así como otros procesos regulados por hormonas tales como el ácido abscísico, el ácido jasmónico, el etileno y las auxinas (Deng et al., 2011). En el caso de la transición floral, se ha descrito a FLC como un represor central de los genes integradores FT y SOC1 (Amasino y Michaels, 2010). La expresión de FLC está regulada negativamente por la ruta de la vernalización y por la ruta autónoma (Figura $1 \mathrm{~d}$ y e). 
La vernalización consiste en la activación de la transición floral por la exposición de las plantas a bajas temperaturas durante un periodo de tiempo relativamente largo (varias semanas o meses, dependiendo de las especies). Para las especies anuales de invierno y bianuales el requerimiento de vernalización asegura una floración en primavera después de las bajas temperaturas invernales. En Arabidopsis, la vernalización provoca una bajada de los niveles de transcrito de $F L C$ que está regulada por cambios epigenéticos a nivel de la cromatina. Así, la exposición a períodos de bajas temperaturas provoca una trimetilación de histonas $\mathrm{H} 3$ en las lisinas 9 (H3K9) y 27 (H3K27) que actúan reprimiendo la expresión de $F L C$, y favorecen por tanto la transición floral (Amasino y Michaels, 2010). Esta metilación está mediada por la actividad de complejos PRC2 ( Repressive Complex 2) (Kim et al., 2005). En Arabidopsis se han descrito los genes

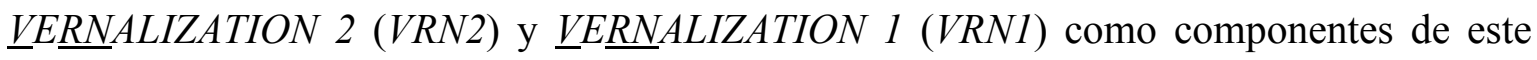
tipo de complejos (Figura 1e) (Bäurle y Dean, 2006).

La ruta autónoma comprende un conjunto de genes que regulan negativamente la función de FLC y son, por tanto, reguladores positivos de la floración. Por esta razón, mutaciones en estos genes dan lugar a niveles elevados del transcrito de FLC y a fenotipos de floración tardía. Los mecanismos bioquímicos que conllevan la regulación de la función de FLC no se conocen en detalle, si bien están fundamentalmente basados en la unión y procesamiento del ARN y en eventos de modificación de cromatina (Amasino y Michaels, 2010). Entre los genes incluidos en la ruta autónoma relacionados con el procesamiento del ARN se encuentran los que presentan dominios de unión al ARN, como FCA y FPA, y el homólogo a los factores de procesamiento de ARN, FY. Por otro lado la ruta autónoma incluye genes con función histona-metil-transferasas, como los miembros de la familia PRMT, y demetilasas de histonas, como FLOWERING LOCUS D, FVE y RELATIVE OF EARLY FLOWERING (Figura 1d) (Amasino y Michaels, 2010).

Por último, las giberelinas tienen un papel importante en la transición floral en Arabidopsis, fundamentalmente en condiciones no inductoras de día corto (Wilson et al., 1992). El precursor de GAs, trans-geranylgeranyl bifosfato, es sometido a un total de doce reacciones enzimáticas hasta la producción final de GAs biológicamente activas. La biosíntesis de GAs está regulada a nivel de las últimas reacciones por el control de las GA 20-oxidasas (GA20ox) y las GA 3-oxidasas (GA3ox) (Mutasa-Göttgens y Hedden, 2009). Las GAs biológicamente activas son percibidas en la célula por los receptores nucleares GID1 (Ueguchi-Tanaka et al., 2007). Esta percepción favorece el marcaje por ubiquitinación dependiente de un complejo SCF con actividad E3 ligasa de ubiquitina y su 
posterior degradación por el proteasoma de proteínas DELLA, las cuales tienen una función represora de la expresión de los genes de respuesta de GAs (Figura 1c) (Murase et al., 2008; de Lucas et al., 2008). Tanto los mutantes de síntesis como los mutantes afectados en la percepción y señalización de GAs muestran fenotipos de floración tardía comparados con las plantas silvestres, mientras que el mutante spy, el cual presenta una señalización constitutiva de GAs, florece prematuramente (Wilson et al., 1992, Blázquez et al., 1998; Mouradov et al., 2002). La aplicación exógena de GAs adelanta la floración en plantas silvestres y recupera el fenotipo de floración de mutantes de síntesis como gal-3 (Wilson et al., 1992), pero no de los mutantes de proteínas DELLA como gibberelic acid insensitive 1 (gail), repressor of GAl-3 (rga) o $\underline{R G A-l i k e ~} 1$ (rgll) (Blázquez et al., 1998), ni en el triple mutante de percepción de GAs gidla-1 gidlb-1 gidlc-1 (Griffiths et al., 2006), lo que indica que es necesaria no sólo la acumulación de GAs, sino también su percepción y señalización. La ruta de floración activada por giberelinas es independiente de las rutas antes descritas (Figura 1c) (Simpson et al., 1999). Las GAs contribuyen a la activación de $F T$ en condiciones de días largos de forma independiente de $\mathrm{CO}$ (Hisamatsu y King, 2008). En días cortos, donde la ruta de las GAs es indispensable para que se produzca la floración (Wilson et al., 1992), las GAs actúan a nivel del SAM donde activan genes integradores de la floración como LFY (Blázquez et al., 1998) y SOC1 (Bonhomme et al., 2000).

Todo lo expuesto hasta ahora muestra que la transición floral es un proceso finamente regulado que depende de factores de tipo ambiental y de naturaleza endógena de la planta. Sin embargo, esta precisa regulación puede verse alterada por distintos factores de estrés, que por lo general actúan como promotores de la floración. Concretamente el adelanto de la floración provocado por estrés de tipo biótico ha sido demostrado en Arabidopsis, ya que plantas de Arabidopsis infectadas con microorganismos patógenos de distinta naturaleza, como las bacterias Pseudomonas syringae y Xanthomonas campestres, o el oomiceto Peronospora parasitica, provocan un adelanto de la floración dependiente de la cantidad de inóculo inicial. Además este adelanto de floración tiene lugar incluso a bajas dosis de inóculo, con las cuales no se observan síntomas de enfermedad (Korves y Bergelson, 2003). El SA, que ha sido ampliamente estudiado por su relación con la respuesta a patógenos en plantas (Glazebrook, 2005; An y Mou, 2011), tiene un papel importante en la aceleración de la floración por ataques patogénicos. El papel promotor de la floración del SA ha sido estudiado no sólo en Arabidopsis (Martínez et al., 2004), sino 
también en otras especies vegetales (Cleland y Tanaka, 1979; Cleland y Ben-Tal, 1982; Wada y Takeno, 2010).

\section{Interacción planta-patógeno}

Las plantas comparten el medio en el que se desarrollan con una amplia variedad de patógenos microbianos de distinta naturaleza, como bacterias, virus $\mathrm{y}$ hongos. Dependiendo del estilo de vida del patógeno sobre la planta, éstos se pueden clasificar en patógenos biotrofos, los cuales se alimentan de tejidos vivos de la planta, y patógenos necrotrofos, que obtienen los nutrientes a partir de células muertas o en proceso de muerte. Existe un tercer grupo de patógenos, denominados patógenos hemi-biotrofos, cuyo estilo de vida depende de las condiciones ambientales y/o de la fase de crecimiento sobre la planta (Glazebrook, 2005).

\subsection{Respuesta de las plantas frente a patógenos}

Las plantas poseen una serie de barreras de tipo físico, como las paredes celulares y la cutícula, que dificulta de forma inespecífica el acceso de los patógenos y la posterior colonización de la planta. En muchos casos, los microorganismos son capaces de esquivar estas barreras y acceder al interior de la planta por aperturas generadas por heridas, o por aperturas naturales como los hidátodos o los estomas. Las plantas sintetizan además compuestos del metabolismo secundario con propiedades antimicrobianas, como las fitoalexinas y los glucosinolatos. A este tipo de defensa general, tanto de naturaleza física como química, se la denomina defensa inespecífica (Figura 4). Además las plantas han desarrollado una serie de respuestas específicas inducidas por el reconocimiento de los microorganismos invasores. Esta respuesta se produce a tres niveles, una respuesta basal inicial, una respuesta inducida específica en el sitio de infección, y una respuesta distal en el resto de la planta (Figura 4).

El primer nivel de percepción de patógenos por las plantas consiste en el reconocimiento de patrones moleculares asociados a patógenos (PAMPs; PathogenAssociated Molecular $\underline{\text { Patterns) }}$ por receptores de reconocimiento de patógenos (PRRs; Pattern Recognition Receptors) situados en las membranas celulares de las plantas. A esta respuesta de las plantas frente a patógenos se la denomina inmunidad desencadenada por PAMPs (PTI; PAMP-Triggered Immunity) (Jones y Dangl, 2006) (Figura 4). Las PAMPs 
son moléculas de distinta naturaleza y conservadas en distintos tipos de microorganismos, tanto patogénicos como inocuos para las plantas, que tienen por lo general funciones enzimáticas y estructurales (Boller y Felix, 2009).

Los microorganismos patógenos han desarrollado estrategias de evasión o disminución de la inmunidad mediada por PAMPs a través de la acción de efectores o factores de virulencia específicos, los cuales además de reducir la PTI pueden tener efectos adversos sobre la planta. El segundo nivel de defensa de la respuesta inmune frente a microorganismos patógenos está mediado por el reconocimiento específico y generalmente intracelular de los efectores por medio de las proteínas R de la planta (Figura 4). La mayoría de las proteínas $\mathrm{R}$ identificadas en plantas contienen un dominio de unión al ADN (NB) y un dominio rico en leucina en su extremo carboxi terminal (LRR). El domino en el extremo amino terminal es variable y va a influir en la ruta de señalización que se desencadenará tras la percepción del patógeno (van der Biezen y Jones, 1998). En cualquier caso, la percepción de efectores por parte de la planta desencadena una respuesta más efectiva, rápida y específica contra la invasión del patógeno. A esta respuesta se le denomina inmunidad inducida por efectores (ETI, Effector-Triggered Inmunity). La ETI provoca en la planta una alteración de los flujos iónicos, una rápida producción de compuestos reactivos de oxígeno $\left(\mathrm{H}_{2} \mathrm{O}_{2}, \mathrm{O}_{2}{ }^{-}\right)$y de nitrógeno $\left(\mathrm{NO}, \mathrm{ONOO}^{-}\right)$, un aumento de la síntesis y acumulación de ácido salicílico (SA), y muerte celular programada (PCD; Programed Cell Death) localizada alrededor del punto de entrada del patógeno,

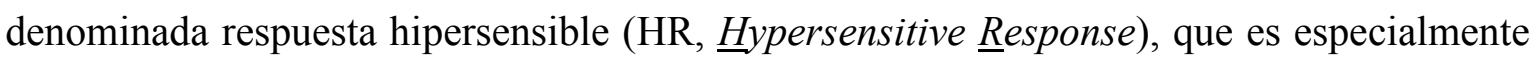
efectiva para la limitación del crecimiento de patógenos de tipo biotrofo (Glazebrook, 2005) (Figura 4).

El reconocimiento de los efectores patogénicos por proteínas $\mathrm{R}$ de la planta se ha explicado con el concepto de respuesta gen a gen propuesto inicialmente por Flor (1971). Según este modelo, el éxito de la planta en la interacción planta-patógeno depende del reconocimiento de un gen de avirulencia del patógeno $(A v r)$ por un gen de resistencia de la planta (R). El reconocimiento gen a gen en la interacción planta-patógeno implica un patógeno de tipo avirulento, un huésped resistente, y una interacción de tipo incompatible. Si por el contrario no hay reconocimiento gen a gen en la interacción, el patógeno es virulento, la planta susceptible, y la interacción es compatible, dando lugar a la aparición de síntomas de enfermedad en la planta (Jones y Dangl, 2006; An y Mou, 2011). 


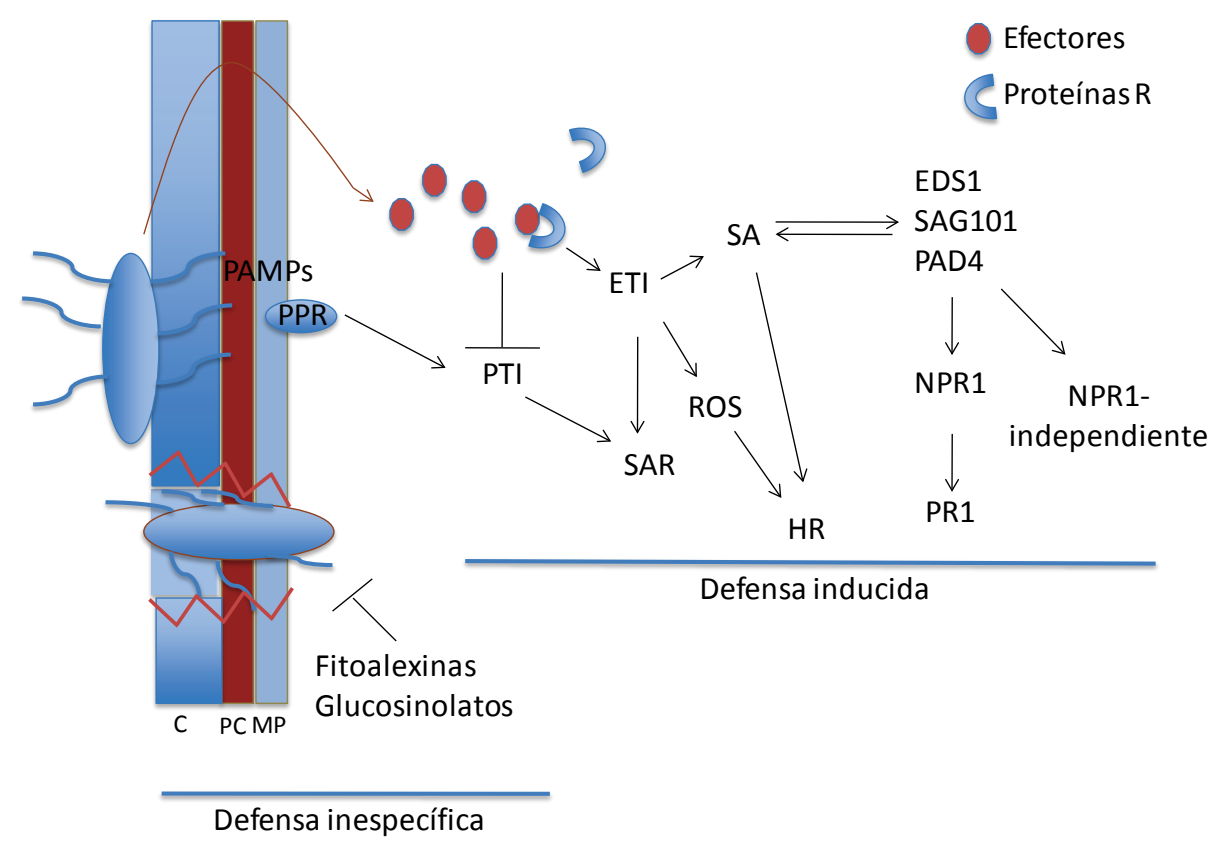

Figura 4. Representación esquemática de la defensa de las plantas frente a patógenos. Las plantas poseen una respuesta inespecífica de tipo físico, constituida por barreras que impiden el paso de patógenos como la cutícula (C) y la pared celular (PC), y de tipo químico, por la producción de compuestos del metabolismo secundario con efectos tóxicos para los microorganismos como las fitoalexinas y los glucosinolatos. El reconocimiento del patógeno por la planta induce una respuesta más efectiva, que puede ser general por el reconocimiento de PAMPs a nivel de la membrana plasmática (MP) denominada respuesta inducida por PAMPs (PTI), o más específica por el reconocimiento de efectores patogénicos generalmente a nivel intracelular denominada respuesta inducida por efectores (ETI). La respuesta inducida conlleva la producción de especies reactivas de oxígeno (ROS), una respuesta hipersensible (HR), y la biosíntesis y acumulación de ácido salicílico (SA). La señal de SA se ve amplificada por el núcleo central EDS1/PAD4/SAG101, que activará una señalización dependiente e independiente de $N P R 1$, y en última instancia genes de respuesta de tipo $P R$. Finalmente, en zonas distales del punto de entrada del patógeno se activa resistencia sistémica adquirida (SAR), que protege a la planta de infecciones posteriores.

Las respuestas locales de tipo PTI y ETI son capaces de activar en el resto de la planta una respuesta sistémica adquirida (SAR, Systemic Acquired Resistance) que la protege de ataques posteriores por sitios distintos a los puntos iniciales de infección (Durrant y Dong, 2004; Mishina y Zeier, 2007). La respuesta SAR implica un aumento de la síntesis y acumulación de SA, y una consecuente activación de la expresión de genes que codifican proteínas PATHOGENESIS RELATED (PR) en toda la planta. No se conoce con exactitud la naturaleza de la señal que transmite la respuesta SAR a los órganos distales de la planta, si bien parece que no se trata de una única molécula, sino más bien de una amalgama de sustancias entre las que se encuentran la forma metilada del SA (MeSA), y compuestos de naturaleza lipídica como el ácido jasmónico y derivados del glicerol-3fosfato (Dempsey y Klessig, 2012). La proteína de transporte lipídico DEFECTIVE IN

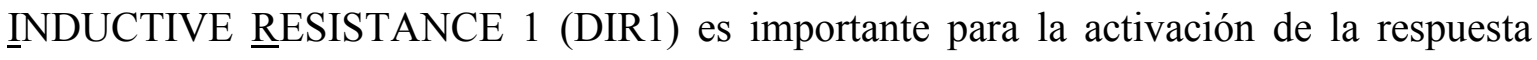
SAR, y se ha propuesto que actúa como transportador de los efectores de naturaleza 
lipídica por la planta (Maldonado et al., 2002) por el tejido floemático (Champigny et al., 2011).

\subsection{Señalización por SA en la defensa frente a patógenos}

La percepción de los distintos tipos de microorganismos patógenos desencadena en las plantas una señalización hormonal que culmina en la activación de genes de defensa. Tradicionalmente se ha descrito una relación antagónica del ácido salicílico y del ácido jasmónico en esta respuesta. Mientras que la señalización por SA es importante para la defensa frente a patógenos de tipo biotrofo, la señalización mediada por JA, conjuntamente con la señalización por etileno (ET), actúa en la activación de genes en respuesta a patógenos necrotrofos e insectos masticadores (Glazebrook, 2005; Thaler et al., 2012). Sin embargo, existen casos de sinergismo entre las rutas de SA y de JA en respuesta a patógenos (León-Reyes et al., 2009; Zander et al., 2010), lo que apunta a la compleja red de señalización hormonal en la respuesta a estrés biótico. Además, otras hormonas, como el ácido abscísico, las citoquininas, las auxinas o los brasinosteroides, son importantes para la modulación de la respuesta frente a patógenos en plantas (Robert-Seilaniantz et al., 2011).

El ácido salicílico se sintetiza en los cloroplastos a partir de corismato y es transportado al citosol celular presumiblemente por medio del transportador de tipo MATE

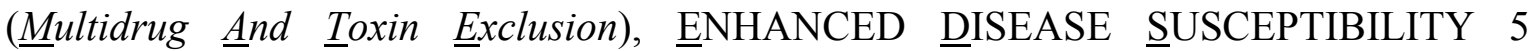
(EDS5)/ㅁALICYLIC ACID INDUCTION DEFICIENT 1 (SID1) (Fragnière et al., 2011). En Arabidopsis, la enzima ISOCHHORISMATE SYNTHASE 1 (ISC1)/SID2 cataliza la conversión de corismato en isocorismato, y es responsable de la biosíntesis de la mayor parte del SA producido (Nawrath y Metraux, 1999; Wildermuth et al., 2001). Una vez en el citosol, el SA puede sufrir modificaciones post-síntesis que evitan posibles efectos citotóxicos, como su conjugación con un residuo glucosídico (SAG), o el éster correspondiente (SGE) para su almacenamiento en vacuolas (Vlot et al., 2009).

Si bien la acumulación de SA en plantas depende de la actividad de enzimas de síntesis o de transporte, como SID1 y SID2 (Nawrath y Metraux, 1999), se han descrito mutaciones en genes implicados en la señalización de SA que presentan alteraciones en la acumulación de SA. Este hecho apunta a un complejo sistema de autorregulación entre la síntesis, acumulación y señalización de esta hormona. Los genes afectados pueden ser reguladores positivos de la señalización de SA, y sus correspondientes mutaciones 
confieren una menor acumulación de SA y una mayor susceptibilidad a patógenos de tipo biotrofo, o bien reguladores negativos, cuyas mutaciones provocan una mayor acumulación de SA y una mayor resistencia a este tipo de patógenos (An y Mou, 2011).

EDS1 es un gen central en la activación de la respuesta basal de tipo PTI y ETI tras la percepción del oomiceto hemi-biotrofo $P$. parasitica por genes $\mathrm{R}$ de tipo TOLLInterleukin-1 Receptor (TIR-NB-LRR) (Falk et al., 1999). Los mutantes eds 1 están comprometidos en la acumulación de SA, la generación de ROS (Reactive Oxigen Species), y la respuesta HR desencadenada tras la infección por patógenos biotrofos (Feys et al., 2001). El mecanismo de acción de EDS1 en la respuesta inducida por efectores depende de la formación de complejos proteicos con los reguladores positivos de SA

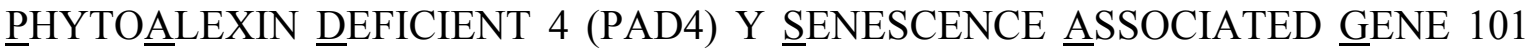
(SAG101) (Feys et al., 2005; García et al., 2010). Se ha descrito un bucle de regulación positiva en el que EDSI es importante para la síntesis y acumulación de SA, y éste a su vez activa tanto $E D S 1$ como $P A D 4$, consiguiéndose así una rápida amplificación de la señal de la respuesta (Shah, 2003). Por otro lado, la activación de genes de tipo $P R$ en respuesta a SA está regulada por NPR1. La regulación de la función de NPR1 se produce a nivel de su transcripción por factores de la familia WRKY (Yu et al., 2001), y a nivel de la monomerización de la proteína correspondiente y posterior translocación al núcleo en respuesta a SA (Kinkema et al., 2000; Mou et al., 2003). La activación de genes $P R$ por NPR1 está mediada por la interacción con factores de transcripción de tipo TGA (Després et al., 2000). Además de estos dos genes centrales en la señalización de SA frente a patógenos se han identificado otros muchos mediante escrutinios de mutantes con respuesta alterada frente a patógenos biotrofos o deficitarios en la síntesis de SA, como NDR1, ALD1, WIN3 o MOS1 (An y Mou, 2011).

Si bien se ha caracterizado a NPRl como un regulador central de la señalización mediada por SA, se ha descrito una ruta activada por SA e independiente de NPR1 en Arabidopsis. Mutaciones en genes de esta ruta acumulan SA y presentan niveles de expresión de genes $P R$ elevados en ausencia de un alelo funcional de $n p r l$. Los mutantes ssi1, ssi2 y ssi4 combinados con $n p r l$ activan PR1 de forma constitutiva, si bien lo hacen en menor grado que los mutantes simples (Shah et al., 2001). Por lo tanto, para la acumulación de PR1 en respuesta a SA se activan rutas paralelas dependientes e independientes de NPRl que actúan de forma aditiva. La participación de sustancias de naturaleza lipídica juega un importante papel en esta ruta independiente de NPR1. Un caso 
ampliamente caracterizado es el del mutante ssi2, el cual está afectado en una enzima implicada en la desaturación del ácido graso esteárico. Los mutantes ssi2 y presentan elevadas cantidades de SA y una mayor acumulación de PR1, así como muerte celular espontánea y una elevada resistencia a diversos patógenos como bacterias y oomicetos (Kachroo et al., 2001; Shah et al., 2001; Kachroo et al. 2005). Por otro lado, plantas ssi2 muestran fenotipos de susceptibilidad frente al hongo necrotrofo Botrytis cinerea, si bien este fenotipo es independiente de los intermediarios de la señalización de SA EDS5 y PAD4 (Nandi et al., 2005). Estos resultados muestran la importancia de la señalización lipídica en la respuesta frente a patógenos por una ruta independiente que comparte componentes de la ruta de señalización tanto por SA como por JA.

4.3. Señalización lipídica en la respuesta frente a patógenos

\subsubsection{Tipos y función de los lípidos en plantas}

Los lípidos son moléculas biológicas de tamaño y naturaleza diversa que desempeñan en las células funciones estructurales, de almacenamiento de energía y de señalización, que pueden ser clasificados en ocho categorías que incluyen ácidos grasos, glicerolípidos, glicerofosfolípidos (o fosfolípidos), esfingolípidos, glucolípidos, policétidos, prenoles y esteroles (Fahy et al., 2011).

Las plantas poseen en su parte aérea una cobertura de naturaleza lipídica llamada cutícula, la cual confiere impermeabilidad al agua, y supone además una barrera para la entrada de agentes contaminantes de tipo biótico y abiótico. La cutícula está compuesta mayoritariamente por ceras (mezcla complejas de ácidos grasos de cadena muy larga), y polímeros de cutina constituidos principalmente por ácidos grasos de 16 y 18 carbonos (Jetter et al., 2007). Además, las membranas plasmáticas de células vegetales son estructuras de naturaleza lipídica que contienen una gran variedad de lípidos entre los que predominan los fosfolípidos y galactolípidos (Samarakoon et al., 2012). Ambas estructuras, la cutícula y las membranas celulares, son críticas en los procesos de interacción planta-patógeno (Chassot et al., 2007; Bouwmeester e al., 2011).

En las últimas décadas se ha estudiado el papel de los lípidos en la señalización frente al ataque de patógenos. Tanto los ácidos grasos y compuestos derivados, como lípidos de mayor complejidad estructural tales como esfingolípidos y fosfolípidos, son 
importantes para la respuesta frente a distintos tipos de patógenos (Shah, 2005; Canonne et al., 2011).

\subsection{2. Ácidos grasos y compuestos derivados}

Los ácidos grasos son los lípidos estructuralmente más sencillos, y constituyen la unidad básica de la mayoría de los lípidos. Están compuestos por un grupo carboxilo ($\mathrm{COOH})$ unido a una cadena lateral hidrocarbonada de longitud variable, que puede presentar diferentes grados de instauración, es decir, dobles enlaces entre dos carbonos adyacentes. La síntesis de ácidos grasos en plantas tiene lugar en los plástidos, y comienza con la reacción de condensación entre un residuo de acetil-CoA y una molécula de $\mathrm{CO}_{2}$, generándose un residuo de malonyl-CoA, el cual se une a una proteína portadora ácida (ACP; acidic carrier protein) mediante un enlace tioéster (Figura 5A). El malonyl-CoAACP entra en una serie de ciclos de condensación con residuos de acetil-CoA, deshidratación y reducción, en cada uno de los cuales se incorporan dos átomos de carbono a la cadena en elongación del ácido graso (Ohlrogge y Jaworski, 1997). Mediante este proceso se sintetizan los ácidos palmítico (16:0) y esteárico (18:0). Estas dos clases de ácidos grasos, o bien sus derivados insaturados, participan directamente en procesos de defensa frente a patógenos (Kachroo y Kachroo, 2009). La mutación en SSI2, que codifica una estearoil-ACP desaturasa (SACPD) que añade el primer doble enlace a los ácidos

grasos 16:0 y 18:0, (Figura 5A), conlleva una menor acumulación de ácido oleico (18:1). Este hecho se traduce fenotípicamente en una mayor susceptibilidad frente a Botrytis cinerea (Chandra-Shekara et al., 2007). Contrariamente, la sobreexpresión de SACPD en berenjena provoca una mayor acumulación de ácidos grasos insaturados, como 16:1, 16:3, y 18:1, y una mayor resistencia frente a Verticillium dahliae (Xing y Chin, 2000). 


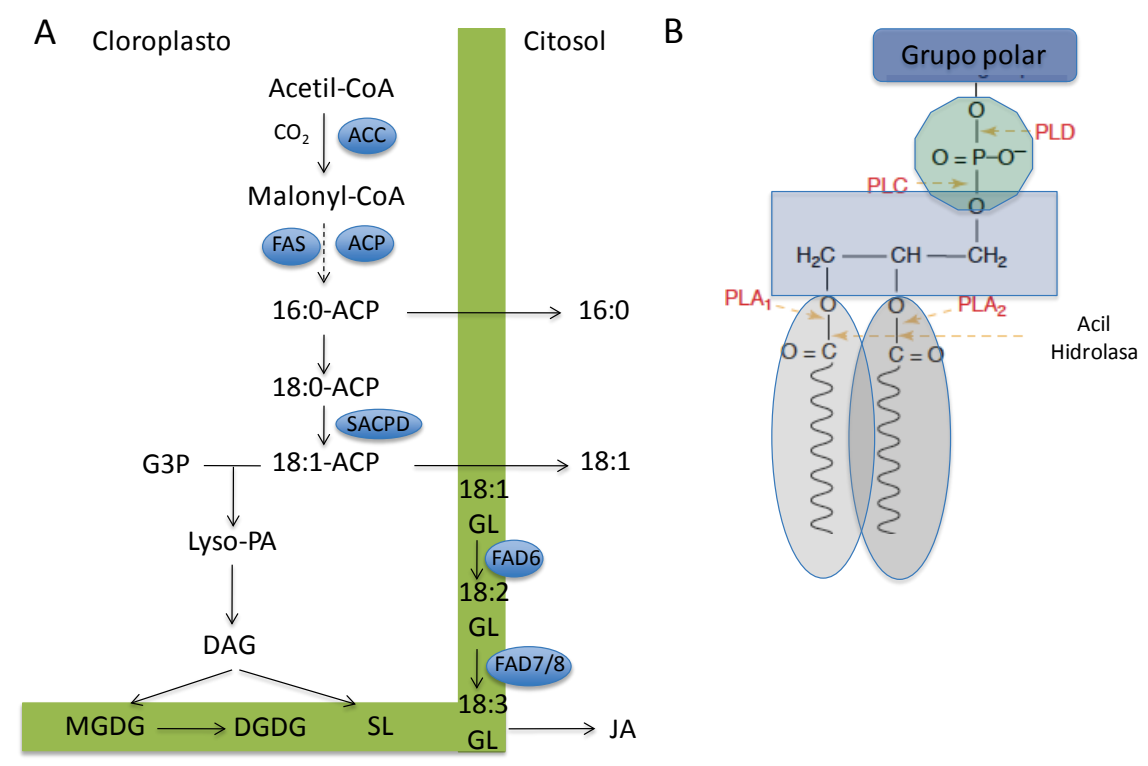

Figura 5. A. Representación esquemática de la biosíntesis de ácidos grasos de 16 y 18 átomos de carbono de cadena lateral y de lípidos de mayor complejidad derivados de éstos. ACC: acetil-CoA carboxilasa. FAS: ácido graso sintasa. ACP: proteína portadora ácida. SACPD: estearoil ACP desaturasa. G3P: glicerol-3fosfato. PA: ácido fosfatídico. DAG: diacilglicerol. MGDG: monogalactosildiacilglicerol. DGDG: digalactosildiacilglicerol. SL: sulfolípido. GL: glicerolípido. JA: ácido jasmónico. Adaptado de Kachroo y Kachroo, 2009. B. Representación esquemática de la estructura de fosfolípidos. Los fosfolípidoslípidos están compuestos por dos residuos de ácidos grasos (gris) y un residuo de glicerol (azul claro) unidos por un enlace fosfato (verde) a un grupo de cabeza polar (azul oscuro). La diferencia estructural de los distintos tipos de lípidos depende de los ácidos grasos que los componen (longitud y grado de instauración), así como del grupo polar. En el esquema se representan los distintos tipos de lipasas que hidrilozan este tipo de lípidos, así como el enlace sobre el que actúan. PL A-D: fosfolipasas A-D. Adaptado de Wang, 2004.

Los ácidos grasos pueden afectar también a la respuesta frente a patógenos de forma indirecta. Las oxipilinas son productos de degradación por oxidación de ácidos grasos, y han sido caracterizados por su función señalizadora en defensa (Andreou et al., 2009; Canonne et al., 2011). Dentro de este grupo de compuestos, el ácido jasmónico y sus derivados han sido ampliamente caracterizados como reguladores tanto de respuestas a estrés como del desarrollo (Wasternack y Kombrink, 2010).

\subsubsection{Fosfolípidos}

Los glicerofosfolípidos o fosfolípidos están formados por un residuo de glicerol unido a dos ácidos grasos y a un grupo fosfato (Figura 5B). Esta estructura básica se une por el grupo fosfato mediante un enlace fosfodiéster a otras moléculas, como colina, serina o etanolamina, dando lugar a distintos tipos de fosfolípidos. Si bien ha sido ampliamente estudiado su función estructural en las membranas plasmáticas de eucariotas y procariotas, 
cada vez son más los trabajos que demuestran su papel de señalización en distintos procesos celulares, y concretamente en la respuesta frente a patógenos.

La producción de ácido fosfatídico (PA; Phosphatidic Acid) está asociada a distintos estímulos relacionados con la respuesta a estrés, como el estrés por herida, tratamientos con ABA y etileno, estrés de tipo osmótico y percepción de elicitores y de PAMPs, y ejerce un papel de modulador celular de la actividad de quinasas, fosfatasas y proteínas de transporte de membrana (Munnik, 2001; Shah, 2005). La biosíntesis de PA se produce por hidrólisis de fosfolípidos de membrana por fosfolipasas de membrana de tipo D (PLD) y C (PLC) (Figura 5B). El reconocimiento de efectores de Pseudomonas, como AvrRpm1 y AvrRpt2, aumenta la actividad de este tipo de fosfolipasas, lo cual desencadena una acumulación de PA en las células importante para la generación de ROS y la activación de genes de respuesta (Canonne et al., 2011).

Por otro lado, las fosfolipasas de tipo A o Hidrolasas Acil Lipídicas (Lipid Acyl Hidrolases, LAH) son capaces de hidrolizar tanto fosfolípidos como galactolípidos de membrana, liberando ácidos grasos y lisofosfolípidos (Figura 5B). Este tipo de enzimas son importantes para la síntesis de JA y otras oxipilinas en respuesta a patógenos. Al igual que sucede con PLD y PLC, la generación de ROS también está modulada por las PLA o LAH (Canonne et al., 2011). Las proteínas EDS1, PAD4 y SAG101, introducidas en el apartado 4.2.1. por su importancia para la acumulación y señalización de SA, tienen una elevada homología con enzimas LAH, si bien no se ha demostrado su actividad fosfohidrolítica (Shah, 2005; Canonne et al., 2011).

\subsubsection{Señalización por el ácido jasmónico}

El ácido jasmónico es una oxipilina derivada de la degradación por $\beta$-oxidación de ácidos grasos 18:3 procedentes de fosfolípidos y/o galactolípidos por la ruta del ácido $\alpha$ linolénico (Figura 5A) (Browse, 2009). La percepción de JA, concretamente en su forma conjugada JA-isoleucina, está mediada por la F-box CORONATINE INSENSITIVE 1 (COI1). En presencia de JA-Ile, COI1 ubiquitina y promueve la posterior degradación vía proteasoma de proteínas de la familia JAZ, que actúan como represores de la respuesta a JA (Fonseca et al., 2009). Tanto el triple mutante en desaturasas fad3fad7fad8, defectivo en la producción de ácido $\alpha$-linolénico y que no acumula por tanto JA (Figura 5A), como el mutante coil muestran fenotipos de hipersensibilidad frente al oomiceto necrotrofo Pythium jasmonium (Vijayan et al., 1998). Además, mutaciones en distintos factores de 
transcripción de respuesta a JA de tipo MYC, que son las dianas de los represores JAZ mejor descritas hasta la fecha (Lorenzo et al., 2004; Fonseca et al., 2009), presentan fenotipos de susceptibilidad frente al ataque de insectos generalistas, al igual que sucede con el mutante coil (Fernández-Calvo et al., 2011). Estos fenotipos demuestran la importancia de la acumulación y señalización de JA en la respuesta frente a patógenos necrotrofos e insectos.

\section{El signalosoma COP9 en Arabidopsis thaliana}

\subsection{Estructura del signalosoma COP9 (CSN)}

El signalosoma COP9 (CSN de $\underline{\text { COP9 }}$ Signalosome) puede definirse como un complejo multiproteico conservado de 450-500 KDa que ha sido identificado en distintas especies animales y vegetales, además de en Drosophila, en la levadura de fisión Schizosaccharomyces pombe, en Caenorhabditis elegans y Aspergilus, cuya función está relacionada con procesos de degradación de proteínas (Wei y Deng, 2003; von Arnim, 2003). Las distintas subunidades de CSN, así como otros genes funcionalmente relacionados, fueron identificadas en diferentes tipos de rastreos en Arabidopsis thaliana, identificándose así los loci CONSTITUTIVE PHOTOMORPHOGENIC / DETIOLATED / FUSCA (COP/DET/FUS). Mutantes para estos loci muestran un fenotipo común consistente en una respuesta fotomorfogénica constitutiva, consistente en cotiledones abiertos, hipocotilos cortos, cloroplastos diferenciados, y una activación constitutiva de genes de respuesta a luz (Wei y Deng, 1996). Trabajos posteriores concluyeron que seis de los loci COP/DET/FUS, COP8, COP9, COP11, FUS5, FUS11 y FUS12, codifican distintas subunidades pertenecientes al complejo CSN (Wei y Deng, 1992; Staub et al., 1996; Serino et al., 1999; Karniol et al., 1999; Peng et al., 2001; Serino et al., 2003).

CSN está formado por ocho subunidades, CSN1-8 en orden decreciente de tamaño molecular (Deng et al., 2000). La conformación del complejo CSN depende de la interacción entre éstas. La pérdida de función de genes de una única subunidad conlleva la desestabilización del complejo y su consecuente pérdida de función. Por lo tanto, mutaciones simples que afectan a las distintas subunidades provocan en Arabidopsis fenotipos similares (Wei y Deng, 1999). La secuencia de las distintas subunidades no presenta una homología con enzimas previamente descritas a partir de la cual se pueda 
inferir una función en la célula. Sin embargo, seis de estas subunidades (CSN 1-4,7 y 8) presentan dominios PCI (Proteasome, $\underline{\mathrm{COP}}$, Initiation factor 3), mientras que las otras dos (CSN 5 y 6) presentan dominios MPN (Mprlp, Pad1p, N-terminal) (Aravind y Ponting, 1998; Ponting et al., 1999). El dominio PCI, localizado por lo general en la región carboxi-terminal de cada subunidad, contiene una estructura de hélice $\alpha$, y se ha caracterizado por su papel en el ensamblaje de complejos proteicos (Tsuge et al., 2001). Por otro lado, el dominio MPN contiene hélices $\alpha$ y hélices $\beta$ y está localizado generalmente en la región amino terminal de las subunidades. Su función se desconoce en detalle, si bien es importante para la captación de sustratos específicos de los complejos de los que forma parte (Fu et al., 2001). Estos dominios han sido descritos previamente en los complejos multiproteicos de la tapa del proteasoma 26S y del Factor 3 de Iniciación de Traducción (eIF3) de eucariotas (Wei et al., 1998). De hecho, las ocho subunidades del signalosoma COP9 son parálogas una a una a las de la tapa del proteasoma 26S, mientras que eIF3 es algo más distante estructuralmente. Estas similitudes estructurales apuntan a un origen común de estos complejos multiproteicos, que es más evidente en el caso de CSN y la tapa del proteasoma 26S. Además de esta homología estructural, se han descrito interacciones entre subunidades de CSN, de la tapa del 26S proteasoma y del complejo eIF3, lo cual apunta a una relación funcional en la acumulación de proteínas (Wei y Deng, 2003).

\subsection{Función de CSN en la regulación de la degradación de proteínas}

El complejo CSN está implicado en la regulación de la ubiquitinación de proteínas. La ubiquitinación de proteínas es un proceso secuencial consistente en tres pasos. En primer lugar se produce la formación dependiente de ATP de un enlace tioéster entre una glicina del extremo C-terminal de la ubiquitina y una enzima activadora E1, que conlleva la activación de los residuos de ubiquitina. Estos monómeros activados son transferidos a una enzima conjugadora de tipo E2 por la formación de un enlace tioéster. La ubiquitina activada y conjugada es transferida finalmente al complejo E3 ligasa de ubiquitina, que en última instancia incorpora los residuos de ubiquitina a lisinas de un sustrato específico. Este proceso se repite varias veces, añadiendo así cadenas de poliubiquitina a dicho sustrato que será posteriormente degradado por el proteasoma 26S (Hershko y Ciechanover, 1998; Merlet et al., 2009; Sadanandom et al., 2012). Existen varios tipos de complejos E3 ligasa de ubiquitina. La superfamilia CRL (ullin Ring-type E3 ubiquitin Ligases) ha sido la más estudiada por su implicación en un amplio rango de procesos 
biológicos. La estructura general de estos complejos consta de una unidad de culina (CUL), con función estructural dentro del complejo, al que se une un residuo RBX (Ring Box $)$ que recibe la subunidad E2 portadora del monómero de ubiquitina. Esta estructura general CUL-RBX es capaz de interaccionar con distintos subunidades que de forma específica van a disponer en el complejo CRL el sustrato a ubiquitinar (Wei et al., 2008). En Arabidopsis se han descrito cuatro tipos de culina, denominadas CUL1, CUL3A, CUL3B y CUL4. Dependiendo del tipo de culina de la unidad E3 ligasa de ubiquitina, la subunidad portadora del sustrato específico pertenece a la familia F-Box (CUL1), BTB/POZ (CUL3A, CUL3B) o DWD (CUL4) . La unón de estas proteínas al complejo CUL-RBX requiere una subunidad adaptadora de tipo SKP1, en el caso de F-Box, y de tipo DDB1, en el caso de DWD (Figura 6) (Stratmann y Gusmaroli, 2012). El genoma de Arabidopsis codifica la síntesis de 4 Culinas, 23 unidades adaptadoras (21 SKPs, 2 DDB1), y unas 860 subunidades de captación de sustrato a ubiquitinar (694 F-Box, 80 BTB/POZ, 85 DWD). Distintas combinaciones de estas subunidades dan lugar a la posibilidad de formar más de 1500 complejos CRLs, implicados en la ubiquitinación de sustratos específicos implicados en distintos procesos biológicos (Hua y Vierstra, 2011; Stratmann y Gusmaroli, 2012).
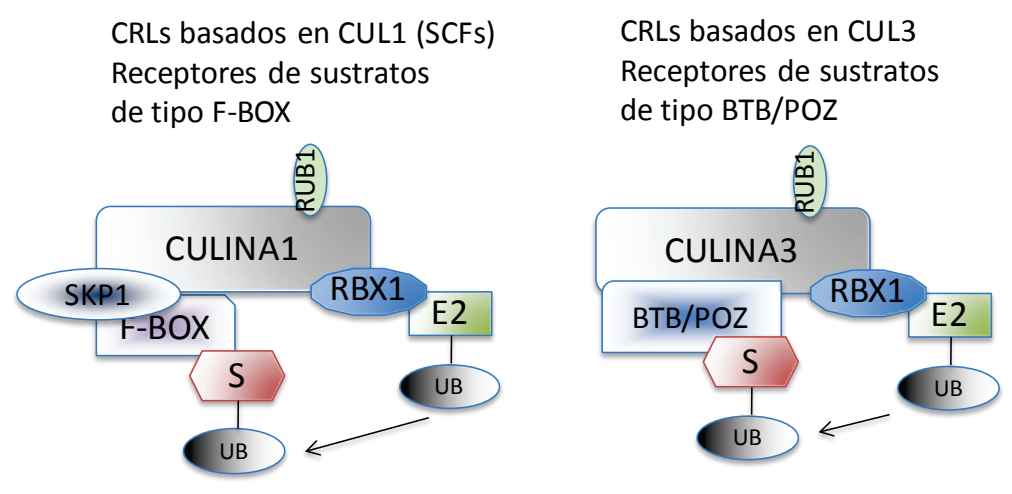

CRLs basados en CUL4 Receptores de sustratos de tipo DWD

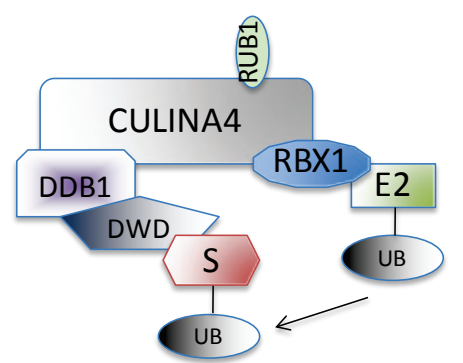

Figura 6. Representación esquemática de los distintos tipos de complejos E3 ligasa de ubiquitinas regulados por CSN en Arabidopsis. Adaptado de Stratmann y Gusmaroli, 2012.

La formación de los complejos CRL E3 ligasa de ubiquitina es un proceso dinámico que está sometido a ciclos de ensamblaje-desensamblaje importantes para su correcto funcionamiento (Figura 7). La liberación del sustrato específico poliubiquitinado requiere el desensamblaje del complejo CRL E3 ligasa de ubiquitina. Este desensamblaje 
es reversible, pudiéndose volver a formar un complejo funcional CRL para la posterior ubiquitinación de otro sustrato (Petroski y Deshaies, 2005). Este proceso está regulado por la unión covalente de residuos similares a los de ubiquitina llamados RUB1 (Related to Ubiquitin 1) a una lisina conservada de la región C-terminal de la subunidad de culina del complejo CRL (Xirodimas, 2008; Merlet et al., 2009). La eliminación de los residuos RUB1 (derubilación) libera el sustrato ubiquitinado del complejo CRL (Serino y Deng, 2003; Stratmann y Gusmaroli, 2012), y provoca un cambio conformacional del complejo que favorece la unión de CAND1 (ㅁLLIN-A ASSOCIATED AND NEDDYLATIONDISSOCIATED 1), impidiendo la formación de un nuevo complejo CRL. Una posterior rubilación provoca la separación de CAND1 de los residuos de culina, y la formación de un nuevo complejo CRL funcional (Wee et al., 2005; Duda et al., 2008) (Figura 7).

Diferentes ensayos de inmunoprecipitación revelan que distintas subunidades de CSN interaccionan físicamente con CUL1 de humanos (hCUL1, Lyapina et al., 2001) y de plantas (Schwechheimer et al., 2001). Además, CSN es capaz de derubilar distintos tipos de culinas in vitro (Lyapina et al., 2001; Menon et al., 2005), por lo que la actividad derubiladora de CSN sobre residuos de culina parece ser directa. Consecuentemente, mutantes en las distintas subunidades de CSN acumulan formas rubiladas de diferentes culinas, mientras que plantas silvestres presentan una mezcla de culinas rubiladas y derubiladas (Schwechheimer et al., 2001). Las interacciones detectadas entre las subunidades de CSN de humanos con culinas de $S$. pombe apunta a que el efecto de CSN sobre la regulación de culinas de los complejos CRLs es un mecanismo conservado en diferentes organismos (Lyapina et al., 2001). Ensayos de mutagénesis dirigida atribuyen al dominio MPN de la subunidad CSN5 la función de derubilación dentro del complejo CSN (Cope et al., 2002). Monómeros de CSN5 carecen sin embargo de actividad hidrolítica, por lo que se deduce que la actividad de CSN5 para el proceso de derubilación requiere la formación de un complejo CSN funcional (Kwok et al., 1998). 


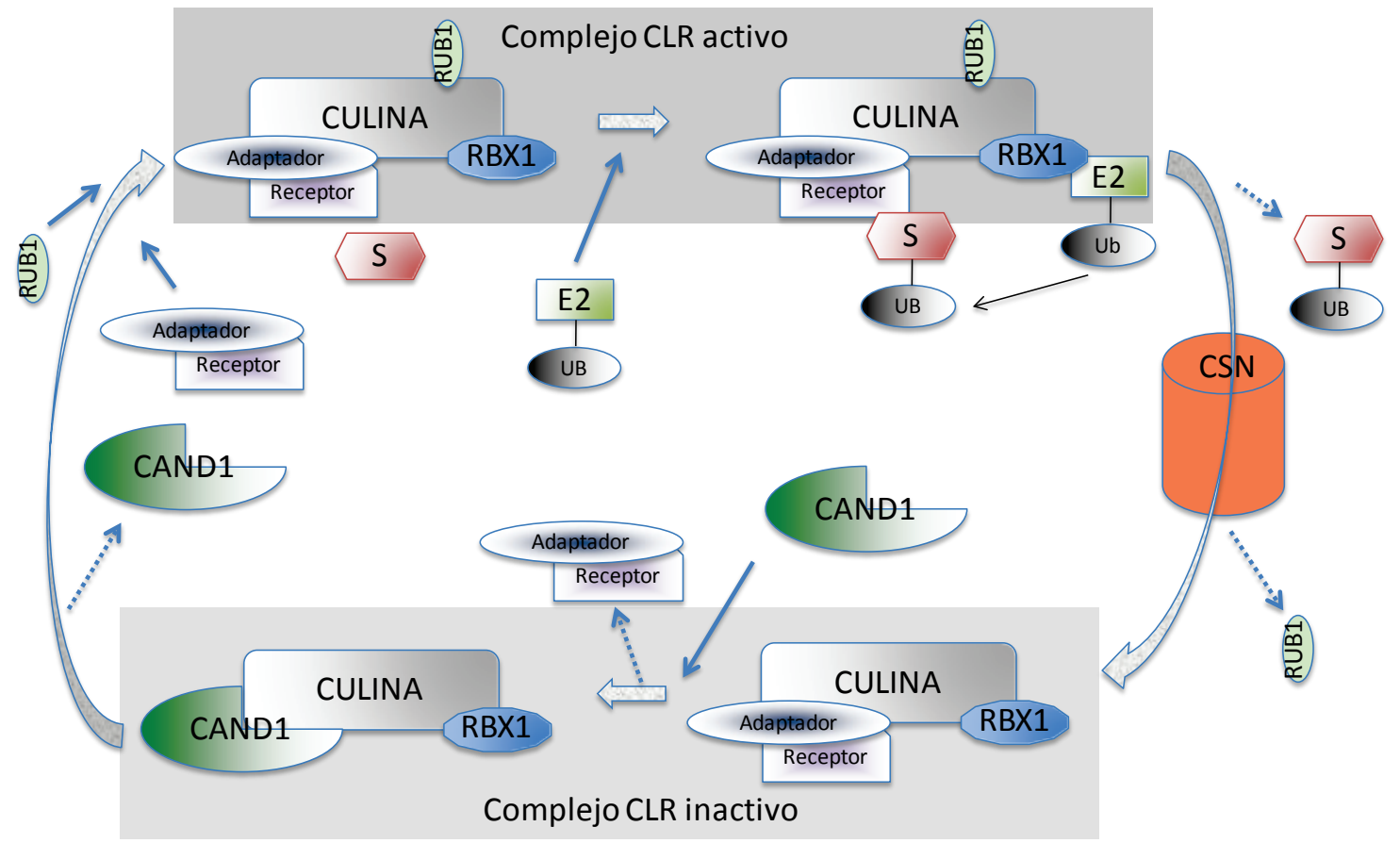

Figura 7. Representación esquemática de los ciclos de ensamblaje / desensamblaje de los complejos CRLs mediados por rubilación. CSN derubila las culinas de los CRLs facilitando su unión a CAND1 y su inactivación funcional. Una posterior rubilación favorece el reensamblaje y la formación de un conplejo CRL funcional. S: sustrato a ubiquitinar. UB: residuo de ubiquitina. Adaptado de Stratmann y Gusmaroli, 2012.

La función de la derubilación de culinas mediada por CSN y la inactivación por CAND1 resulta algo paradójica. Por un lado, tanto la derubilación como la unión de CAND1 a los residuos de culina son reguladores negativos de la ubiquitinación in vitro, ya que actúan como desestabilizadores de los complejos CRLs (Serino y Deng, 2003; Wu et al., 2006). Sin embargo, mutantes que afectan a ambos procesos, como los mutantes csn o los mutantes candl, presentan deficiencias en la ubiquitinación de proteínas que conllevan fuertes alteraciones fenotípicas. El desensamblaje de los complejos CRLs es importante en primer lugar para la liberación de los sustratos a ubiquitinar y su consecuente degradación por el proteasoma 26S. Además, la permanencia del complejo completo y funcional CRLs en ausencia de sustrato conlleva la autoubiquitinación del mismo y a su posterior degradación. Por estas razones, la regulación de la actividad ubiquitinadora y la alternancia de ciclos de activación y desactivación de los complejos CRLs son importantes para garantizar el proceso de ubiquitinación en la célula de forma rápida, específica y eficaz. 


\subsection{Función de CSN en la regulación transcripcional}

La elevada alteración transcripcional de mutantes nulos y parciales de las distintas subunidades que componen el complejo incita a pensar en un papel adicional de CSN a nivel de la transcripción. Si bien es cierto que la alteración de la degradación de proteínas por ubiquitinación da lugar a cambios transcripcionales, por ejemplo, por acumulación de proteínas represoras o activadoras de la transcripción, se ha demostrado la regulación directa de factores de transcripción por su fosforilación mediada por quinasas dependientes de CSN (Chamovitz, 2009). El efecto de la fosforilación por quinasas dependientes de CSN en la actividad de los factores de transcripción puede ser positivo y favorecer su función, como es el caso del activador c-Jun en humanos implicado en la regulación de la transcripción de genes de respuesta a estrés (Seeger et al., 1998), o bien negativo por la degradación de estos factores, como en el caso del supresor de tumores p53 (Bech-Otschir et al., 2001).

Además, CSN es capaz de unirse al ADN (Chamovitz et al., 1996), y se han detectado, de hecho, distintas subunidades de CSN en preparaciones de cromatina en diferentes trabajos en distintos organismos (Groisman et al., 2003; Ullah et al., 2007; Menon et al., 2007). Estos trabajos apuntan a la regulación de CSN a nivel del ADN, bien de forma autónoma o bien por la regulación de la actividad y estabilidad de factores de transcripción a nivel de la cromatina. A pesar de que varias subunidades de CSN han sido detectadas por su asociación a la cromatina, todavía no se ha demostrado in vivo la unión directa a secuencias nucleotídicas del complejo CSN ni de subunidades individuales.

\subsection{Función fisiológica de CSN en Arabidopsis}

\subsubsection{Función de CSN en el desarrollo de Arabidopsis}

\subsubsection{CSN y fotomorfogénesis}

El complejo CSN es un regulador negativo de la fotomorfogénesis en condiciones de oscuridad en Arabidopsis (Wei y Deng, 1992). El papel de CSN sobre la expresión de genes relacionados con la fotomorfogénesis está mediado por la regulación funcional de la E3 ligasa de ubiquitina COP1, la cual interacciona y ubiquitina para su degradación factores de transcripción de respuesta a luz, como HY5 y HLH, en condiciones de oscuridad (Osterlund et al., 2000; Holm et al., 2002), bajo las cuales se ha descrito una localización nuclear de COP1 (von Arnim y Deng, 1994). En condiciones de luz, sin 
embargo, COP1 se localiza mayoritariamente en el citoplasma por lo que no se produce la degradación de los factores de respuesta a luz (von Arnim y Deng, 1994). Se ha descrito que la localización nuclear de COP1 en condiciones de oscuridad se ve alterada en mutantes cop9 y depende de la formación de un complejo CSN funcional (Chamovitz et al., 1996). La regulación de la localización de COP1 por CSN está mediada por la interacción de COP1 con la subunidad CSN1, posiblemente por la retención de la proteína en el núcleo más que por el transporte de ésta desde el citosol (Wang et al., 2009). Este proceso es además independiente de la actividad derubiladora de culinas de CSN.

\subsubsection{Otras alteraciones del desarrollo en mutantes csn}

Dado que CSN actúa como regulador de la función de complejos CRLs por rubilación, los procesos de desarrollo que implican CRLs se ven alterados en mutantes csn. Entre los procesos de desarrollo alterados en estos mutantes se encuentran los relacionados con la señalización de auxinas y de giberelinas, así como la formación de órganos florales (Schwechheimer y Isono, 2010; Stratmann y Gusmaroli, 2012).

Se ha descrito la interacción de CSN con la E3 ligasa de ubiquitina SCF ${ }^{\mathrm{TIR} 1}$ implicada en la degradación de factores represores de respuesta a auxinas (Schwechheimer et al., 2001). Las auxinas controlan un amplio rango de procesos de desarrollo, desde el crecimiento de la raíz principal, hasta la inhibición de la formación de ramificaciones secundarias o dominancia apical (Zhao, 2010). Sin embargo, la comparación de fenotipos relacionados con la percepción y señalización de auxinas con los de mutantes csn sugiere que CSN juega un papel parcial en el control del desarrollo controlado por estas hormonas (Dohmann et al., 2008). Otra interacción de CSN descrita que implica su relación con procesos de desarrollo es la relativa a $\mathrm{SCF}^{\mathrm{UFO}}$ (Wang et al., 2003). La pérdida de función del complejo CSN conlleva en Arabidopsis la formación de órganos florales aberrantes, así como una regulación a la baja del gen de identidad floral $A P 3$ y una baja fertilidad, fenotipos similares a los observados en mutantes $\underline{u}$ usal floral organs (ufo) de Arabidopsis (Zhao et al., 2001). Por último, el fenotipo de reducida fertilidad, germinación, y enanismo de mutantes csn, similar al de mutantes deficientes en la señalización por giberelinas, podría explicarse por la regulación mediada por CSN de la E3 ligasa de ubiquitina $\mathrm{SCF}^{\mathrm{SLY} 1}$, implicada en la degradación dependiente de GAs de proteínas DELLA represoras de genes de respuesta a esta hormona (McGinnis et al., 2003). No se ha descrito una interacción física de $\mathrm{CSN}$ y $\mathrm{SCF}^{\mathrm{SLY} 1}$, si bien el mutante $\operatorname{csn} 5 a$ presenta una elevada 
acumulación de la proteína DELLA REPRESSOR OF GA1-3 (RGA) (Dohmann et al., 2010).

\subsubsection{Función relacionada con la respuesta al estrés biótico}

El papel de CSN en defensa ha sido descrito en mamíferos por su implicación en la respuesta inmune. A diferencia de los mamíferos, las plantas carecen de un sistema inmune, si bien se han caracterizado distintos complejos CRLs y distintas hormonas vegetales implicadas en defensa. El papel regulador del complejo CSN sobre la función de complejos CRL y consecuentemente sobre las rutas de señalización hormonal apuntan a una alteración de la respuesta a estrés biótico cuando se interfiere la función del signalosoma COP9 (Stratmann y Gusmaroli, 2012).

Como se indicó anteriormente, el ácido jasmónico es una hormona importante para la respuesta frente a patógenos de tipo necrotrofo (Glazebrook, 2005), y su percepción está mediada por la E3 ligasa de ubiquitina COI1 (Fonseca et al., 2009). Se ha descrito la interacción física de la F-box COI1 con distintas subunidades de CSN y la formación in vivo de un complejo SCF ${ }^{\mathrm{COI}}$-CSN (Feng et al., 2003). Esta interacción conlleva además una relación funcional de COI1 y CSN en distintos procesos celulares regulados por JA, no sólo relativos a la respuesta frente a estrés, sino también en procesos relacionados con la fotosíntesis, con el metabolismo de polisacáridos y de aminoácidos, y con procesos de generación energética (Feng et al., 2003). Además, mutantes débiles csn muestran un fenotipo parcialmente insensible a JA y una alteración de la activación de genes de respuesta, lo que indica que la formación de complejos CSN es importante para la respuesta a esta hormona (Feng et al., 2003). CSN también es importante para la acumulación de JA en respuesta a estrés por patógenos o por herida. Líneas transgénicas de tomate con niveles reducidos de CSN5 acumulan menores cantidades de JA que plantas control en respuesta a herida $\mathrm{y}$, consecuentemente, una menor expresión de genes de respuesta. Concomitantemente, estas líneas son más susceptibles al patógeno necrotrofo Botrytis cinerea y al ataque del lepidóptero Manduca sexta (Hind et al., 2011). Estos fenotipos coinciden con los de mutantes coil en Arabidopsis (Thomma et al., 1998; Glauser et al., 2008). Todos estas observaciones indican que el complejo CSN es un modulador importante para la señalización de JA en plantas, tanto en procesos de desarrollo como en procesos de defensa, posiblemente por la regulación por rubilación de CUL1 dentro del complejo SCF ${ }^{\mathrm{COI} 1}$ (Ren et al., 2005). 
Por otro lado, la señalización por SA en la respuesta a patógenos dependiente de NPR1 descrita en el apartado 4.2. también está modulada por CSN. El recambio de los monómeros de NPR1 en el núcleo es importante para una correcta función de esta proteína en respuesta a SA. Esta renovación se produce por su degradación por ubiquitinación, y síntesis de novo de moléculas de NPR1. Se ha descrito que NPR1 interacciona en el núcleo con CUL3 y con algunas subunidades del complejo CSN, y que esta interacción está favorecida por el SA (Spoel et al., 2009). Mutantes cul3 tratados con SA muestran una menor activación de genes de respuesta de la familia WRKY que plantas silvestres. El signalosoma CSN interviene en la degradación de NPR1 ya que mutantes cop9, a diferencia de las plantas silvestres, acumulan NPR1 en forma monomérica (Spoel et al., 2009).

Además de actuar como modulador funcional de la respuesta a estrés biótico dependiente de JA y SA, el complejo CSN puede interferir directamente sobre genes R de reconocimiento de patógenos, si bien el mecanismo por el que actúa no se conoce en detalle. En Nicotiana benthamiana la respuesta frente al Virus del Mosaico del Tabaco (TMV, Tobacco Mosaic irus) está controlada por el gen de resistencia $N$, el cual requiere el gen NbRarl para una respuesta inicial efectiva frente a TMV (Marathe et al., 2002). NbRar1 interacciona con el componente de la SCF E3 ligasa de ubiquitina NbSGT1, que forman a su vez un complejo multiproteico con CSN en Nicotiana. La interferencia de la función de CSN8 por vectores virales da lugar a una menor acumulación de CSN4 y CSN8, y a la no formación de un complejo CSN funcional. Esta alteración conlleva la anulación de la resistencia mediada por el gen $N$ a TMV, al igual que sucede con la interferencia de la función de otros genes del complejo multiproteico formado, como NbRarl y NbSGT1 (Liu et al., 2002). El efecto de CSN sobre la susceptibilidad a TMV parece ser específico de huésped, ya que el silenciamiento de CSN5 en plantas de tomate no muestran una alteración de la resistencia frente a TMV con respecto a plantas silvestres (Hind et al., 2011).

\section{Antecedentes}

PCC1 fue identificado inicialmente como un gen cuya expresión se activaba fuertemente por cepas avirulentas de Pseudomonas syringae AvrRpt2 (Sauerbrunn y Schlaich, 2004). La relación funcional de PCC1 con la defensa de plantas frente a 
microorganismos patógenos queda evidenciada por los fenotipos de resistencia de líneas sobreexpreoras de PCC1 frente al patógeno biotrofo obligado Peronospora parasitica Noco (Sauerbrunn y Schlaich, 2004). PCC1 muestra un patrón de expresión controlado por el reloj circadiano, siendo su expresión máxima a las 12 horas de luz en condiciones de días largos (Sauerbrunn y Schlaich, 2004; Segarra et al., 2010). Además, la expresión de PCC1 depende de SA y se induce por irradiación con luz UV-C de forma dependiente de SA (Segarra et al., 2010). Un estudio in silico basado en residuos conservados de cisteína apunta a que PCC1 contiene un dominio en su extremo carboxi terminal homólogo a hélices transmembrana de tipo CYSTM. Las proteínas identificadas en este estudio pertenecen a distintos organismos eucariotas y tienen la característica común de estar implicadas en distintos tipos de estrés, tanto biótico como abiótico (Venancio y Aravind, 2010). Todos estos datos apuntan a una clara relación de PCC1 con la respuesta a estrés en Arabidopsis.

Análisis de secuencia indican que PCC1 pertenece una familia génica de 6 miembros repartidos en los cromosomas 1, 2 y 3 del genoma de Arabidopsis. Entre los genes de la familia de PCC1 se encuentra el gen At3g22240, situado en la región 3' de PCC1 (At3g22231), el gen At1g05340, y tres genes situados en tandem en el cromosoma 2, identificados como At2g32190, At2g32200 y At2g32210 (Sauerbrunn y Schlaich, 2004). Técnicas de hibridación con sondas radioactivas específicas revelan que PCC1 presenta ortólogos en especies de brásicas como Brassica oleracea var. capitata alba (col blanca). Se han detectado además genes ortólogos en Hordeum vulgare (cebada), Zea mays (maíz), Nicotiana tabacum (tabaco) y Oryza sativa (arroz), si bien presentan unos tamaños ligeramente distintos a los observados en Arabidopsis. No se han detectado genes ortólogos en Phaseolus vulgaris (haba), Lycopersicum sculentum (tomate) ni en Saccaromyces cerevissiae (levadura), por lo que apunta a que PCC1 no es un gen universalmente conservado en el reino vegetal ni en el resto de eucariotas (Sauerbrunn y Schlaich, 2004).

Por otro lado PCCl se ha identificado como un regulador de procesos de desarrollo, concretamente el proceso de transición floral en Arabidopsis. Líneas de interferencia de ARN específicas para el silenciamiento de PCC1 (iPCC1) muestran un fenotipo de floración tardía con respecto a plantas control bajo condiciones de días largos (Segarra et al., 2010). En condiciones fotoperiódicas no inductoras de 8 horas de luz diaria las líneas iPCC1 muestran fenotipos de floración similares a los de plantas control, por lo 
que $P C C 1$ se considera un gen que participa en la ruta de floración del fotoperiodo (Segarra, 2009). Los niveles de transcrito del gen de integración floral $F T$, pero no los del gen $S O C 1$, se ven fuertemente reducidos en plantas iPCC1. Además, el mutante co-1 presenta en condiciones basales una menor expresión de $P C C 1$ que plantas silvestres, que es mucho más evidente en plantas irradiadas con UV-C (Segarra et al., 2010). Por esta razón se propuso que PCC1 podría ser un intermediario de la activación de FT por CO.

Las plantas iPCC1 presentan además alteraciones relacionadas con el desarrollo distintas al tiempo de floración (Segarra, 2009). La pérdida de función de PCCl confiere a las plantas de Arabidopsis una roseta más compacta y con hojas más grandes, así como un mayor grosor de los tallos. Las silicuas de las líneas iPCC1 son más largas y están dispuestas sobre los tallos formando un menor ángulo con respecto a éste que en las plantas silvestres. Además, las flores en las plantas iPCC1 son de mayor tamaño y se agrupan en mayor número formando inflorescencias con un mayor grado de compactación (Segarra, 2009). Además las líneas iPCC1 muestran una senescencia forzada en oscuridad prematura, por lo que PCC1 parece actuar como una proteína con función antisenescente en Arabidopsis (Segarra, 2009).

Los fenotipos descritos para las líneas con alteraciones en los niveles de PCC1 relacionados con la respuesta a estrés biótico y con el desarrollo en Arabidopsis apuntan a que PCC1 pueda tener un papel importante en la modificación de patrones de desarrollo en respuesta a estrés. La incapacidad de activar la floración en respuesta a estrés generado por irradiación con luz UV-C en plantas iPCC1 (Segarra et al., 2010), apunta a que PCC1 pueda ser un gen de respuesta a la percepción del estrés, que actúe activando la transición floral en Arabidopsis, con la ventaja evolutiva que esto conlleva descrita en el apartado 1 de la introducción. En la presente tesis doctoral nos disponemos a profundizar en el entendimiento de cómo PCC1, una proteína de $8.4 \mathrm{kDa}$, puede regular procesos tan dispares molecularmente como son la transición floral y la respuesta frente a patógenos en Arabidopsis. 

Objetivos 

Para la caracterización funcional y molecular de PCC1 nos hemos planteado los siguientes objetivos:

- Análisis espacio-temporal de la expresión de PCC1

- $\quad$ Estudio molecular de la topología de PCC1 en la célula

- Análisis funcional de PCC1 en la transición floral

- Búsqueda de proteínas interactoras de PCC1 por escrutinio de doble híbrido en levadura

- Estudio de la función de PCC1 mediante análisis transcriptómico de líneas iPCC1 frente a plantas silvestres 

Resultados 

1. Análisis in silico de la proteína PCC1 y sus homólogos en Arabidopsis

\subsection{Características generales de PCC1}

Pathogen and Circadian Controlled 1 (PCC1) fue identificado inicialmente como un gen de respuesta a Pseudomonas syringae (Sauernburn y Schlaich, 2004), y posteriormente se identificó en una búsqueda de genes candidatos a activar la floración por irradiación con luz UV-C de forma dependiente del ácido salicílico (Segarra et al., 2010). PCC1 (At3g22231) es un locus situado en una región genómica cercana a los 7,8 Mbp del cromosoma 3 de Arabidopsis thaliana (he Arabidopsis Information Resource, TAIR; Figura 8A). En la región genómica 5' del locus At3g22231 se encuentran los genes At3g22220, de función desconocida, y At3g22230, que codifica una proteína de la familia de proteínas ribosomales L27e (Carroll et al., 2008). En la región 3' del locus PCC1 están anotados un conjunto de pseudogenes, At3g22232, At3g22234, At3g22237 y At3g22238, además de los genes At3g22235 y At3g22240. El gen At3g22240 ha sido identificado como un gen de la familia de 6 miembros de PCC1 (Sauernbunn y Schlaich, 2004). PCC1 es un gen de pequeño tamaño que contiene tres exones de 31,154 y $61 \mathrm{bp}$, separados por dos intrones de 111 y 127 bp. Las 246 bp de la región codificante de PCC1 se traducen en una proteína de 81 aminoácidos y de $8,4 \mathrm{kDa}$ de peso molecular (Figura $8 \mathrm{~B}$ ). Su composición aminoacídica revela una elevada cantidad relativa de serina, prolina y cisteína, mientras que carece de aminoácidos como la histidina y el triptófano (Tabla 1). PCC1 presenta un valor de punto isoeléctrico de 4.25 y un coeficiente de inestabilidad de 60.45 , lo que sugiere que se trata de una proteína poco estable (ProtParam-ExPASy; Gasteiger et al., 2005).

\begin{tabular}{|c|c|c|c|c|c|}
\hline & $\mathrm{N}^{\circ}$ residuos & $\%$ & & $\mathrm{~N}^{\circ}$ residuos & $\%$ \\
\hline Ala & 6 & 7.4 & Lys & 2 & 2.5 \\
\hline Arg & 1 & 1.2 & Met & 3 & 3.7 \\
\hline Asn & 4 & 4.9 & Phe & 3 & 3.7 \\
\hline Asp & 2 & 2.5 & Pro & 9 & 11.1 \\
\hline Cys & 7 & 8.6 & Ser & 12 & 14.8 \\
\hline Gln & 3 & 3.7 & Thr & 6 & 7.4 \\
\hline Glu & 5 & 6.2 & Trp & 0 & 0 \\
\hline Gly & 5 & 6.2 & Tyr & 3 & 3.7 \\
\hline His & 0 & 0 & Val & 6 & 7.4 \\
\hline Ile & 3 & 3.7 & Leu & 1 & 1.2 \\
\hline
\end{tabular}

Tabla 1. Composición aminoacídica de PCC1. 


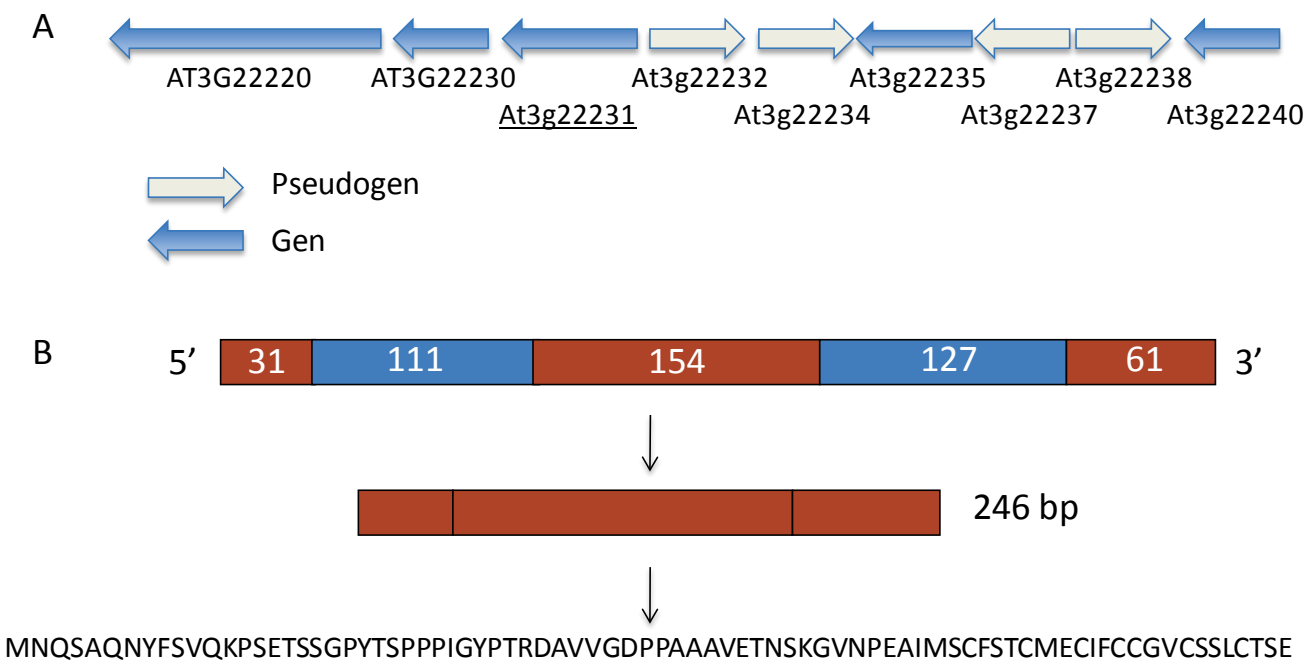

Figura 8. A. Región genómica del locus At3g22231 (PCC1). B. Representación esquemática de la estructura génica de PCC1, y secuencia aminoacídica de la proteína codificada correspondiente.

Las modificaciones post-traduccionales de proteínas son importantes moduladores de su función (van Kasteren, 2012). Concretamente, se ha descrito que la fosforilación/defosforilación de proteínas puede afectar no sólo a su función, sino también a su localización subcelular, interacción con otras proteínas o a su estabilidad, y se ha observado este tipo de regulación post-traduccional para proteínas implicadas en la gran mayoría de procesos biológicos en plantas (Luan, 2003). La herramienta bioinformática NetPhos 2.0 (ExPASy; Blom et al., 1999) predice la potencialidad de una secuencia de aminoácidos de ser fosforilada en sus residuos de serina, tirosina o treonina. Hemos analizado in silico la secuencia primaria de PCC1 con esta herramienta. El resultado revela que en la secuencia de PCC1 existen tres residuos de serina y dos de tirosina con una elevada probabilidad de ser fosforilados in vivo (Figura 9). Sin embargo, la herramienta NetPhos utiliza algoritmos de predicción basados en sustratos de quinasas de mamíferos, algunas de las cuales no tienen homólogos en Arabidopsis, lo cual puede dar lugar a falsos positivos, es decir, a la identificación de sitios de fosforilación en una secuencia problema que no se fosforila en plantas. Por esta razón hemos acudido a la base de datos Phos PhAt 4.0 (Heazlewood et al., 2008; Durek et al., 2010), donde se encuentra recopilado el total de sitios de fosforilación de proteínas de Arabidopsis identificados in vivo por distintos grupos de investigación en diferentes trabajos. En un estudio de la identificación de proteínas de membrana plasmática fosforiladas (Nühse et al, 2004), detectaron la fosforilación de la tirosina situada en la posición 8 de la secuencia de PCC1, para la cual se 
ha determinado una probabilidad de fosforilación del 0.626 con la herramienta NetPhos 2.0, valor superior al umbral teórico de fosforilación (Figura 9). En otro trabajo independiente se identificó PCC1 como proteína fosforilada en una muestra de proteínas totales obtenidas a partir del tallo en Arabidopsis (Reiland et al., 2009). En este caso el aminoácido de la secuencia de PCC1 fosforilado fue la serina situada en la posición 24 (Figura 9). Para esta serina sin embargo, no se ha obtenido una probabilidad de fosforilación muy elevada (0.398) con la herramienta NetPhos 2.0 (Figura 9). En el primer caso, pero no en el segundo, hemos obtenido una predicción real de fosforilación de PCC1. Para el resto de sitios de fosforilación predichos a partir de la secuencia de PCC1 por la herramienta NetPhos 2.0 no se han encontrado residuos fosforilados in vivo hasta la fecha.

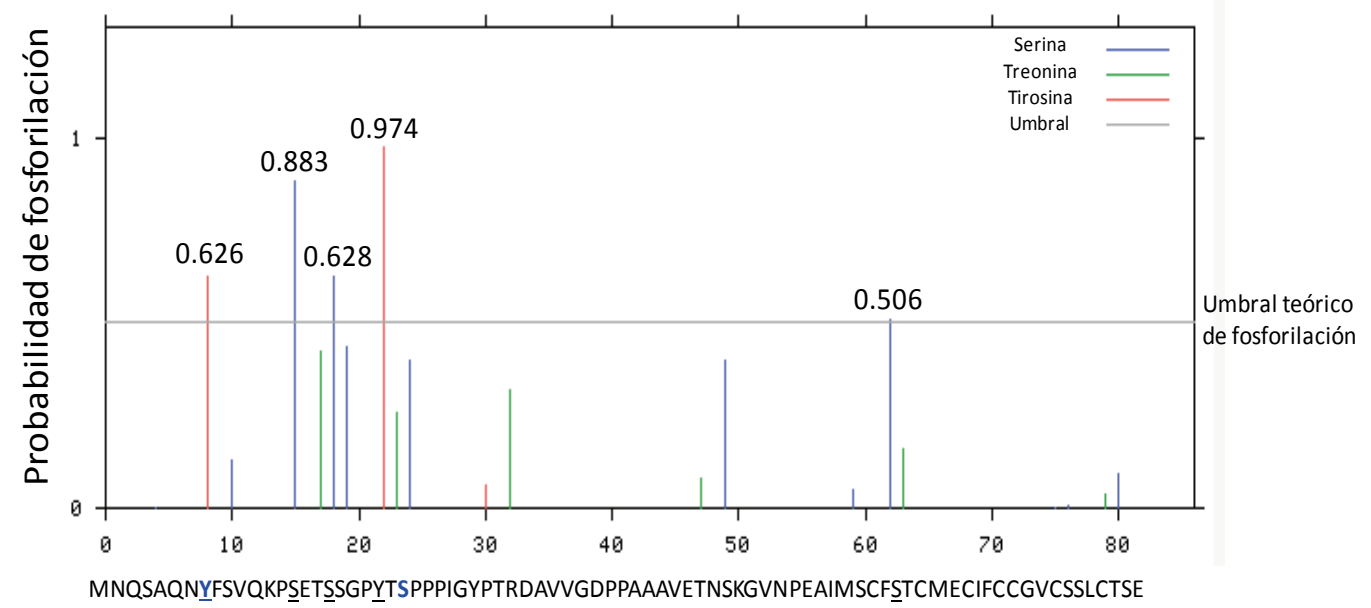

Figura 9. Predicción de sitios de fosforilación a lo largo de la secuencia de PCC1 mediante la herramienta bioinformática NetPhos2.0 (ExPASy; Blom et al., 1999). Los residuos subrayados son potencialmente fosforiados según la herramienta NetPhos 2.0 con las probabilidades indicadas en cada caso. Los residuos marcados en letra azul se han detectado in vivo en diferentes trabajos (Nühse et al, 2004; Reiland et al., 2009).

La palmitoilación es una modificación de proteínas que consiste en la unión covalente de ácidos grasos de 16 carbonos a residuos de cisteína, y menos comúnmente de serina y treonina. Esta modificación de proteínas es frecuente en proteínas de membrana, y funciona aumentando la hidrofobicidad de éstas contribuyendo así a su asociación a las estructuras membranosas. La elevada cantidad de residuos de cisteína ya comentada junto con la pontencialidad de ubicación en la membrana plasmática que se detallará a continuación apuntan a que PCC1 sea potencialmente un blanco de palmitoilación. Si bien no se ha descrito una secuencia consenso para el proceso de palmitoilación de proteínas, existen patrones de secuencias aminoacídicas comunes en proteínas con este tipo de 
modificaciones identificadas previamente. Estos patrones aminoacídicos se clasifican en tres grupos, los de tipo I (-CC-), los de tipo II (-CXXC-), siendo C un residuo de cisteína y $\mathrm{X}$ cualquier otro residuo, y los de tipo III (otros patrones). Hemos analizado in silico la presencia de sitios de palmitoilación en la secuencia de PCC1 con el uso de la herramienta bioinformática CSS-PALM $\quad 3.0 \quad$ (Ren et al., 2008; http://csspalm.biocuckoo.org/online.php). La secuencia aminoacídica de PCC1 muestra seis residuos de cisteína que potencialmente podrían estar palmitoilados, cuatro de los cuales presentan un valor de puntuación al menos un punto por encima del valor umbral (Tabla 2). Todos estos sitios de palmitoilación se encuentran en la región rica en cisteínas presente en su región carboxi-terminal que será discutida más adelante.

\begin{tabular}{|c|c|c|c|c|}
\hline Posición & Sitio de Palmitoilación & Puntuación & Umbral & Tipo \\
\hline 60 & NPEAIMSCFSTCMEC & 0,343 & 0,308 & I \\
\hline 64 & IMSCFSTCMECIFCC & 0,972 & 0,497 & II \\
\hline 67 & CFSTCMECIFCCGVC & 1,491 & 0,497 & II \\
\hline 70 & TCMECIFCCGVCSSL & 2,671 & 0,308 & I \\
\hline 71 & CMECIFCCGVCSSLC & 1,565 & 0,497 & II \\
\hline 74 & CIFCCGVCSSLCTSE & 4,019 & 0,497 & II \\
\hline
\end{tabular}

Tabla 2. Predicción de sitios de palmitoilación con la herramienta bioinformática CSS-PALM 3.0 (Ren et al., 2008; http://csspalm.biocuckoo.org/online.php).

El óxido nitrico es una molécula muy reactiva capaz de modificar la función de proteínas por su unión a grupos tiol de aminoácidos (S-nitrosilación) como la cisteína, o a través de la formación de peroxinitrito que reacciona con residuos de tirosina (nitración). Hemos analizado in silico la capacidad de S-nitrosilación y de nitración con las herramientas bioiformáticas GPS-SNO (Xue et al., 2010; http://sno.biocuckoo.org/) y GPS-YNO (Liu et al., 2011b; http://yno2.biocuckoo.org/), respectivamente. Con estas herramientas hemos identificado un potencial sitio de S-nitrosilación en el residuo C60 y dos para modificaciones por nitración en Y8 e Y22 (Tabla 3). Los valores de puntuación obtenidos por estos algoritmos son, sin embargo, sólo ligeramente superiores a los valores umbral, por lo que la posibilidad de que PCC1 pueda modificarse postraduccionalmente por NO no es, en principio, muy probable y requeriría de la comprobación experimental. 


\begin{tabular}{|c|c|c|c|c|c|}
\hline Modificación & Posición & Secuencia & Puntuación & Umbral & Herramienta \\
\hline $\mathrm{C}-\mathrm{NO}$ & 60 & NPEAIMSCFSTCMEC & 2,739 & 2,443 & GPS-SNO \\
\hline \multirow{2}{*}{$\mathrm{Y}^{-N^{2}}{ }_{2}$} & 8 & MNQSAQNYFSVQKPS & 1,1 & 0,725 & \multirow{2}{*}{ GPS-YNO } \\
& 22 & SETSSGPYTSPPPIG & 0,772 & 0,725 & \\
\cline { 2 - 5 } & & & & \\
\hline
\end{tabular}

Tabla 3. Predicción de sitios de S-nitrosilación (C-NO) e Y-nitración $\left(\mathrm{Y}-\mathrm{NO}_{2}\right)$ con las herramientas bioinformáticas CSS-SNO (Xue et al., 2010; http://sno.biocuckoo.org/) y CSS-YNO (Liu et al., 2011b; http://yno2.biocuckoo.org/), respectivamente.

Hemos analizado la posibilidad de otro tipo de modificaciones, tales como la ubiquitinación, la sumoilación y la pupilación, y no se han predicho in silico sitios específicos de estas modificaciones post-traduccionales en la secuencia aminoacídica de PCC1.

PCC1 ha sido identificada en distintos análisis de proteínas de membrana plasmática en Arabidopsis (Marmagne et al., 2004; Nühse et al, 2004). Una característica común para la ubicación de proteínas en un entorno hidrofóbico como las membranas celulares es su elevada hidrofobicidad. El índice GRAVY (Grand average of hydropathicity) nos da un valor de hidrofobicidad de una secuencia aminoacídica, siendo ésta tanto más hidrofóbica cuanto mayor sea el valor de índice GRAVY (Kyte y Doolittle, 1982). El índice global GRAVY estimado para PCC1 es de -0.129 (ProtParam-ExPASy; Gasteiger et al., 2005), un valor atípico para proteínas asociadas a la membrana plasmática. Sin embargo, si se analiza la hidrofobicidad a lo largo de su secuencia (ProtScale-ExPASy; Gasteiger et al., 2005), se observa que entre los residuos 65 a 75 de la región carboxiterminal el valor de hidrofobicidad en la escala Kyte-Doolittle es superior a 1.5, valor típico de proteínas de membrana (Figura 10A). La herramienta TMPred (Koffmann y Stroffel, 1993; EMBnet) predice a lo largo de una secuencia de aminoácidos la presencia de zonas transmembrana. El análisis de la secuencia de PCC1 con esta herramienta bioinformática indica la presencia de una posible hélice transmembrana en su región carboxi-terminal (Figura 10B) coincidente con su región más hidrofóbica (Figura 10A). El modelo más probable generado por esta herramienta ( $>>0$, Figura $10 \mathrm{~B}$ ) consiste en una disposición de la región amino-terminal en el exterior celular, y una hélice transmembrana entre los residuos 56 y 75 (puntuación de 1024). Un modelo alternativo generado con esta herramienta (o>i, Figura 10B), consistente en la región amino-terminal con disposición intracelular y una hélice transmembrana entre residuos 60 y 78, presenta una puntuación de 983. Con estos datos no es posible predecir la disposición exacta de la proteína en la membrana. Para corroborar la presencia de zonas transmembrana en PCC1 mediante una 
herramienta alternativa, hemos utilizado la herramienta bioinformática Phobious (Käll et al., 2004), obteniéndose un resultado similar al obtenido anteriormente. Según esta herramienta, PCC1 presenta una región transmembrana entre los residuos 56 y 80 de su región carboxi-terminal, y, con mayor probabilidad, expondría su región amino-terminal a la superficie extracelular (Figura 10C).
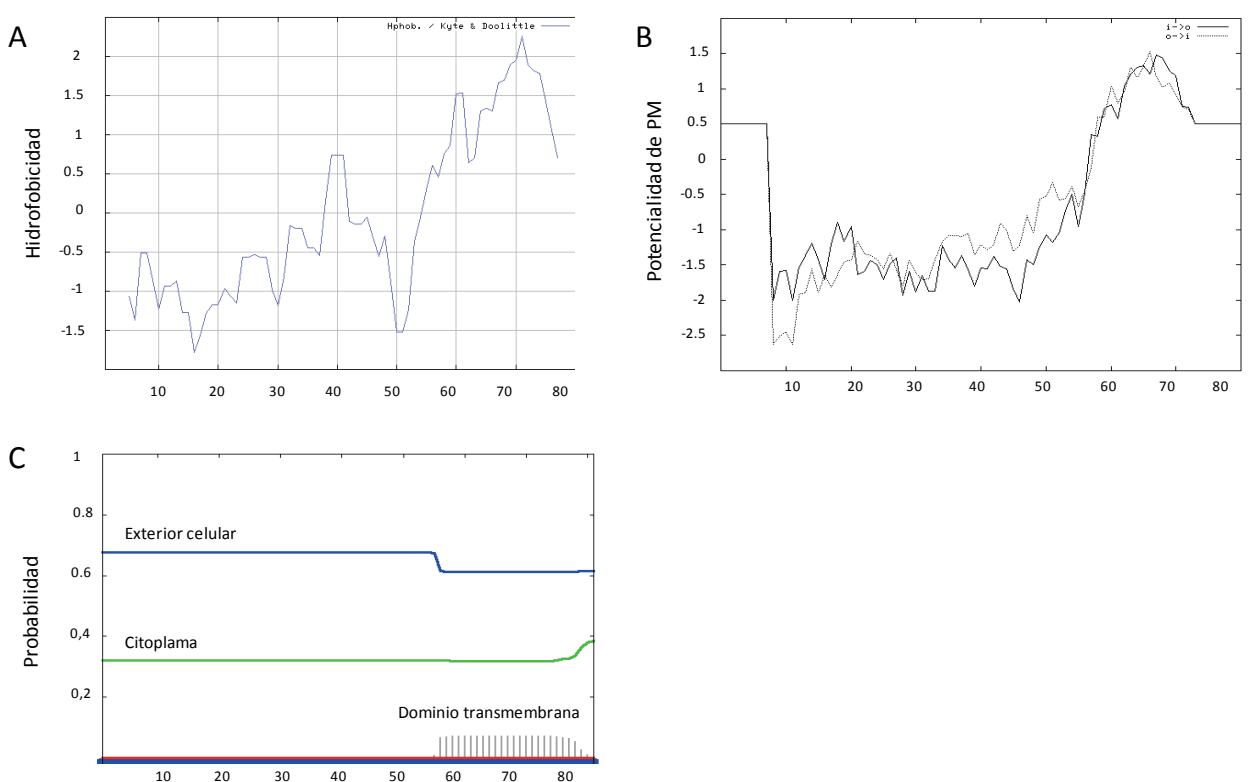

Figura 10. Predicción de la ubicación en estructuras membranosas celulares de PCC1 por distintas aproximaciones in silico. A. Estimación de la hidrofobicidad según la escala de Kyte-Doolittle a lo largo de la secuencia de PCC1 mediante el uso de la herramienta ProtScale (ExPASy; Gasteiger et al., 2005). B y C. Predicción de la presencia de dominios transmembrana partir de la secuencia de PCC1 utilizando las herramientas bioinformáticas TMPred (B; Koffmann y Stroffel, 1993) y Phobious (C; Käll et al., 2004).

Las herramientas bioinformáticas utilizadas son específicas para proteínas de membrana, lo cual no significa que PCC1 se pueda clasificar como una proteína de membrana utilizando un programa de localización celular generalista. De hecho, en la base de datos de Arabidopsis TAIR, PCC1 está anotada como una proteína nuclear y de membrana. Para estudiar in silico la localización de PCC1 hemos utilizado una serie de herramientas bioinformáticas que predicen la localización subcelular de proteínas a partir de su secuencia, y se han obtenido resultados dispares (Tabla 4). Algunas de las herramientas utilizadas apuntan a una localización nuclear (AtSUB P, Kaundal et al., 2010; CELLO, Yu et al., 2006), mientras que otras predicen una ubicación de PCC1 en cloroplastos (LOCtree, Petersen et al., 2011; IPSORT, Bannai et al., 2002) o en el citoplasma (SubLoc v1.0; Hua y Sun, 2001). Algunas herramientas indican incluso que se trata de una proteína extracelular (CELLO, Yu et al., 2006; Multiloc, Blum et al., 2009). 
Por esta razón, será necesario el uso de técnicas moleculares que demuestren la localización subcelular real de PCC1.

\begin{tabular}{|l|l|l|}
\hline Herramienta & Localización & Ref. Bibliográfica \\
\hline CELLO & $\begin{array}{l}\text { Extracelular / } \\
\text { Nuclear }\end{array}$ & Yu et al., 2006 \\
\hline iPSORT & Cloroplasto & Bannai et al., 2002 \\
\hline LOCtree & Cloroplasto & Petersen et al., 2011 \\
\hline SubLoc v1.0 & Citoplasma & Hua y Sun, 2001 \\
\hline MultiLoc & Extracellular & Blum et al., 2009 \\
\hline AtSUB P & Nuclear & Kaundal et al., 2010 \\
\hline
\end{tabular}

Tabla 4. Predicción de la localización celular de PCC1 utilizando herramientas bioinformáticas generalistas de localización subcelular.

1.2. Análisis de secuencia de genes homólogos a PCC1 en Arabidopsis

PCC1 pertenece a una familia de 6 genes en Arabidopsis (Sauernbunn y Schlaich, 2004). Si se buscan genes homólogos utilizando la secuencia codificante de $P C C 1$ con la herramienta del TAIR WU-BLAST (http://www.arabidopsis.org/wublast/index2.jsp), encontramos dos loci adicionales, At3g22235 y At1g56060, que podrían ser incluidos en esta familia por su elevada homología de secuencia con PCC1. Del total de los 7 genes de la familia de PCC1, dos de ellos se ubican en el cromosoma 1 (At1g05340 y At1g56060), tres más se disponen en tándem en el cromosoma 2 (At2g32190, At2g32200 y At2g32210), y los otros dos, mencionados anteriormente, se disponen en el cromosoma 3 en tándem con PCC1 (At3g22235 y At3g22240). Todos estos genes presentan un tamaño de la secuencia codificante y una estructura génica similar, consistente en 3 exones y dos intrones. Consecuentemente, las proteína potencialmente codificadas por estos genes presentan un número de aminoácidos y unos pesos moleculares similares, si bien difieren en su punto isoeléctrico, siendo PCC1 la que menor pI presenta (Tabla 5). 


\begin{tabular}{|c|c|c|c|}
\hline & Longitud (aa) & P. Mol. (Da) & pI \\
\hline At1g05340 & 72 & 7479,5 & 7,1721 \\
\hline At1g56060 & 71 & 7812,1 & 6,7339 \\
\hline At2g32190 & 71 & 7380,4 & 5,555 \\
\hline At2g32200 & 75 & 7799,8 & 4,629 \\
\hline At2g32210 & 71 & 7337,2 & 5.555 \\
\hline At3g22231 & 81 & 8478,4 & 3,9901 \\
\hline At3g22235 & 71 & 7317,1 & 4,0738 \\
\hline At3g22240.1 & 52 & 5984 & 9,4046 \\
\hline At3g22240.2 & 72 & 7524,5 & 4,7924 \\
\hline
\end{tabular}

Tabla 5. Características físico-químicas de las proteínas de la familia de PCC1.

El alineamiento del conjunto de genes de la familia de PCCl basado en su secuencia nucleotídica y aminoacídica con la herramienta bioinformática CLUSTAL-W (EMBL-EBI, http://www.ebi.ac.uk/Tools/msa/clustalw2/), permite obtener árboles filogenéticos basados en homología de secuencia. Los árboles filogenéticos generados a partir de la secuencia de ADN muestran una subagrupación de PCC1 y sus dos homólogos en tándem (At3g22235 y At3g22240). Algo más distanciados filogenéticamente se encuentran los genes ubicados en el cromosoma 1. Los genes en tándem del cromosoma 2 son los más distantes en cuanto a similitud de secuencia nucleotídica con respecto al resto de genes de la familia (Figura 11A). El árbol filogenético generado a partir de la secuencia aminoacídica muestra una tendencia similar, si bien presenta ligeras diferencias (Figura 11B).

A

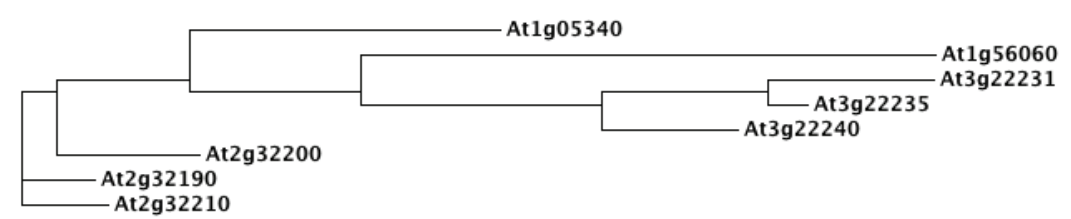

B

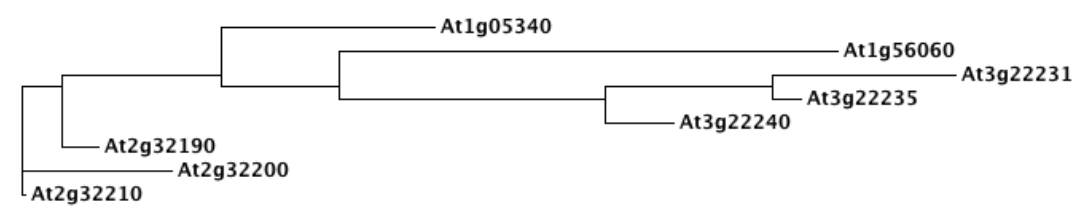

Figura 11. Árboles filogenéticos basados en la similitud de secuencia nucleotídica (A) y aminoacídica (B) obtenidos mediante el uso de la herramienta bioinformática CLUSTAL-W (EMBL-EBI). 
La expresión de $P C C 1$ en plántulas de Arabidopsis es relativamente baja a tiempos cortos tras la germinación (6 días tras la germinación, dtg), y va aumentando a medida que la planta se acerca a los 10 días, momento en el que se ha propuesto que suceden los primeros cambios moleculares que diferencian el meristemo vegetativo en meristemo floral (Segarra et al., 2010). Con el fin de ver la distribución espacio-temporal de la expresión de $P C C l$ se han generado líneas transgénicas de Arabidopsis que expresan la proteína $\beta$-Glucuronidasa (GUS) bajo el control de un fragmento de 1180 pares de bases de la región promotora de PCC1 ( $P P C C 1$ 1180::GUS), y se ha estudiado su expresión espacial en distintos estados de desarrollo de la planta, y en los distintos órganos mediante la técnica de tinción histoquímica GUS.

La expresión espacial de PCC1 presenta un patrón de desarrollo diferencial a lo largo de los primeros días de desarrollo de las plántulas (Figura 12). En los primeros días de desarrollo post-germinativo ( $3 \mathrm{dtg}$ ), se observa una fuerte y específica tinción en los estomas de los cotiledones y en la vasculatura de la raíz (Figura 12A, Figura 13 A y B), que se mantiene durante los días 6 a 10 tras la germinación (Figura 12 B-D; Figura 13 A y B). Durante estos primeros días de desarrollo se observa tinción en la parte apical del cotiledón (Figura 13B) y, aunque de forma irregular, en haces vasculares (Figura 13I). La tinción en la raíz se mantiene durante todo el periodo postgerminativo, y se ciñe al tejido vascular de la misma (Figura 13 E y F). Además, las zonas apicales que incluyen células en elongación tanto de la raíz principal como de las raíces secundarias están exentas de tinción (Figura 13 E y G). Sí que se observa tinción, sin embargo, en las células situadas en la zona apical coincidente con la cofia radicular (Figura 13H). A los 10 días tras la germinación, se observa en el primer par de hojas verdaderas una fuerte tinción en el peciolo de las mismas, así como en su parte basal, incluyendo los haces vasculares (Figura 12 D; Figura 13J). La tinción en las hojas verdaderas se extiende desde la base hasta el ápice de la misma a los 12 días de tras la germinación (Figura 12E; Figura 13K). La zona del meristemo apical no muestra tinción GUS en ninguno de los tiempos ensayados (Figura 13D). 

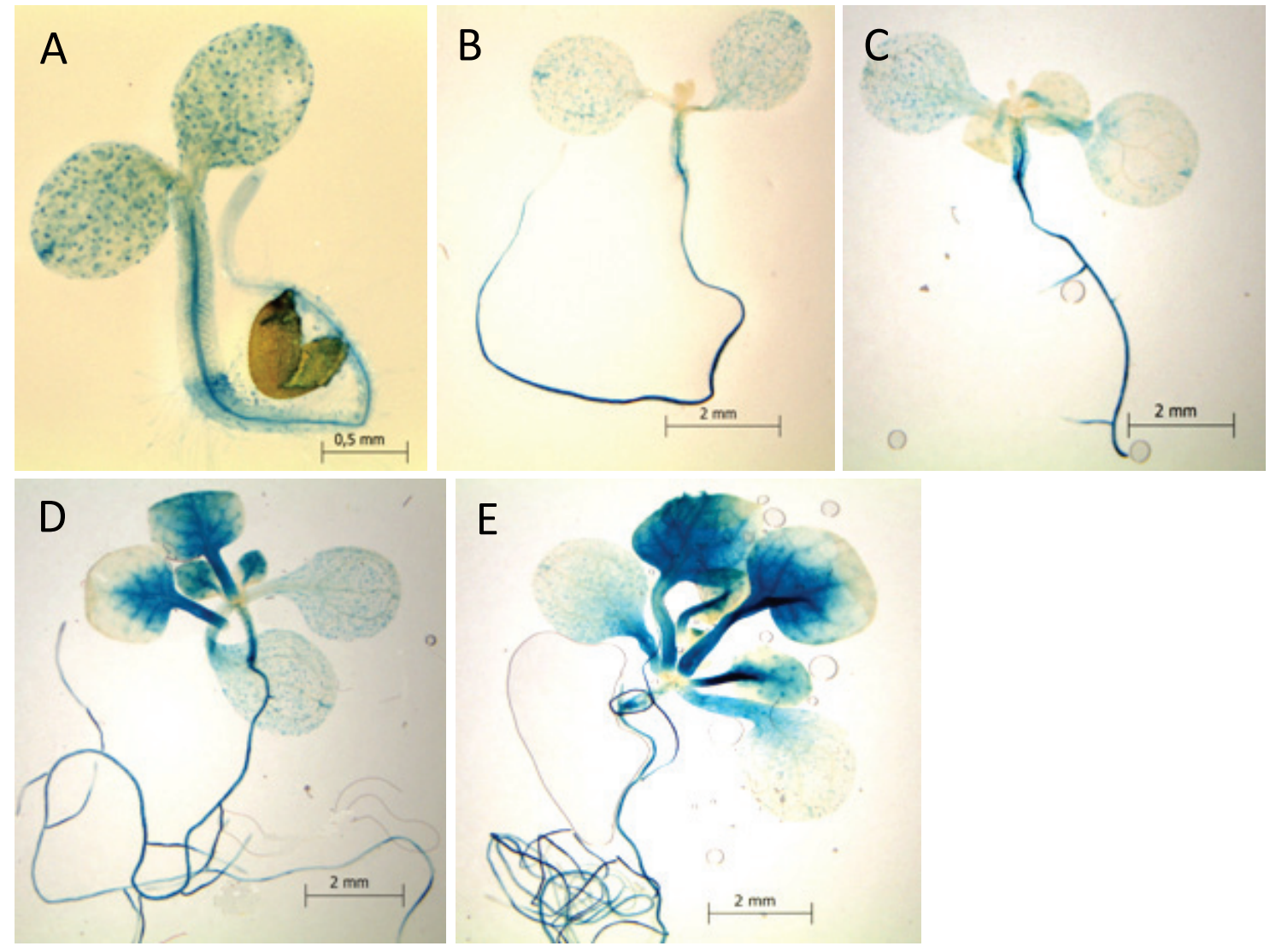

Figura 12. Tinción histoquímica GUS de plantas transgénicas de Arabidopsis (pPCC1 1180::GUS) de 3 (A), 6 (B), 8 (C), 10 (D), y 12 (E) días tras la germinación.

En planta adulta, la tinción histoquímica GUS realizada con plantas transgénicas pPCC1 1180::GUS revela una fuerte tinción en la superficie de hojas tanto de roseta (Figura 14A) como caulinares (Figura 14B), incluyendo los haces vasculares. Ni en los órganos florales (Figura 14C), ni en las silicuas y las semillas (Figura 14D) se observa tinción, lo cual apoya lo observado con anterioridad (Segarra et al., 2010). 

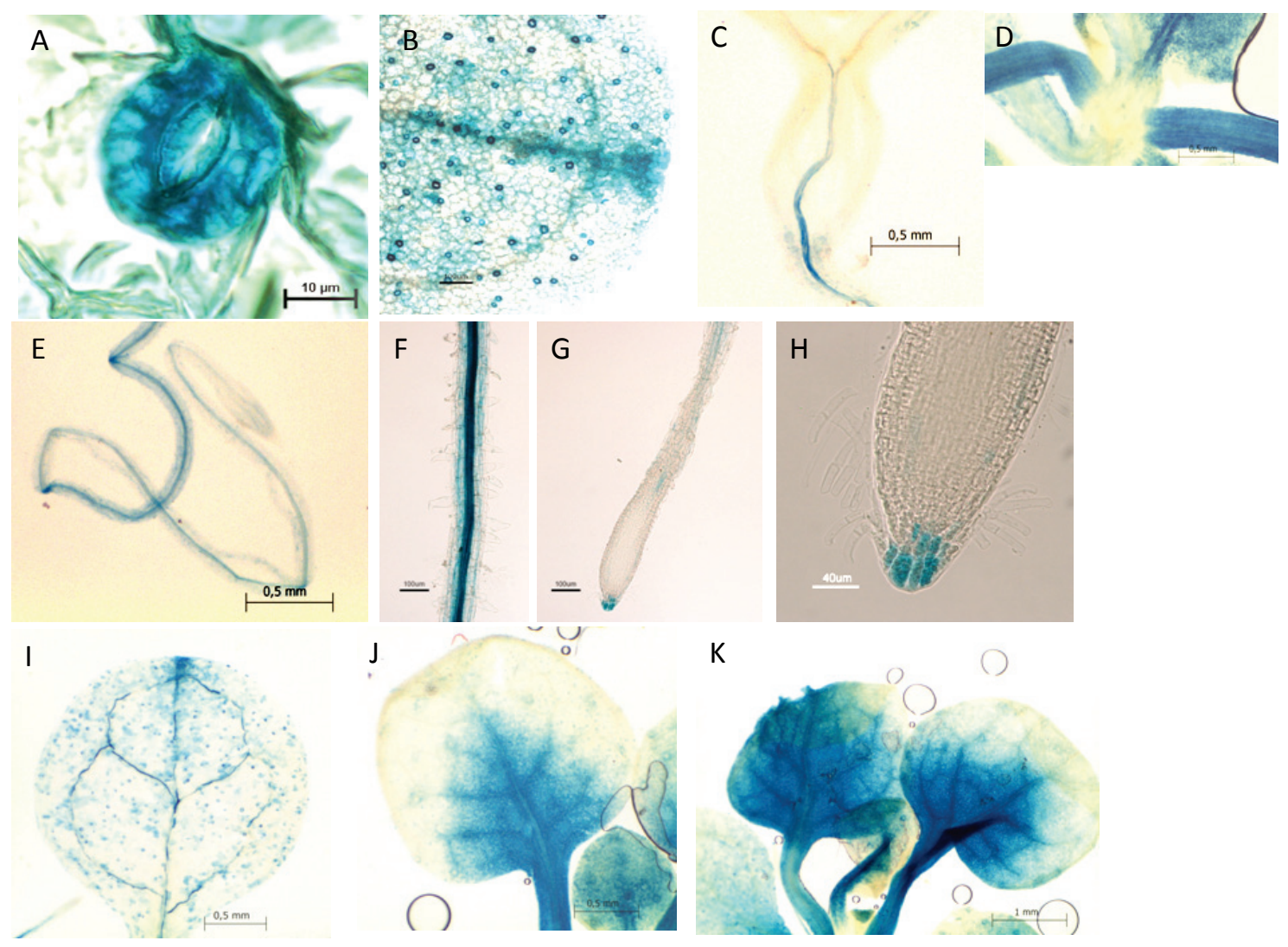

Figura 13. Detalles de órganos y tejidos tras la tinción histoquímica GUS de plantas transgénicas $p P C C 1$ 1180::GUS. Tinción en estomas detectada en cotiledones de plántulas de 8 días (A y B); en el sistema vascular de la zona de transición entre la raíz y la parte aérea en plantas de 8 días (C); en la zona del meristemo apical de plantas de 10 días (D); en el tejido vascular de raíces (E y F); en la zona de elongación (G) y la zona apical de la raíz (H); en cotiledones de plántulas de 8 dtg (I); y en el limbo y peciolo de hojas verdaderas de plántulas de $10(\mathrm{~J})$ y $12(\mathrm{~K})$ días tras la germinación.
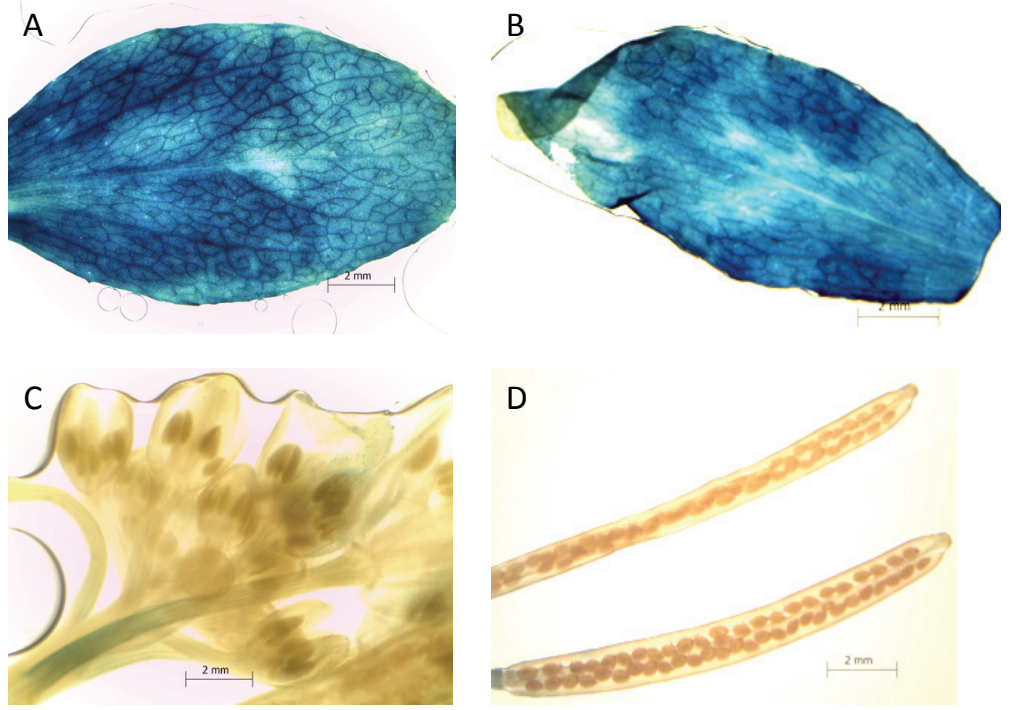

Figura 14. Tinción histoquímica GUS de plantas transgénicas pPCC1 1180::GUS adultas. Hojas de roseta (A), hojas caulinares (B), órganos florales (C) y silicuas (D). 
La aplicación de ácido salicílico (SA) activa la transcripción de PCCl (Segarra et al., 2010). Para analizar más detalladamente cómo afecta la aplicación de SA a la expresión de PCC1, se aplicó SA $50 \mu \mathrm{M}$ a plántulas de 14 dtg, y se observó la tinción GUS a las 24 horas. La aplicación de SA a plántulas de Arabidopsis provoca un aumento y una extensión de la expresión de PCC1 a toda la superfície de la planta. Las plantas transgénicas tratadas presentan una fuerte tinción GUS en prácticamente la totalidad de la planta, tanto en la superficie completa de las hojas, incluyendo los haces vasculares, como en los peciolos y el sistema radicular (Figura 15B). Cuando la tinción se realiza en condiciones más restrictivas (vid. Materiales y Métodos, apartado 12.1), se observa una fuerte tinción en haces vasculares de cotiledones, en comparación con la tinción observada en el resto de la planta (Figura 16 B y C), lo cual encaja con el papel propuesto de activador de la transición floral en respuesta a estrés dependiente de SA.
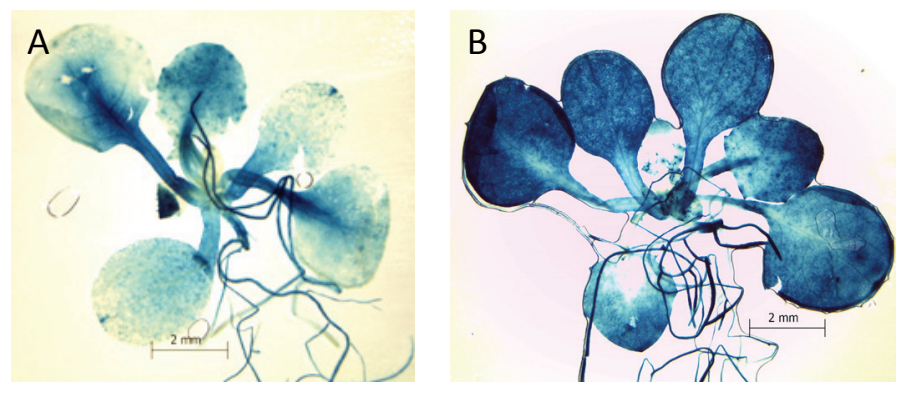

Figura 15. Tinción histoquímica GUS de plántulas $p P C C 1 \quad 1180: \because G U S$ de 14 días tras la germinación en condiciones control (A) y tratadas con SA $50 \mu \mathrm{M}$ durante 24 horas (B).
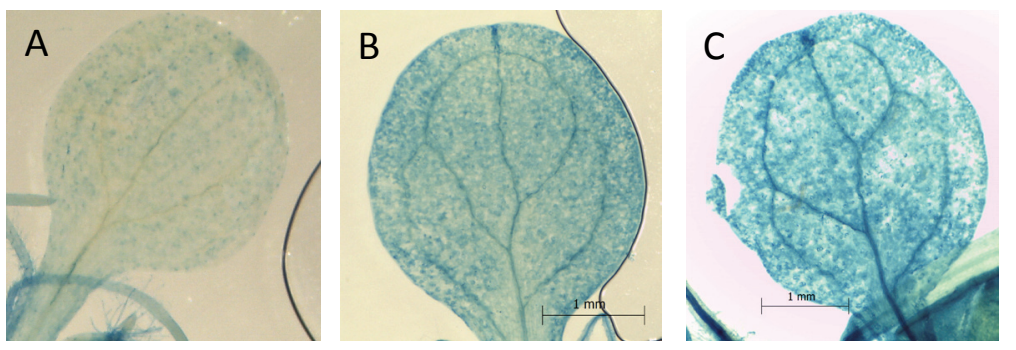

Figura 16. Detalle de cotiledones tras la realización de una tinción histoquímica GUS de plántulas $p P C C 1$ 1180::GUS de 14 días tras la germinación en condiciones estándar (A) y tratadas con $50 \mu \mathrm{M}$ (B) y $150 \mu \mathrm{M}$ (C) de SA. En este caso se han utilizado unas condiciones más restrictivas para la tinción (vid. Materiales y Métodos, apartado 12.1). 


\section{Localización celular de PCC1}

3.1. Localización celular de PCC1 fusionada a GFP en plantas de Nicotiana transformadas transitoriamente y en plantas transgénicas de Arabidopsis

Tanto el análisis in silico mostrado en el apartado 1.1, como distintas aproximaciones de tipo proteómico (Marmagne et al., 2004) y bioinformático (Venancio y Aravind, 2010), sugieren que PCC1 puede estar asociada a la membrana plasmática. Para confirmar este hecho mediante técnicas moleculares se han generado proteínas recombinantes de PCC1 fusionadas a la proteína verde fluorescente GFP (Green Fluorescence Protein) tanto por su extremo amino- como carboxi-terminal bajo el control transcripcional del promotor constitutivo $35 \mathrm{~S}$ del virus del mosaico de la coliflor (CaMV). Como control se ha diseñado una construcción GFP-S-PCC1 en la que se incluye un codón de parada ( $\mathrm{S} \equiv \mathrm{STOP})$ antes del primer aminoácido correspondiente a PCC1, lo que supone una ruptura de la fusión traduccional de GFP y PCC1 y, por tanto, una sobreexpresión de GFP libre. Las proteínas recombinantes fueron expresadas transitoriamente en Nicotiana benthamiana según se describe en Materiales y Métodos. En la figura 17A se muestra un análisis Western de proteínas totales extraídas a partir de discos de plantas de Nicotiana benthamiana agroinfiltradas con las construcciones indicadas en cada caso. Las proteínas recombinantes PCC1-GFP y GFP-PCC1 tienen un tamaño de $36 \mathrm{kDa}$, mientras que GFP, según lo esperado, tiene unos $28 \mathrm{kDa}$. Por lo tanto, las proteínas de fusión generadas se corresponden con los productos esperados y pueden ser utilizadas para la visualización de la proteína PCC1 fusionada a GFP en células de Nicotiana benthamiana mediante microscopía confocal.

En plantas agroinfiltradas con la construcción GFP-S-PCC1 que expresa GFP libre se detecta una señal de fluorescencia fundamentalmente en el citosol y en el núcleo celular (Figura 17B). Sin embargo, la proteína PCC1 fusionada a GFP tanto por su extremo amino- como carboxi-terminal emite una fluorescencia limitada a la periferia celular, que es compatible con una localización en la membrana plasmática (Figura 17B). No obstante, el gran tamaño de la vacuola celular de las células vegetales hace que sea difícil discernir entre una localización en la membrana plasmática, citosólica, o asociada a la pared celular. Para comprobar que la fluorescencia detectada se limita a membranas celulares se procedió a una tinción específica de membranas con FM64 (Bolte et al., 2004) y con yoduro de propidio (Link et al., 2011; Vogel et al., 2007). En ambos casos, la señal del canal verde de 
GFP coincide con la señal del canal rojo de cada uno de los colorantes, dando lugar a un color mayoritariamente amarillo en la imagen superpuesta de ambos canales (Figura 18).

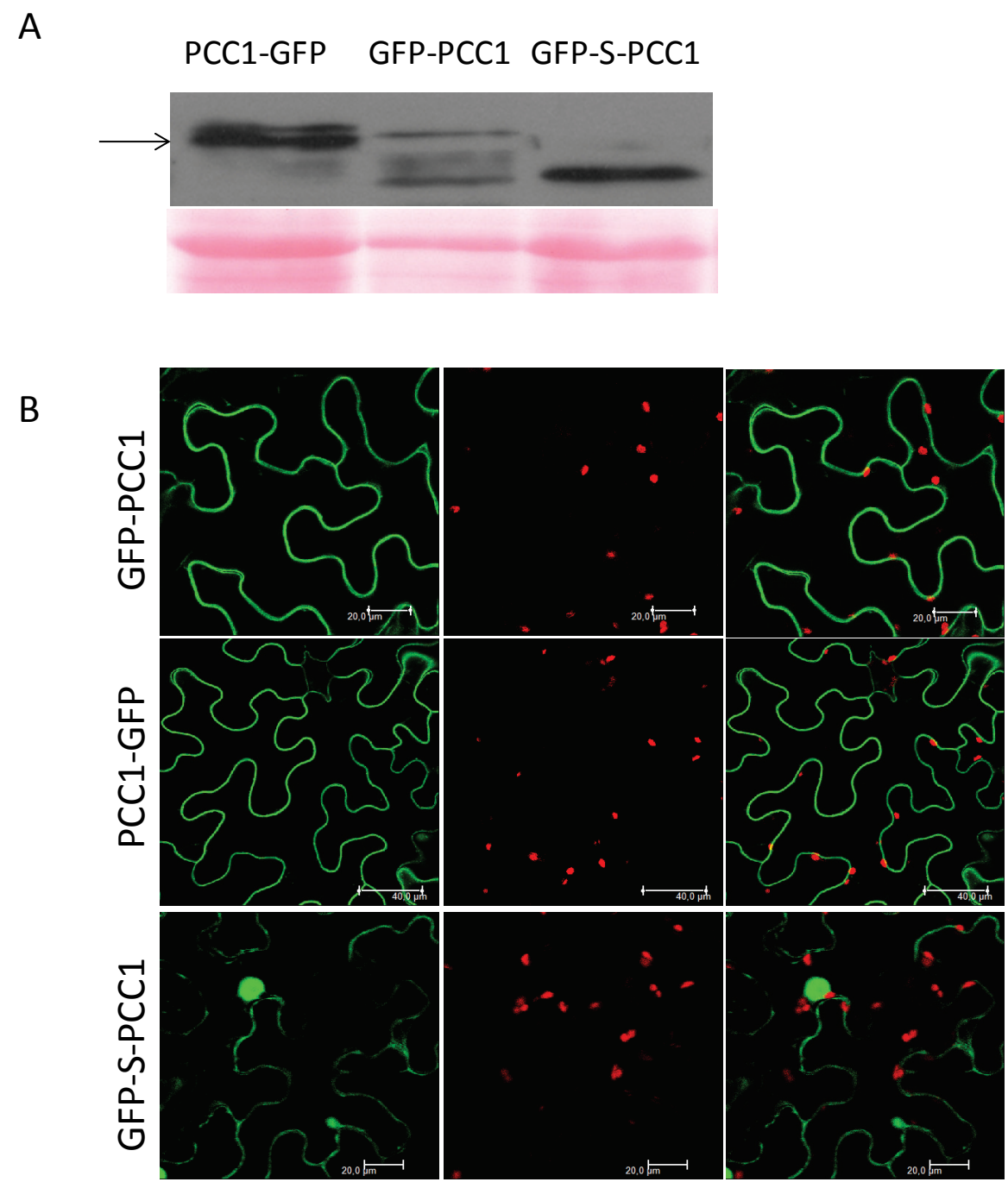

Figura 17. A. Análisis Western de muestras de plantas de Nicotiana benthamiana transformadas transitoriamente con construcciones que expresan PCC1-GFP, GFP-PCC1, y con la construcción GFP-SPCC1 que expresa GFP libre. B. Imágenes obtenidas por microscopía confocal de plantas de Nicotiana transformadas transitoriamente con construcciones que expresan proteínas recombinantes de PCC1 fusionadas en su extremo amino-terminal (GFP-PCC1) y en su extremo carboxi-terminal (PCC1-GFP) a GFP, comparadas con plantas que expresan GFP (GFP-S-PCC1). 

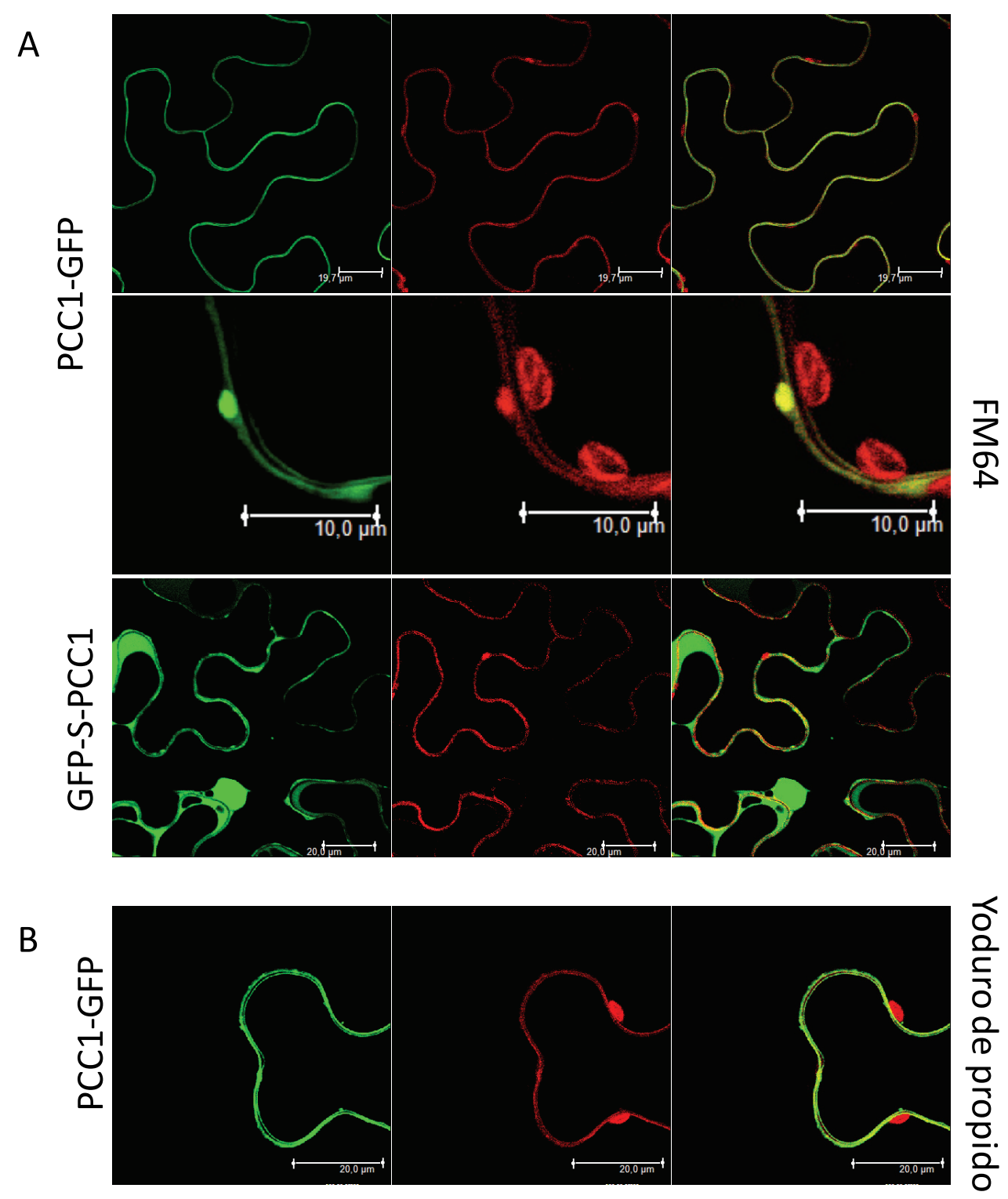

Figura 18. Imágenes obtenidas por microscopía confocal de plantas de Nicotiana bentamiana agroinfiltradas con PCC1 etiquetada con GFP y teñidas con FM64 (A) y yoduro de propidio (B).

Por otro lado, para descartar la posibilidad de que PCC1 pudiera estar asociada a la pared celular se procedió a la preparación de protoplastos a partir de hojas de Nicotiana benthamiana transformadas con PCC1-GFP y GFP libre. La figura 19 muestra imágenes obtenidas por microscopía confocal que muestran la fluorescencia asociada a PCC1-GFP y GFP-PCC1 en el contorno de los protoplastos, mientras que la señal de GFP libre se observa de forma más irregular por el citosol celular y solapa con la señal del canal rojo que recoje la autofluorescencia emitida por cloroplastos (Figura 19). Este resultado 
excluye la posibilidad de la asociación de PCC1 a las paredes celulares, y apunta de nuevo a su ubicación en la membrana plasmática en células de Nicotiana benthamiana.

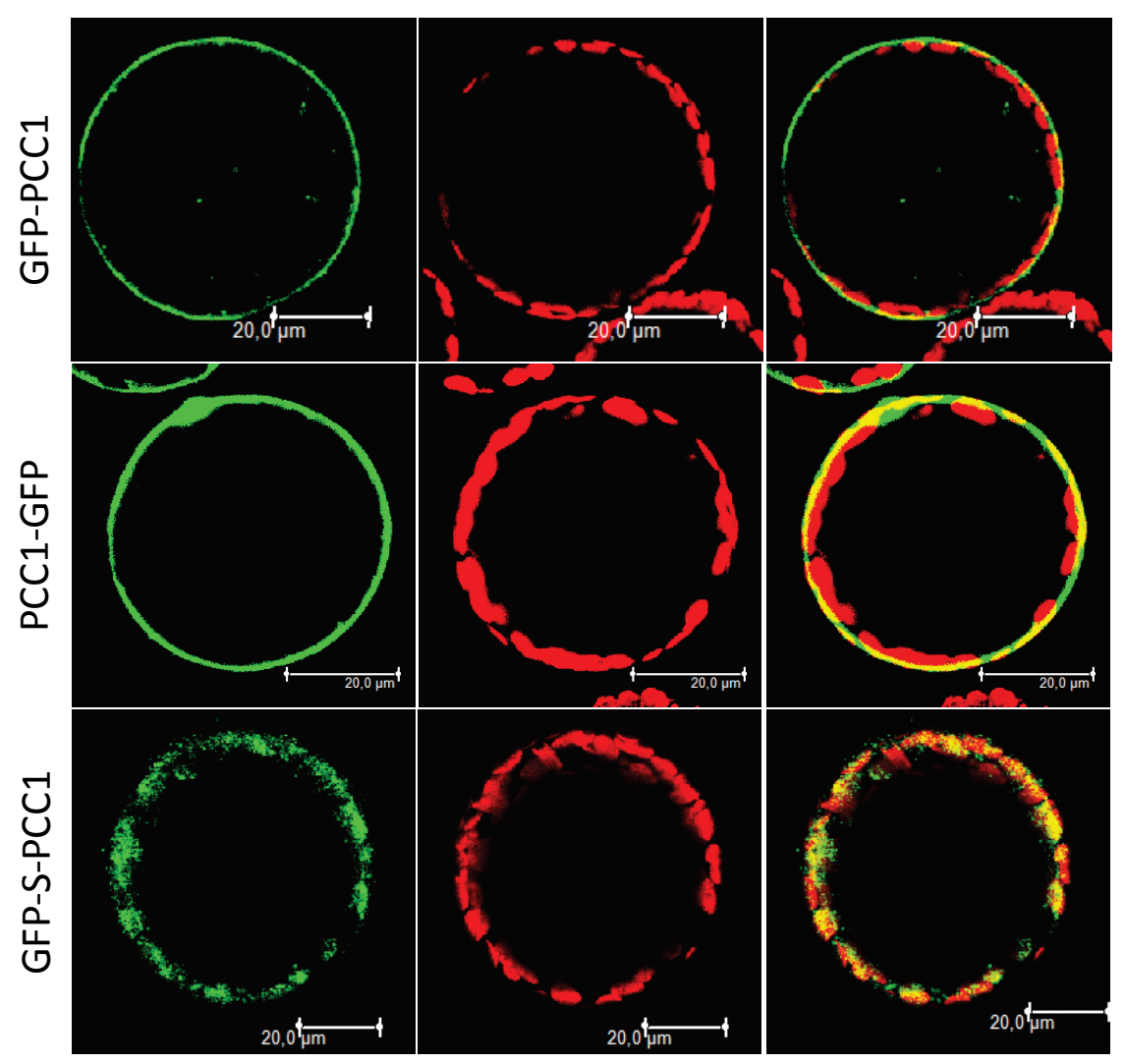

Figura 19. Imágenes obtenidas por microscopía confocal de protoplastos de hojas de Nicotiana benthamiana transformadas transitoriamente con PCC1-GFP, GFP-PCC1 y GFP-S-PCC1, según se indica en cada caso.

El uso de detergentes en los tampones de extracción de proteínas favorece la solubilización de proteínas integrales de membrana, así como de proteínas ancladas a membranas celulares (Speers y Wu, 2007). Con el fin de sustentar molecularmente la ubicación de PCC1 en la membrana plasmática hemos analizado la capacidad de extracción de proteínas recombinantes PCC1-GFP a partir de discos de hojas de Nicotiana agroinfiltradas mediante el uso de tampones de extracción Tris salino (TBS; 10mM Tris $\mathrm{pH} 4,150 \mathrm{mM} \mathrm{NaCl}$ ) suplementados o no con detergentes de distinta naturaleza, como detergentes iónicos (ㅇodio Dodecil S Sulfato, SDS 2\%), detergentes no iónicos (Np-40 1\%), o detergentes anfóteros (3-(cloroamido propil)-dimetilamonio-1- propanosulfato, CHAPS $5 \%$ ) seguido del correspondiente análisis Western con anticuerpo policlonal anti-GFP. La figura 20A muestra que la proteína recombinante PCC1-GFP sólo se extrae eficientemente cuando se suplementa el tampón de extracción con cualquiera de los detergentes utilizados. 
Para comprobar que la necesidad de detergentes en el tampón de extracción es una característica propia de PCC1 y no de la etiqueta GFP, se generaron proteínas PCC1 recombinantes fusionadas a otras etiquetas, como la hemaglutina de la gripe humana (Human Influenza Hemagglutin; HA) y el polipéptido c-Myc. De nuevo, las correspondientes proteínas PCC1 etiquetadas se detectaron mayoritariamente cuando el tampón de extracción se suplementó con SDS (figura 20B), ya sea suplementando el tampón TBS con 2\% de SDS o utilizando tampón Laemmli (60 mM Tris-Cl pH 6.8, 2\% SDS, $10 \%$ glicerol, $5 \% \beta$-mercaptoetanol, $0.01 \%$ azul de bromofenol).

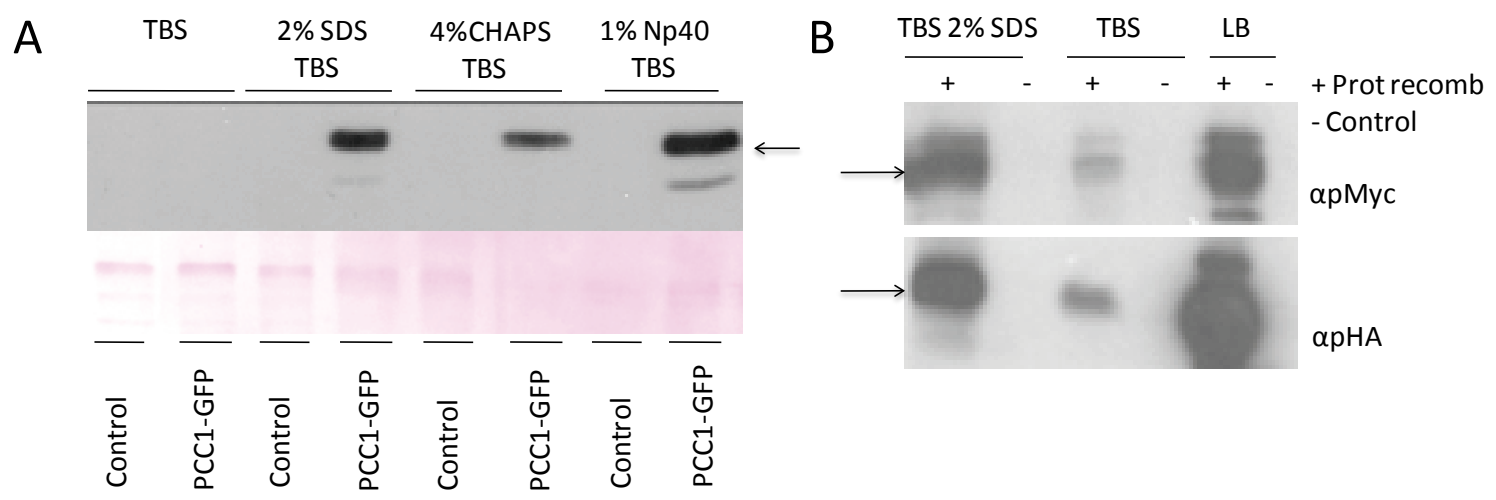

Figura 20. A. Detección por análisis Western anti-GFPp de proteínas recombinantes PCC1-GFP en un extracto crudo proteico de muestras de plantas de Nicotiana transformadas transitoriamente (PCC1-GFP) y plantas control no transformadas, extraídas con los tampones indicados en cada caso. B. Detección por análisis Western con anticuerpos específicos de proteínas recombinantes PCC1-Myc y PCC1-HA expresadas transitoriamente en Nicotiana $(+)$ y plantas control no transformadas (-). Los tampones utilizados se indican en cada caso. En ambos casos, las plantas control fueron infiltradas con tampón de agroinfiltración.

Con el fin de descartar que la localización celular en membranas plasmáticas de PCC1 observada en plantas de Nicotiana agroinfiltradas se debiese a un efecto particular de la sobreexpresión conseguida a partir de la transformación transitoria o bien a la particularidad de la especie vegetal empleada, se analizó la localización celular de PCC1 en plantas de Arabidopsis transformadas de manera estable. Para ello, se sobreexpresó PCC1-GFP bajo el promotor 35S CaMV (líneas 35S:PCC1-GFP), y se observó una fluorescencia emitida por la proteína GFP en la zona periférica de las células, tanto epidérmicas como en las células oclusivas de los estomas, lo que apunta de nuevo a una ubicación en la membrana celular (Figura 21A). Hemos analizado además la capacidad de extracción de PCC1 con y sin detergentes en el tampón de extracción. En este caso se 
extrajeron las proteínas totales con un tampón TBS, y se procedió a una segunda extracción de proteínas a partir del precipitado resultante con un tampón TBS suplementado con el detergente no iónico Np-40. Mientras que GFP libre es extraída totalemte con un tampón libre de detergentes, PCC1-GFP se extrae eficientemente en la reextracción de proteínas totales cuando el tampón es suplementado con Np-40 (Figura 21B), de igual forma a lo observado para la sobreexpresión de PCC1-GFP en plantas de Nicotiana (Figura 20). Este resultado apoya la localización de PCC1 en la membrana plasmática también en Arabidopsis (Figura 21B).
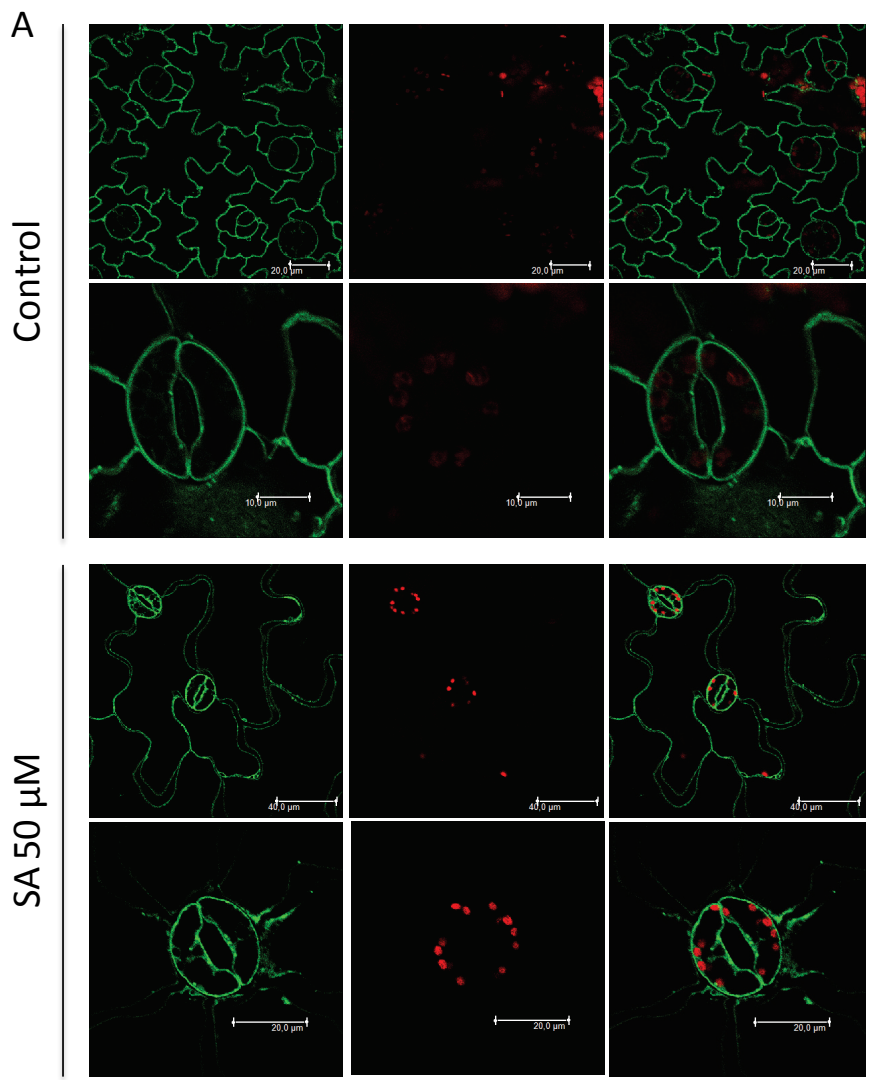

\section{B}
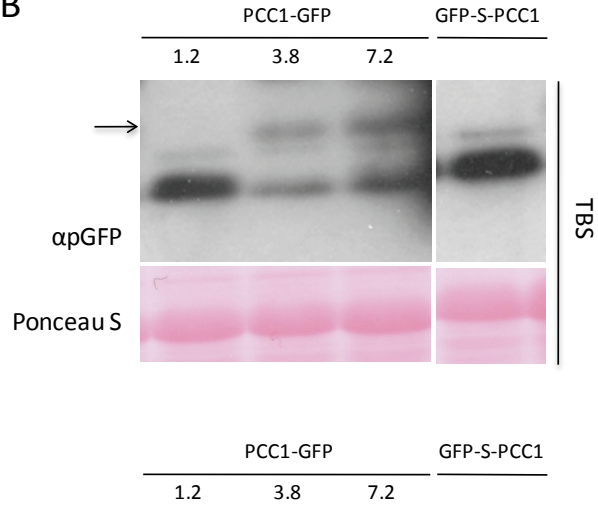

PCC1-GFP 3.8

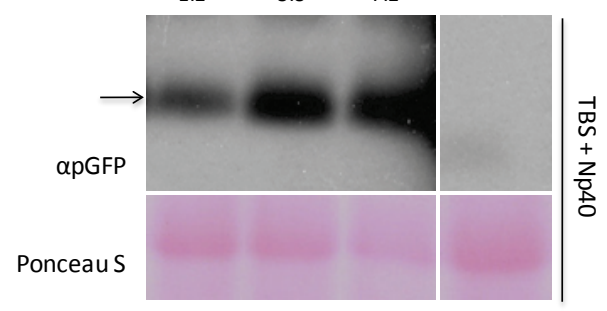

Figura 21. A. Detección por microscopía confocal de la señal de GFP en la línea 35::PCC1-GFP 3.8 de Arabidopsis en condiciones estándar de crecimiento y tratadas con SA $50 \mu \mathrm{M}$. B. Detección por análisis Western de proteínas recombinantes PCC1-GFP y de GFP libre en extractos crudos proteicos de plantas transgénicas de Arabidopsis. Cada carril corresponde a extractos crudos procedentes de las diferentes líneas homocigotas independientes identificadas como 1.2, 3.8 y 7.2. Las proteínas fueron extraídas inicialmente con TBS (panel superior), y se procedió a una reextracción de proteínas con TBS suplementado con el detergente $\mathrm{Np}-40$ a partir del precipitado obtenido en la primera extracción. 


\subsection{La aplicación de SA altera la localización de PCC1 en Arabidopsis}

Se ha descrito en plantas que algunos factores de transcripción asociados a membranas celulares son liberados de las mismas tras percibir un estímulo, y se acumulan en el núcleo donde activan la expresión de genes relacionados con procesos de desarrollo (Slabaugh y Brandizzi, 2011), y concretamente con procesos relacionados con la transición floral (Kim et al., 2007; Li et al., 2010). Aunque no hay indicios de que PCC1 pueda tener función de activador transcripcional, su putativo papel regulador en la aceleración de la floración por estrés así como su patrón de expresión fuertemente activado por SA (Segarra et al., 2010), nos incita indagar la alteración de su localización celular en respuesta a SA. En la figura 21A se muestran imágenes de microscopía confocal de la línea 35S::PCC1GFP 3.8 tratadas con SA. Mientras que las plantas no tratadas muestran en la periferia celular un contínuo en la señal de GFP, las plantas tratadas muestran una señal discontínua, siendo de mayor grosor en algunas zonas concretas de las células (Figura 21A). En el caso de las células estomáticas, la detección de señal GFP en la región citosólica es todavía más evidente (Figura 21A). Este resultado apunta a una liberción de PCC1 hacia el citosol celular en respuesta a SA.

\subsection{Homodimerización de PCC1}

Como se ha descrito en los apartados anteriores, PCC1 es una proteína asociada a la membrana plasmática en plantas. No disponemos, sin embargo, de datos que garanticen dicha localización en células de levadura. Antes de realizar ensayos de interacción con un sistema convencional de doble híbrido en levadura, se comprobó si PCC1 puede ser expresada en levadura y, también, si la correspondiente proteína puede ser extraída con tampones que no solubilizan membranas. La figura 22A muestra un análisis Western usando un anticuerpo específico para el dominio de activación de la transcripción

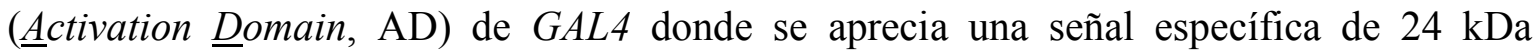
correspondiente a la proteína de fusión AD-PCC1. Esta señal es específica de la construcción $\mathrm{AD}-\mathrm{PCC} 1$, ya que en los carriles correspondientes a extractos totales proteicos de levaduras silvestres sin transformar (Mav203) y de un control de interacción positiva (Control E) no se observa ninguna señal (figura 22A). Por lo tanto se podría concluir que PCC1 en levadura se expresa en levadura y está, al menos parcialmente, libre en el citosol celular, si bien cabría esperar por la naturaleza parcialmente hidrofóbica de PCC1 que la mayor parte de la proteína de AD-PCC1 esté asociada a la membrana celular. 
A

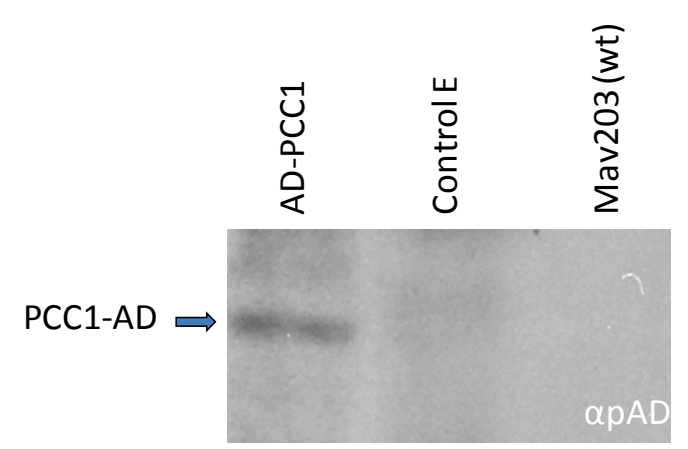

B

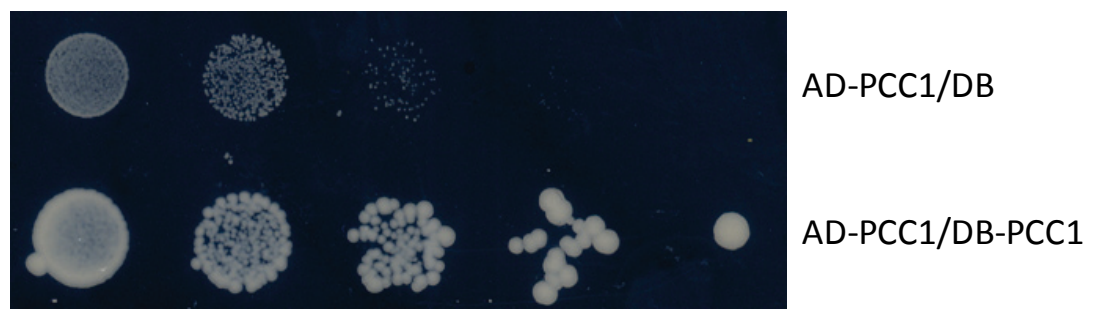

Figura 22. A. Detección por análisis Western utilizando un anticuerpo específico para el dominio de activación de GAL4 (AD) de proteínas recombinantes AD-PCC1en extractos crudos proteicos de levaduras transformadas. Como controles negativos se han utilizado extractos crudos proteicos de levaduras sin transformar (Mav203) y un control de interacción positivo (Control E; Mav203 transformada con DBGAL4/AD). La extracción de proteínas se realizó con el tampón TBS sin detergentes. B. Detección de la interacción PCC1-PCC1 por doble híbrido. La detección de la interacción se visualizó por su capacidad de crecimiento en medios carentes de histidina de levaduras co-transformadas con versiones de PCC1 fusionadas a GAL4 AD y GAL4 DB, en comparación con las cotransformadas con PCC1 fusionada a GAL4 AD y con GAL4 DB libre.

Frente a este escenario, hemos decidido testar con un sistema convencional de doble híbrido la interacción PCC1-PCC1. Las levaduras co-transformadas con proteínas recombinantes de PCC1 fusionadas a GAL4AD (pPC86-PCC1) y a GAL4DB (pDBLeuPCC1) fueron seleccionadas en medios carentes de triptófano y leucina para la selección respectiva de ambos plásmidos. Las levaduras co-transformadas fueron crecidas durante 24 horas hasta la saturación, y sembradas en medios básicos sin histidina a distintas diluciones. Como control de transactivación se usó una levadura co-transformada con pPC86-PCC1 (AD-PCC1) y pDBLeu (GAL4DB). En la figura 22B se muestra que las levaduras co-transformadas con pPC86-PCC1y pDBLeu-PCC1 crecen hasta una dilución $1 / 1000$, mientras que el control apenas crece a concentraciones de 1/100. Este resultado apunta a una posible dimerización de PCC1 usando un sistema heterólogo.

Hemos comprobado si PCC1 forma dímeros también en planta utilizando un sistema de complementación bimolecular de fluorescencia (BiFC, Bimolecular Fluorescence Complementation). Para ello se ha expresado transitoriamente en plantas de 
Nicotiana benthamiana monómeros de PCC1 fusionados a los extremos amino y carboxi terminal de YFC. La posible interacción se detectará si ambos fragmentos de la YFC interaccionan y resultan en la reconstitución de la molécula completa de YFC, que emite por tanto fluorescencia detectable mediante microscopía confocal. Como controles negativos se han utilizado tanto la versión amino-YFP como la carboxi-YFP, coexpresadas en cada caso con la versión complementaria de YFC fusionada a PCC1. La figura 23 muestra que cuando se co-expresan monómeros de PCC1 fusionados a los dos extremos de YFP se detecta fluorescencia en la periferia celular, de forma similar a la obtenida en la sobreexpresión de PCC1 fusionada a GFP. En el caso de la BiFC, se observa además fluorescencia en estructuras vesiculares adyacentes a la membrana que no se observan en ningún caso en las construcciones con GFP.

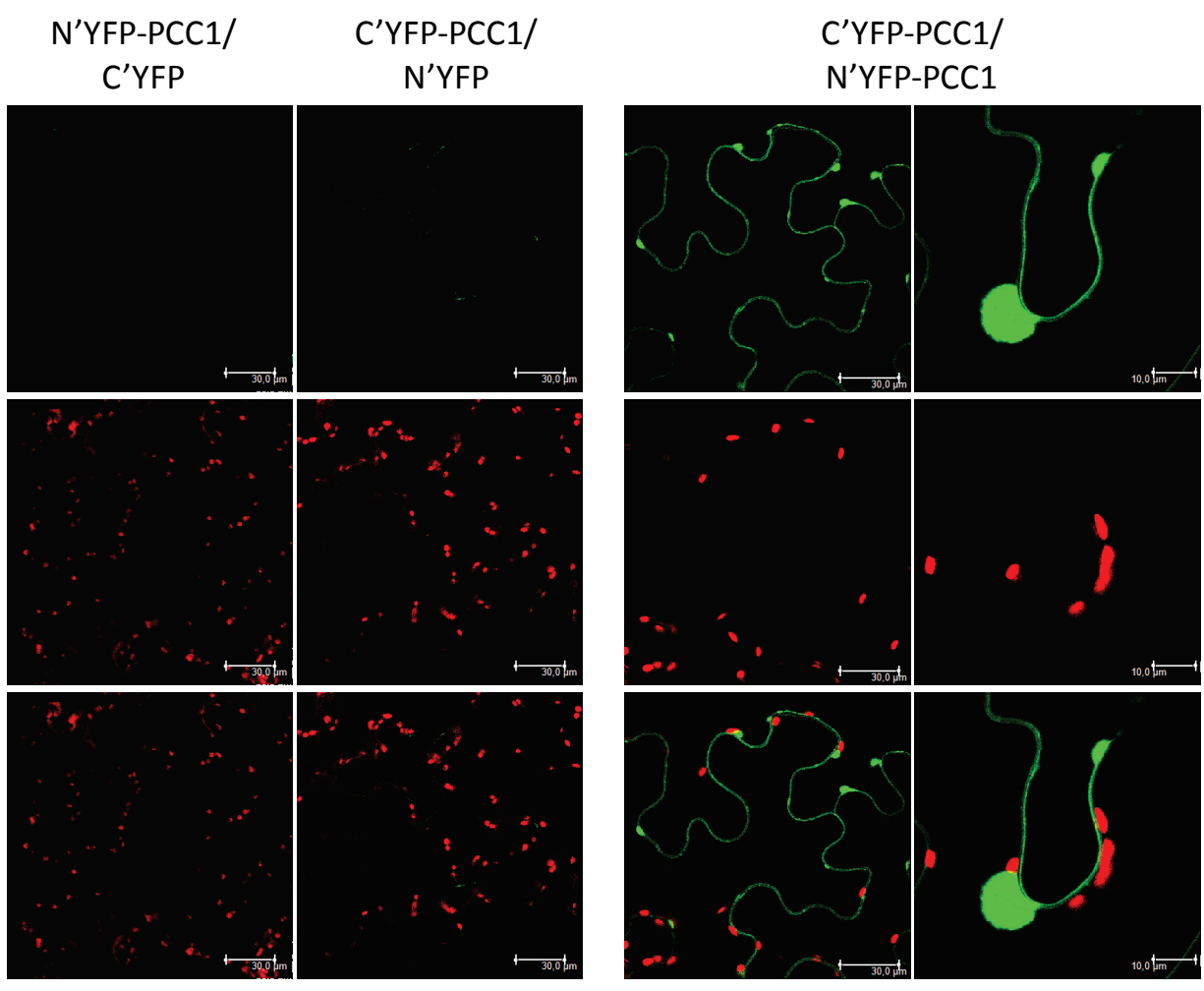

Figura 23. Detección por BiFC de la interacción PCC1-PCC1. Las imágenes obtenidas por microscopía confocal muestran una interacción de ambos monómeros de PCC1 a nivel de la membrana plasmática (C'YFP-PCC1/N'YFP-PCC1). Para los controles negativos (N'YFP-PCC1/C'YFP, C'YFP-PCC1/N'YFP) no se observa fluorescencia.

Por último, para confirmar la homodimerización de PCC1 hemos procedido a un ensayo de co-inmunoprecipitación (CO-IP) de proteínas recombinantes. Para ello se han 
co-expresado en plantas de Nicotiana versiones de PCC1 etiquetadas con HA (PCC1-HA) y con GFP, tanto en su extremo amino- (GFP-PCC1) como en su extremo carboxi- (PCC1GFP) termimal, y se ha procedido a una inmunoprecipitación de PCC1-HA con bolas magnéticas tapizadas con anticuerpo anti-HA (Figura 24). La interacción se ha detectado por análisis Western con anticuerpos frente a GFP en los inmunoprecipitados (IPs) antiHA. Como control se ha co-expresado GFP libre (GFP-S-PCC1) y PCC1-HA, y se ha procedido de igual manera. En el panel superior de la figura 24 se detecta señal de GFP en los carriles correspondientes a IPs anti-HA cuando se co-expresa PCC1-HA con PCC1GFP (carril 1) o con GFP-PCC1 (carril 3), pero no cuando se co-expresa con GFP libre (carril 2), ni con PCC1-Myc (carril 4). De idéntica forma se procedió a la co-expresión de PCC1-HA y PCC1 etiquetada con Myc (PCC1-Myc). En el panel 2 de la figura 24 se observa que únicamente se observa señal específica para Myc en la IP anti-HA de muestras que contienen PCC1-MYC (carril 4), pero en ningún caso para el resto de muestras. En el panel 3 de la figura 24 se muestra un análisis Western utilizando un anticuerpo específico para HA de los eluídos de la IP anti-HA, con el fin de corroborar que hemos inmunoprecipitado proteínas PCC1 etiquetadas con HA en todos los casos, y con unas cantidades muy similares (carriles 1 a 4; Figura 24).
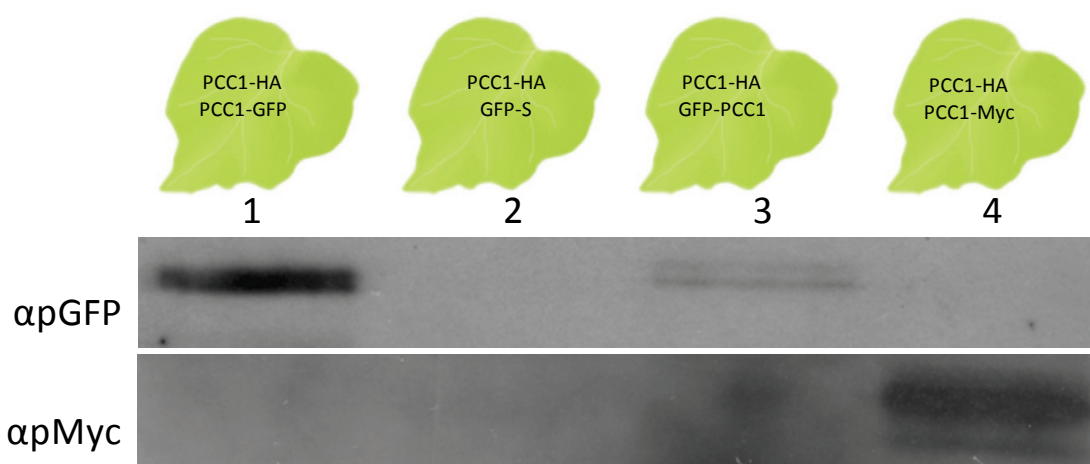

3

4
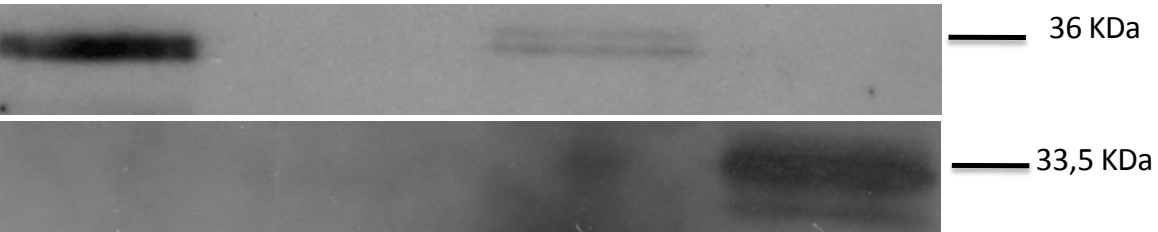

apHA

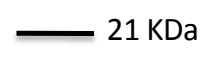

Figura 24. Detección in planta por co-inmunoprecipitación de la interacción PCC1-PCC1. Las columnas corresponden a las co-agroinfiltraciones de PCC1-HA con PCC1-GFP (1), GFP-S-PCC1 (2), GFP-PCC1 (3) y PCC1-Myc (4). Los extractos crudos se inmunoprecipitaron con bolas magnéticas tapizadas con anti-HA. La detección de las interacciones se realizó por Western anti-GFP (columnas 1, 2 y 3), y anti-Myc (4). La cantidad de proteína inmunoprecipitada se comprobó por Western anti-HA. Los extractos crudos proteicos fueron preparados con TBS suplementado con un 2\% de CHAPS para favorecer la solubilización de PCC1. 
3.4. El dominio CYSTM de PCC1 es el responsable de la homodimerización y del anclaje a la membrana plasmática

Para mapear el dominio de PCC1 responsable del anclaje a la membrana así como de su homodimerización, hemos generado proteínas recombinantes de PCC1 truncadas en su región hidrofóbica carboxi-terminal que contiene el dominio CYSTM, mediante el clonaje de los primeros 177 nucleótidos de la secuencia nucloetídica de $P C C 1$ y su fusión traduccional a GFP en su extremo carboxi-terminal ( $\mathrm{N}^{\prime}{ }_{\mathrm{t}}$ 177-PCC1-GF P) (Figura 25A). Por análisis Western hemos comprobado el tamaño ligeramente menor que el de la proteína PCC1-GFP (Figura 25A). Mediante el uso de microscopía confocal, hemos analizado la localización subcelular de estas proteínas truncadas en hojas de plantas de Nicotiana benthamiana agroinfiltradas. A diferencia de lo que ocurre con la proteína completa de PCC1, la versión truncada generada muestra una localización citosólica y nuclear (Figura 25B), lo que demuestra molecularmente que el extremo carboxi terminal de PCC1 es el responsable del anclaje de la proteína a la membrana.

A

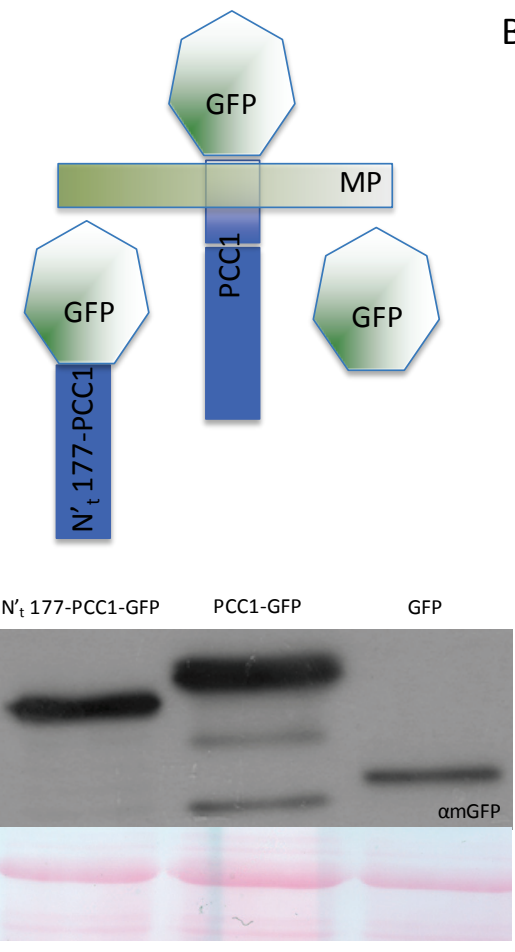

B

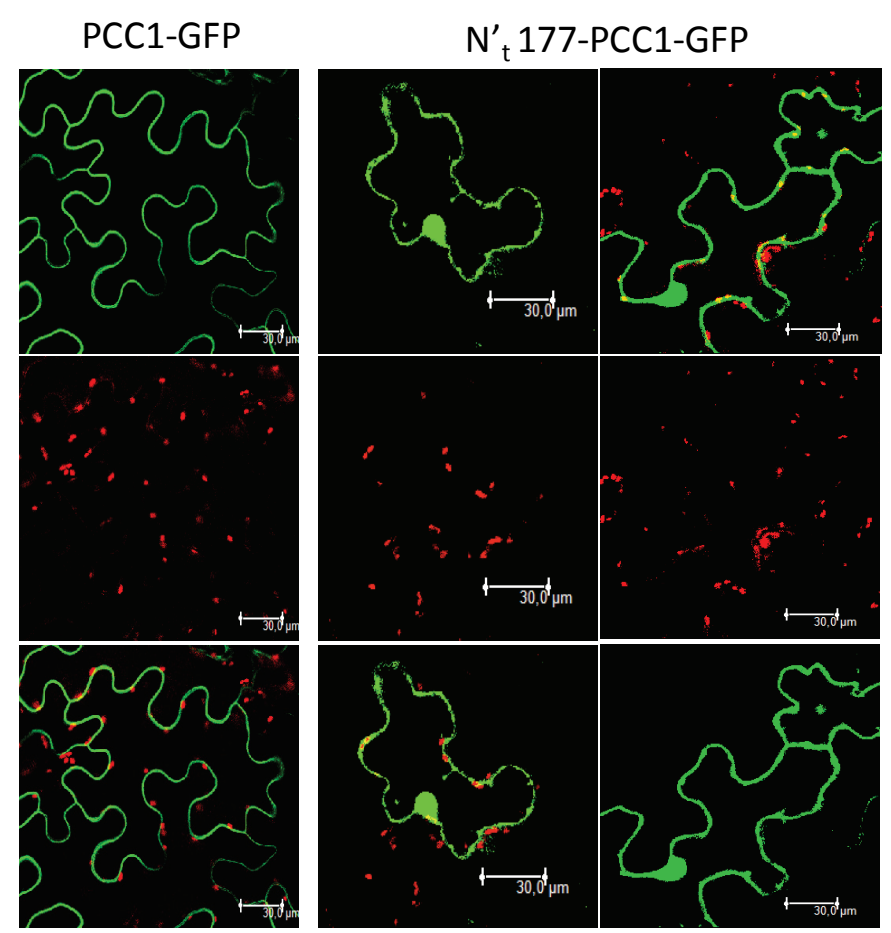

Figura 25. A. Generación de versiones truncadas de PCC1 en su extremo carboxi-terminal, y detección por análisis Western en extractos crudos proteicos de plantas de Nicotiana transformadas transitoriamente con N't177-PCC1-GFP, PCC1-GFP y GFP libre. B. Detección por microscopía confocal de GFP. La señal de GFP en proteínas PCC1-GFP queda limitada a la membrana plasmática, mientras que si se elimina la región carboxi-terminal, la señal de GFP es detectada mayoritariamente en el citosol y en el núcleo. 
Para comprobar que el dominio CYSTM es el responsable del anclaje a la membrana plasmática en Arabidopsis se han transformado plantas con la construcción antes descrita N't177-PCC1-GFP. Las plantas T2 han sido analizadas mediante microscopía confocal. Al igual que sucede cuando se expresa esta construcción en plantas de Nicotiana, en plantas de Arabidopsis se observa una deslocalización de la versión truncada en su extremo carboxi-terminal, detectándose señal de GFP en núcleos y citoplasma de células epidérmicas y células oclusivas de los estomas (Figura 26).
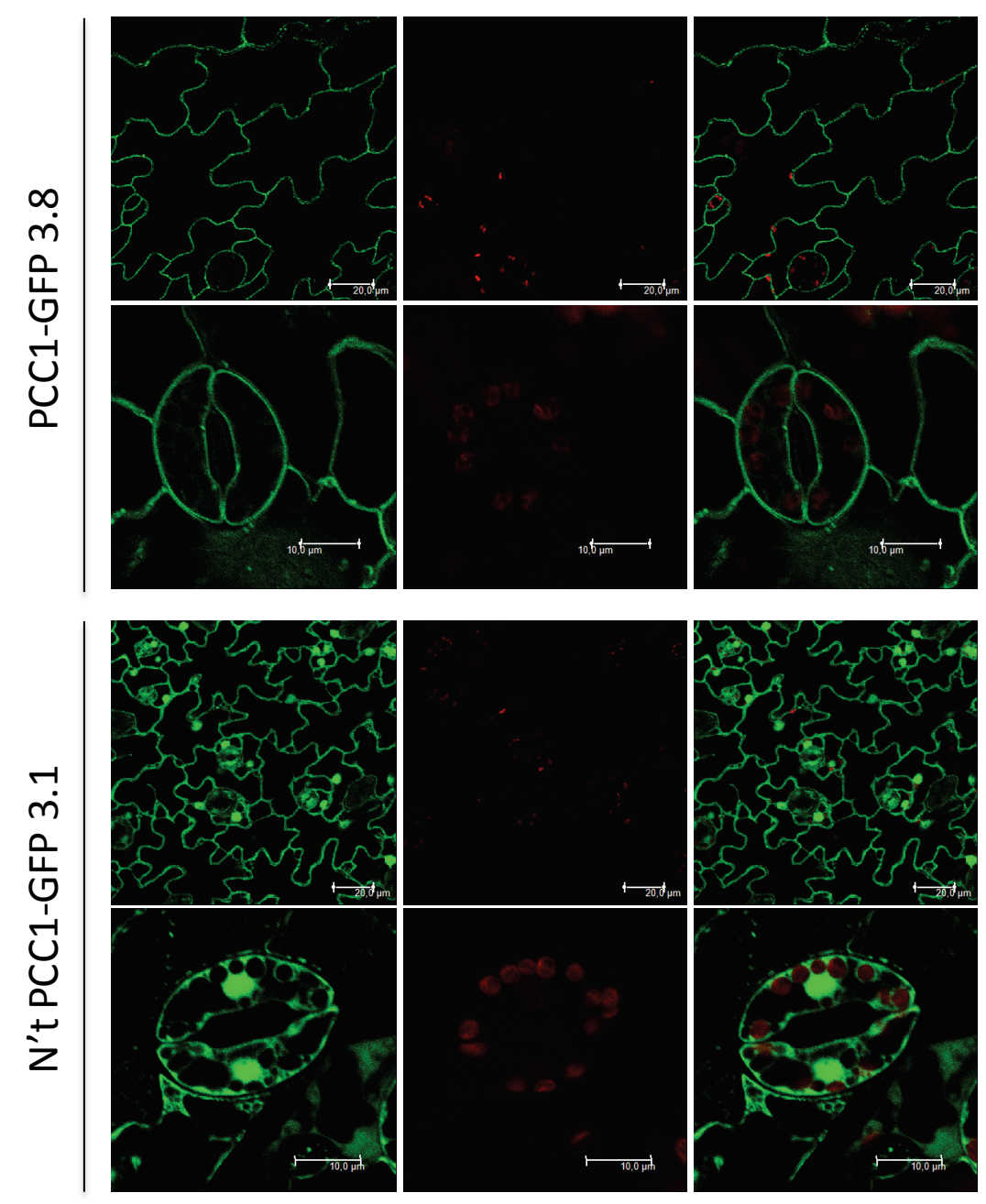

Figura 26. Imágenes obtenidas por microscopía confocal de plantas de Arabidopsis T2 que sobreexpresan versiones truncadas en la región carboxi-terminal (dominio CYSTM) de PCC1 (N'tPCC1-GFP), y se han comparado con las obtenidas en la línea PCC1-GFP 3.8.

Por otro lado, para comprobar que la proteína dimeriza por su dominio CYSTM se ha realizado un experimento de co-inmunoprecipitación de forma similar al mostrado en el apartado 3.3. En este caso se ha co-agroinfiltrado la versión truncada en su extremo 
carboxi terminal fusionada a GFP $\left(\mathrm{N}_{\mathrm{t}}{ }_{\mathrm{t}} 177-\mathrm{PCC} 1-\mathrm{GFP}\right)$ junto con la proteína completa fusionada a HA (PCC1-HA). Como control positivo de interacción se han utilizado versiones de PCC1 completa fusionada a GFP y HA, y como control negativo se utilizó la sobreexpresión de GFP (GFP-S-PCC1) con PCC1-HA. Mientras que la interacción PCC1PCC1 se observa por análisis Western de los inmunoprecipitados anti-HA con un anticuerpo policlonal de GFP (Figura 27, Carril 3, panel A), cuando se expresa la versión truncada en el extremo carboxi-terminal de PCC1 ( $\left.{ }^{\prime}{ }_{t} 177-P C C 1-G F P\right)$ junto con PCC1HA, no se observa señal, al igual que pasa con la co-expresión de GFP libre con PCC1-HA (Figura 27, Carriles 2 y 1, panel A). Además, hemos realizado una Co-IP inversa, consistente en la inmunoprecipitación de proteínas etiquetadas con GFP, y posterior detección de interacciones con anticuerpos específicos para HA. De igual forma a la observada anteriormente se detecta interacción con las versiones completas de la proteína (Figura 27, Carril 3, panel C), pero no cuando se utiliza la versión truncada (Figura 27, Carril 2, panel C) o la sobreexpresión de GFP libre (Figura 27, Carril 1, panel C). En ambos experimentos se realizó la comprobación de que en todos los casos se han inmunoprecipitado proteínas etiquetadas con HA (Figura 27, panel B) y con GFP (Figura 27, panel D).

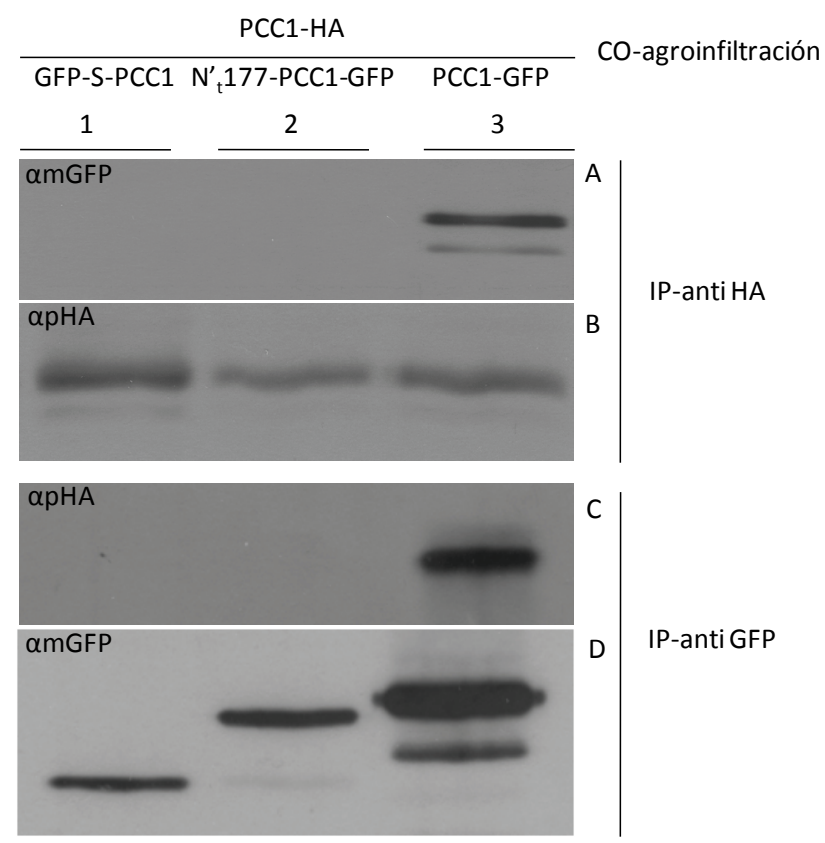

Figura 27. Detección in planta por co-inmunoprecipitación de la interacción PCC1-PCC1 por su región carboxi-terminal. Las columnas corresponden a las co-agroinfiltraciones de PCC1-HA con GFP libre (1), N't177-PCC1-GFP (2) y PCC1-GFP (3). Se ha procedido a inmunoprecipitar proteínas etiquetadas con HA y detectar interacciones con GFP (IP-anti HA), y viceversa (IP-anti GFP). La interacción PCC1-PCC1 sólo se detecta cuando se utiliza la versión completa de la proteína (carril 3), y no cuando está truncada por su extremo carboxi terminal (carrril 2) ni cuando se utiliza GFP libre (carril 1). 
4. Función de PCC1 en la transición a la floración en Arabidopsis

\subsection{CONSTANS no es un activador transcripcional de PCC1}

Se ha descrito que la activación de $P C C 1$ por irradiación con luz UV-C requiere de la función de CONSTANS (CO), ya que su activación no ocurre en el mutante $c o-1, \mathrm{y}$, por otro lado, que líneas de interferencia de RNA específica para PCC1 presentan niveles de transcrito de FT muy bajos (Segarra et al., 2010). Para comprobar si PCC1 podría actuar como intermediario de la activación de $F T$ por $\mathrm{CO}$, se han utilizado líneas de sobreexpresión bajo un promotor CaMV 35S de una versión de $\mathrm{CO}$ fusionada al receptor de glucocorticoides (35S::CO-GR (co-2); Simon et al., 1996). En condiciones control, las plantas acumulan CO-GR en el citosol, mientras que la aplicación del ligando de GR dexametasona (+DEX) dirige la proteína recombinante al núcleo celular donde activa la expresión de genes, en este caso de $F T$. Plántulas de 4 días fueron aclimatadas en medio MS líquido durante 48 horas. En estas condiciones se reemplazó el medio MS por medio MS suplementado con $10 \mu \mathrm{M}$ DEX, o con la cantidad equivalente de etanol utilizado como solvente del glucocorticoide. Los niveles de $C O$ en líneas 35S:CO-GR son mucho más elevados que en plantas silvestres en ambas condiciones ensayadas (Figura 28A). A las 24 horas después de realizar el tratamiento con DEX los niveles de transcrito de $F T$ aumentaron en líneas 35S::CO-GR con respecto al control Col-0 (Figura 28B). Los niveles de PCC1 no se vieron alterados significativamente tras la aplicación de DEX (Figura 28C), y por tanto $P C C 1$ no parece ser un blanco de activación por el factor de transcripción CO.
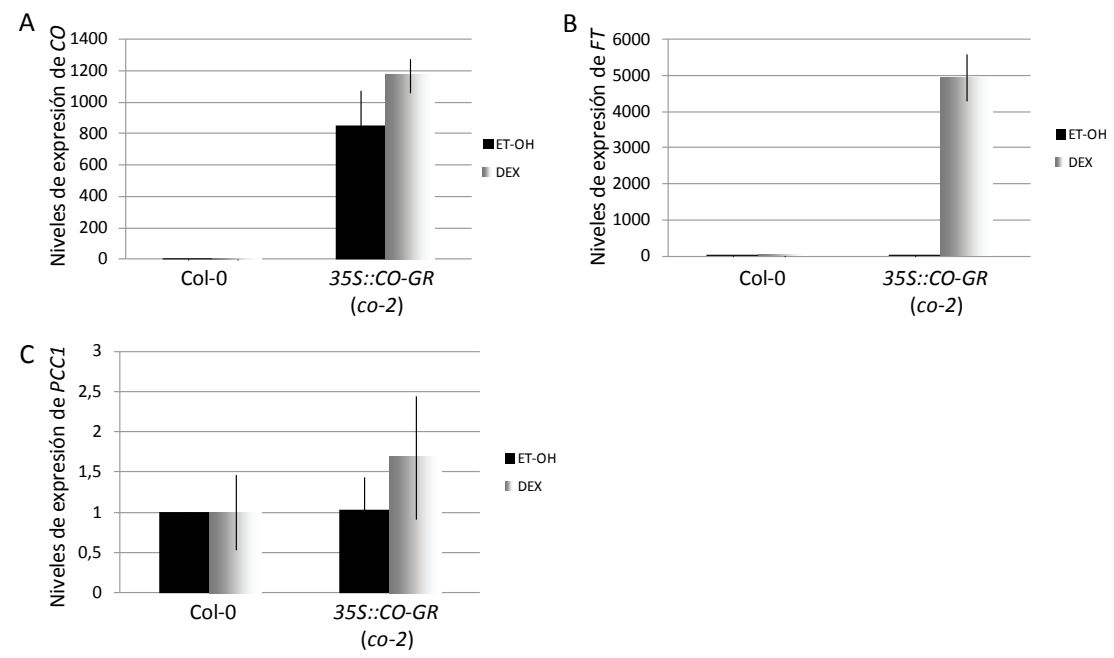

Figura 28. Niveles de expresón de CONSTANS (A), FLOWERING LOCUS T (B) y PATHOGEN AND CIRCADIAN CONTROLLED 1 (C) en plantas silvestres (Col-0) y líneas 35S::CO-GR (co-2) en condiciones control (etanol, ET-OH) y tratadas con $10 \mu \mathrm{M}$ de dexametasona (DEX). 


\subsection{PCC1 no interacciona con $\mathrm{CO}$}

Una posibilidad que podría explicar los niveles reducidos de $F T$ en las líneas iPCC1 es que PCC1 interfiriese, mediante interacción proteína-proteína, en la función activadora de $\mathrm{CO}$ sobre FT. Se ha analizado la potencial interacción de PCC1 y CO mediante la técnica de complementación bimolecular de fluorescencia. Para ello se procedió de igual forma que la descrita en el apartado 3.2. La figura 29 muestra las imágenes obtenidas por microscopía confocal cuando se co-agroinfiltraron plantas de Nicotiana con N'YFP-CO y C'YFP-PCC1. Como control negativo se han utilizado las construcciones para BiFC N'YFP-FT y C'YFP-PCC1, y como control positivo las relativas a la interacción descrita para FT y FD (Abe et al., 2005). La interacción FT-FD se aprecia claramente en los núcleos de células de Nicotiana agroinfiltrados, mientras que tanto para el control negativo FT-PCC1, como para el ensayo en cuestión, PCC1-CO, no se aprecia fluorescencia (Figura 29). Esto indica que PCC1 no interacciona con $\mathrm{CO}$, y por tanto sugiere que PCC1 no funciona según este mecanismo en la activación de $F T$ por CO.

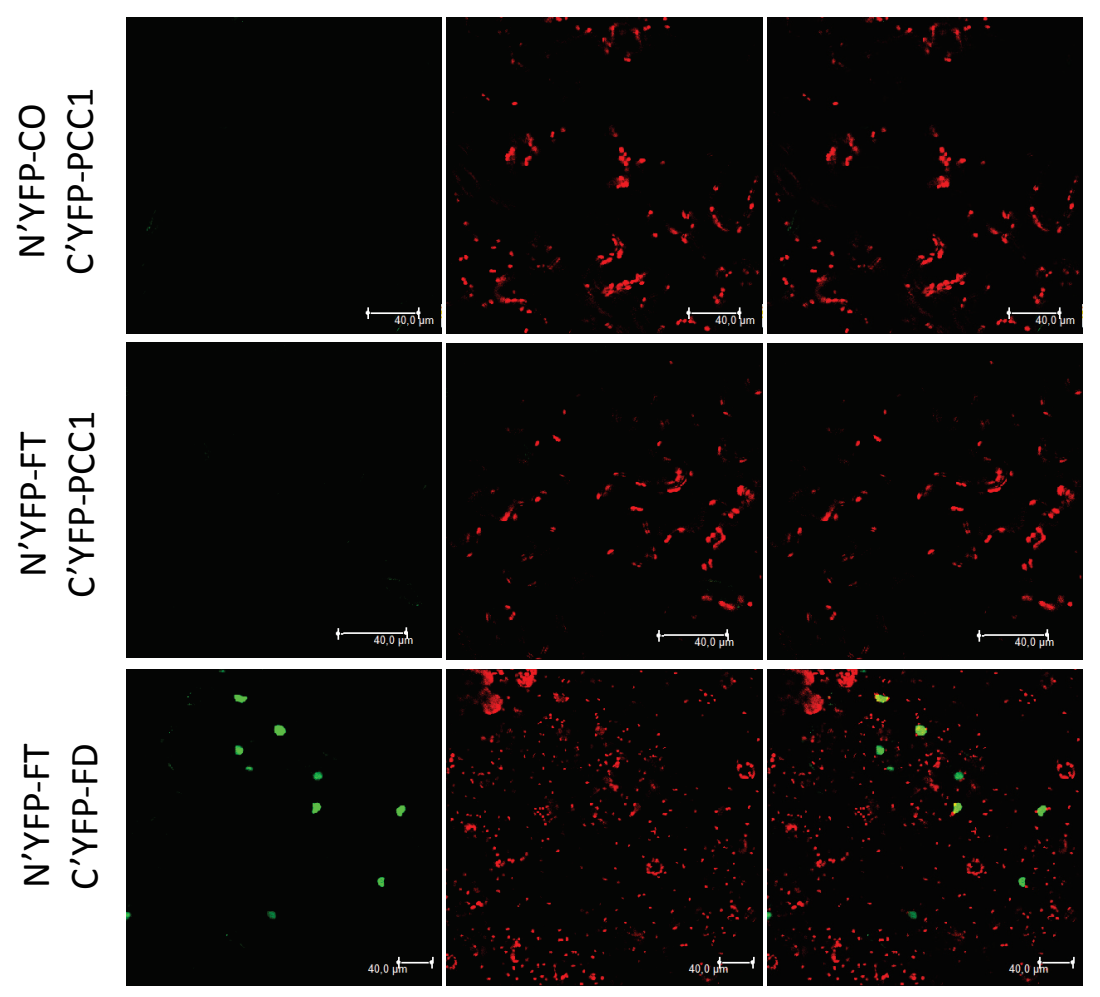

Figura 29. Imágenes obtenidas por microscopía confocal para detectar la posible interacción de PCC1 con CO mediante la técnica de BiFC. Como control negativo se ha utilizado la interacción PCC1-FT, y como control positivo la interacción de FT-FD en núcleos. 


\subsection{PCC1 no es necesario para la activación de FT por CO}

Los datos obtenidos hasta el momento no apuntan a un papel relevante de PCC1 en la activación de $F T$ por $\mathrm{CO}$, ya sea como intermediario transcripcional o como proteína interactora de CO. Para corroborarlo molecular y fenotípicamente se ha analizado la activación de $F T$, así como el tiempo de floración, en plantas que sobreexpresan $C O-G R$ y que presentan niveles reducidos de PCC1 (iPCC1 x 35S::CO-GR). Ambas líneas parentales presentan resistencia a kanamicina. Por esta razón se ha procedido a la selección de plantas homocigóticas de la F2 mediante un sistema de genotipado basado en PCR utilizando cebadores directos específicos para el promotor CaMV35S (CaMV35S-D) común a ambas construcciones, y cebadores reversos específicos para cada una de las construcciones genéticas en cuestión (CO-R y PCC1-R). Este sistema de genotipado se ha testado inicialmente en plantas Col-0, en las cuales no se obtiene ningún amplicón por la ausencia de promotor 35SCaMV, y en plantas parentales 35S::CO-GR (co-2) e iPCC1, en las que se obtienen amplicones de 740 y 630 pares de bases, respectivamente (Figura 30A). No hemos considerado, sin embargo, la segregación de la mutación co-2 en las plantas del cruce, ya que está fuera de nuestro interés. Se analizaron mediante esta estrategia al menos 30 plantas descendientes de las plantas F2 procedentes del cruce, y se seleccionaron aquéllas cuya descendencia presentaba ambos transgenes en homocigosis (Figura 30B). Los niveles de transcrito de $C O$ y de $P C C 1$ se analizaron por RT-qPCR. Las plantas doblemente homocigotas presentan niveles de $C O$ regulados al alza, mientras que los niveles de PCC1 son comparables a los de plantas iPCC1 (Figura 30C). Por lo tanto, disponemos de un sistema de sobreexpresión inducible de $C O$ y de interferencia de ARN de PCC1.
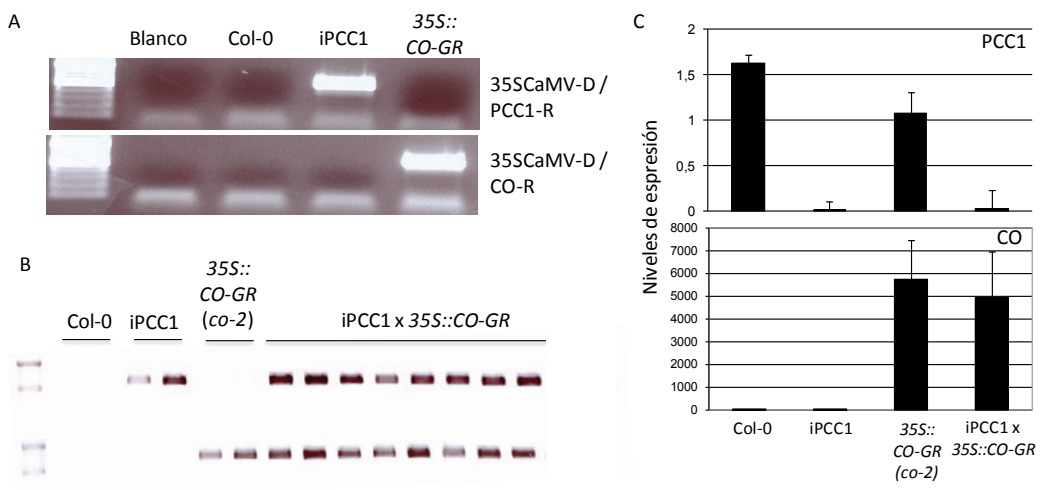

Figura 30. Generación de plantas iPCC1 x 35S::CO-GR. A. Amplificación específica por PCR de alelos iPCC1 y $35 S:: C O-G R$. B. Genotipado de la descendencia de plantas F2. C. Niveles de transcrito de PCC1 y de $C O$ de plantas homocigotas del cruce, plantas parentales y plantas silvestres Col-0. 
Para comprobar si PCC1 es necesario para la activación de $F T$ por $\mathrm{CO}$ se analizaron los niveles de transcrito de $F T$ en condiciones control y tras la aplicación de DEX en plantas iPCC1 x 35S::CO-GR. En la figura 31A se aprecia que los niveles de transcrito de $F T$ en plantas iPCC1 x $35 S:: C O-G R$ tratadas con $10 \mu \mathrm{M}$ de dexametasona (DEX) durante 24 horas son muy elevados comparados con los niveles de plantas silvestres, y similares a los observados en plantas 35S::CO-GR (co-2). De forma concomitante, la aplicación de dexametasona en plantas iPCC1 x 35S::CO-GR conlleva un adelanto del tiempo de floración medido como el número de hojas de la roseta primaria y de hojas caulinares, al igual que sucede en plantas parentales $35 S:: C O-G R$ (co-2) (Figura 31B). De estos resultados se puede concluir que PCC1 no es necesaria para la activación de $F T$ por CO.
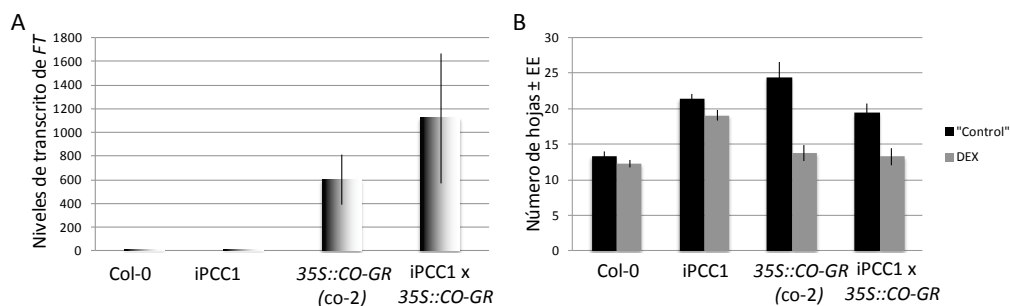

Figura 31. Análisis molecular y fenotípico de plantas iPCC1 x 35S::CO-GR. A. Niveles de expresión de $F T$ de plantas del cruce iPCC1 x $355:: C O-G R$, de los parentales respectivos y de plantas silvestres, en condiciones de inducción por $10 \mu \mathrm{M}$ de dexametasona (DEX). B. Tiempo de floración medido por el número total de hojas ( \pm Error Estándar) de plantas iPCC1 x 35S::CO-GR comparado con el de los parentales y con el de plantas silvestres.

\subsection{La expresión de PCC1 no depende de $\mathrm{CO}$}

Todos estos resultados hacen difícil interpretar el significado biológico de la regulación de $P C C 1$ por $\mathrm{CO}$ en el mutante $c o-1$. Para comprobar si la regulación a la baja de $P C C l$ observada en el mutante $c o-1$ es debida a la mutación en si, o al fondo genético donde ha sido generado, hemos utilizado un mutante de $C O$ distinto. En este caso, los niveles de expresión de $P C C 1$ en el mutante $c o-10$ no varían con respecto a los de plantas silvestres (Figura 32A), por lo que descartamos que PCC1 sea una diana del factor de transcripción $C O$. Hemos cuantificado los niveles de $P C C 1$ en un mutante $f t-10$, y, como era previsble, tampoco hemos observado alteraciones trancripcionales de $P C C 1$ por la pérdida de función de $F T$ (Figura 32A). Finalmente, hemos analizado la exprsión de $C O$ a las 12 horas de luz en plantas iPCC1 cultivadas bajo condiciones de fotoperiodos de días 
largos, y no observamos diferencias con respecto a plantas silvestres (Figura 32B), por lo que $P C C 1$ no parece regular, al menos a nivel transcripcional, la función de $C O$.
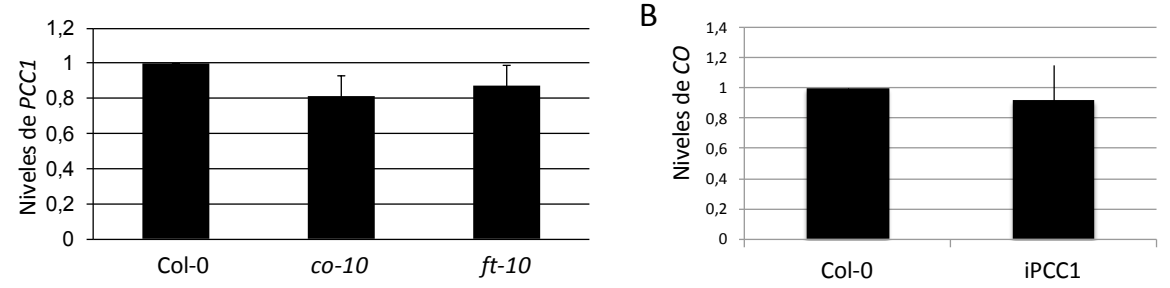

Figura 32. Cuantificación por RT-qPCR de los niveles de transcrito de $P C C 1$ en los mutantes $c o-10$ y ft-10 (A) y de $C O$ en líneas iPCC1 (B), comparados con plantas silvestres.

4.5. Implicación de PCC1 en la transición floral dependiente de vernalización y de giberelinas

Si bien PCCl no actúa como mediador de la activación de FT por CO, el tiempo de floración en días largos y días cortos de líneas iPCC1 sugieren su participación en la ruta del fotoperiodo para la activación de la transición floral (Segarra, 2009). Para corroborar este hecho, se generaron líneas de interferencia de RNA específicas para $P C C l$ en fondos mutantes $f t$-20 (Segarra, 2009), y se han estudiado los tiempos de floración en condiciones de dias largos. Las diferentes líneas iPCC1 (ft-20) presentan un fenotipo de floración similar al parental $f t-20$, que es más tardío al observado para las plantas iPCC1, y mucho más que las plantas silvestres Col-0 (Figura 33A).

Hemos estudiado además la implicación de PCCl en otras rutas de floración distintas a la ruta del fotoperiodo. Para ello, se han analizado los tiempos de floración de líneas iPCC1 en el fondo genético mutante de la ruta autónoma $f_{c} a 9$, y los hemos comparado con los fenotipos de las plantas parentales. Las plantas iPCC1 (fca9) presentan un tiempo de floración más tardío que los parentales iPCC1 y $f c a 9$ (Figura 33B), lo que apunta a que ambos genes están implicados en diferentes rutas que contribuyen de forma independiente y aditiva a la transición floral. Por otro lado, hemos sometido a estas plantas a un tratamiento de vernalización a $4^{\circ} \mathrm{C}$ durante 5 semanas, y hemos comparado los tiempos de floración con los de plantas no vernalizadas. La vernalización provoca un ligero adelanto de la floración en plantas Col-0 (Figura 33B) y de mayor intensidad en plantas $f c a 9$. Las plantas iPCC1 responden al tratamiento de vernalización adelantando la 
floración, por lo que excluímos que PCCl pueda tener algún papel en esta ruta de floración. Por último, y de acuerdo con las observaciones anteriores, las líneas iPCC1 ( $f c a 9)$ también responden a la vernalización (Figura 33B).

La aplicación de giberelinas acelera el proceso de transición floral en Arabidopsis (Wilson et al, 1992). La figura 33C muestra el tiempo de floración porcentual de plantas tratadas con $200 \mu \mathrm{M}$ de la giberelina biológicamente activa $\mathrm{GA}_{3}$, con respecto al tiempo en condiciones no tratadas, tanto en condiciones de dias largos como de días cortos. Las plantas silvestres muestran un adelanto del 20 y de 35\% en DL y DC, respectivamente, cuando son tratadas con $\mathrm{GA}_{3}$ (Figura 33C). La respuesta de las líneas iPCC1 es algo mayor que la que se ha observado en plantas silvestres (Figura 33C). En cualquier caso, la aplicación de giberelinas a plantas iPCC1 adelanta el tiempo de floración lo que indica que PCC1 no está implicado en la activación de la floración por la ruta de las giberelinas.

A

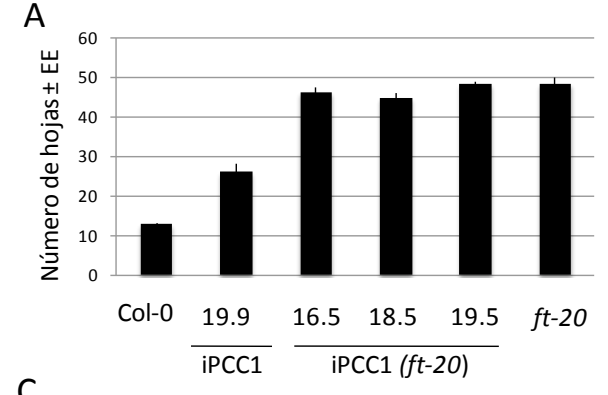

C

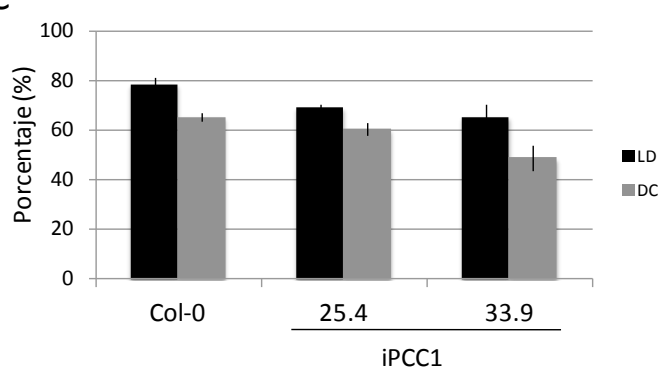

B

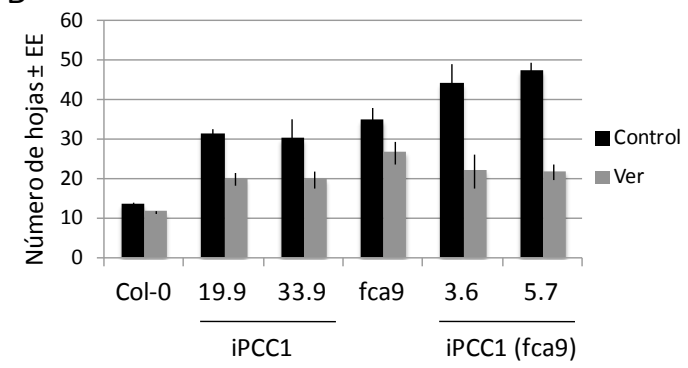

Figura 33. A. Tiempo de floración de plantas silvestres, líneas iPCC1 generadas en un fondo silvestre Col-0, tres líneas independientes iPCC1 generadas en un fondo mutante $f t-20$, y del mutante $f t-20$ en condiciones de días largos. B. Tiempo de floración de plantas silvestres, mutantes $f c a 9$, líneas iPCC1 y líneas iPCC1 (fca9) sometidas a vernalización $\left(5\right.$ semanas a $\left.4^{\circ} \mathrm{C}\right)$ comparado con el de plantas no vernalizadas. C. Tiempo de floración porcentual de plantas sivestres y líneass iPCC1 tratadas con $200 \mu \mathrm{M}$ de $\mathrm{GA}_{3}$ en condiciones de días largos (DL) y días cortos (DC). Los porcentajes se estimaron considerando como $100 \%$ el tiempo de floración en condiciones no tratadas de cada genotipo. 
4.6. El fenotipo de floración tardía en plantas iPCC1 podría estar relacionado con alteraciones en la señalización por luz

Se ha descrito que $P C C 1$ tiene un patrón de expresión controlado por el reloj circadiano en Arabidopsis (Sauerbrunn y Schlaich, 2004). La percepción de la luz es un aspecto fundamental que regula el funcionamiento del reloj circadiano en animales, cianobacterias y plantas. Por esta razón nos planteamos la posibilidad de que la expresión génica de $P C C l$ esté alterada en mutantes de percepción de distintos tipos de luz, como en los mutantes de percepción de luz roja lejana y luz roja, $p h y A$ y phy $B$, o en los mutantes de percepción de luz azul cryl y cry2. Los niveles de transcrito de PCCl están regulados al alza en mutantes $p h y B$, mientras que no se ven alterados en mutantes phyA (Figura 34A). Este resultado apunta a que PHYB esté regulando negativamente la expresión de PCC1. Por otro lado, cuando se analizan los niveles de acumulación de proteína PHYB en plantas con niveles reducidos de PCC1 no se observan cambios (Figura 34B), lo que sugiere que PHYB modula la activación de PCC1, pero no a la inversa. La percepción de luz azul también parece ser crítica para la expresión de $P C C 1$, ya que los mutantes cryl y cry2 presentan niveles de transcrito de PCC1 más reducidos que los de las plantas control. Además, los niveles de transcrito de $P C C l$ en el doble mutante crylcry2 es mucho menor que en los parentales, por lo que CRY1 y CRY2 participan aditivamente en la expresión de PCC1 (Figura 34C). Estos datos sugieren que la percepción de distintas calidades de luz puede ser importante para la expresión de $P C C 1$. 

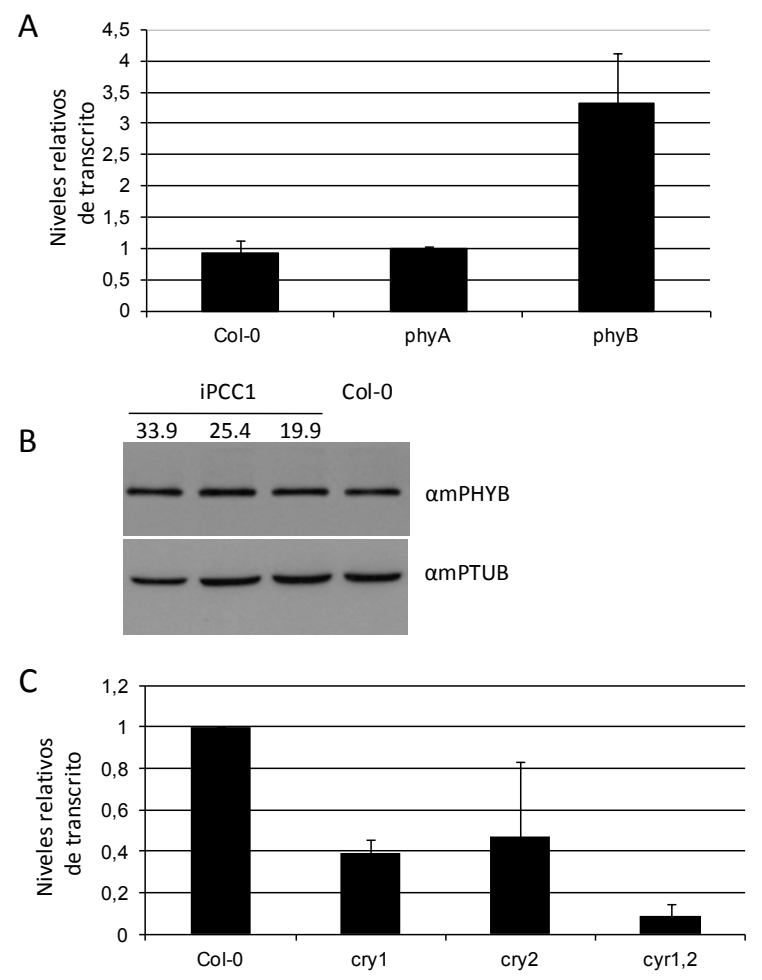

Figura 34. Cuantificación del transcrito de $P C C 1$ por RT-qPCR en mutantes de percepción de luz roja y roja lejana, phy $A$ y phyB (A) y en mutantes de percepción de luz azul, cryl, cry2, y el doble mutante cryl cry 2 (C). B. Detección de la acumulación de PHYB por análisis Western en líneas iPCC1. Como control de carga se ha determinado la acumulación de tubulina.

Para comprobar si la péridida de función de PCC1 conlleva alteraciones en la percepción de la luz hemos analizado la longitud de los hipocotilos en plántulas iPCC1 tras su crecimiento durante 3 días en luz blanca continua y en oscuridad, y las hemos comparado con la de plantas silvestres. Los hipocotilos de plantas iPCC1 son más largos que los de plantas silvestres en condiciones de luz continua, mientras que en oscuridad no se aprecian diferencias significativas (Figura 35 A y B). Esto apunta a que la interferencia de PCC1 conlleva una alteración en la percepción de luz en plantas de Arabidopsis, y que no se trata de una mayor tasa de crecimiento del hipocotilo en cualquier condición. 
A

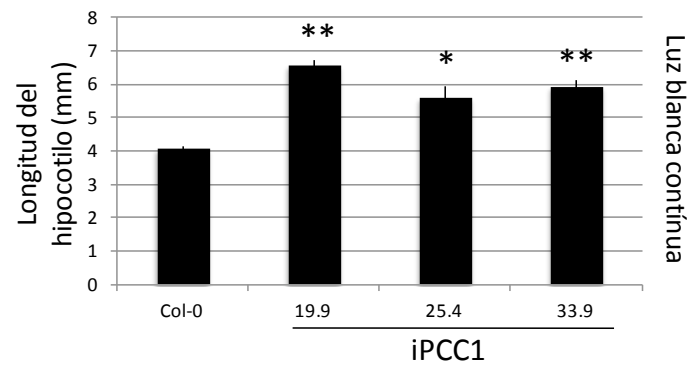

B

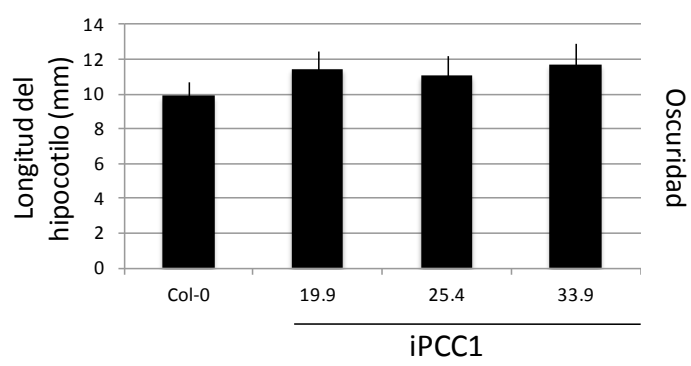

Figura 35. Longitud de hipocotilos de plantas transgénicas iPCC1 y plantas control en condiciones de luz blanca continua (A) y oscuridad (B). Se ha estimado la significancia estadística por la prueba T de Student, siendo la probabilidad de error inferior a $0.05\left(^{*}\right)$ o $0.01(* *)$, según se indica en cada caso.

Para examinar fenotípicamente si PCC1 puede participar en la señalización por un tipo concreto de luz o si se trata de una deficiencia general en la percepción o señalización de luz, hemos analizado la longitud de hipocotilos de plantas iPCC1 bajo condiciones de luz roja, luz roja lejana, y luz azul tras tres días de crecimiento en cada una de estas condiciones. En la figura 36A se muestran los valores de la longitud de hipocotilos medidos bajo las distintas condiciones lumínicas, donde se observa que las líneas iPCC1 presentan hipocotilos más largos en todas las condiciones de luz ensayadas (Figura 36A). Finalmente, para analizar si la mayor longitud de los hipocotilos pudiera ser debida a una mayor acumulación o señalización por GAs en plantas iPCC1, hemos analizado la longitud de hipocotilos bajo las distintas condiciones lumínicas en presencia de paclobutrazol (PAC). Si bien la presencia de PAC conlleva una disminución en la longitud de hipocotilos tanto en plantas silvestres como en plantas iPCC1, los hipocotilos de plantas iPCC1 en estos medios son significativamente más largos que los de plantas silvestres en todas las condiciones lumínicas ensayadas (Figura 36B). Estos resultados apuntan a que la función de PCC1 sea necesaria para la percepción de luz de diferentes longitudes de onda, y que su papel no depende al menos totalmente de la acumulación de GAs. 
A
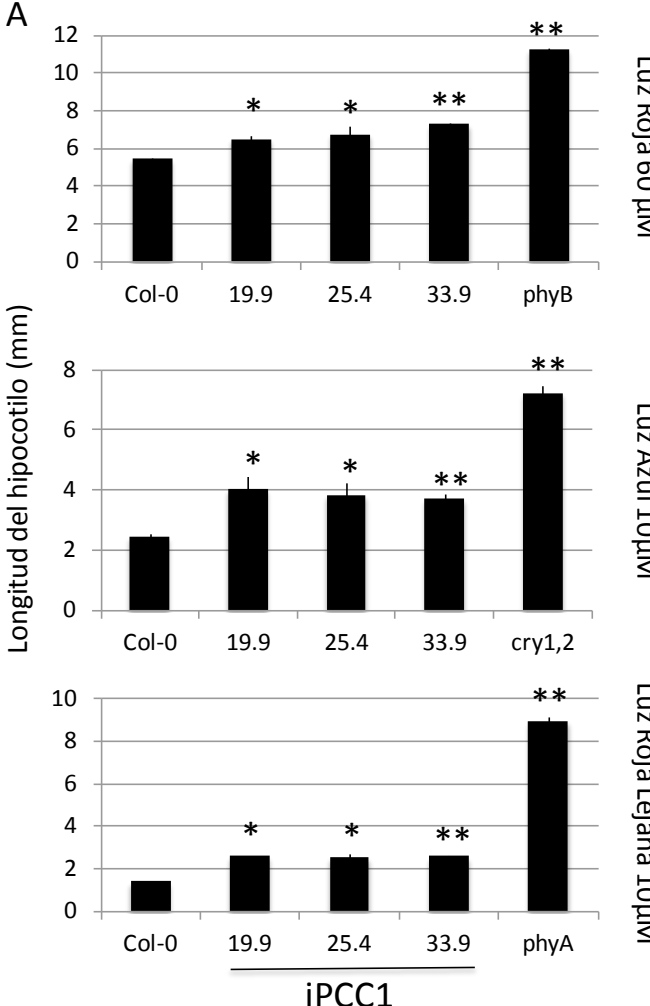

B

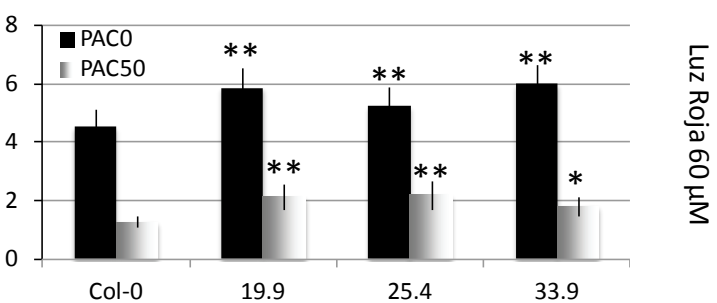

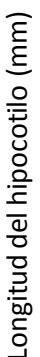

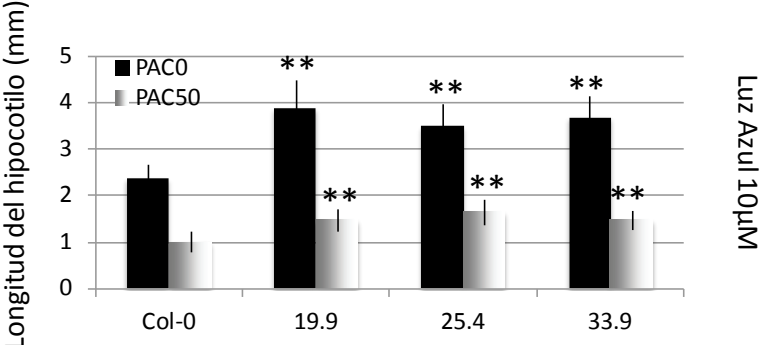

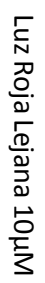

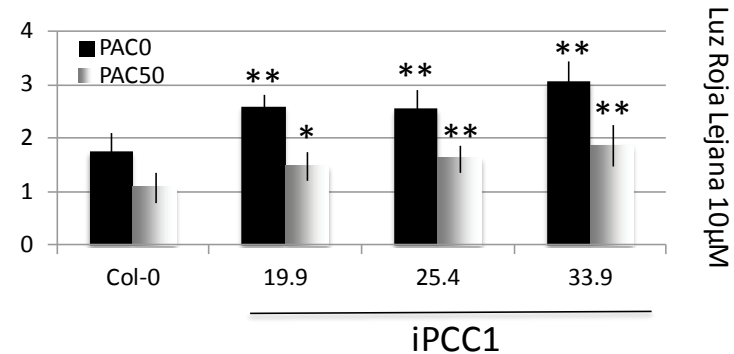

Figura 36. Longitud de hipocotilos de plantas transgénicas iPCC1 tras tres días de crecimiento bajo condiciones de luz roja $(60 \mu \mathrm{M})$, luz azul $(10 \mu \mathrm{M})$ y luz roja lejana $(10 \mu \mathrm{M})$ en medios MS (A) y en medios MS suplementados con $50 \mu \mathrm{M}$ de PAC (B). Como controles de los experimentos en medios MS se han usado el doble mutante crylcry 2 para el experimento de luz azul, y los mutantes phyB y phy $A$ en los experimentos de luz roja y roja lejana, respectivamente. Se ha estimado la significancia estadística por la prueba $\mathrm{T}$ de Student, siendo la probabilidad de significancia inferior a $0.05(*)$ o $0.01(* *)$, según se indica en cada caso.

\section{Interacción de PCC1 con otras proteínas de Arabidopsis}

5.1. Escrutinio de posibles interactores de PCC1 por doble híbrido en levadura

La identificación de interactores de una proteína puede clarificar la función que ésta ejerce en la planta, y mediante qué mecanismos la ejerce. Con este objetivo, se ha llevado a cabo en colaboración con la empresa Hybrigenics (París, Francia; http://www.hybrigenicsservices.com/) un escrutinio de doble híbrido en levadura. Para ello, y con el fin de excluir la región transmembrana de $\mathrm{PCC} 1$ y eludir los posibles problemas de tipo técnico derivados del anclaje a la membrana por su extremo C-terminal, se ha utilizado como cebo los primeros 59 aminoácidos de PCC1 codificados por los 177 nuceótidos contenidos en el extremo 5 ' de la secuencia codificante ( $\left.{ }^{\prime}{ }_{t} 177-\mathrm{PCC} 1\right)$. En el escrutinio se ha utilizado una genoteca de 98,8 millones de clones de ADNs complementarios (cDNAs) elaborada a 
partir de plántulas de 7 días de Arabidopsis thaliana. El servicio de búsqueda de interactores por doble híbrido mediante esta plataforma ha sido utilizado previamente con otras proteínas de plantas (Qi et al., 2012; Ajjawi et al., 2011).

Del escrutinio realizado se obtuvo un único interactor de PCC1 con una fiabilidad moderada. Se obtuvieron 3 clones de interacción que contenían la región del ADN complementario entre los nucleótidos 90 y 1207 del gen At1g71230 (AJH2, Tabla 6), que codifica la subunidad CSN5B del signalosoma COP9. Además de este posible interactor se han obtenido 21 clones que contenían distintas regiones del ADN complementario del gen At1g22920, gen que codifica la subunidad CSN5A del signalosoma (Tabla 6). Se ha descrito anteriormente que la subunidad CSN5A del signalosoma es capaz de unirse al dominio de unión a ADN de GAL4, siendo frecuente su identificación en estudios de escrutinio de doble híbrido en levadura (Nordgård et al., 2001). Por esta razón se considera este clon como un falso positivo en este tipo de estudios (Servicio técnico de Hybrigenics, comunicación personal). Además de estos dos clones, en el escrutinio de doble híbrido se han obtenido otros clones, si bien ha sido descartada su interacción fiable por distintos motivos, fundamentalmente porque dichos clones contenían las correspondientes secuencias fuera de fase de lectura o contenían secuencias en antisentido (Tabla 6).

\begin{tabular}{|c|c|c|}
\hline & & \\
$\mathrm{N}^{0}$ Clones & Gen & Región \\
\hline 3 & AJH2 & $90 . .1207$ \\
\hline 1 & AT1G65010 & $2732 . .3237$ \\
\hline 1 & AT1G74070 & $22 . .1090$ \\
\hline 1 & AT3G02450 & $-177 . .788$ \\
\hline 2 & CSN5A & $-52 . .726$ \\
\hline 1 & CSN5A &. .1053 \\
\hline 2 & CSN5A &. .1209 \\
\hline 2 & CSN5A & $51 . .1242$ \\
\hline 1 & CSN5A & $51 . .914$ \\
\hline 2 & CSN5A & 72 \\
\hline 2 & CSN5A & 87 \\
\hline 1 & CSN5A & $87 . .1053$ \\
\hline 1 & CSN5A & $108 . .1036$ \\
\hline 2 & CSN5A & 135 \\
\hline 3 & CSN5A & $141 . .1209$ \\
\hline 2 & CSN5A & $141 . .1240$ \\
\hline 2 & IGPD1 & $-28 . .933$ \\
\hline 2 & PIP1B & $678 . .331$ \\
\hline
\end{tabular}

Tabla 6. Clones identificados en el escrutinio de interactores de $\mathrm{N}_{\mathrm{t}}$ 177-PCC1 por doble híbrido. 
Para corroborar la fiabilidad e intensidad de la interacción entre CNS5B y PCC1 se cotransformaron células competentes de levadura AH109 con los respectivos plásmidos obtenidos en el escrutinio de doble híbrido. Las levaduras co-transformadas se cultivaron durante 24 horas en medio líquido, y se plaquearon diluciones seriadas en un medio mínimo SC (-His-Leu-Tri) con distintas concentraciones de 3-aminotriazol (3-AT). Los plásmidos utilizados fueron pB66-A8 (GAL4AD-CSN5B) y pP6-N'달-PCC1(GAL4DB$\left.\mathrm{N}_{\mathrm{t}}{ }_{1} 177-\mathrm{PCC} 1\right)$. Las levaduras así co-transformadas muestran un fuerte crecimiento en ausencia de 3-AT en comparación con el control co-transformado con pB66-CSN5B/pP6 (Figura 37), lo cual es indicativo de una interacción real entre PCC1 y CSN5B detectada con esta técnica. El crecimiento de levaduras co-transformadas con ambos plásmidos disminuye gradualmente cuando se suplementa el medio con 10 y con $20 \mathrm{mM}$ de 3 -AT (Figura 37), si bien siempre es mucho mayor que el de levaduras control. El hecho de que las levaduras crezcan en concentraciones de hasta $20 \mathrm{mM}$ de 3-AT evidencia la fuerte interacción entre PCC1 y CSN5B.

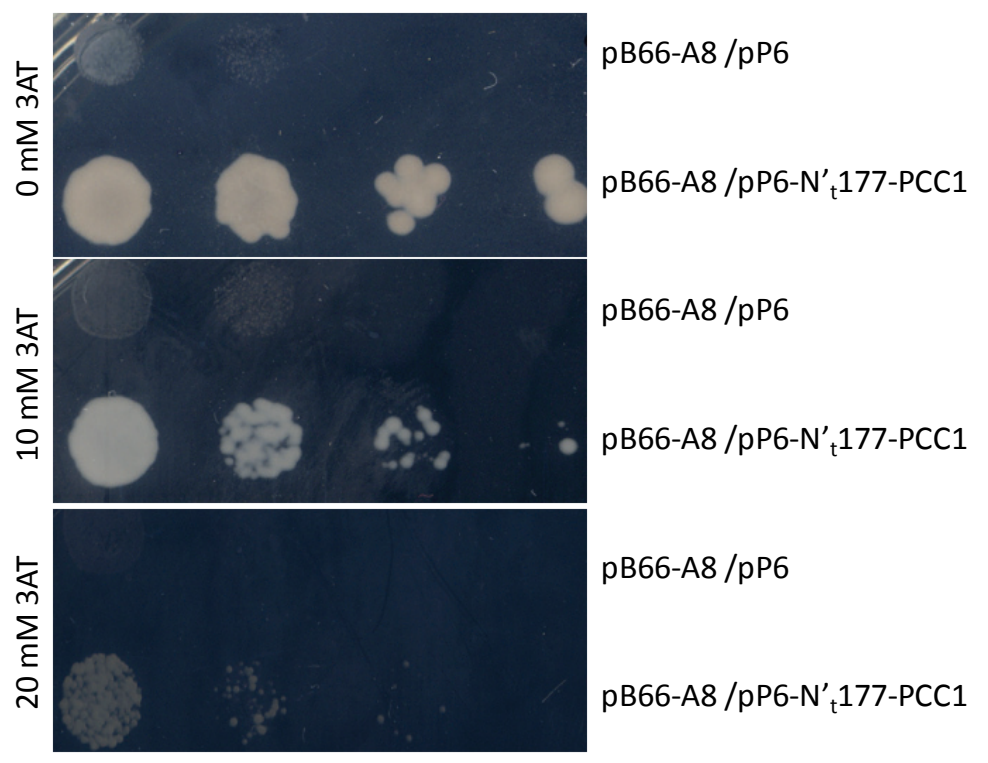

Figura 37. Comprobación por doble híbrido en levadura de la interacción de $\mathrm{N}_{t} 177-\mathrm{PCC} 1$ con la subunidad CSN5B del signalosoma. Se han cotransformado cepas de AH109 con versiones truncadas de PCC1 en N' terminal $\left(\mathrm{N}_{\mathrm{t}}\right.$ 177-PCC1) fusionadas a GAL4 DB (pP6- $\left.{ }^{\prime}{ }_{t} 177-\mathrm{PCC} 1\right)$ con el fragmento genómico situado entre los núcleotidos 90-1207 de la CDS de CSN5B (A8) fusionados a GAL4 AD (pB66-A8). La interacción de estas dos proteínas se ha estudiado por la capacidad de crecimiento en medios sin histidina, y con distintas concentraciones de 3-Aminotriazol (3AT). Como control negativo se han utilizado levaduras cotransformadas con GAL4 DB (pP6) y pB66-A8. 


\subsection{Localización subcelular de CSN5B}

Un aspecto importante a la hora de interpretar interacciones entre proteínas es la localización subcelular de éstas, ya que proteínas localizadas en distintos compartimentos estarían inhabilitadas para su interacción in vivo, al menos en condiciones basales. Como se ha mostrado previamente, PCC1 está asociada a la membrana plasmática por su región carboxi-terminal y expone previsiblemente su extremo amino-terminal al citosol celular. Se ha descrito que la subunidad CSN5A se localiza en su forma monomérica tanto en el citosol como en núcleos (Kwok et al., 1998; Bounpheng et al., 2000; Maytal-Kivity et al., 2002), por lo que una interacción entre ésta y la parte amino-terminal de PCC1 utilizada como cebo en el escrutinio de doble híbrido en levadura presentado en el apartado 5.1 sería factible, al menos topológicamente. En nuestro conocimiento no se ha descrito la localización subcelular de la subunidad CSN5B de COP9. Por esta razón se han generado construcciones para la sobreexpresión de CSN5B fusionada en su extremo amino-terminal a GFP (35S::GFP-CSN5B). La figura 38 muestra la fluorescencia registrada por microscopía confocal de discos de hojas de Nicotiana benthamiana que expresan transitoriamente esta construcción. Al igual que lo descrito para la subunidad CSN5A, la subunidad CSN5B se localiza tanto en el citosol como en el núcleo (Figura 38).

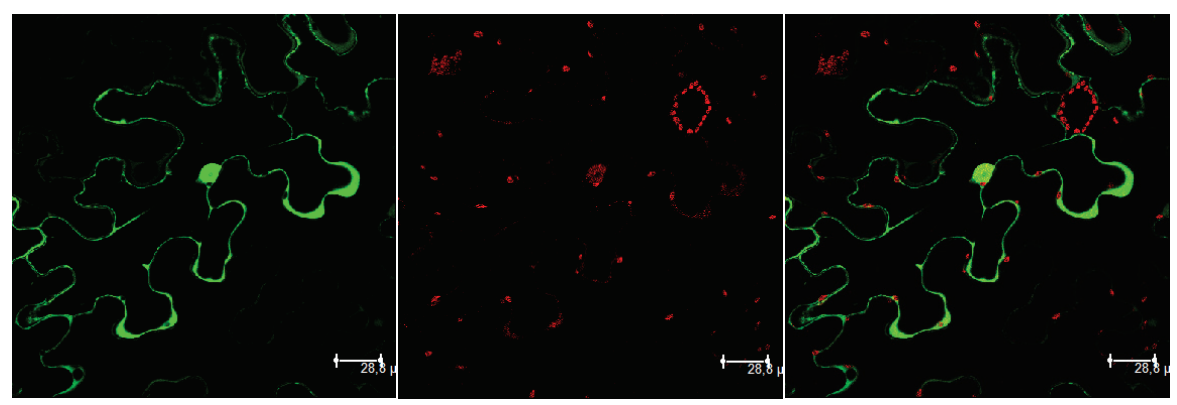

Figura 38. Imágenes obtenidas por microscopía confocal de plantas de Nicotiana transformadas transitoriamente con GFP-CSN5B.

\subsection{Confirmación de las interacciones de PCC1 con CSN5A y CSN5B in planta}

Para corroborar mediante técnicas alternativas la interacción de PCC1 con ambas subunidades CSN5 de COP9 se ha llevado a cabo un análisis de Complementación Bimolecular de Fluorescencia, para lo cual se utilizó la proteína completa PCC1 fusionada a una de las mitades de YFP y las subunidades CSN5A o CSN5B fusionadas a la mitad complementaria de YFP. Si bien ambas subunidades CSN5A y CSN5B se localizan tanto 
en citosol como en núcleo, la interacción de éstas con PCC1 tiene lugar exclusivamente en la región citosólica a nivel de la membrana plasmática (Figura 39 A y B).
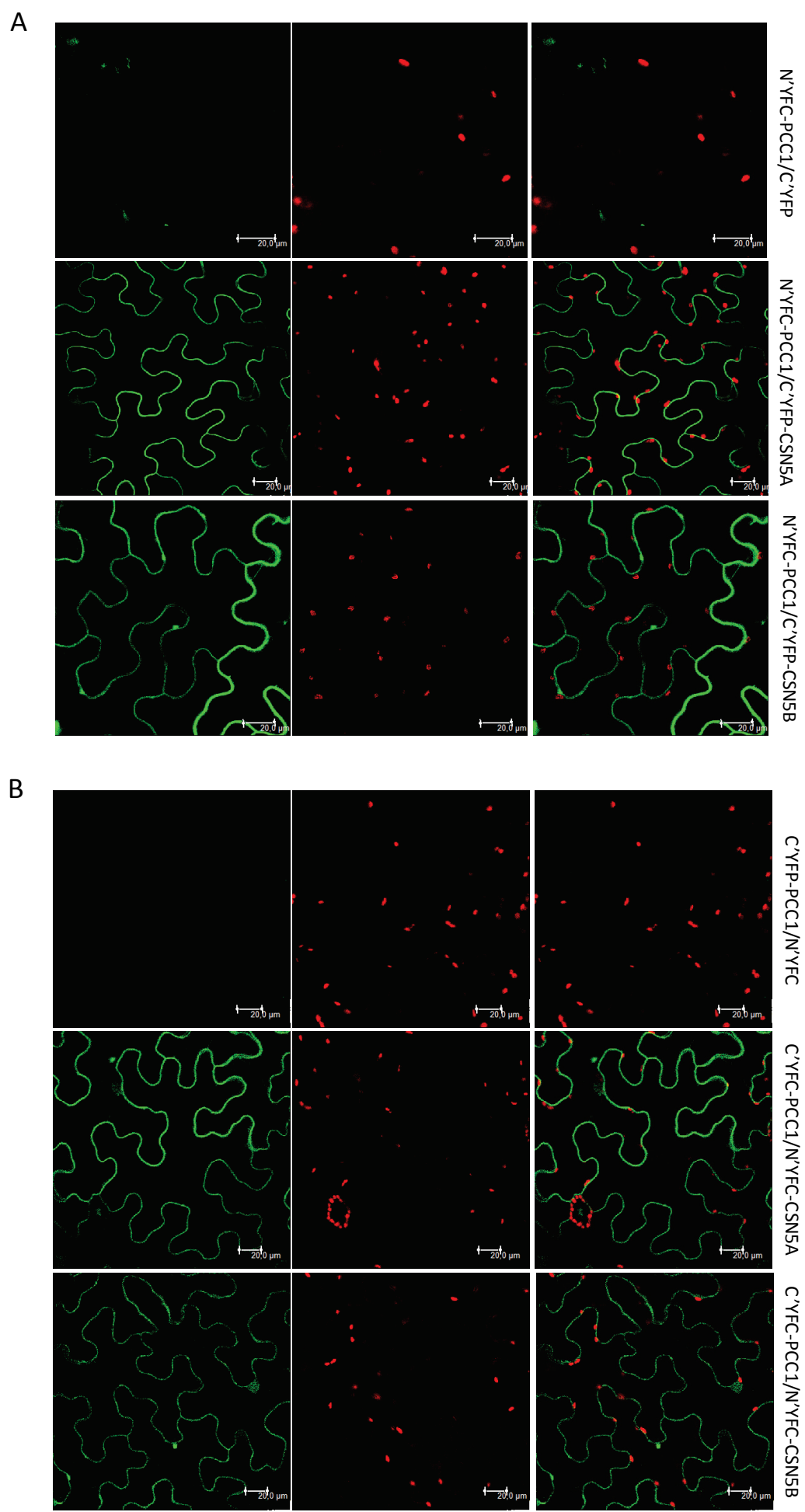

Figura 39. Interacción in planta por BiFC de PCC1 con las subunidades CSN5A y CSN5B del signalosoma COP9. Las interacciones se han detectado etiquetando PCC1 con la versión N'terminal de YFP (A) y con la versión C'terminal de YFP (B) y co-expresándolas en Nicotiana con las CSN5A y CSN5B etiquetadas con las versiones complementarias de YFP. Como control negativo se ha utilizado PCC1 etiquetada con ambos fragmentos de YFP, y el fragmento de YFP complementario en cada caso, de igual forma a la descrita en el apartado 3.3. 
La función de regulación del complejo CSN en la degradación de proteínas está mediada por la eliminación de residuos RUB1 de culinas, lo cual supone una inactivación de los complejos CRL E3 ligasa de ubiquitina que es necesaria para el correcto funcionamiento de éstos en el marcaje de sustratos específicos (Serino y Deng, 2003; Stratmann y Gusmaroli, 2012). Con el fin de estudiar si la interferencia de PCC1 puede afectar al estado de rubilación de CUL1 hemos analizado por análisis Western la acumulación de las formas rubiladas y derubiladas en líneas iPCC1, y la hemos comparado con la de plantas silvestres. Las plantas iPCC1 muestran una acumulación de forma rubilada de CUL1 (RUB1-CUL1) similar a las plantas silvestres (Figura 40), por lo que la interferencia de $P C C 1$ no parece alterar el equilibrio entre formas rubiladas y derubiladas de CUL1.

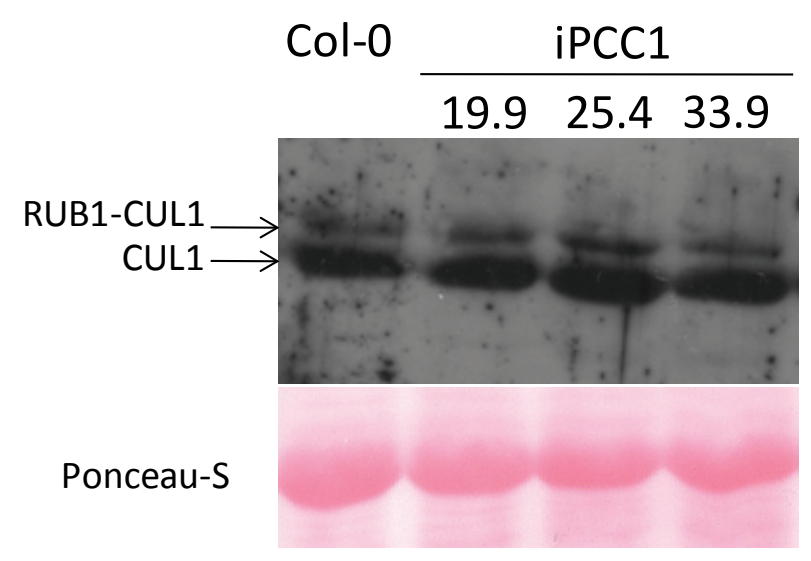

Figura 40. Acumulación de CUL1 y RUB1-CUL1 en plantas silvestres y plantas iPCC1 por análisis Western con un anticuerpo específico para CUL1 ( $\alpha$ pCUL1).

\section{Análisis transcriptómico de líneas iPCC1}

Con la finalidad de profundizar en los procesos en los que interviene PCCl así como posibles mecanismos por los que ejerce su función, hemos realizado un análisis transcriptómico de plantas iPCC1 con respecto a plantas silvestres como referencia. Dicho análisis transcriptómico se ha realizado hibridando ARNs de plantas silvestres y de líneas iPCC1 sobre micromatrices de oligonucleótidos de Affymetrix en la unidad de genómica del Centro Nacional de Biotecnología (CNB, Madrid, España; 
http://www.cnb.csic.es/index.php/es/servicios/genomica.html), según se indica en Materiales y Métodos.

La comparación global del transcriptoma de plantas silvestres versus plantas iPCC1 revela que un total de 1463 transcritos se ven significativamente alterados con un valor de p corregido para FDR ( False Discovery $\underline{\text { Rate}}$ ) inferior a 0.05 . De los genes cuya transcripción se ve alterada significativamente, 1037 presentan un aumento o disminución de 1.5 en valor absoluto en los niveles de transcrito en líneas iPCC1 con respecto a plantas silvestres. De este conjunto de genes, 517 están regulados al alza y 520 a la baja en las líneas iPCC1 con respecto a plantas silvestres.

\subsection{Categorías funcionales sobrerrepresentadas en el análisis transcriptómico}

Mediante la herramienta AgriGO (Zhou et al., 2010; http://bioinfo.cau.edu.cn/agriGO/) hemos analizado las categorías funcionales sobrerrepresentadas en los genes regulados al alza y los genes regulados a la baja. Las categorías funcionales más sobrerrepresentadas de los genes regulados al alza en el análisis transcriptómico comprenden procesos de localización lipídica, metabolismo y biosíntesis de glucosinolatos, y respuesta al ácido abscísico (Tabla 7A). Las categorías funcionales sobrerrepresentadas entre los genes que están regulados a la baja son la respuesta frente a patógenos y la muerte celular (Tabla 7B). 
A

\begin{tabular}{|l|c|c|c|c|}
\hline Categoría funcional. & $\begin{array}{c}\text { Genes } \\
\text { alterados }\end{array}$ & $\begin{array}{c}\text { Genes } \\
\text { totales }\end{array}$ & p-value & FDR \\
\hline Localización Lipídica & 9 & 24 & $2.5 \mathrm{e}-11$ & $2,00 \mathrm{E}-08$ \\
\hline Proceso de biosíntesis de glucosinolatos & 6 & 41 & $2.3 \mathrm{e}-05$ & 0.0044 \\
\hline Proceso de metabolismo de glucosinolatos & 7 & 62 & $2.8 \mathrm{e}-05$ & 0.0044 \\
\hline Respuesta a ABA & 17 & 378 & $4,00 \mathrm{E}-05$ & 0.005 \\
\hline Metabolismo de azufre & 10 & 220 & 0.00064 & 0.027 \\
\hline Transporte de membrana de ácidos orgánicos & 7 & 78 & $6.9 \mathrm{e}-05$ & 0.008 \\
\hline
\end{tabular}

B

\begin{tabular}{|l|c|c|c|c|}
\hline Categoría funcional. & $\begin{array}{c}\text { Genes } \\
\text { alterados }\end{array}$ & $\begin{array}{c}\text { Genes } \\
\text { totales }\end{array}$ & p-value & FDR \\
\hline Respuesta a defensa & 52 & 766 & $5.6 \mathrm{e}-19$ & $6,00 \mathrm{E}-16$ \\
\hline Muerte celular & 28 & 286 & $5.9 \mathrm{e}-15$ & $2,00 \mathrm{E}-12$ \\
\hline Defesna frente a hongos & 8 & 108 & $8.3 \mathrm{e}-0.5$ & 0.0055 \\
\hline Respuesta inmune innata & 24 & 347 & $6.3 \mathrm{e}-10$ & $9,00 \mathrm{E}-08$ \\
\hline Actividad de percepción de membrana & 13 & 171 & $4.4 \mathrm{e}-07$ & 0.00011 \\
\hline Interacción incompatible, defensa & 12 & 143 & $1.4 \mathrm{e}-06$ & 0.0001 \\
\hline
\end{tabular}

Tabla 7. Categorías funcionales sobrerrepresentadas en genes regulados al alza (A) y a la baja (B) en líneas iPCC1 obtenidas en el análisis transcriptómico. Se ha utilizado la herramienta bioinformática AgriGo (Zhou et al., 2010).

6.2. Comprobación por RT-qPCR de los datos del análisis transcriptómico

Para validar los datos del análisis transcriptómico se extrajeron nuevos ARNs de muestras tomadas en idénticas condiciones a las descritas para el análisis transcriptómico y se cuantificaron por RT-qPCR algunos transcritos de genes seleccionados al azar. La figura 41 muestra el ratio entre el valor de expresión en líneas iPCC1 con respecto a Col-0 obtenidos por ambas técnicas. Valores superiores a 1 indican una regulación al alza en las líneas iPCC1, mientras que valores inferiores a 1 indican una regulació a la baja. En esta gráfica se observa una buena correlación entre genes regulados ligeramente al alza, como $M Y B 28, H R S 1$ y $A D H 1$, así como para genes que se ven fuertemente regulados al alza, como $R G L 2$ e IRT3. De igual forma, genes regulados a la baja como EDS1, NPR1 y RPP4, también muestran correlación utilizando ambas técnicas (Figura 41). Con este ensayo confirmamos que los datos obtenidos a partir del transcriptoma no son dependientes del tipo de técnica, de la toma de muestras, ni del proceso de extracción y manipulación de los ARNs. 


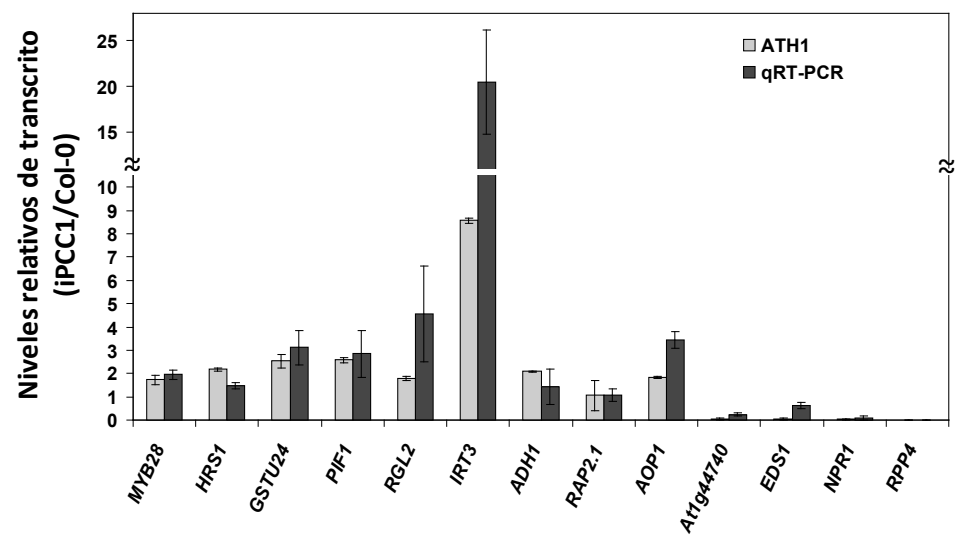

Figura 41. Validación de los datos obtenidos en el análisis transcriptómico. Esta gráfica muestra la correlación entre niveles relativos de transcritos de algunos de los genes alterados en líneas iPCC1 obtenidos en el análisis transcriptómico (ATH1) y medidos por RT-qPCR.

\subsection{Hipersensibilidad al ABA de las líneas iPCC1}

El ácido abscísico (ABA) es una fitohormona implicada en un amplio rango de procesos fisiológicos, desde procesos de desarrollo hasta respuesta frente a estrés biótico y abiótico. Recientemente se ha caracterizado en detalle el mecanismo de percepción y transducción de la señal mediada por ABA en Arabidopsis (Cutler et al., 2010). En condiciones basales, la familia de fosfatasas de tipo PP2C bloquea la acción de quinasas de tipo SnRK2, que son reguladores positivos de la señalización por ABA. Bajo condiciones de respuesta a $\mathrm{ABA}$, se produce su síntesis en la planta y posterior percepción por una familia de 14 proteínas PYR/PYL/RCAR, las cuales son capaces de interaccionar de forma dependiente de ABA con las fosfatasas de tipo PP2C. Esta interacción conduce a la inhibición de las fosfatasas PP2C y, por tanto, a la libreación de las quinasas SnRK2 que fosforilan y activan factores de transcripción de distintas familias relacionados con la respuesta a $\mathrm{ABA}$.

Los datos del análisis transcriptómico muestran una sobrerrepresentación de genes regulados al alza relacionados con la señalización de ABA (Tabla 7A). Ninguno de los genes que codifican receptores de ABA de la familia PYL/PYR/RCAR se ven transcripcionalmente alterados (Tabla 8A). En cambio, cuatro de los nueve genes que codifican fosfatasas de tipo PP2C están regulados al alza $(>1.5)$ en líneas iPCC1 (Tabla 8B). Además, dos de los 10 genes que codifican quinasas de tipo SnRK2 están regulados a la baja, mientras que otro se activa en líneas iPCC1 (Tabla 8C). Por último, las plantas iPCC1 presentan dos genes que codifican factores de transcripción de respuesta a ABA que 
están ligeramente regulados al alza (Tabla 8D). Si bien se trata de cambios transcripcionales moderados en la mayoría de los casos, en conjunto parece obvia la alteración del proceso de transducción de la señal mediada por el ABA en líneas iPCC1.

\begin{tabular}{|c|c|c|c|c|}
\hline & Código AGI & Gen & Expresión & FDR \\
\hline \multirow[t]{10}{*}{ A } & At4g17870 & PYR1 & $-1,09$ & $>0,05$ \\
\hline & At5g46790 & PYL1 & $-1,23$ & $>0,05$ \\
\hline & At2g26040 & PYL2 & $-1,08$ & $>0,05$ \\
\hline & At1g73000 & PYL3 & -1 & $>0,05$ \\
\hline & At2g38310 & PYL4 & $-1,3$ & $>0,05$ \\
\hline & At5g05440 & PYL5 & $-1,03$ & $>0,05$ \\
\hline & At2g40330 & PYL6 & 1,22 & $>0,05$ \\
\hline & At4g01026 & PYL7 & 1,12 & $>0,05$ \\
\hline & At5g53160 & PYL8 & 1,04 & $>0,05$ \\
\hline & At1g01360 & PYL9 & 1,16 & $>0,05$ \\
\hline \multirow[t]{9}{*}{ B } & At4g26080 & ABI1 & $-1,07$ & $>0,05$ \\
\hline & At5g57050 & ABI2 & 1,55 & 0,0431 \\
\hline & At1g72770 & HAB1 & 1,94 & 0,0488 \\
\hline & At1g17550 & HAB2 & 1,13 & $>0,05$ \\
\hline & At5g59220 & HAI1 & 3,71 & 0,0174 \\
\hline & At1g07430 & HAI2 & 1,65 & $>0,05$ \\
\hline & At2g29380 & HAI3 & 1,17 & $>0,05$ \\
\hline & At5g51760 & AHG1 & 1,19 & $>0,05$ \\
\hline & At3g11410 & AHG3 & 1,46 & $>0,05$ \\
\hline \multirow[t]{10}{*}{$\mathrm{C}$} & At5g08590 & SnRK2.1 & $-1,02$ & $>0,05$ \\
\hline & At3g50500 & SnRK2.2 & $-1,53$ & 0,0089 \\
\hline & At5g66880 & SnRK2.3 & 1,2 & $>0,05$ \\
\hline & At1g10940 & SnRK2.4 & $-1,07$ & $>0,05$ \\
\hline & At5g63650 & SnRK2.5 & 1,06 & $>0,05$ \\
\hline & At4g33950 & SnRK2.6 & 1,24 & $>0,05$ \\
\hline & At4g40010 & SnRK2.7 & 1,6 & 0,038 \\
\hline & At1g78290 & SnRK2.8 & 1,11 & $>0,05$ \\
\hline & At2g23030 & SnRK2.9 & $-1,52$ & $>0,05$ \\
\hline & At1g60940 & SnRK2.10 & $-1,04$ & $>0,05$ \\
\hline \multirow[t]{5}{*}{$\mathrm{D}$} & At1g49720 & $\mathrm{ABF} 1$ & 1,24 & $>0,05$ \\
\hline & At3g56850 & $\mathrm{ABF} 2$ & 1,15 & $>0,05$ \\
\hline & At4g34000 & ABF3 & 1,75 & 0,0586 \\
\hline & At3g19290 & ABF4 & 1,21 & $>0,05$ \\
\hline & At2g36270 & ABI5 & 1,39 & 0,0328 \\
\hline
\end{tabular}

Tabla 8. Niveles de transcrito de genes implicados en la percepción, selañalización y respuesta a ABA obtenidos mediante análisis transcriptómico de plantas silvestres versus plantas iPCC1, y valor de FDR obtenido en dicho estudio. 
Por último hemos analizado los niveles de transcrito por RT-qPCR de genes de respuesta a $\mathrm{ABA}$ identificados en el análisis transcriptómico, como RD29B $(+3.14)$ y GSTU24 (+2.53), y hemos observado una regulación de ambos a alza concordante con el análisis transcriptómico (Figura 42). Por esta razón nos planteamos estudiar la respuesta de estas líneas a $\mathrm{ABA}$ en distintos procesos de desarrollo, tales como la germinación, el establecimiento de plántula, y el crecimiento de la raíz en medios suplementados con ABA.

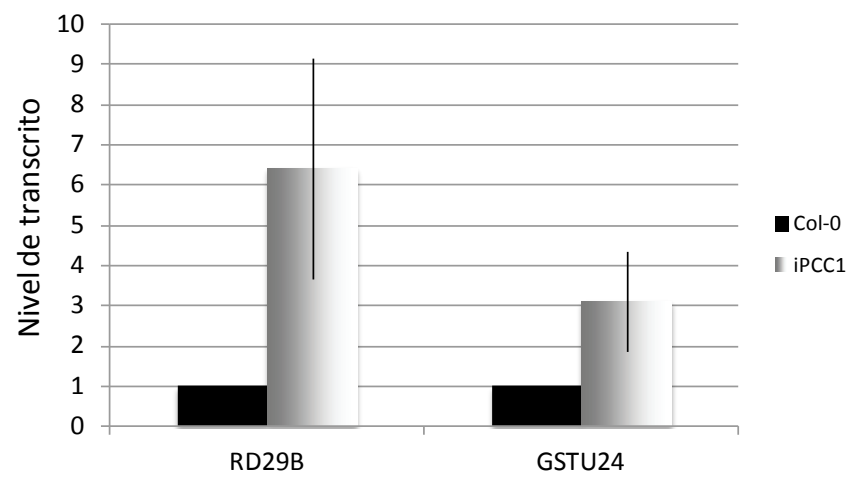

Figura 42. Cuantifcación de los niveles de transcrito por RT-qPCR de genes de respuesta a ABA identificados en el análisis transcriptómico.

Se ha descrito al ABA como un inhibidor de la germinación (Nambara y MarionPoll, 2003). Con el fin de estudiar cómo afecta la activación constitutiva de la señalización por $\mathrm{ABA}$ en líneas iPCC1 a la germinación, hemos analizado sus porcentajes de germinación y los hemos comparado con los de plantas silvestres en medios control y en medios suplementados con ABA. En condiciones control, esto es, sin ABA en el medio, las semillas procedentes de las distintas líneas iPCC1 presentan cierto retraso en la germinación a las 24 horas, si bien se equipara a las 48, 72 y 96 horas tras la siembra, llegando a ser del 90\% tanto en plantas Col-0 como en plantas iPCC1. Estos porcentajes de germinación similares indican que la respuesta al ABA endógeno de la planta no se ve alterada en líneas iPCC1. Sin embargo, cuando se suplementa el medio con ABA, incluso a concentraciones de $0.2 \mu \mathrm{M}$, se aprecia un descenso significativo del porcentaje de germinación de semillas con función reducida de $P C C l$ con respecto al de plantas silvestres (Figura 43A). Por lo tanto, las semillas procedentes de plantas iPCC1 presentan hipersensibilidad a ABA cuando germinan en medios suplementados con ABA. 
La estratificación de las semillas provoca un descenso de los niveles de ABA en las semillas, viéndose favorecida su germinación (Gubler et al., 2005). Hemos analizado el efecto de la estratificación ( 3 días a $4^{\circ} \mathrm{C}$ ) sobre plantas silvestres en nuestras condiciones de ensayo, y hemos observado que tras 24 horas después de la siembra no ha germinado ninguna semilla cuando éstas no han sido sometidas a un tratamiento previo de estratificación, mientras que casi el 30\% de las semillas estratificadas han germinado a las 24 horas (Figura 43B). En cualquier caso, el porcentaje de germinación tras 72 y 96 horas es similar para semillas estratificadas y semillas no estratificadas, por lo que se trata de un retraso más que de un bloqueo de la germinación. Para ver cómo afecta la no estratificación a la germinación de semillas procedentes de plantas iPCC1, hemos comparado los porcentajes de germinación de éstas respecto a los de semillas silvestres sin previo tratamiento de estratificación. Bajo estas condiciones se observa que las semillas procedentes de plantas iPCC1 muestran un mayor retraso de la germinación que las semillas silvestres (Figura 43C). El hecho de que en condiciones basales la interferencia de PCC1 no provoque un retraso de germinación con respecto a semillas silvestres cuando se estratifican, pero sí cuando no se estratifican, indica que los niveles de ABA presentes en las semillas antes de la estratificación son suficientes para retrasar la germinación en semillas iPCC1. 
A 100
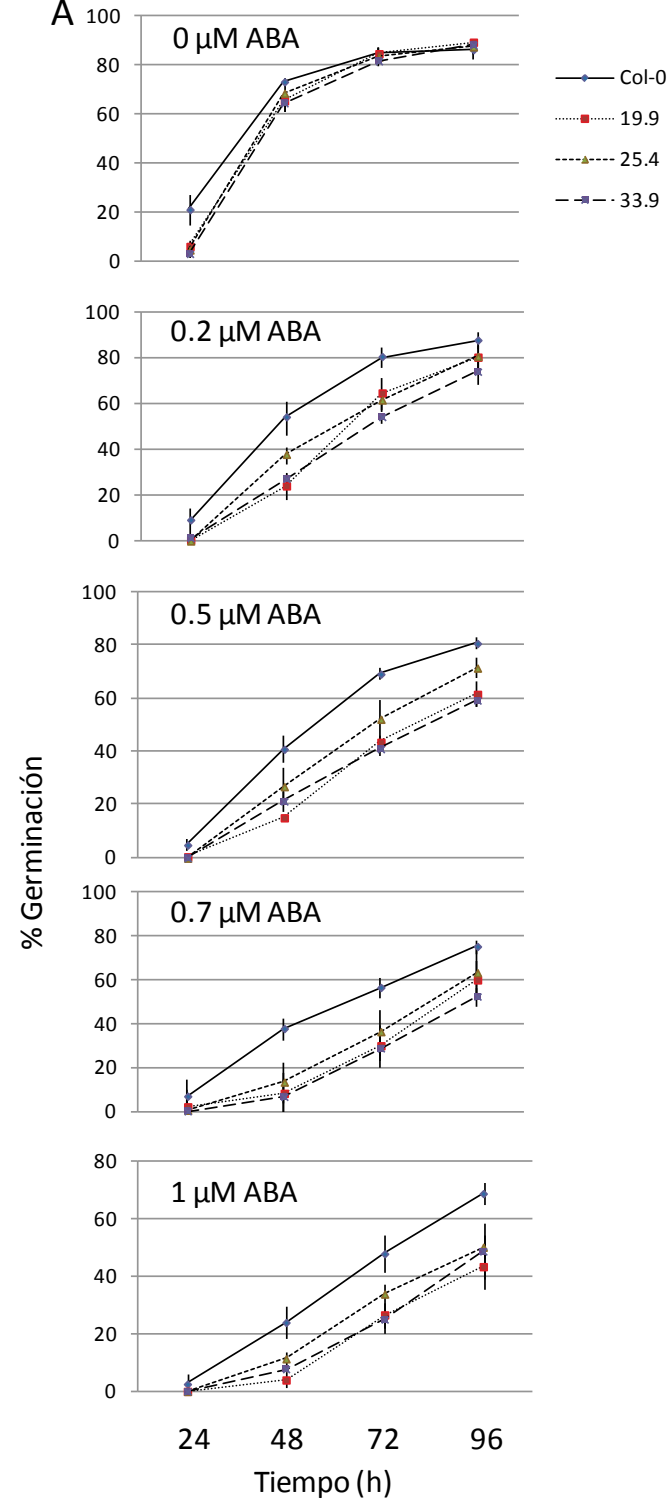

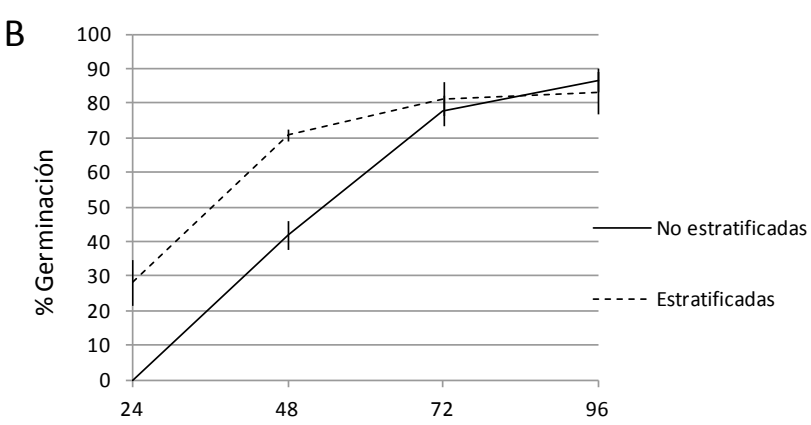

C

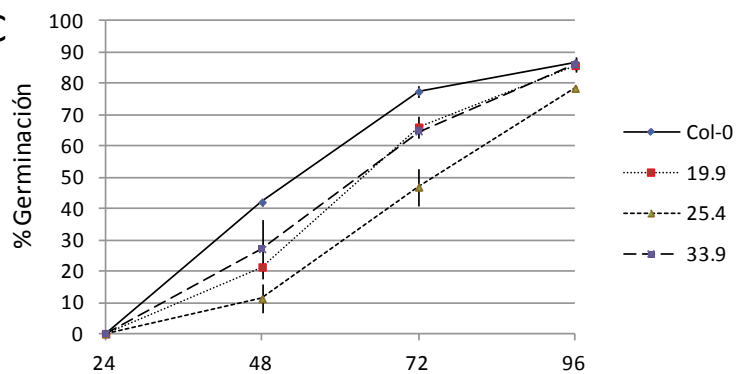

Figura 43. Porcentajes de germinación de semillas procedentes de plantas silvestres y de plantas transgénicas iPCC1 en distintas condiciones. A. Porcentajes de germinación en medios MS y medios MS suplementados con concentraciones crecientes de ABA. B. Porcentajes de germinación de semillas silvestres con y sin previo tratamiento de estratificación. C. Porcentajes de germinación de semillas silvestres y semillas iPCC1 sin previo tratamiento de estratificación. En todos los casos, el tratamiento de estratificación consistió en someter a las semillas a temperaturas de $4^{\circ} \mathrm{C}$ durante 3 días antes de pasarlas a condiciones óptimas para la germinación.

Hemos estudiado además cómo se ve afectado el establecimiento de plántula a los 10 días de crecimiento en medios suplementados con ABA. Para ello hemos considerado que una plántula está completamente establecida cuando presenta sus cotiledones verdes y expandidos. En plántulas silvestres, cuando se suplementa el medio con ABA a concentraciones de 0.2 y $0.5 \mu \mathrm{M}$, se obtiene una reducción del 50 y el $75 \%$ de plántulas 
establecidas, respectivamente (Figura 44). Estos porcentajes de reducción del establecimiento de plántula son de hasta el 80 y 95\% en líneas iPCC1 (Figura 44) cuando crecen en medios suplementados con 0.2 y $0.5 \mu \mathrm{M}$ de ABA, respectivamente. Este fenotipo en medios suplementados con ABA apunta de nuevo a una hipersensibilidad de plantas de Arabidopsis con función reducida de PCC1.
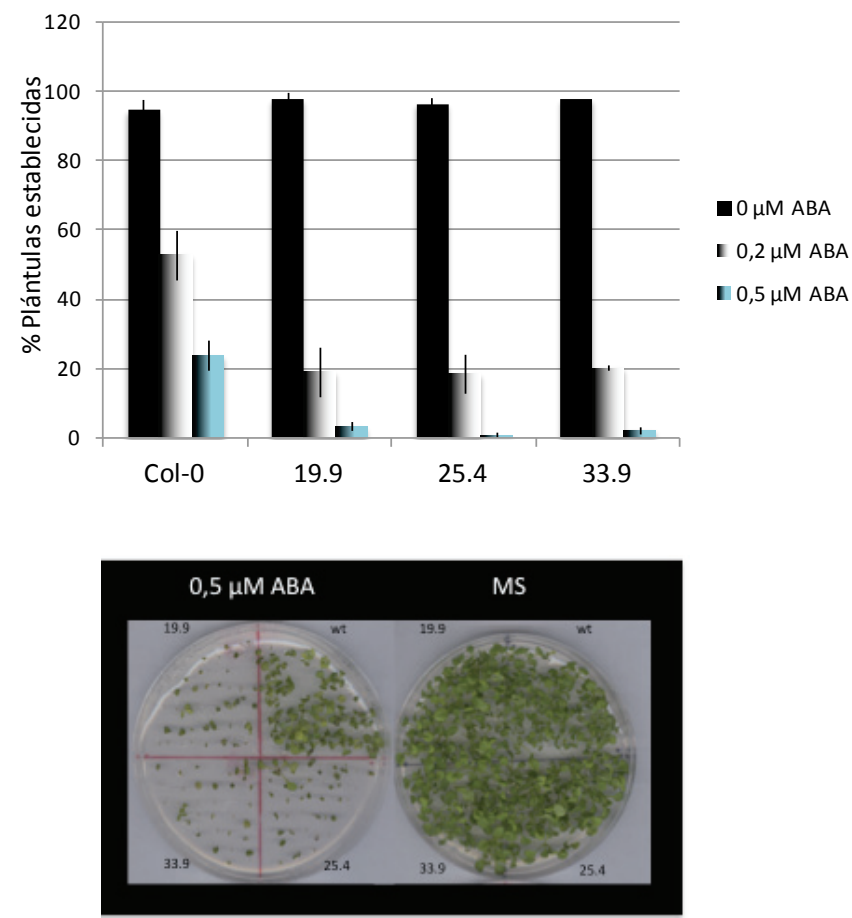

Figura 44. Establecimiento de plántula en medios control y medios suplementados con ABA. El establecimiento de plántula se estimó como el porcentaje de plántulas que presentan los cotiledones verdes y completamente expandidos.

Existe una correlación entre la respuesta a ABA y a la presencia de osmolitos como manitol y cloruro sódico (Lee y Zhu, 2010; Xiong et al., 2001). Por esta razón hemos ensayado la germinación y el establecimiento de plántula en medios suplementados con $250 \mathrm{mM}$ de manitol y $125 \mathrm{mM}$ de $\mathrm{NaCl}$ en plantas iPCC1 con respecto a plantas silvestres. Las plantas iPCC1 presentan unos menores porcentajes de germinación (Figura 45A) y establecimiento (Figura 45B) en medios suplementados con manitol que las plantas silvestres. En los ensayos realizados con cloruro sódico, sin embargo, los resultados de germinación y establecimiento son dependientes de la línea. La línea iPCC1 25.4 presenta porcentajes de germinación (figura 45C) y de establecimiento (Figura 45D) 
significativamente por debajo de los de plantas silvestres, mientras que las líneas iPCC1 19.9 y 33.9 se comportan de forma similar a las plantas control (Figura 45 C y D).
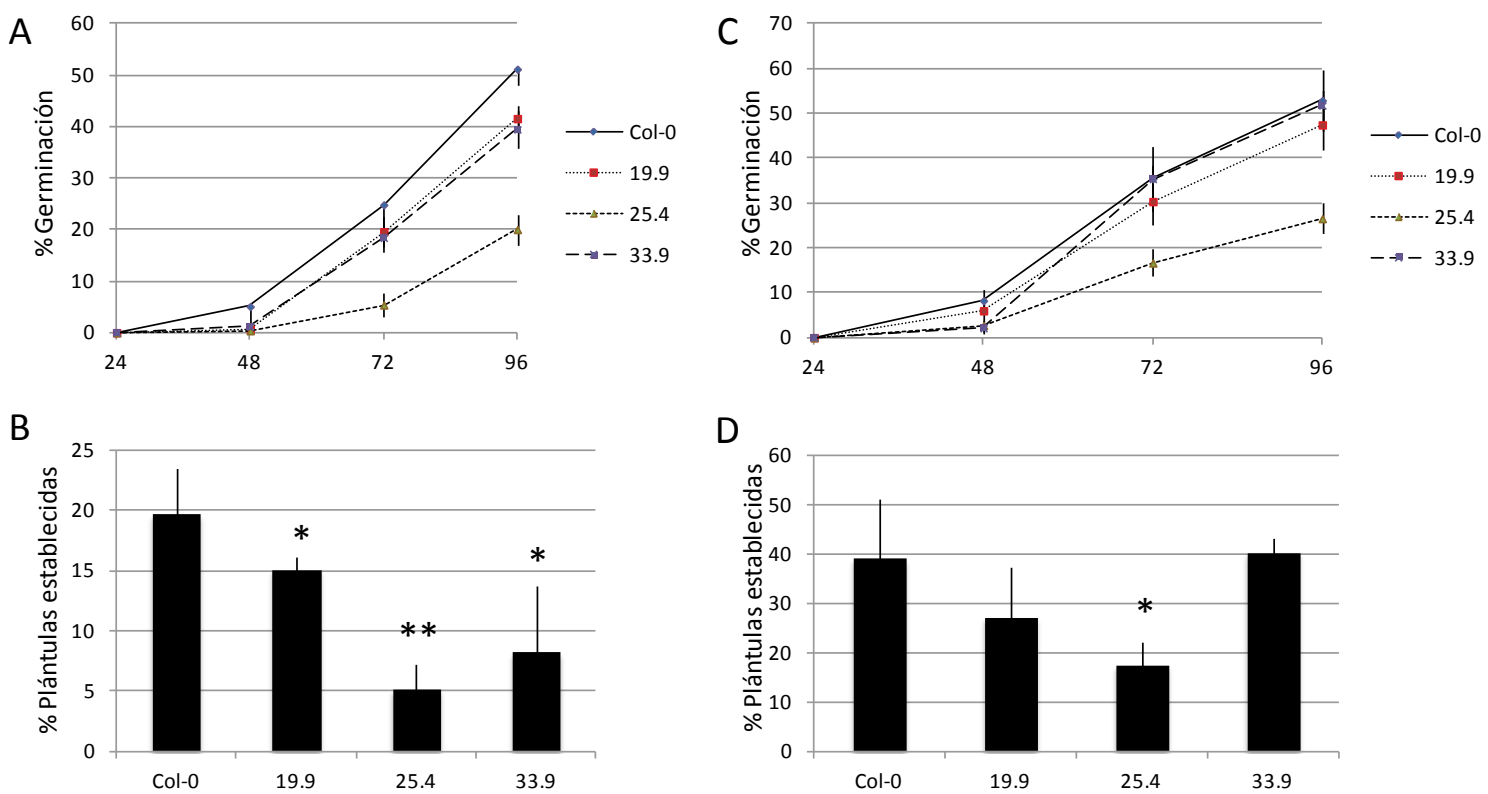

Figura 45. Medidas de los porcentajes de germinación y establecimiento de plántula en medios suplementados con manitol y NaCl. Porcentajes de germinación (A) y de establecimiento de plántula (B) en medios suplementados con $250 \mathrm{mM}$ de manitol de plantas iPCC1 comparadas con plantas silvestres. Porcentajes de germinación (C) y de establecimiento de plántula (D) en medios suplementados con $125 \mathrm{mM}$ de $\mathrm{NaCl}$ de plantas iPCC1 comparadas con plantas silvestres.

Por último, para estudiar cómo responden las plantas iPCC1 a ABA en términos de crecimiento de raíz, se sembraron semillas Col-0 y iPCC1 en placas verticales conteniendo MS. Tras 6 días de crecimiento bajo condiciones controladas (días largos, $22^{\circ} \mathrm{C}$ ), las plántulas fueron transferidas a medios suplementados con 0,15 y $30 \mu \mathrm{M}$ de ABA. Tras 9 días de crecimiento en estas condiciones se midió la longitud de las raíces considerando como 0 la longitud de raíces a los 6 días. Las plantas silvestres presentan una reducción del crecimiento de la raíz de un $43 \%$ y un $70 \%$ en medios suplementados con 15 y $30 \mu \mathrm{M}$, respectivamente, mientras que las plantas $\mathrm{iPCC} 1$ presentan en promedio reducciones de un $80 \%$ y un $85 \%$ en los medios suplementados con 15 y $30 \mu \mathrm{M}$, respectivamente (Figura 46). Este resultado apunta de nuevo a hipersensibilidad a ABA de las líneas iPCC1 respecto a plantas silvestres. 
Por lo tanto, tomando como referencia distintos parámetros de desarrollo como la germinación, el establecimiento de plántula, y el crecimiento de raíces en medios suplementados con ABA, se observa una hipersensibilidad de plantas de Arabidopsis cuando se interfiere la función de $P C C 1$ con respecto a plantas silvestres.
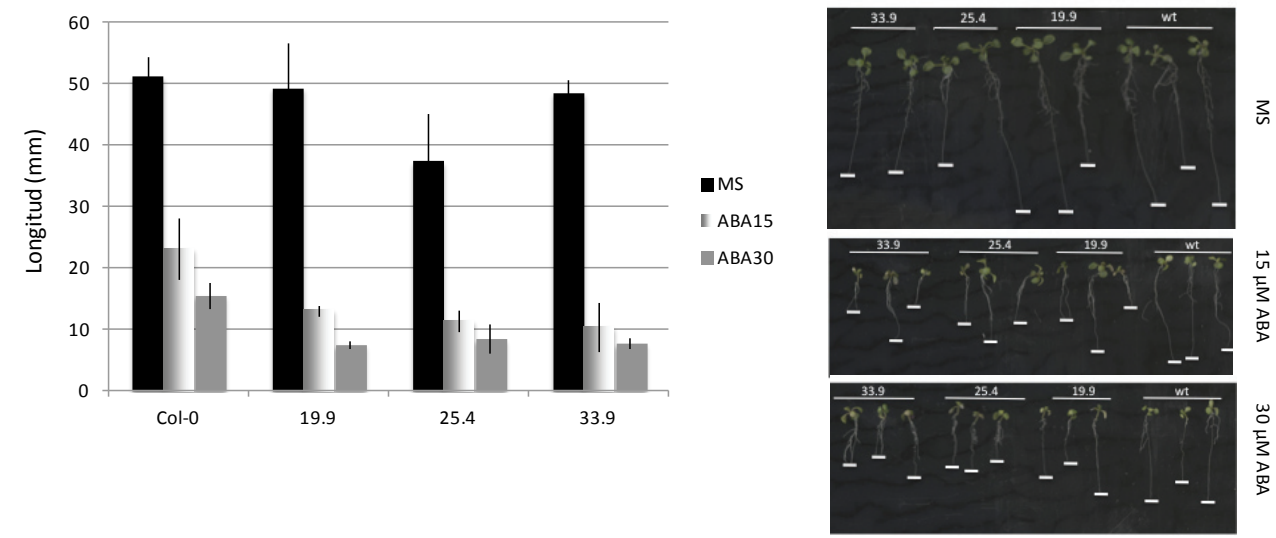

Figura 46. Medida de la longitud de las raíces de plantas silvestres Col-) y plantas iPCC1 de 15 dtg en medios control y medios suplementados con $15 \mu \mathrm{M}$ y $30 \mu \mathrm{M}$ de ABA.

Por último, dada la relación directa descrita entre el ácido abscísico y el cierre estomático hemos procedido a estudiar la respuesta a ABA sobre el cierre de los estomas de plantas iPCC1 y la hemos comparado con la de plantas silvestres. Para ello se incubaron plántulas de ocho días en un medio de apertura estomática según se indica en el apartado 9.4 de los materiales y métodos. Tras 2-3 horas de incubación se reemplazó el medio por medio fresco suplementado con 0,5 y $50 \mu \mathrm{M}$ de ABA, y se midió el cierre estomático a las 2 horas. Las plántulas se tiñeron con yoduro de propidio para favorecer la visualización de los estomas según se indica en el apartado 10.2 de los materiales y métodos. Se recogieron imágenes por microscopía confocal de 20-25 estomas de diferentes plántulas de cada genotipo y se procedió a la medida del cierre estomático como la relación entre el radio (r) y la longitud (1) (Figura 47A). Las líneas iPCC1 presentan unos estomas más cerrados que las correspondientes plantas control en condiciones basales sin ABA en el medio (Figura $47 \mathrm{~B}$ y C). El tratamiento con $5 \mu \mathrm{M}$ de $\mathrm{ABA}$ en plantas iPCC1 provoca un mayor cierre en estomas que en plantas silvestres, que es similar al observado en ambos genotipos cuando se aplican oncentraciones de $50 \mu \mathrm{M}$ de $\mathrm{ABA}$ (Figura $47 \mathrm{~B}$ y C). El cierre estomático en las 
plantas iPCC1 es igual al observado para plantas silvestres a concentraciones de $50 \mu \mathrm{M}$ de ABA (Figura 47 B y C). Para analizar si el cierre estomático observado en las líneas iPCC1 se traduce en una menor pérdida de agua, se midió la pérdida de agua estimada como pérdida de peso fresco en plántulas de 12 días según se describe en los materiales y métodos. La figura 47D muestra que las líneas iPCC1 muestran una pérdida de agua similar a la observada para las plantas silvestres (Figura 47D).

A

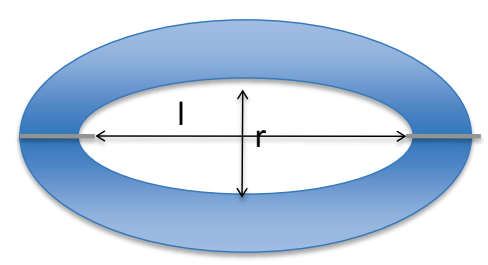

B

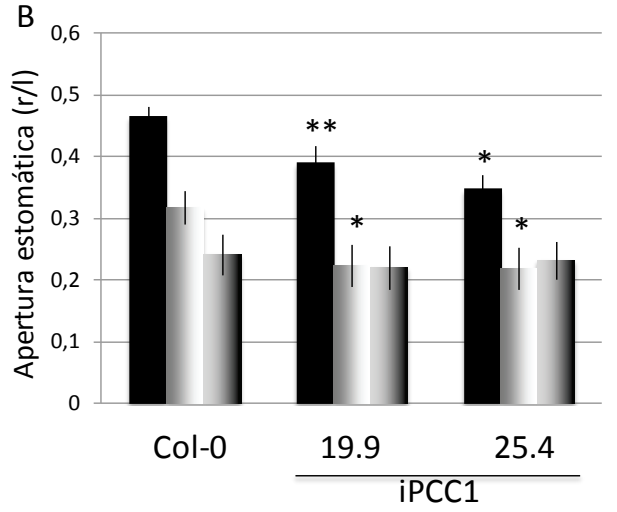

D

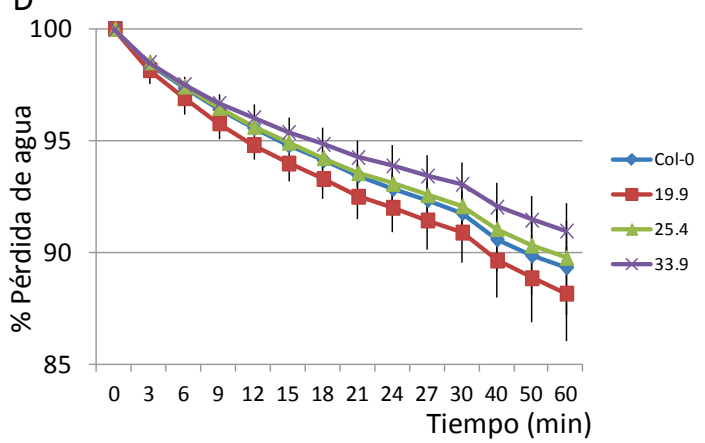

C
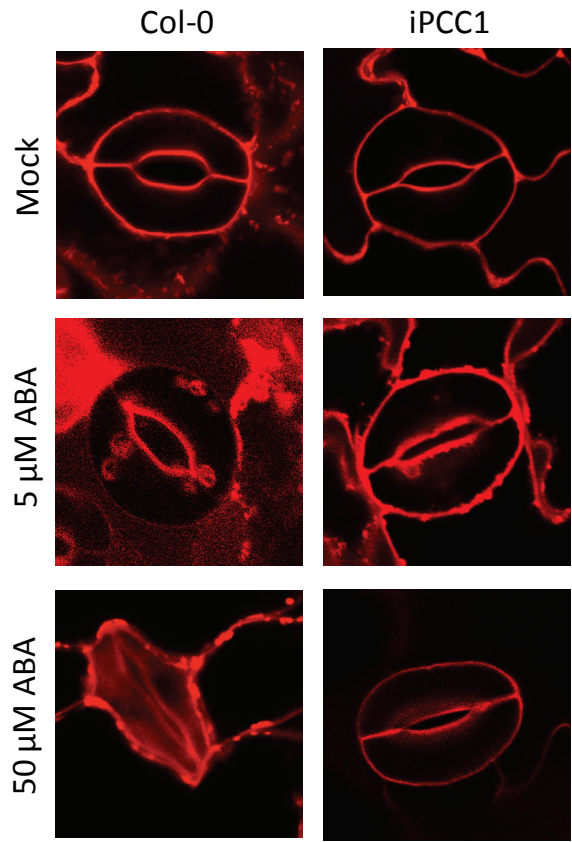

Figura 47. A. Representación esquemática de un estoma y los criterios de medida del cierre estomático. El cierre estomático se midió como la proporción entre el radio (r) y la longitud (l) del estoma. Cuanto menor sea el valor calculado, más cerrados estarán los estomas. B. Representación gráfica de los valores de cierre estomático observado en plantas silvestres y líneas iPCC1 en condiciones control y condiciones de inducción de cierre estomático por ABA. C. Imágenes representativas por microscopía confocal de estomas de plantas silvestres y de las líneas iPCC 19.9 y 25.4 en medio control y medio sumplementado con ABA. Para facilital la visualización de los estomas las plantas fueron sometidas a una tinción con yoduro de propidio. D. Medida de la pérdida de agua calculada como la pérdida de peso fresco con el tiempo en plantas de 12 días. 


\subsection{Alteración de la composición lipídica en plantas iPCC1}

La comparación de los transcriptomas de plantas iPCC1 con respecto a plantas silvestres revela una alteración de la categoría funcional relacionada con la síntesis, localización y señalización lipídica. Entre los genes transcripcionalmente alterados en las líneass iPCC1 encontramos genes con homología a lipasas y fosfolipasas, genes relacionados con la movilidad de lípidos en la célula y la biosíntesis de fosfolípidos, y, en menor medida, genes implicados en la biosíntesis de ácidos grasos. Concretamente están alterados 16 y 4 genes homólogos a lipasas y fosfolipasas, respectivamente, y 7 genes de la familia de transportadores de lípidos LTP (Lipid $\underline{\text { Transfer }}$ Protein), implicada en la biosíntesis y movilidad de lípidos en las membranas celulares (D’Angelo et al., 2008). Estos datos sugieren que la biosíntesis y la distribución de lípidos en las plantas podrían depender directa o indirectamente de la función de PCC1.

Con el fin de estudiar una posible alteración en la composición lipídica en las plantas con función reducida de PCC1 hemos analizado la cantidad de ácidos grasos y de lípidos polares en las líneas iPCC1 y los hemos comparado con la de plantas silvestres Col0 . La cantidad total de ácidos grasos en plantas iPCC1 es un $25 \%$ inferior a la observada en plantas silvestres (Figura 48A). Esta menor acumulación de ácidos grasos totales se reparte en ligeras reducciones de las cantidades de los distintos ácidos grasos de 16 y 18 carbonos con distintos grados de insaturación, a excepción del ácido graso 16:1 (Figura 48C). Sin embargo, cuando analizamos los porcentajes de los distintos tipos de ácidos grasos no se observan diferencias entre plantas iPCC1 y plantas silvestres (Figura 48D). Por otro lado, si bien la cantidad total de lípidos polares son similares para ambos genotipos (Figura 48A), cuando analizamos las distintas clases de estos lípidos se observan diferencias estre las plantas silvestres y las plantas iPCC1. Las plantas iPCC1 acumulan un 75\% menos de fosfatidilinositol (PI) que las plantas silvestres (Figura 48B). Las cantidades de otros fosfolípidos, como la fosfatidilserina (PS), la fosfatidilcolina (PC) y, en menor medida, la fosfatidiletanolamnina (PE), también son inferiores en plantas iPCC1, si bien los cambios no son tan acusados (Figura 48B). Por otro lado se observa una mayor acumulación de monogalactosil diacilglicerol (MGDG) y de fosfatidil glicerol (PG) en las líneas iPCC1 que en las plantas silvestres (Figura 48B). Otros fosfolípidos, como el ácido fosfatídico (PA), el diacilgicerol fosfato (DGDG) y el sulfoquinovosil (SQ) no presentan alteraciones en su acumulación en plantas iPCC1 con respecto a plantas Col-0 (Figura 48B). 

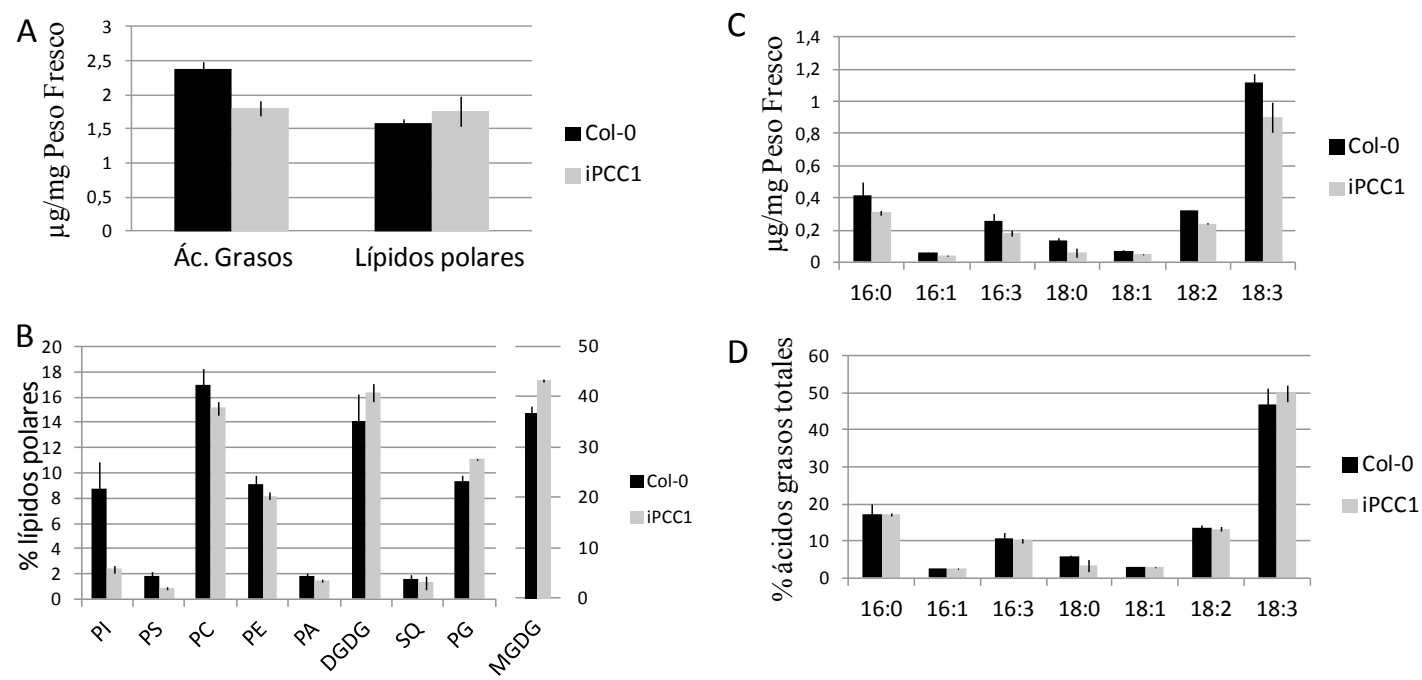

Figura 48. A. Cantidad total de ácidos grasos libres de cadenas laterales de 16 y 18 carbonos con distintos grados de instauración y de lípidos polares en plantas iPCC1 y plantas silvestres Col-0. B. Cantidad relativa de distintos tipos de fosfolípidos (PI: fosfoinositol; PS: fosfatidilserina; PC: fosfatidilcolina; PE: fosfatidiletanolamina; PA: ácido fosfatídico; MGDG: monogalactosil diacilglicerol fosfato; DGDG: digalactosil diacilglicerol fosfato; SQ: sulfoquinovosil; PG: fosfoglicerato).

Los lípidos polares están compuestos por un residuo de glicerol al que se le une un grupo polar que confiere diversidad estructural y funcional a este grupo de compuestos, y dos unidades de ácidos grasos. Hemos analizado las cantidades y el grado de insaturación de ácidos grasos 16C y 18C contenidos en los distintos tipos de lípidos polares en plantas iPCC1 y los hemos comparado con los de plantas silvestres. En general las plantas iPCC1 presentan una menor acumulación de ácidos grasos saturados 16:0 y 18:0, en favor de la acumulación de los correspondientes ácidos grasos insaturados 16:3 y 18:3 (Figura 49A). Si analizamos en detalle la cantidad de ácidos grasos en los distintos tipos de lípidos polares estudiados se observan diferencias significativas en el grado de instauración de ácidos grasos de 18C en los residuos de fosfatidilinositol (PI) y de fosfatidilserina (PS). Para ambos tipos de fosfolípidos se observa un mayor grado de insaturación (18:1, 18:2, 18:3) en las plantas iPCC1 que en plantas silvestres, las cuales acumulan mayor cantidad de 16:0 y 18:0 (Figura 49 B y C). Por el contrario, el nivel de insaturación de los ácidos grasos del ácido fosfatídico es ligeramente menor en plantas iPCC1 que en plantas silvestres (Figura 49D). La cantidad relativa de ácidos grasos del resto de lípidos polares analizados no varía significativamente en plantas Col-0 y plantas iPCC1. 

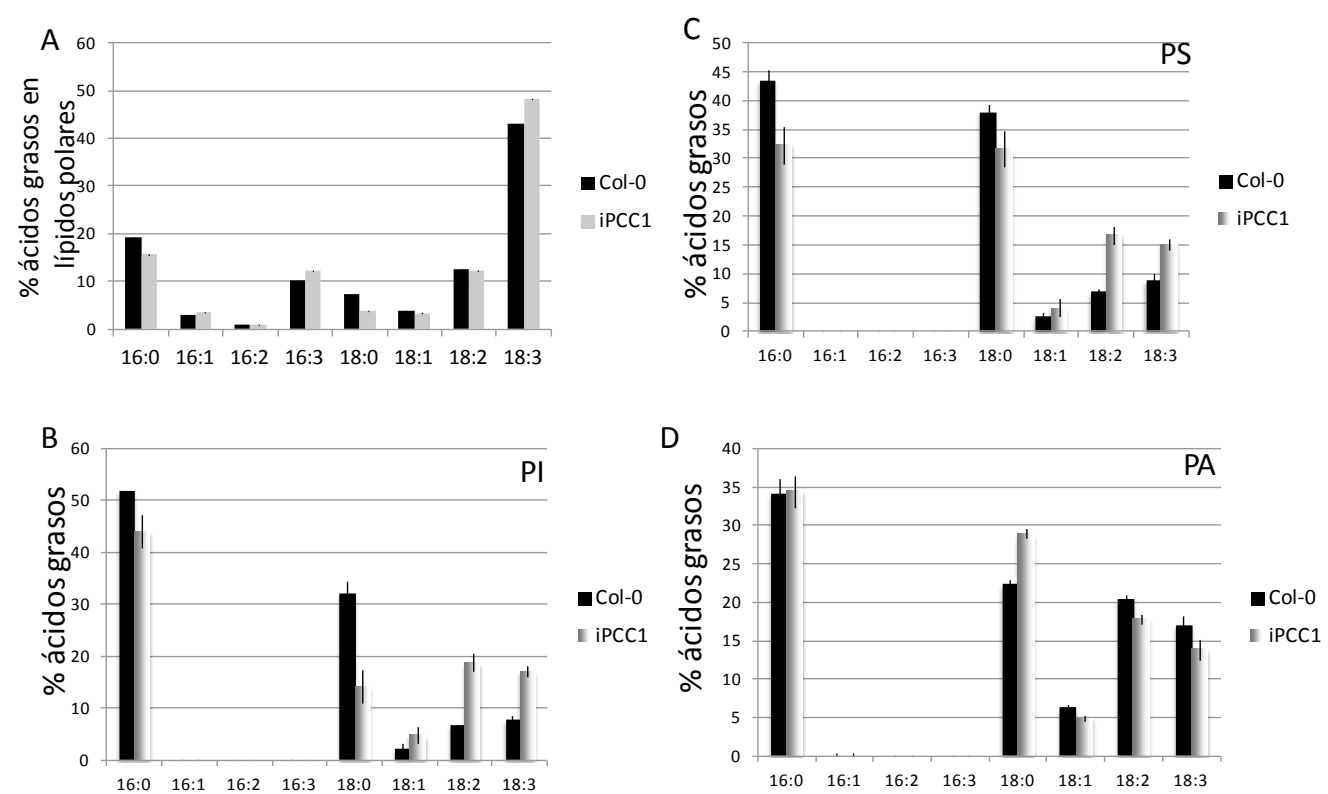

Figura 49. Cantidades relativas de los distintos tipos de ácidos grasos de cadenas laterales de 16 y 18 átomos de carbono y distinto grado de insaturación que componen los lípidos polares en su conjunto (A), y los fosfolípidos fosfatidilinositol (PI; B), la fosfatidilserina (PS; C) y el ácido fosfatídico (PA; D).

6.5. Fenotipos de defensa de líneas iPCC1 frente a distintos tipos de patógenos

El análisis transcriptómico realizado en este proyecto revela una regulación a la baja de genes pertenecientes a la categoría funcional de defensa y de muerte celular. Este hecho encaja con el papel relacionado con defensa frente a patógenos biotrofos propuesto originalmente para PCC1 (Sauerbrunn y Schlaich, 2004). Sin embargo, de los genes de defensa alterados transcripcionalmente en líneas iPCC1 se encuentran genes de respuesta frente a patógenos tanto de tipo biotrofo como de tipo necrotrofo, lo cual apunta a un papel general de PCC1 en defensa.

El análisis transcriptómico muestra una ligera regulación a la baja del gen central de señalización por SA NPRl (-1,57), que se ha descrito como regulador negativo de $P R 1$ (Zhou et al., 2000). Sin embargo, si bien los niveles de PRl obtenidos en el análisis transcriptómico son elevados en plantas iPCC1 con respecto a plantas silvestres $(+3,73)$, el valor FDR es de 0.069 , por encima del umbral considerado estadísticamente significativo en este trabajo. Por esta razón se ha procedido a estudiar los niveles de $P R I$ en plantas iPCC1 por RT-qPCR, y se ha observado una mayor expresión constitutiva de PRl en líneas iPCC1 con respecto al de plantas silvestres (Figura 50A). Los niveles de NPR1 también han sido corroborados por RT-qPCR, y hemos observado una reducción de la 
expresión de este gen del 90\% en plantas iPCC1 con respecto al de plantas control (Figura 50C). Hemos analizado además la acumulación de PR1 en condiciones inducidas por aplicación de SA, y hemos observado que la mayor expresión de $P R 1$ se traduce en una mayor acumulación de proteína en estas condiciones (Figura 50B). Por esta razón es de esperar que la pérdida de función de $P C C l$ confiera una mayor resistencia frente a Pseudomonas syringae. Sin embrago, experimentos realizados utilizando plántulas de 2 semanas de edad en condiciones control (Figura 51A) y tratadas con SA (Figura 51B), y plantas de 4-5 semanas (Figura 51C), muestran que las plantas iPCC1 responden de forma similar a plantas silvestres en ensayos de infección con Pseudomonas syringae, mientras que las plantas transgénicas $n a h G$ utilizadas como control negativo son más susceptibles en todas las condiciones ensayadas. PCC1 se identificó como un gen de respuesta a la bacteria avirulenta Pseudomona syringae portadora del gen de avirulencia avrRpt2 (Sauerbrunn y Schlaich, 2004). Las líneas iPCC1 presentan una ligera regulación a la baja del gen RPS2 relacionado con la percepción y respuesta frente a esta cepa bacteriana (Bent et al., 1994). Hemos analizado los fenotipos de respuesta de plantas iPCC1 frente a $P$. syringae avrRpt2, y hemos observado un comportamiento similar de las plantas iPCC1 y las plantas silvestres. En este caso el mutante rps 2 utilizado como control muestra un mayor crecimiento de las bacterias tal como se espera (Figura 51D).
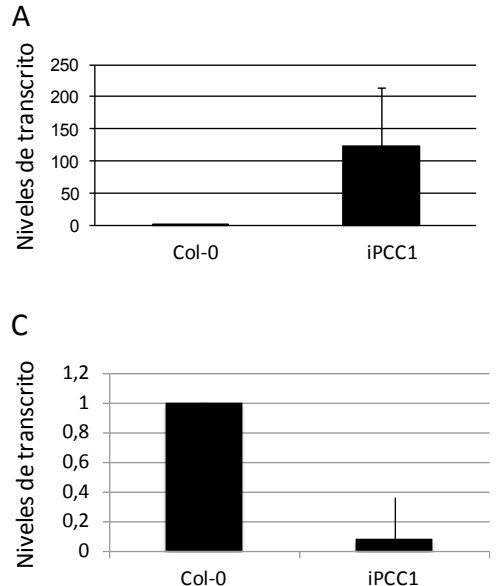

$B$

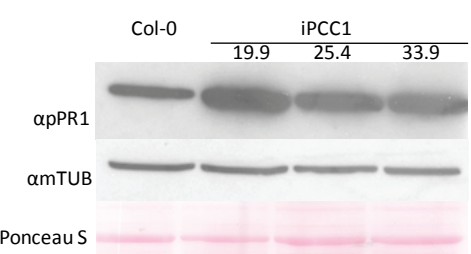

Figura 50. Cuantificación por RT-qPCR de los niveles de transcrito de PR1 (A) y NPR1 (C) en plantas silvestres y plantas iPCC1 de 2 semanas. B. Niveles de acumulación de proteína PR1 en plantas silvestres y plantas iPCC1 de cuatro semanas de edad tras 24 horas de la aplicación por spray de SA 500 $\mu \mathrm{M}$. 

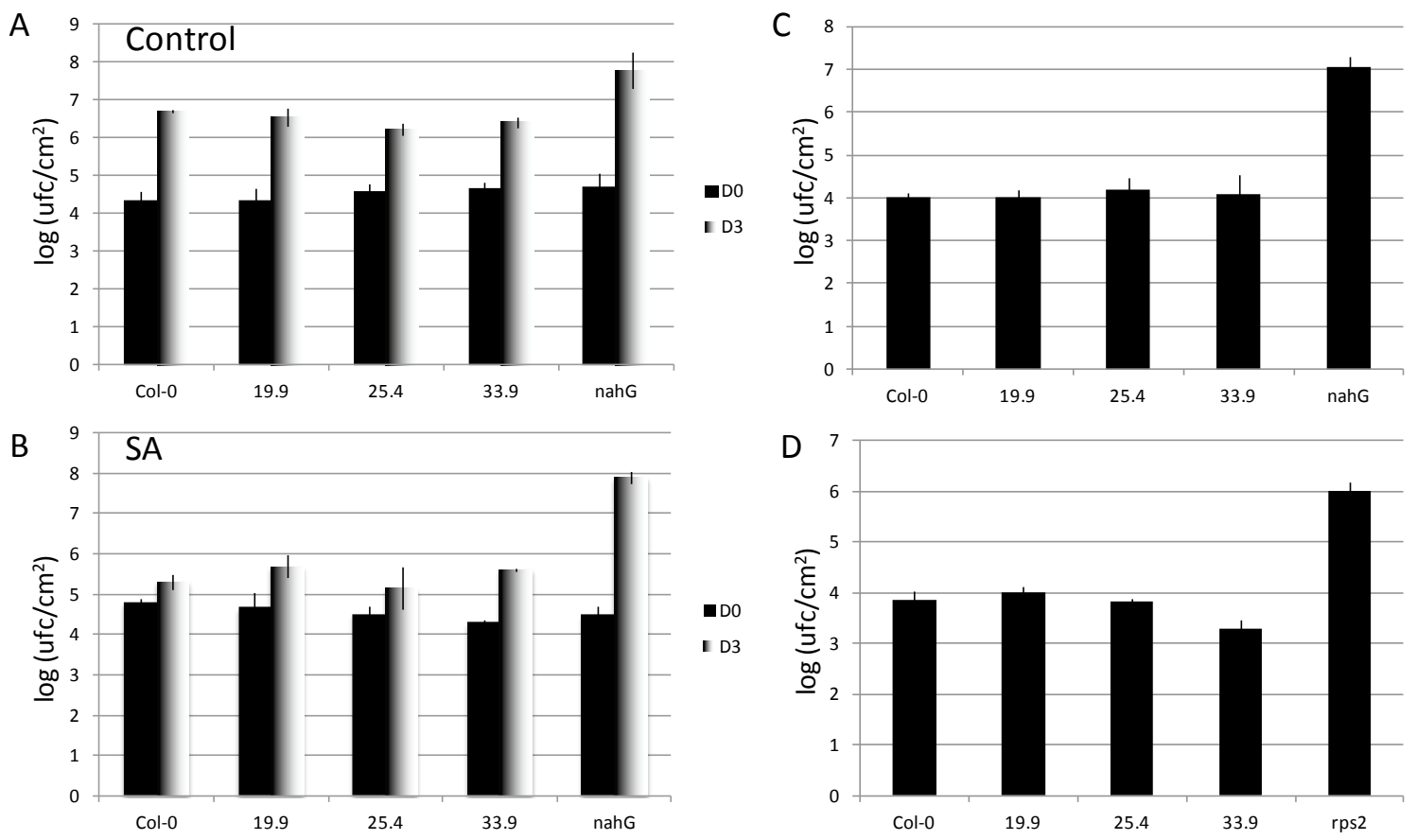

Figura 51. Fenotipos de resistencia frente a Pseudomonas syringae de líneas iPCC1 y de plantas silvestres. A y B. Crecimiento de $P$. syringae DC3000 sobre plántulas de 2 semanas crecidas en condiciones control (A) y en condiciones de defensa inducida por SA (B). C. Crecimiento de P. syringae DC3000 sobre plantas adultas de 4-5 semanas infectadas por infiltración. D. Crecimiento de P. syringae avrRpt2 sobre plantas adultas de 45 semanas. Para estos experimentos se ha utilizado como control negativo la planta transgénica portadora del gen bacteriano $n a h G$ en los experimentos de $P$. syringae DC 3000 , y el mutante rps 2 en el caso de $P$. syringae avrRpt2.

Se ha descrito que la sobreexpresión de PCC1 confiere a plantas de Arabidopsis una mayor resistencia al oomiceto biotrofo obligado Peronospora parasitica NOCO (Sauerbrunn y Schlaich, 2004). Este hecho concuerda con los bajos niveles de los transcritos de genes de reconocimiento relacionados con este patógeno que presentan las líneas iPCC1 (Tabla 9), lo que sugiere una mayor susceptibilidad de estas plantas frente a este tipo de patógenos.

\begin{tabular}{|c|c|c|c|}
\hline Cambio & Locus & Nombre & FDR \\
\hline$-7,23$ & At3g46530 & RPP13 (Recognition of Peronospora Parasitica 13) & 0,00011165 \\
\hline$-7,42$ & At4g16950 & RPP5 (Recognition of Peronospora Parasitica 5) & 0,00006481 \\
\hline$-8,47$ & At4g16860 & RPP4 (Recognition of Peronospora Parasitica 4) & 0,00003805 \\
\hline
\end{tabular}

Tabla 9. Genes relacionados con la respuesta frente a Peronospora parasitica alterados en líneas iPCC1 obtenidos en el análisis transcriptómico. 
Por último hemos procedido a estudiar la respuesta de las plantas iPCC1 frente a patógenos de distinta naturaleza. Hemos estudiado la respuesta de plantas iPCC1 frente al oomiceto hemibiotrofo Phytophtora brassicae, para lo cual se han infectado plantas de 4 semanas de edad con una suspensión de esporas de P. brassicae y se ha evaluado los síntomas tras 8 días de infección, según se indica en los Materiales y Métodos. La pérdida de función de $\mathrm{PCCl}$ en Arabidopsis provoca una mayor severidad de los síntomas respecto a plantas control en las condiciones ensayadas (Figura 52). Por otro lado hemos estudiado el comportamiento de plantas iPCC1 frente al patógeno necrotrofo Botrytis cinerea B05. En este caso las plantas iPCC1 muestran una ligera resistencia en términos de diámetro de lesión necrótica provocada por Botrytis en comparación con plantas silvestres (Figura 53).
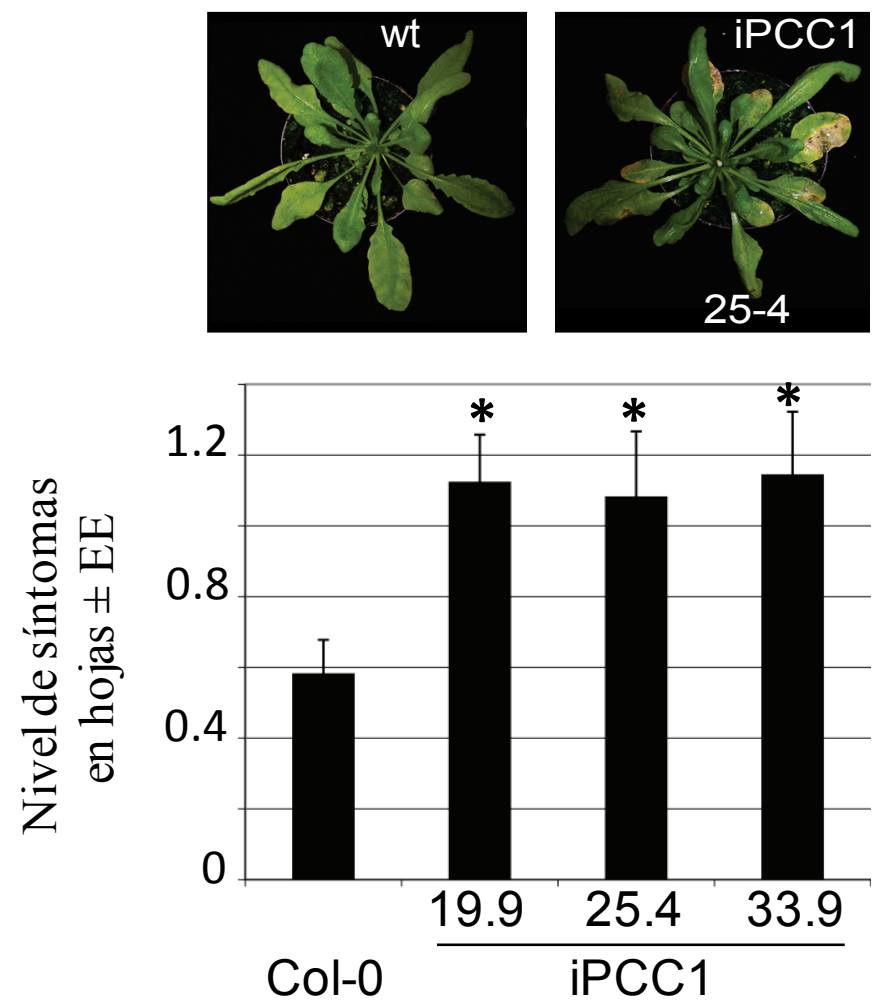

Figura 52. Fenotipos de respuesta frente a Phytophtora brassicae de líneas y plantas silvestres. 

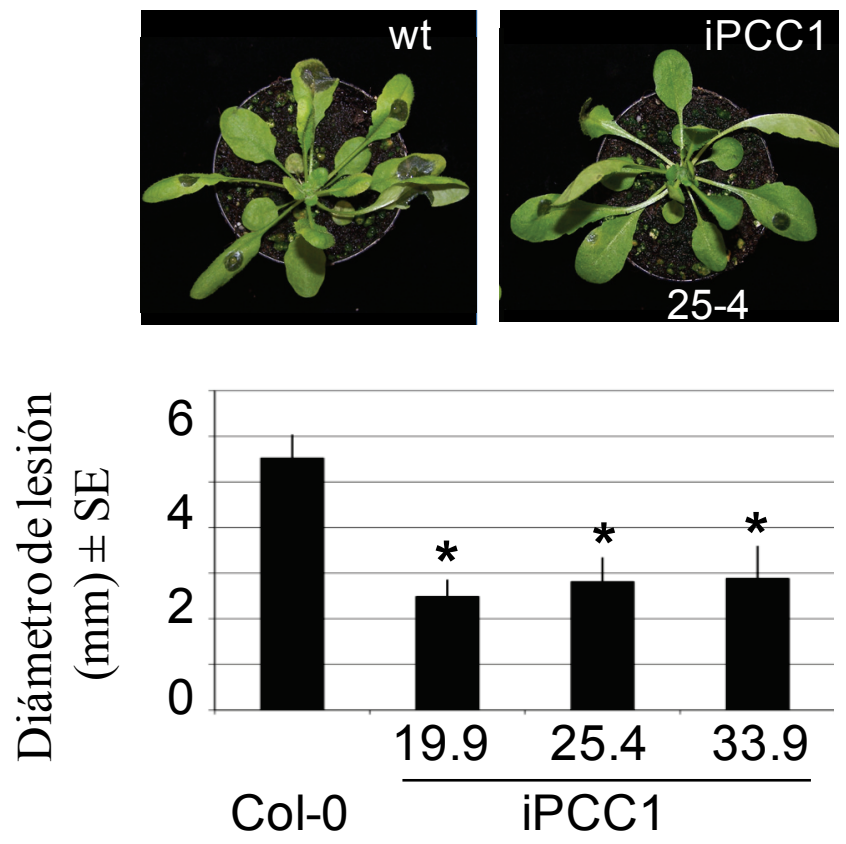

Figura 53. Fenotipos de respuesta frente a Botrytis cinerea B05 de líneas iPCC1 y de plantas silvestres.

La respuesta frente a patógenos necrotrofos, y concretamente frente a Botrytis cinerea, está mediada fundamentalmente por la fitohormona ácido jasmónico (Thomma et al., 1998). En una búsqueda más minuciosa de genes alterados en Arabidopsis por la pérdida de función de $P C C 1$, se encuentran una serie de genes regulados al alza relacionados con la señalización de esta fitohormona (Tabla 10), que podría explicar en parte los fenotipos observados, quedando patente la relación inversa entre las rutas de señalización frente a patógenos biotrofos y necrotrofos.

\begin{tabular}{|c|c|c|c|}
\hline Cambio & Locus & Nombre & FDR \\
\hline 24,63 & At1g54040 & ESP (Epithiospecifier Protein) & 0,00000177 \\
\hline 2,38 & At2g14580 & ATPRB1 & 0,01898719 \\
\hline 2,32 & At2g26690 & NTP2 (Nitrate Transporter) & 0,00258721 \\
\hline 1,8 & At5g46050 & PTR3 (Peptide Transporter 3) & 0,00535262 \\
\hline 1,64 & At4g22870 & Antocianina Sintasa & 0,00892487 \\
\hline 1,5 & At5g13220 & JAZ10 (Jasmonate-ZIM-Domain Protein 10) & 0,03645262 \\
\hline
\end{tabular}

Tabla 10. Genes relacionados con la señalización de JA alterados en líneas iPCC1 obtenidos en el análisis transcriptómico. 
Discusión 



\section{PCC1 está asociada a la membrana plasmática}

Hemos analizado in silico la localización subcelular de PCC1, y hemos obtenido resultados dispares según la herramienta utilizada, clasificándola como proteína citosólica, cloroplástica, nuclear, e incluso como proteína secretada al medio extracelular. El análisis detallado de la hidrofobicidad de PCC1 a lo largo de su secuencia aminoacídica, así como el uso de herramientas específicas para proteínas de membrana, indican la presencia de un dominio transmembrana coincidente con la región más hidrofóbica de la proteína en su región carboxi-terminal. La predicción de localización subcelular con este tipo de herramientas puede dar lugar a resultados dispares que deben considerarse con prudencia. De hecho, para la proteína GIGANTEA se identificaron hasta once dominios transmembrana basándose en programas de predicción de localización subcelular (Fowler et al., 1999), mientras que en un trabajo posterior fue descrita su localización nuclear por técnicas moleculares (Huq et al., 2000). Por esta razón hemos procedido al estudio de la localización celular de versiones etiquetadas de PCC1 con GFP. Las imágenes de microscopía confocal tanto de plantas de Nicotiana como de plantas de Arabidopsis que expresan PCC1 fusionadas a GFP apuntan a una localización en la periferia celular coincidente con la membrana plasmática. El hecho de observar señal fluorescente de GFP en la membrana de protoplastos de Nicotiana apoya su localización en la membrana plasmática, si bien no excluye completamente una posible asociación de una fracción de PCC1 a la pared celular. En el supuesto de que PCC1 se asociara también a la pared celular, la digestión de ésta provocaría una liberación de las proteínas PCC1-GFP al medio de suspensión de los protoplastos, que se perderían durante el proceso de su purificación. El gran tamaño de la vacuola de las células vegetales hace en ocasiones compleja la distinción entre la localización citosólica y en membranas plasmáticas de proteínas con esta técnica. Para confirmar mediante una aproximación distinta la asociación de PCC1 a estructuras membranosas, hemos aprovechado la capacidad de distintos tipos de detergentes para la solubilización de membranas y liberación de sus componentes al medio de extracción (Speers y Wu, 2007), protocolo que ha sido utilizado con anterioridad con ligeras modificaciones para la extracción de la proteína de membrana RPM1 (Boyes et al., 1998). Con esta técnica hemos demostrado que, tanto en expresión heteróloga en Nicotiana como en transformaciones estables en plantas de Arabidopsis, PCC1 se extrae mayoritariamente cuando se añaden detergentes en el tampón de extracción. Sin embargo, cuando se extrajeron proteínas con TBS sin detergentes, también se detectó señal específica de la etiqueta correspondiente en el análisis Western. Este hecho puede deberse 
a que parte de la proteína PCC1 se encuentre en la fracción soluble citosólica, o bien a que se liberó de las membranas por su ruptura mecánica durante el proceso de extracción. En cualquier caso, la fracción de proteína PCC1 en las estructuras membranosas, es decir, extraídas con tampón suplementado con detergente, fue mayoritaria en todos los casos.

Los datos obtenidos indican por tanto el anclaje de PCC1 a la membrana plasmática. Además, hemos demostrado que el anclaje a la membrana plasmática de PCC1 se produce por su región más hidrofóbica situada en su extremo carboxi-terminal. La sobreexpresión de versiones truncadas de PCC1 por su extremo carboxi-terminal fusionadas a GFP ( $\left.{ }^{\prime}{ }_{t} 177-P C C 1-G F P\right)$, tanto de forma transitoria en Nicotiana como de forma estable en Arabidopsis, muestra una deslocalización de la señal de GFP por el citoplasma y por el núcleo celular, al igual que ocurre con la sobreexpresión de GFP libre. Un aspecto importante es la disposición de PCC1 en la membrana plasmática. Existen dos posibilidades para la disposición de la proteína, bien con su extremo amino-terminal en la región citosólica o bien en la región extracelular. El uso de herramientas bioinformáticas no aporta una información esclarecedora a cerca de la disposición de PCC1 en la membrana, ya que se obtienen puntuaciones muy parecidas para ambas disposiciones con los algoritmos de predicción utilizados. En este trabajo hemos determinado la interacción de PCC1 con las proteínas CSN5a y CSN5b por BiFc. Esta técnica nos permite además estudiar el lugar en la célula donde se produce la interacción. En este caso, hemos observado que la interacción se produce a nivel de la membrana plasmática por la región amino-terminal de PCC1 con la fracción citosólica de CSN5a y CSN5b. Estos resultados muestran inequívocamente que la región amino-terminal de PCC1 queda orientada al citoplasma.

Un análisis bioinformático realizado por Venancio y Aravind (2010) permitió identificar un conjunto de proteínas de distintos organismos eucariotas que presentan una hélice transmembrana en su extremo carboxi-terminal rico en cisteínas y definir así un dominio al que se denominó CYSTM. La ubicación en membranas plasmáticas de algunas de las proteínas identificadas en este análisis ha sido demostrada experimentalmente, como es el caso de las proteínas de Saccharomyces cerevisiae YDL012C, YDR210W y YBR016W (Beilharz et al., 2003) y la proteína de Digitaria ciliaris DcCDT1 y su ortólogo en arroz OsCDT1 (Kuramata et al., 2009). En esta Tesis hemos demostrado no sólo la ubicación de PCC1 en la membrana plasmática, sino además el anclaje a ésta por su región carboxi-terminal donde se localiza el dominio CYSTM. Por otro lado, según propusieron Venancio y Aravind en su modelo, hemos demostrado la interacción de monómeros de 
PCC1 a través de su dominio CYSTM. Los datos que hemos obtenido confirman la interacción intermolecular entre monómeros de PCC1 dando lugar a la formación de dímeros, pero no podemos descartar tampoco la formación de oligómeros.

Todos los datos mencionados sugieren que PCC1 se pueda incluir en el grupo de proteínas con dominio CYSTM, las cuales forman una familia conservada en distintos organismos eucariotas, desde levaduras de fisión hasta organismos vegetales. Todas estas proteínas incluida $\mathrm{PCC} 1$, además del dominio CYSTM y las propiedades que éste les aporta, tienen en común su pequeño tamaño y su elevado contenido en cisteínas. Además, las proteínas identificadas en este análisis bioinformático están implicadas, por lo general, en la respuesta frente a distintos tipos de estrés (Venancio y Aravind, 2010), de igual forma que sucede con PCC1 (Sauernburn y Schlaich, 2004; Segarra et al., 2010). El elevado contenido en cisteínas y el pequeño tamaño de estas proteínas son características comunes de proteínas implicadas en la detoxificación y transporte de metales pesados, como las metalotioneinas (MT), las fitoquelatinas (PC) y la familia de proteínas de membrana Pcr10 (Song et al., 2004). Si bien no hemos estudiado en profundidad los efectos que la pérdida de función de $P C C 1$ pueda tener sobre el transporte de metales pesados, las líneas iPCC1 presentan elevados niveles de los genes de la familia ZIP de 15 miembros de transportadores IRT3 (+8.57 veces sobre los niveles de plantas silvestres) y ZIP1 $(+2.58$ veces sobre los niveles de plantas silvestres). IRT3 es una proteína situada en la membrana plasmática implicada en el transporte de metales, específicamente de Fe y de Zn (Lin et al., 2009). ZIP1 se expresa en la vasculatura de raíces a excepción de su región apical (Milner et al., 2013), lo que coincide con la tinción observada en las líneas pPCC1 1180::GUS. Además, la expresión de ZIPl en raíces se induce en respuesta a la deficiencia de Zn y de Fe, mientras que no se ve alterada en medios carentes de $\mathrm{Cu}$ o Mn (Milner et al., 2013). Estos datos apuntan a que PCC1 pudiera estar relacionada con la respuesta frente a metales pesados como Zn y Fe, y que su actividad esté relacionada con las enzimas IRT3 y ZIP1.

\section{La regulación de la transición floral por PCC1 podría estar relacionada con} alteraciones en la transmisión de la señal de la luz

Las plantas iPCC1 muestran un fenotipo de floración tardía en condiciones fotoperiódicas de días largos, mientras que en condiciones de días cortos no presentan alteraciones en el tiempo de floración con respecto a plantas silvestres (Segarra, 2009), lo que sugiere que PCC1 esté implicado en la ruta del fotoperiodo de la transición floral. En el presente trabajo hemos observado que las plantas iPCC1 responden tanto a tratamientos 
de vernalización como a la aplicación exógena de giberelinas, resultados que no sugieren, en principio, la implicación de PCC1 en estas rutas de activación de la floración. Hemos observado que $P C C 1$ se expresa en haces vasculares de cotiledones y de hojas verdaderas durante la ventana temporal de la transición floral, al igual que FT y CO (Takada y Goto, 2003), resultado que apoyaría un posible papel de PCC1 como modulador del núcleo central de la ruta del fotoperiodo formada por CO-FT. Además, mientras que plantas silvestres son capaces de acelerar la floración de forma dependiente de SA cuando se las irradia con luz UV-C (Martínez et al., 2004), las líneas iPCC1 no muestran dicho adelanto (Segarra et al., 2010). Cuando utilizamos condiciones más restrictivas de tinción GUS, observamos que el aumento de expresión de $P C C 1$ producido por la aplicación de SA es especialmente intenso en los haces vasculares, lo cual apoyaría una conexión funcional de PCC1 y FT, en la regulación de la transición floral en condiciones de estrés.

Inicialmente se propuso que PCC1 podría ser un intermediario de la activación transcripcional de $F T$ por el factor de transcripción de tipo dedo de zinc $\mathrm{CO}$, ya que líneas iPCC1 muestran niveles reducidos de $F T$ y el mutante $c o-1$ no expresa $P C C 1$, a diferencia de lo que sucede en plantas silvestres (Segarra et al., 2010). En el presente trabajo hemos observado, sin embargo, que la sobreexpresión funcional de $C O$ no activa PCC1, pero sí a su diana FT, lo que sugiere que PCC1 no es intermediario en la activación de FT por CO. Se han descrito varios escenarios que explican el mecanismo de unión de $\mathrm{CO}$ a la región promotora de $F T$, que incluyen la formación de complejos con otras proteínas de unión a ADN (Song et al., 2008; Song et al., 2012; Kumimoto et al., 2010). La formación de complejos multiproteicos HAP ( $\underline{\text { Heme }}$ Activation Protein), también denominados Nuclear Factor Y (NF-Y) o CCAAT $\underline{B}$ ox Factor (CBF), es importante para la unión de CO a las cajas CCAAT del promotor de FT (Wenkel et al., 2006; Kumimoto et al., 2010). Los fenotipos de floración de mutantes y de líneas sobreexpresoras de los distintos genes que codifican este complejo multiproteico apuntan a una fina regulación de la unión de $\mathrm{CO}$ al promotor de FT dependiente de niveles de las distintas proteínas, así como de las condiciones ambientales o de estrés a las que la planta se ve sometida (Wenkel et al., 2006; Cai et al., 2007; Chen et al., 2007; Kumimoto et al., 2008; Kumimoto et al., 2010). Aunque PCC1 no presenta dominios de unión al ADN y su localización en membrana hacen improbable que pudiera estar afectando la actividad transcripcional de $\mathrm{CO}$ en el núcleo, nos hemos planteado la posibilidad de que PCC1 pudiera interferir de alguna manera en la función activadora de $\mathrm{CO}$ por su interacción con ésta. Las imágenes obtenidas por microscopía confocal de los ensayos de BiFC no muestran, sin embargo, 
interacción de PCC1 con $\mathrm{CO}$, por lo se ha descartado la función de PCC1 como coactivador junto con $\mathrm{CO}$ de $F T$.

Hemos analizado a nivel molecular y fenotípico plantas iPCC1 x $35 S: \because C O-G R$. La aplicación de dexametasona en estas plantas conlleva una activación transcripcional de $F T$ así como un adelanto de la floración en condiciones de días largos, al igual que sucede con las líneas 35S::CO-GR (co-2). Con este resultado podemos concluir que PCC1 no es necesaria para la activación de $F T$ por $\mathrm{CO}$, y que los niveles reducidos de $F T$ en las líneas iPCC1 deben ocurrir de manera independiente de CO. Los niveles reducidos de PCC1 en el mutante $c o-1$ observados previamente (Segarra et al., 2010) pueden ser debidos a efectos del fondo genético del mutante utilizado, ya que cuando se analizan los niveles de PCC1 en el mutante co-10 se observa tan solo una ligera reducción con respecto a plantas silvestres, al igual que sucede con el mutante $f t-10$. Este resultados descartan la posibilidad de regulación transcripcional de $P C C 1$ por el factor de transcripción $\mathrm{CO}$. Por último, las líneas iPCC1 no presentan alteraciones en el transcrito de $C O$, por lo que descartamos la posibilidad de que PCC1 pueda modular la actividad o acumulación regulada por los componentes del reloj PRR5 y PRR7 (Nakamichi et al., 2007) de factores de tipo CDF1-5 (Imaizumi et al., 2005; Fornara et al., 2009), u otros mecanismos de control transcripcional de $C O$ desconocidos hasta la fecha. Si PCC1 regula la expresión de FT por su acción en la acumulación de $\mathrm{CO}$ queda por determinar, ya que no disponemos de datos que indiquen alteraciones de la proteína $\mathrm{CO}$ en las líneas iPCC1.

La expresión de $F T$ es basípeta, es decir, su expresión se activa inicialmente en los haces de la parte apical de las hojas en formación y se va extendiendo a los haces de las zonas basales de las hojas. La expresión de PCC1 en los haces de hojas verdaderas es, en cambio, acrópeta, con una dinámica opuesta a la observada para FT. PCC1 se expresa inicialmente en la zona basal de las hojas en formación, tanto en el mesófilo como en las estructuras vasculares, y se expande hacia la región apical. Los patrones de expresión de $F T$ y de $P C C 1$ en hojas indican que el efecto de $P C C 1$ sobre la activación transcripcional de FT podría ejercerse de forma indirecta, a través del efecto negativo de PCC1 sobre represores de la expresión de $F T$. Los genes TEMPRANILLO1 y TEMPRANILLO2 se han descrito como represores transcripcionales de FT (Castillejo y Pelaz, 2008). TEM1 se expresa en toda la superficie foliar de hojas a días tempranos, y se va apagando a tiempos cercanos a la transición floral desde la base de la hoja hasta el ápice, momento en el que se activa la expresión de FT en la vasculatura de la parte basal de las hojas (Castillejo y Pelaz, 2008, Osnato et al., 2012). La expresión espacio-temporal de PCC1 observada es 
completamente opuesta a la de TEM1. A medida que TEM1 se empieza a apagar desde la parte basal de las hojas, PCC1 se activa, y su expresión se va extendiendo hacia la parte más apical. Los patrones de tinción GUS observados podrían indicar un efecto negativo de PCC1 sobre la expresión de TEM1. En el contexto de la activación de la transición floral mediada por estrés, TEM2/RAV2 ha sido identificado como un gen inducido en plantas deficientes en SA (Segarra et al, 2010), por lo que se podría considerar como un gen candidato a codificar un represor de la floración regulado negativamente por SA. Si bien se han descrito líneas de fusión del promotor de TEM2 a GUS, así como sus patrones de tinción a 6 y 14 días tras la germinación (Kagaya et al., 1999), no disponemos de una dinámica de tinción clara durante la ventana temporal que nos ayude a inferir el posible efecto negativo de PCC1 sobre TEM2.

En este trabajo hemos observado que mutaciones en los genes que codifican algunos fotorreceptores alteran los niveles de expresión de $P C C 1$. La mutación phyB provoca un aumento de los niveles de $P C C 1$, mientras que la mutación phyA no altera su transcripción. Por otro lado, los criptocromos actúan como activadores de $P C C l$ de forma aditiva, ya que mutaciones simples en cada uno de los criptocromos dan lugar a una reducción del $40-50 \%$ en los niveles de transcrito de $P C C 1$ mientras que el doble mutante crylcry 2 presenta una reducción del 90\% comparados con plantas silvestres. Por lo tanto, PHYB actúa como represor de $P C C 1$, mientras que los criptocromos CRY1 y 2 actúan como activadores. Estos resultados encajan con el papel activador de la transición floral de PCC1, y con los fenotipos de floración temprana observados en mutantes phyb, y de floración tardía de los mutantes cryl/2 (Lin, 2000). PCC1 muestra una expresión cíclica regulada por el reloj circadiano (Sauernburn y Schlaich, 2004; Segarra et al., 2010). Si la alteración en los niveles de expresión de PCC1 observada en los distintos mutantes de fotorreceptores es debido a alteraciones en el reloj producidas por fallos en el input o percepción de la luz, o bien si se trata de un efecto directo de éstos, queda por determinar. Por otro lado, los datos del análisis transcriptómico realizado en este proyecto no muestran una alteración de los niveles de transcrito de ninguno de los receptores de luz en líneas iPCC1, y por análisis Western hemos visto que los niveles de acumulación de proteína PHYB tampoco se ven alterados. De estos resultados se puede concluir que la expresión de PCC1 depende de la percepción de las distintas calidades de luz, y que la pérdida de su función no altera la expresión de los fotorreceptores, y en el caso de PHYB tampoco altera la acumulación de la proteína correspondiente. Por lo tanto, PCCl debe de estar implicado en la señalización aguas abajo de la percepción de la luz en Arabidopsis. 
Los mutantes de percepción de luz muestran alteraciones en el tiempo de floración, bien debido al control que ejercen sobre el correcto funcionamiento del reloj circadiano (Fankhauser y Staiger, 2002; Quail, 2002), o bien por la acción directa sobre la acumulación de CO (Valverde et al., 2004). Se ha descrito además la regulación directa del transcrito de $F T$ por el dímero formado por CRY2 y el factor de transcripción de tipo bHLH CRYPTOCRHOME-INTERACTING BASIC-HELIX LOOP-HELIX (CIB1) en condiciones de luz azul (Liu et al., 2008a). PHYB es importante para la reducción de los niveles de CONSTANS a primeras horas del día por su degradación por ubiquitinación mediada por COP1, y es por tanto un represor de la floración (Jang et al., 2008). Los datos de expresión obtenidos en este trabajo muestran también un efecto represor de PHYB sobre $P C C 1$, si bien se ha estudiado a nivel del transcrito únicamente, y no a nivel de acumulación de la proteína correspondiente. La secuencia aminoacídica de PCC1 no muestra in silico sitios probables de ubiquitinación, por lo que la regulación de PCC1 por degradación vía proteasoma es poco probable. Además, si bien se ha estudiado el patrón circadiano del transcrito de $P C C 1$, no tenemos datos que muestren una regulación circadiana en la acumulación de la proteína correspondiente. Sin embargo, sabemos que PCC1 se acumula cuando se sobreexpresa en plantas de Nicotiana en oscuridad, por lo que la degradación de PCC1 durante el periodo de oscuridad es poco probable. Por otro lado, tanto los criptocromos como el fitocromo PHYA son activadores de la floración por su efecto estabilizador de la proteína CONSTANS (Valverde et al., 2004). CRY1 y CRY2, pero no PHYA, son activadores de la expresión de $P C C 1$. Una posible hipótesis es que PCC1 actuara como mediador de la acumulación de $\mathrm{CO}$ por los distintos tipos de receptores de luz.

Para corroborar fenotípicamente la alteración en la percepción de la luz en plantas iPCC1, hemos analizado su respuesta fotomorfogéncia, y la hemos comparado con la de plantas silvestres. La percepción de luz en Arabidopsis promueve el desarrollo fotomorfogénico, caracterizado en parte por la inhibición de la elongación de hipocotilos (Quail, 2002). Las plantas iPCC1 presentan hipocotilos de mayor longitud cuando crecen en condiciones de luz continua, mientras que en condiciones de oscuridad no se observan diferencias significativas. Esta alteración de la percepción de luz no es específica de un tipo concreto de luz, ya que las plantas iPCC1 presentan hipocotilos de mayor longitud que las plantas silvestres en todas las condiciones de luz ensayadas, si bien estas longitudes son menores que las observadas para los mutantes $p h y B$ en luz roja, phyA en luz roja lejana, y el doble mutante crylcry2 en luz azul, utilizados como control en cada caso. Estos datos 
confirman que $P C C 1$ es un regulador positivo del desarrollo fotomorfogénico en Arabidopsis y actúa como intermediario de la señal percibida por el fitocromo PHYB y los criptocromos CRY1 y CRY2. Los resultados relativos a los niveles de transcrito de PCC1 en fondos mutantes de los fotorreceptores y al crecimiento de hipocotilos son, sin embargo, algo contradictorios. PHYB ha sido caracterizado por su papel central en el desarrollo fotomorfogénico (Quail, 2002, de Lucas et al., 2008), y por otro lado es un represor de PCC1, caracterizado en este trabajo como modulador positivo de la fotomorfogénesis. El mecanismo por el cual PCC1 favorece el desarrollo fotomorfogénico podría implicar otros fotorreceptores, como CRY1 y CRY2, pero no PHYB. La acumulación de criptocromos depende de los complejos COP1-SPA, y está regulada por PHYA (Weidler et al., 2012). Se ha descrito que CRY1 interacciona con SPA1 (SUPRESSOR OF PHYA1) en condiciones de luz azul. SPA1 es una proteína interactora de COP1 en condiciones de oscuridad, que favorece su acción de degradación de factores de respuesta a luz, y por tanto un desarrollo escotomorfogénico. La percepción de luz azul y la consecuente interacción de CRY1 con SPA provoca la liberación e inactivación de COP1, lo cual favorece un desarrollo fotomorfogénico (Liu et al., 2011a). PCC1 podría actuar como modulador positivo de la fotomorfogénesis por un posible efecto sobre la acumulación de CRY1, o sobre la interacción de ésta con SPA1, y en definitiva como regulador negativo de COP1.

Por otro lado, a diferencia del efecto inhibidor del crecimiento de hipocotilos por la luz, las GAs tienen un efecto que favorece el desarrollo escotomorfogénico caracterizado por el alargamiento de los hipocotilos (Alabadí et al., 2004; de Lucas et al., 2008). Por esta razón hemos medido los hipocotilos de plantas iPCC1 en las distintas condiciones lumínicas en presencia del inhibidor de la síntesis de GA paclobutrazol (PAC) con el fin de descartar que el mayor crecimiento de los hipocotilos de plantas iPCC1 sean debidos a una mayor acumulación o señalización de GA. En todas las condiciones lumínicas ensayadas se observa que los hipocotilos de plantas iPCC1 siguen siendo significativamente más largos que los observados en las plantas silvestres. Por lo tanto, la pérdida de función de PCC1 conlleva un desarrollo parcialmente escotomorfogénico de forma independiente de la señalización y acumulación de GA. Este resultado apoya la similitud de la longitud de hipocotilos observado en plantas iPCC1 y plantas silvestres crecidas en condiciones de oscuridad, condiciones bajo las cuales las GA tienen un mayor papel en el control del crecimiento de los hipocotilos (Alabadí et al., 2004). 
El mecanismo exacto por el cual PCC1 regula tanto la floración como la fotomorfogénesis no puede ser establecido con los resultados obtenidos en esta tesis doctoral. Hemos observado, sin embargo, que PCC1 interacciona con las subunidades CSN5a y CSN5b del complejo CSN a nivel de la membrana plasmática. El complejo CSN fue identificado inicialmente como un represor de la fotomorfogénesis, ya que mutantes csn presentan un fenotipo fotomorfogénico en condiciones de oscuridad (Wei y Deng, 1992; Wei y Deng, 1996). Como se indicó anteriormente, PCC1 actúa como un regulador positivo de la fotomorfogénesis, por lo que PCC1 actuaría modulando negativamente la acción de CSN. CSN retiene la E3 ligasa de ubiquitina COP1 en el núcleo en condiciones de oscuridad, donde se produce la degradación de factores de transcripción de respuesta a luz (Osterlund et al., 2000; Holm et al., 2002), mientras que en condiciones luminosas COP1 se acumula en el citosol donde permanece inactiva favoreciéndose un crecimiento fotomorfogénico (Wang et al., 2009). En este contexto, PCC1 podría actuar como una proteína que interacciona con CSN por su subunidad CSN5, y retiene el complejo en el citosol a nivel de la membrana. La localización de CSN en el citosol conllevaría a una localización de COP1 mayoritariamente en el citosol, favoreciéndose así el desarrollo fotomorfogénico. Según esta hipótesis, en las líneas iPCC1 crecidas en condiciones lumínicas CSN se localizaría mayoritariamente en el núcleo, lo cual favorecería la acumulación nuclear de COP1, y por tanto el mayor desarrollo escotomorfogénico, evidenciado fenotípicamente por la mayor longitud de los hipocotilos en los distintas calidades de luz ensayadas.

Otro mecanismo descrito para la represión de la fotomorfogénesis implica la actividad derubiladora de CSN de culinas CUL4, que forma un complejo CRL con RBX1 y el complejo CDD (ㅁP10, DDB1, DET1). Este complejo multiproteico actúa potenciando la capacidad ubiquitinadora de COP1 en el núcleo, y por tanto actúa como represor de la fotomorfogénesis (Chen et al., 2006) y de la transición floral, especialmente en condiciones de días cortos (Chen et al., 2010). La regulación por derubilación de CSN de la culina CUL4 que forma parte del complejo es importante para la funcionalidad de éste en ambos procesos. En este contexto, considerando que CSN favorece la derubilación de CUL4 para el correcto funcionamiento del complejo CUL4-CDD-COP1 en el control del desarrollo escotomorfogénico en condiciones de oscuridad, PCC1 actuaría de nuevo como modulador negativo de CSN, posiblemente por la retención de éste en la región citosólica. Si bien hemos observado que las formas rubiladas/derubiladas de CUL1 no se ven alteradas en plantas iPCC1 con respecto a plantas silvestres, no tenemos datos de la 
acumulación de formas modificadas de CUL4 en las líneas iPCC1. El efecto de la posible regulación de CUL4 por PCC1 en la transición floral no parece tan probable, ya que CUL4 actúa como un represor de la floración en condiciones de días cortos (Chen et al., 2010), bajo las cuales no se observan diferencias fenotípicas entre las plantas iPCC1 y las plantas silvestres.

\section{La comparación transcriptómica de plantas iPCC1 y plantas Col-0 revela una} clara implicación de PCC1 en defensa

Varias líneas de evidencia apoyan que PCC1 tenga una función en defensa frente a patógenos. El gen $P C C 1$ se induce rápidamente tras la infección de plantas de Arabidopsis con Pseudomonas syringae avrRpt2 y, además, líneas sobreexpesoras de PCC1 muestran resistencia frente a Peronospora parasitica (Sauernburn y Schlaich, 2004). Por otro lado la aplicación de SA, fitohormona caracterizada tradicionalmente por su relación con la respuesta frente a patógenos (Shah, 2003), activa transcripcionalmente a PCC1 (Segarra et al., 2010). Hemos detectado por tinción histoquímica GUS de líneas pPCC1 1180::GUS la expresión de $\mathrm{PCCl}$ en estomas a días tempranos del desarrollo post-germinativo. Estas estructuras suponen aperturas naturales en las hojas y son, por tanto, potenciales puntos de entrada de patógenos (Zeng et al., 2010, Melotto et al., 2006). La expresión de PCC1, manifestada por una fuerte tinción GUS en estomas, podría estar relacionada con la implicación de PCC1 en mecanismos de defensa directos contra la entrada del patógeno, al menos durante las primeras fases de desarrollo de la planta cuando sus mecanismos de defensa constitutivos e inducibles pueden no estar plenamente desarrollados.

De acuerdo con lo expuesto, el análisis transcriptómico realizado en este proyecto revela una sobrerrepresentación de la categoría funcional relacionada con defensa de los genes regulados a la baja en líneas iPCC1. De entre los genes regulados a la baja en plantas iPCC1 se encuentran numerosos genes R, como los genes de reconocimiento de Peronospora parasitica RPP4, RPP5 y RPP13, y de Pseudomonas syringae RPS2, RPS5 y SNC1. Además se han obtenido un total de 10 genes adicionales con dominios NB-LRR, ocho de los cuales pertenecen a la subfamilia TIR-NB-LRR. Coincidente con este hecho se observa una ligera represión transcripcional del regulador positivo de la respuesta frente a patógenos biotrofos y hemi-biotrofos EDS1 (-1.59 veces respecto a los niveles en plantas silvestres; Wiermer et al., 2005), el cual se activa en respuesta a SA tras el reconocimiento de efectores patogénicos por proteínas R de la subclase TIR-NB-LRR (Falk et al., 1999). El resultado obtenido en este trabajo encaja con lo observado previamente para el mutante 
del gen $\mathrm{R}$ de tipo TIR-NB-LRR snc1-1, el cual expresa una forma constitutivamente autoactivada de la proteína SNC1 que conlleva una expresión constitutiva del gen de resistencia PR1, y consecuentemente una mayor resistencia frente a Pseudomonas (Zhang et al., 2003). Paradójicamente, y a pesar de esta reducción de los niveles tanto de SNC1, como de EDS1 y de NPR1, observamos una mayor expresión y acumulación de PR1 en las plantas iPCC1 tratadas con SA, por lo que deben de existir mecanismos independientes relacionados con la función de PCC1 para la regulación de la acumulación de PR1. A pesar de la clara alteración transcripcional de genes implicados en la señalización frente a patógenos biotrofos mediada por SA observada en líneas iPCC1, no hemos observado diferencias fenotípicas en la respuesta frente a cepas avirulentas ni virulentas de Pseudomonas syringae de las líneas iPCC1 en comparación con plantas silvestres. Este hecho puede ser debido a que los ligeros cambios a nivel transcripcional o a nivel de la acumulación de PR1 no sean suficientes para provocar una mayor o menor resistencia frente a Pseudomonas. Por otro lado, no podemos descartar la posibilidad de que exista una redundancia funcional entre los distintos miembros de la familia de PCC1. No se ha descrito una función de los distintos miembros de la familia de PCC1 relacionada con la respuesta frente a patógenos, si bien se han identificado algunos de ellos como genes transcripcionalmente alterados en respuesta frente a patógenos de distinto hábito, como cepas de Pseudomonas virulentas (Thilmony et al., 2006) y avirulentas (de Torres et al., 2003), Peronospora parasitica (Eulgem et al., 2007), Sclerotinia sclerotiorum (Zhao et al., 2007), o geminivirus (Ascencio-Ibáñez et al., 2008).

Con el fin de estudiar fenotípicamente cómo afecta la pérdida de función de $P C C 1$ a la respuesta frente a otros tipos de patógenos de diferente hábito, hemos analizado los fenotipos frente al oomiceto hemibiotrofo Phytophtora brassicae y al hongo necrotrofo Botrytis cinerea de líneas iPCC1 y los hemos comparado con los de plantas silvestres. Hemos observado que las plantas iPCC1 son más susceptibles que plantas silvestres a la infección con P. brassicae, lo que es consistente con el fenotipo de resistencia observado en líneas sobreexpresoras de PCC1 infectadas con el oomiceto Peronospora parasitica (Sauernburn y Schlaich, 2004). La respuesta en Arabidopsis frente a Phytophtora no depende de las rutas de señalización de SA ni de la de JA/ET (Roetschi et al., 2001), sino a la acumulación de metabolitos secundarios derivados del triptófano, como los indol glucosinolatos y la camalexina (Roetschi et al., 2001; Schlaeppi et al., 2010). Entre las categorías sobrerrepresentadas en genes alterados en plantas iPCC1 con respecto a plantas silvestres esta la relativa al metabolismo e hidrólisis de glucosinolatos. Hemos analizado 
por HPLC los niveles tanto de camalexina como de los glucosinolatos indólicos indol-3metil-GS y 4-metoxi-Indol-3-metil GS, y no hemos observado diferencias en su acumulación entre plantas silvestres y plantas iPCC1. Por otro lado, la integridad de la membrana plasmática y la adhesión entre la membrana y la pared celular, así como el mantenimiento de un continuo entre ambas estructuras, es importante para la respuesta frente a patógenos de tipo fúngico (Mellersh y Heath, 2001). La correcta adhesión entre membranas y paredes celulares está mediada por proteínas asociadas a membranas con dominios RGS (Arg-Gly-Asp), como la proteína LecRK1.9 en Arabidopsis, cuya mutación provoca una mayor susceptibilidad frente a Phytophtora infestans (Bouwmeester et al., 2011). La localización en la membrana plasmática de PCC1, así como el impacto a nivel transcripcional en plantas iPCC1 de genes relacionados con las membranas plasmáticas y la alteración en el contenido en fosfolípidos en líneas iPCC1, apunta a que la susceptibilidad observada en plantas iPCC1 frente a $P$. brassicae pueda ser debida a alteraciones en la estructura de la membrana plasmática.

Por otro lado, hemos observado que las plantas iPCC1 muestran una mayor resistencia que las plantas silvestres a Botrytis cinerea. La señalización por JA es importante para la respuesta frente a este tipo de patógenos, y se ha descrito una relación antagónica de la señalización por SA y por JA. El JA y otras oxilipinas son sintetizados a partir de ácidos grasos 18:3 procedentes de la hidrólisis de fosfolípidos y glucolípidos de las membranas por fosfolipasas de tipo A (PLA, Canonne et al., 2011), por lo que la mayor acumulación de ácidos grasos saturados (18:3) detectado en algunos de los lípidos polares en las líneas iPCC1 podría conllevar una mayor síntesis de JA en estas plantas. El análisis transcriptómico, sin embargo, no revela una alteración de genes que codifican la síntesis de enzimas PLA, y no disponemos de información acerca de los niveles de JA en plantas iPCC1. Por otro lado, la interacción de PCC1 con las subunidades CSN5a y b de CSN podría perturbar la respuesta al JA por la alteración de la regulación por rubilación/derubilación de culinas del complejo $\mathrm{SCF}^{\mathrm{COI} 1}$. Se ha descrito que la percepción de JA implica la proteína F-box COI1 (Fonseca et al., 2009), la cual forma complejos SCF in planta dependientes de CUL1 (Xu et al., 2002), y que la formación de estos complejos es importante para su señalización (Ren et al., 2005). Hemos analizado los niveles de CUL1 en su forma rubilada/derubilada en las plantas iPCC1 y no hemos observado diferencias con respecto a plantas control. Finalmente el análisis transcriptómico no muestra una clara alteración en genes de respuesta a JA en plantas iPCC1. Todos estos 
datos apuntan a que la mayor resistencia frente a Botrytis en las líneas iPCC1 no sea debida a una mayor acumulación o señalización de JA. Otro aspecto importante para la respuesta frente a Botrytis cinerea es la permeabilidad de la cutícula. Se ha descrito que tanto la expresión de enzimas con actividad cutinasa en Arabidopsis como mutantes alterados en la permeabilidad de la cutícula son más resistentes a Botrytis (Bessire et al., 2007; Chassot et al., 2007; Chassot et al., 2008). La cutícula presenta una composición fundamentalmente lipídica, por lo que la alteración en la composición lípidica en plantas iPCC1 podría conllevar la formación de una cutícula más permeable, y consecuentemente a una mayor resistencia frente a Botrytis cinerea, como ha sido descrito previamente para mutantes lacs2 (Bessire et al., 2007) o bdg (Kurdyukov et al., 2006). Además, el análisis transcriptómico muestra una fuerte regulación a la baja del gen At2g03980 (-5.07 veces respecto a los niveles en plantas silvestres), el cual codifica una lipasa de la familia GDSLlike implicada en el metabolismo de ceras de la cutícula (Kannangara et al., 2007; Panikashvili et al., 2010). Por último hemos observado una alteración en la transcripción de 6 genes de la familia de transporte lipídico (LTP, Lipid Transport $\underline{\text { Protein). Se ha }}$ especulado con la posibilidad de que las proteínas LTPs sean importantes para la correcta formación de una cutícula impermeable en plantas, bien por su papel como transportadores de los precursores de cutina, o bien por una función estructural (Yeats y Rose, 2008). Todos estos datos apuntan a que las plantas iPCC1 puedan presentar una cutícula permeable que sea responsable de su mayor respuesta frente a $B$. cinerea. Sin embargo, el análisis de la permeabilidad de cutícula por su permeabilidad a azul de toluidina no revela que las plantas iPCC1 presenten una cutícula más permeable que las plantas control. Las plantas iPCC1 muestran una reducción del diámetro de la lesión necrótica provocada por la infección con Botrytis del 30-40\% con respecto a la lesión observada en plantas silvestres. Los mutantes de cutícula permeable, sin embargo, apenas muestran síntomas de lesión necrótica tras la infección con Botrytis. El mecanismo por el cual las plantas con alteraciones en la cutícula son completamente resistentes a este hongo necrotrofo no se conoce en detalle, si bien parece estar relacionado con la mayor y más rápida difusión y reconocimiento de los efectores patogénicos, lo cual conlleva a una rápida activación de respuesta frente a Botrytis. De hecho, mutantes de cutícula como bdg o lacs2.1 producen ROS después de tres horas de infección, mientras que la producción de ROS en plantas silvestres no se detecta hasta las 24 horas tras la infección (L'Harindon et al., 2011). Por lo tanto podemos especular con que las plantas iPCC1 presenten una permeabilidad parcial en su cutícula que provoque los fenotipos de resistencia observados. Por último, el ABA se ha 
caracterizado recientemente como una hormona importante para la respuesta frente a patógenos (Cao et al., 2011), por lo que no podemos descartar una mayor resistencia frente a Botrytis por la mayor señalización de esta fitohormona observada en líneas iPCC1.

\section{PCC1 está implicado en el antagonismo funcional de las hormonas SA y ABA}

Se ha descrito una relación antagónica en la señalización del ABA y la respuesta frente a cepas avirulentas avrRps 4 de Pseudomona syringae y cepas virulentas DC3000 (Kim et al., 2011). La activación de la respuesta basal y de la respuesta inducida por efectores del nodo SNC1/EDS1/PAD4 confiere a plantas de Arabidopsis una menor sensibilidad al ABA (Kim et al., 2011). Nuestros datos transcriptómicos muestran un patrón de la relación SA-ABA opuesto y complementario al descrito previamente por Kim y colaboradores (2011). Por un lado hemos observado la ya mencionada regulación a la baja de $S N C 1$ y EDS1, y además una mayor activación de genes relacionados con la señalización por ABA, que se corresponde con una hipersensibilidad a esta fitohormona de las plantas iPCC1 en distintos aspectos de desarrollo, como la germinación, el establecimiento, y el crecimiento de la raíz. Además, al igual que sucede en el análisis transcriptómico realizado en este proyecto, la desregulación transcripcional de genes implicados en la señalización por ABA producida por la activación de respuesta frente a Pseudomonas dependiente de SNC1/EDS1/PAD4 afecta fundamentalmente a genes que codifican fosfatasas PP2C implicadas en la represión de genes de respuesta a ABA (6 de las 9 fosfatasas PP2C están reguladas a la baja; Kim et al., 2011). Este hecho apunta a la implicación de $P C C 1$ en las redes de señalización antagónica relacionadas con el ABA y la respuesta frente a patógenos dependiente de SA. Esta relación antagónica entre el ABA y el SA ha sido descrita además en mutantes de mimetismo de lesión, como constutive expressor of $\underline{P R}$ genes 22 (cpr22), el cual acumula mayor cantidad de SA y muestra una mayor resistencia frente a varios patógenos, y presenta fenotipos de insensibilidad a ABA de forma dependiente de la acumulación de SA (Mosher et al., 2010).

Por último, las plantas iPCC1 presentan en condiciones basales unos estomas más cerrados que las plantas silvestres. Los fenotipos de germinación, establecimiento de plántula y crecimiento de las raíces no se ven afectados en plantas iPCC1 crecidas en condiciones basales, por lo que la hipersensibilidad a ABA de las plantas iPCC1 sólo se observa tras aplicación exógena de esta hormona. Este hecho sugiere que los efectos de hipersensibilidad a ABA se manifiestan a partir de un determinado umbral de la hormona. Por esta razón se puede predecir que el mayor cierre estomático observado en plantas 
iPCC1 no sea debido a una mayor señalización del ABA endógeno, sino a un efecto de $P C C 1$ sobre el proceso de apertura estomática. Se ha descrito que, al igual que PCC1, FT se expresa en estomas y la pérdida de su función en el mutante $f t-1$ conlleva un mayor cierre de estomas en condiciones basales (Kinoshita et al., 2011). Además, la regulación del cierre estomático por FT comparte genes de la ruta de activación de la floración, y depende de la percepción de luz azul por las fototropinas PHOT1/2. Por esta razón, el mecanismo por el cual PCC1 regula el cierre estomático podría estar relacionado con la función de FT en este proceso. Por otro lado, los estomas son sitios de entrada de patógenos (Zeng et al., 2010; Cao et al., 2011), por lo que un mayor y más rápido cierre estomático conlleva fenotipos de resistencia frente a Pseudomonas psyringae (Melotto et al., 2006). Sin embargo, a pesar del mayor cierre estomático observado en plantas iPCC1, cuando se infectan las plantas iPCC1 con Pseudomonas psyringae DC3000 por inmersión no se observan diferencias en el crecimiento de la bacteria con respecto a plantas control. Por tanto es de esperar que el mayor cierre estomático observado en condiciones basales en las plantas iPCC1 no se produzca en condiciones de inducción de cierre de estomas, como es el caso de la infección con Pseudomonas (Melotto et al., 2006). De igual forma, el cierre de estomas en plantas iPCC1 y en plantas silvestres es similar cuando se las somete a un tratamiento de con una elevada concentración de ABA, y no se observan diferencias en la pérdida de agua entre los distintos genotipos.

Resumiendo, PCC1 parece estar implicado en el antagonismo funcional entre la señalización por $\mathrm{SA}$ y $\mathrm{ABA}$, ya que las plantas $\mathrm{iPCC} 1$ presentan una señalización por $\mathrm{SA}$ regulada a la baja, mientras que la señalización por $\mathrm{ABA}$ se ve incrementada con respecto a plantas silvestres. El mayor cierre estomático observado en plantas iPCC1 podría deberse a la regulación a la baja de $F T$ en las líneas iPCC1, y se produce en condiciones basales pero no en condiciones inducidas por la aplicación de elevadas concentraciones de ABA.

\section{Las líneas iPCC1 presentan una alteración en la composición lipídica}

El análisis transcriptómico revela una sobrerepresentación de genes relacionados con el metabolismo y transporte de lípidos. Entre estos genes destacan los relacionados con la biosíntesis de ácidos grasos, la degradación de lípidos (lipasas), y el transporte de lípidos (LTP, Lipid Transport Protein). Los ácidos grasos, concretamente los de 16 y 18 átomos de carbono, han sido caracterizados por su función señalizadora en defensa de plantas (Kachroo y Kachroo, 2009). Hemos analizado la acumulación global de ácidos grasos totales de 16 y 18 átomos de carbono con distinto grado de instauración en su cadena 
lateral, y hemos observado que la pérdida de función de $P C C 1$ conlleva una reducción del $30 \%$ en la acumulación de estos compuestos. Esta menor acumulación se distribuye en los diferentes tipos de ácidos grasos, concretamente en 16:0, 16:3, 18:0, 18:2 y 18:3. Sin embargo, cuando analizamos la cantidad porcentual de los distintos tipos de ácidos grasos no hemos observado diferencias significativas en las líneas iPCC1 con respecto a plantas silvestres. Como se ha expuesto en la presente tesis doctoral, PCC1 es una proteína asociada a la membrana plasmática. Sin embargo, los ácidos grasos son sintetizados casi exclusivamente en los cloroplastos, donde se produce además la desaturación de sus cadenas (Ohlrogge y Jaworski, 1997; Ohlrogge et al, 1979). Por esta razón, la influencia directa de PCC1 sobre la biosíntesis de ácidos grasos en los cloroplastos es algo improbable.

La cantidad de ácidos grasos libres en la planta constituye un pequeño porcentaje del total de ácidos grasos en la planta, la mayoría de los cuales se encuentran formando parte de lípidos más complejos, como fosfolípidos y glicolípidos (Xing y Chin, 2000). Por esta razón hemos estudiado la acumulación porcentual de los ácidos grasos en distintos tipos de lípidos polares en plantas iPCC1 y plantas silvestres. Los datos de este análisis muestran que las líneas iPCC1 presentan un mayor grado de poliinstauración de ácidos grasos $16 \mathrm{C}$ y $18 \mathrm{C}$, ya que se observa una menor acumulación de 16:0 y 18:0 en favor de la mayor cantidad detectada de 16:3 y 18:3. Si analizamos el estado de saturación de los ácidos grasos que componen los distintos lípidos polares, observamos que específicamente la fosfatidilserina (PS) y el fosfatidilinositol (PI) presentan ácidos grasos 16C y 18C con mayor grado de instauración ( 2 y 3 dobles enlaces), en detrimento de la acumulación de los correspondientes ácidos grasos saturados. El mayor grado de instauración en los fosfolípidos de la membrana plasmática confiere a éstas una mayor fluidez (Nozawa, 2011), y se ha descrito la importancia de esta característica en diversos tipos de respuesta a estrés, como la respuesta al estrés por frío (Wu et al., 1997). Además, como se indicó anteriormente, la integridad de la membrana plasmática es importante para la respuesta frente a patógenos (Mellersh y Heath, 2001). La relación entre el mayor grado de instauración de ácidos grasos y la posible mayor fluidez de la membrana de plantas iPCC1, con la integridad de ésta, así como con la respuesta frente a patógenos observada en líneas iPCC1, queda por determinar en trabajos futuros.

Finalmente, los resultados transcriptómicos revelan una clara alteración de genes que codifican proteínas con homología a lipasas, cuatro de las cuales tienen presumiblemente actividad fosfolipasa. Por esta razón hemos analizado la acumulación de 
distintos tipos de lípidos polares en plantas iPCC1 y los hemos comparado con la de plantas silvestres. Este análisis muestra una drástica reducción de fosfatidilinositol (PI) en las líneas iPCC1. Se ha descrito que la aplicación de SA en cultivos celulares de Arabidopsis conlleva la reducción de los niveles de PI, en favor de la producción de derivados fosforilados PI (4)-P y PI- (4,5)- $\mathrm{P}_{2}$, y que esta acumulación depende de PI-4quinasas de tipo III (Krinke et al., 2007). Esta alteración en el estado de fosforilación de PI se detecta además a tiempos muy cortos de tratamiento (2-15 minutos), pero no a tiempos más largos (24 horas), donde se observan los cambios moleculares típicos de la respuesta a SA, como la activación de PR1. Las formas fosforiladas de PI presentan per se actividad señalizadora (Munnik et al., 1998), que es de gran importancia en la respuesta temprana a SA (Krinke et al., 2007). PCC1 se ha descrito como un gen de respuesta rápida a la infección con Pseudomonas, y su activación transcripcional por SA se detecta a las tres horas de tratamiento (Sauernburn y Schlaich, 2004), por lo que el efecto de PCC1 sobre la respuesta frente a patógenos, o al menos sobre la respuesta mediada por SA, parece producirse en las primeras horas tras el reconocimiento de patógenos y del incremento de la síntesis de SA en la planta. El efecto de PCC1 en la activación de la respuesta podría estar en parte explicada por su función, posiblemente indirecta, en la acumulación de PI y de sus derivados fosforiladosEn el presente trabajo no se han medido las cantidades de los derivados fosforilados de PI (PI-(4)-P y PI-(4,5)-P 2 ), pero la regulación al alza de genes de la familia de fosfatidilinositol (PI)-4-quinasas de tipo III en las líneas iPCC1, concretamente la codificada por At5g24240 (+ 4.22 veces respecto a los niveles en plantas silvestres), apuntan a que las plantas iPCC1 puedan acumular mayores cantidades de PI(4)-P y PI-(4,5)- $\mathrm{P}_{2}$ en detrimento de la acumulación de PI. Admás, el derivado PI-(4,5)-P 2 es posteriormente degradado en inositol-1,4,5-trifosfato $\left(\mathrm{IP}_{3}\right)$ y diacilglicerol (DAG) por la acción de enzimas de la familia fosfolipasa $\mathrm{C}$, que en última instancia producirán ácido fosfatídico (PA) a partir del DAG (Laxalt y Munnik, 2002). Los datos lipidómicos muestran que la cantidad de PA en plantas iPCC1 no se ve alterada con respecto a plantas silvestres, por lo que el efecto de PCC1 en la señalización temprana de SA mediada por PI parece ser debido a su efecto sobre la acumulación de los derivados fosforilados del PI, y no tanto al efecto del PA. Por último, si bien se ha observado una inducción de genes de síntesis que codifican enzimas PLC por estrés (Munnik et al., 1998), éstas no parecen estar implicadas en la señalización temprana de SA (Krinke et al., 2007).

La pérdida de función de $P C C l$ conlleva además una reducción de la acumulación de otras clases de fosfolípidos, como PS y PC, además de una mayor cantidad de los 
glucolípidos MGDG y GDGD, especialmente abundantes en membranas de los cloroplastos, los cuales son importantes para la función y el mantenimiento de la actividad fotosintética (Shimojima, 2011). PCC1 es por tanto un regulador de la función de enzimas responsables tanto de los procesos de oxidación de ácidos grasos como de los procesos de hidrólisis de algunos lípidos polares en Arabidopsis. El mecanismo por el cual una proteína con las características propias de PCC1 puede regular la acumulación de los distintos tipos de lípidos polares, así como su composición de ácidos grasos queda por determinar. En cualquier caso, el efecto directo de PCC1 sobre la actividad de las enzimas de biosíntesis de lípidos es poco probable. PCC1 presenta en su extremo carboxi-terminal un aminoácido ácido (E, ácido glutámico), característica que apunta a su asociación específica con lípidos polares cargados negativamente, como la fosfatidiletanolamina o la fosfatidilcolina (von Heijne, 2007; Vance y Vance, 2008). Además, en el análisis in silico realizado en este trabajo se ha obtenido una elevada probabilidad de modificación por palmitoilación por la unión de ácidos grasos a la región carboxi-terminal de PCC1. En este sentido se puede especular con la posibilidad de que la ausencia de PCC1 en las membranas de las células de Arabidopsis pueda conllevar una alteración de la composición y a una reestructuración de ésta en cuanto a su composición por un mecanismo de regulación independiente pero relacionado con PCC1.

\section{Perspectivas}

En esta tesis doctoral hemos caracterizado en parte la función de PCC1 en los procesos relacionados con la transición floral y con la respuesta a diferentes tipos de patógenos. El mecanismo por el cual una proteína de pequeño tamaño y localizada en la membrana plasmática puede regular estos procesos tan distantes molecularmente queda, sin embargo, lejos de su pleno entendimiento con los resultados obtenidos. PCC1 interacciona con la subunidad CSN5 del complejo multiproteico CSN, implicado en la regulación de la degradación de proteínas por ubiquitinación. La degradación de proteínas por ubiquitinación ha sido ampliamente estudiada, tanto en los procesos de floración (Piñeiro y Jarillo, 2013), como en los de respuesta frente a patógenos (Furlan et al., 2012), y se ha descrito que la fitohormona SA juega un papel importante en ambos procesos (Shah, 2003; Martínez et al., 2004; Wada y Takeno, 2010). La evidencia de la conexión molecular de los procesos de floración y defensa por ubiquitinación ha sido descrita para la E3 ligasa de ubiquitina PUB13 en Arabidopsis (Liu et al., 2012). PUB13 poliubiquitina FLS2 para su posterior degradación (Lu et al., 2011), y mutantes pub13 muestran elevada 
resistencia frente a patógenos biotrofos y hemi-biotrofos y mayor susceptibilidad frente a los necrotrofos (Li et al., 2012). Por otro lado, PUB13 se ha descrito como un regulador negativo de la floración dependiente de SA ( $\mathrm{Li}$ et al., 2012). El mecanismo de ubiquitinación de PUB13 no se conoce en detalle, pero los fenotipos de defensa y de floración apuntan a que PCC1 pueda ejercer un papel negativo sobre la función ubiquitinadora de PUB13. 

Conclusiones 

- PCC1 presenta, durante el desarrollo post-germinativo, una expresión restringida a la vasculatura en las raíces, en las células de guarda de los estomas y, posteriormente, en los haces vasculares de los cotiledones, y un patrón acrópeto en las hojas verdaderas.

- PCC1 es una proteína que dimeriza y que está asociada a la membrana plasmática para lo que requiere de su dominio más hidrofóbico coincidente con su extremo carboxi-terminal. La región amino-terminal de PCC1 queda expuesta al citosol.

- La expresión de PCC1 está regulada por el fitocromo PHYB y los criptocoromos CRY1/2, pero no por el fitocromo PHYA. La pérdida de función de PCC1 conlleva un desarrollo parcialmente escotomorfogénico bajo distintas calidades de luz y de forma independiente de la acumulación de giberelinas, lo que sugiere que PCC1 podría estar implicada en mecanismos generales de la transmisión de la señal luminosa.

- Aunque plantas con función reducida de PCC1 presentan floración tardía sólo bajo condiciones de día largo, PCC1 no actúa como un intermediario de la activación de FT por CO, proceso descrito como esencial para que se active la transición floral bajo estas condiciones. El fenotipo de floración tardía de las líneas iPCC1 podría deberse a alteraciones en la transmisión de la señal luminosa.

- La pérdida de función de PCC1 conlleva una alteración de genes de respuesta frente a patógenos y una mayor susceptibilidad frente al oomiceto Phytophtora brassicae y una mayor resistencia frente al hongo Botrytis cinerea.

- Las plantas iPCC1 presentan una expresión constitutiva de genes de respuesta a ABA, y son más sensibles a esta fitohormona en distintos fenotipos, como la germinación de las semillas, el establecimiento de plántula, el cierre estomático, y el crecimiento de raíces.

- Las plantas iPCC1 presentan una menor acumulación de lípidos polares como el fosfatidilinositol y la fosfatidilserina que las plantas silvestres, los cuales presentan además un mayor grado de insaturación de sus ácidos grasos. Por el contrario, se observa una mayor acumulación de lípidos polares cloroplásticos.

- PCC1 interacciona a nivel de la membrana plasmática con las subunidades CSN5a y CSN5b del signalosoma CSN. La pérdida de función de PCC1 no conlleva, sin embargo, una alteración de los niveles de rubilación de CUL1 en Arabidopsis. 

Materiales y Métodos 

1. Material biológico y condiciones de cultivo

1.1. Material vegetal y condiciones de cultivo

\subsubsection{Material vegetal}

En el presente trabajo se ha utilizado el ecotipo Columbia-0 (Col-0) como control en los experimentos realizados, así como fondo genético para la obtención de las líneas transgénicas generadas. Para el estudio de la función de PATHOGEN AND CIRCADIAN CONTROLLED 1 ( $P C C 1)$ se utilizaron líneas de interferencia de RNA específicas para PCC1 (iPCC1) generadas en el laboratorio del Dr. José León (Segarra et al., 2010). Los mutantes de floración co-10 y ft-10, y la línea de sobreexpresión inducible en un fondo mutante co-2, 35S::CO-GR (co-2) fueron cedidos por el Dr. Federico Valverde (IBVF, Sevilla). Los mutantes de la ruta autónoma de floración $f c a 9$ y fve3 fueron cedidos por la Dra. C. Dean (John Innes Centre, UK) y por el Dr. Martínez-Zapater (CNB, Madrid), respectivamente. El Dr. José Antonio Jarillo (CBGP, Madrid) proporcionó los mutantes de percepción de luz azul cryl, cry2, y crylcry2. Los mutantes phyA y phyB se obtuvieron de NASC (The European Arabidopsis Stock Centre). Para los experimentos de resistencia a Pseudomona syringae DC3000 se usó como control negativo la planta transgénica portadora del gen bacteriano $n a h G$ (Delaney et al., 1994). En el caso de cepas avirulentas de Pseudomona syringae AvrRpt2 se utilizó el mutante rps2. Las plantas nahG y rps2 fueron cedidas por el Dr. Pablo Tornero (IBMCP, Valencia).

Para la realización de experimentos de expresión transitoria se usaron plantas de Nicotiana benthamiana de entre 4 y 6 semanas de edad.

\subsubsection{Condiciones de cultivo}

Para experimentos ex vitro las semillas correspondientes se mantuvieron durante una noche a $-20^{\circ} \mathrm{C}$, y se estratificaron durante 3-4 días a $4^{\circ} \mathrm{C}$. Posteriormente se sembraron en un sustrato compuesto por turba, vermiculita y perlita en proporciones $2: 1: 1$. Las plantas crecieron bajo condiciones de días largos (DL; 16 horas de luz, 8 horas de oscuridad) o días cortos (DC; 8 horas de luz, 16 horas de oscuridad), según se indique en cada caso. Las condiciones de intensidad lumínica $\left(150 \mu \mathrm{E} \mathrm{m}^{-2} \mathrm{~s}^{-1}\right)$, temperatura $\left(20-22^{\circ} \mathrm{C}\right)$ y humedad relativa (50-60\%) se mantuvieron constantes. Únicamente en el caso de los experimentos realizados con bacteria Pseudomona syringae se utilizó discos Jiffy-7 como sustrato (grupo Jiffy). 
Para el crecimiento de plantas en condiciones in vitro las semillas fueron esterilizadas en un medio hermético rico en cloro gaseoso (obtenido a partir de $100 \mathrm{ml}$ de lejía comercial suplementado con $3 \mathrm{ml}$ de ácido clorhídrico) durante 3-4 horas. Las semillas estériles fueron sembradas en placas Petri con medio de cultivo Murashige-Skoog (Murashige y Skoog, 1962) suplementado con 1\% de sacarosa y $0,8 \%$ de agar, y se estratificaron durante 3-4 días a $4^{\circ} \mathrm{C}$. Las plantas se cultivaron in vitro en condiciones de días largos a una temperatura de entre $20-22^{\circ} \mathrm{C}$. Para la selección de plantas transgénicas se utilizaron los medios descritos suplementados con kanamicina $(50 \mu \mathrm{g} / \mathrm{ml})$ o higromicina (20 $\mu \mathrm{g} / \mathrm{ml})$, dependiendo de la resistencia conferida por el plásmido utilizado para la transformación.

Las semillas de Nicotiana benthamiana se sembraron en semilleros comunes y se transplantaron a macetas individuales 1-2 semanas tras su siembra. En estas condiciones se mantuvieron bajo condiciones fotoperiódicas de días largos bajo temperaturas de $22-24^{\circ} \mathrm{C}$ durante 2-4 semanas. Tras la agroinfiltración se mantuvieron en las mismas condiciones.

1.2. Material microbiológico: cepas utilizadas y condiciones de cultivo

\subsubsection{Escherichia coli}

Para la propagación y purificación de plásmidos se utilizo la cepa de Escherichia coli DH5 $\alpha$. El crecimiento de las bacterias se realizó en medio Luria-Bertani (LB). En el caso de células crecidas en medios sólidos se suplementó el medio con $1.5 \%$ de agar. Para la selección de transformantes o para el cultivo de bacterias portadoras de un plásmido de interés, el medio se suplementó con los antibióticos adecuados, según el plásmido en cuestión. Las bacterias se incubaron durante $12-24$ horas a $37^{\circ} \mathrm{C}$. En el caso de cultivos líquidos se aplicó al cultivo una agitación constante de 200 r.p.m..

\subsubsection{Agrobacterium tumefaciens}

Tanto las transformaciones estables de Arabidopsis como las transformaciones transitorias de Nicotiana se realizaron con la cepa C58PMP90 de Agrobacterium tumefaciens. El cultivo de esta bacteria se realizó de igual forma que en el caso de E. coli, a diferencia del tiempo y la temperatura de crecimiento $\left(2-3\right.$ días a $\left.28^{\circ} \mathrm{C}\right)$. Además esta cepa es resistente a rifampicina (Deblaere et al., 1985), por lo que en todos los casos se añadió este antibiótico al medio, además de los antibióticos correspondientes al plásmido exógeno de interés. 


\subsubsection{Saccharomyces cerevisiae}

Para los estudios de interacción de proteínas se utilizaron las cepas AH109 y Mav203 de Saccharomyces cerevisiae. El medio de cultivo utilizado para el crecimiento rutinario de levaduras fue el YPD (20 g/l Difco Peptona, $10 \mathrm{~g} / 1$ Extracto de levadura). La selección de levaduras transformadas se realizó en medios SD compuestos por $1.7 \mathrm{~g}$ de extracto de levadura libre de aminoácidos, $5 \mathrm{~g}$ de sulfato amónico, $20 \mathrm{~g}$ de dextrosa, y una mezcla completa de aminoácidos, a excepción de leucina y triptófano, por cada $500 \mathrm{ml}$ de medio. Las interacciones entre proteínas se estudiaron en estos mismos medios libres de histidina. Los medios sólidos se realizaron añadiendo a los medios descritos agar al $2 \%$.

\subsubsection{Pseudomonas psyringae}

Para el estudio de la interacción planta-patógeno se utilizaron la cepa virulenta de Pseudomonas psyringae pv. tomato DC3000 y la cepa avirulenta DC3000 transformada con el plásmido de avirulencia AvrRpt2. El cultivo de estas bacterias se realizó en medios LB sólidos suplementados con rifampicina, y, en el caso de la cepa avirulenta, se le añadió además kanamicina. El crecimiento de estas bacterias se realizó a una temperatura de $19^{\circ} \mathrm{C}$.

\subsubsection{Botrytis cinerea}

Con ayuda de un asa de siembra se tomaron esporas de Botrytis cinerea B05.10 conservadas a $-80^{\circ} \mathrm{C}$, y se depositaron suavemente sobre una placa petri conteniendo medio PDA ( $5 \%$ de extracto de malta-agar, $0.2 \%$ extracto de levadura). Las placas selladas se incubaron durante $1-2$ semanas a $17-20^{\circ} \mathrm{C}$ en oscuridad. El micelio generado por el hongo se recogió en un tubo de ensayo de $50 \mathrm{ml}$ añadiendo un total de $50 \mathrm{ml}$ de agua en dos tandas de $25 \mathrm{ml}$ con la ayuda de una varilla de vidrio. La suspensión de esporas se agitó y se filtró con una tela de algodón. A continuación el filtrado se centrifugó a 800 rpm durante 10 minutos a $4^{\circ} \mathrm{C}$. Tras eliminar el sobrenadante, las esporas se resuspendieron cuidadosamente en $500 \mu \mathrm{l}$ de agua estéril. La concentración de esporas se estimó a partir de una dilución 1:2000 en celdas Jessen según la fórmula:

$$
\mathrm{C}=\mathrm{n} \times 2000 \times \mathrm{V}
$$

Siendo C la concentración de esporas, expresada como el número de esporas / $\mathrm{ml}, \mathrm{n}$ el promedio del número de esporas en cada cuadrado de la celda Jessen, 2000 el factor de dilución y $\mathrm{V}$ el volumen de cada cuadrado de la celda Jessen. 


\subsubsection{Phytophtora brassicae}

Phytophtora brassicae D (CBS179.89) se sembró en medios comerciales V8® al $20 \%$ (v/v) suplementado con $0.35 \% \mathrm{CaCO}_{3}$ y $2.1 \%$ de agar. Tras una semana de crecimiento en este medio a $18^{\circ} \mathrm{C}$ en oscuridad, el micelio formado se puso en contacto con 15 discos estériles de $10 \mathrm{~mm}$ de diámetro, y se subcultivaron en $10 \mathrm{ml}$ de medio líquido V8® al 10\% v/v. Tras 3-4 días de crecimiento estático se sustituyó el medio por 10 $\mathrm{ml}$ de medio Schmidthenner $\left(0.75 \% \mathrm{KH}_{2} \mathrm{PO}_{4}, 0.91 \% \mathrm{~K}_{2} \mathrm{HPO}_{4} \mathrm{H}_{2} \mathrm{O}\right)$ para favorecer la formación de esporas durante 4 días. Finalmente se sustituyó el medio líquido por $10 \mathrm{ml}$ de agua estéril y se favoreció la liberación de esporas por incubación a $4^{\circ} \mathrm{C}$ durante 4 horas. La suspensión de esporas se filtraba consiguiéndose por lo general concentraciones del orden de $10^{6}$ esporas / $\mathrm{ml}$.

\section{Tratamientos aplicados a las plantas}

\subsection{Aplicación de dexametasona}

Los tratamientos con dexametasona para la inducción del gen CONSTANS en líneas $35 S:: C O-G R(c o-2)$ y en el cruce iPCC1 $x$ 35S::CO-GR (co-2) se realizaron aclimatando durante 2 días plántulas de 3-4 días en medio MS líquido, y sustituyendo éste por medio MS suplementado con $10 \mu \mathrm{M}$ de dexametasona, o el volumen equivalente del disolvente (etanol) en muestras control. Las muestras para la cuantificación de transcritos se tomaron a las 24 horas después de hacer el tratamiento.

\subsection{Tratamientos con hormonas}

La aplicación de ácido salicílico se realizó por pulverización con una solución acuosa de $200 \mu \mathrm{M}$ SA y $0.02 \%$ de Silwet L-77 hasta que la superficie foliar quedara completamente cubierta de líquido. Los tratamientos se realizaron 48 y 24 horas previas a la toma de muestras para la cuantificación de la expresión de $P R I$ o a la aplicación de bacteria, según el caso. En el caso del estudio de la alteración de la localización subcelular por SA, se aplicó $200 \mu \mathrm{M}$ SA y $0.02 \%$ de Silwet L-77 sobre plántulas de Arabidopsis 35S::PCC-GFP o plantas de Nicotiana benthamiana transformadas transitoriamente 24 horas antes de la observación al microscopio confocal. En los ensayos de activación de PCC1 por tinción histoquímica GUS se aplicó SA $200 \mu \mathrm{M}$ y $0.02 \%$ de Silwet L-77 por 
pulverización sobre plantas cultivadas in vitro, y se realizó la tinción histoquímica a las 24 horas.

El tratamiento con giberelinas para el estudio del adelanto de la transición floral se realizó por pulverización de una solución acuosa de $\mathrm{GA}_{3} 200 \mu \mathrm{M}$ y $0.02 \%$ de Silwet L-77 desde la primera semana tras la siembra, hasta el momento de detección del botón floral. La aplicación se repitió entre 2 y 3 veces por semana.

\subsection{Infección con microorganismos patógenos}

\subsubsection{Infección con Pseudomonas syringae}

Para el análisis del crecimiento de Pseudomonas syringae sobre plantas de Arabidopsis, las bacterias se extendieron sobre medios de LB suplementados con los antibióticos apropiados en cada caso (apartado 1.2.4). En estas condiciones se dejaron crecer durante 2 días a $19^{\circ} \mathrm{C}$. El tapiz resultante del crecimiento de bacterias se resuspendió y recogió en $10 \mathrm{ml}$ de una solución $10 \mathrm{mM} \mathrm{ClMg}_{2}$ con ayuda de un palillo de madera, y se preparó una suspensión bacteriana a una $\mathrm{OD}_{600}$ de 0.1. Esta preparación de bacterias se diluyó 1:500 (baja dosis de bacteria), y se infiltró en el apoplasto en 4-6 hojas de cada una de las plantas de Arabidopsis ensayadas con ayuda de una jeringuilla sin aguja por su zona abaxial. Para cada genotipo se infiltraron entre 4 y 8 plantas en cada uno de los ensayos realizados, y se analizaron al menos 3 réplicas biológicamente independientes. Las plantas infiltradas se dejaron en las mismas condiciones de crecimiento $\left(22^{\circ} \mathrm{C}\right.$, días cortos) durante 3 días, momento en el cual se tomaron muestras para el análisis del crecimiento bacteriano. De cada planta infectada se tomaron 4 discos de $7 \mathrm{~mm}$ de diámetro con ayuda de un sacabocados, y se introdujeron en $250 \mu \mathrm{l}$ de una solución $10 \mathrm{mM}$ de $\mathrm{ClMg}_{2}$. Se homogeneizaron y se llevó a un volumen final de $1 \mathrm{ml}$. Esta solución de bacterias inicial se diluyó en placas de 96 pocillos de $200 \mu \mathrm{l}$ de volumen en factores de dilución 1/10 hasta una dilución final $10^{-6}$, y se plaquearon $5 \mu$ de cada dilución en placas de LB suplementadas con los correspondientes antibióticos, según la cepa utilizada. El cálculo del crecimiento de bacterias se representó como el logaritmo del número de unidades formadoras de colonias por superficie foliar.

En el caso de la aplicación de Pseudomona syringae sobre plántulas por pulverización, las bacterias se prepararon de idéntica forma a la descrita, y se aplicaron con pulverizadores sobre plántulas de 2 semanas de edad crecidas en condiciones de días 
cortos. Tras una hora (considerado como tiempo cero) y tres días (día tres), se tomaron 5-6 plántulas en $1 \mathrm{ml} \mathrm{de} \mathrm{ClMg}_{2}$, se pesaron, y se incubaron 1 hora a $28^{\circ} \mathrm{C}$ en agitación para favorecer la liberación de las bacterias al medio. Se prepararon diluciones seriadas y se calculó el número de unidades formadoras de bacterias de igual forma que la descrita anteriormente.

\subsubsection{Infección con Botrytis cinerea}

Para el estudio de la respuesta de líneas iPCC1 frente a Botrytis cinerea, se procedió a una preparación stock de esporas según se indicó en el apartado 1.2.5. La suspensión de esporas de $B$. cinerea se llevó a una concentración de $5 \cdot 10^{4}$ esporas $/ \mathrm{ml}$ en medio 1/4 PDB a partir de la solución stock. Se depositaron $6 \mu$ de esta suspensión de esporas sobre 5-6 hojas de cada planta del ensayo. Para favorecer condiciones de elevada humedad, las bandejas contenedoras de las plantas se regaron bien y se taparon con un material plástico. Las plantas fueron así incubadas durante 3 días en condiciones de baja luminosidad, momento en el cual se procedió a la medida del diámetro de lesión con ayuda de un pie de rey. Con el fin de eliminar efectos de posición y aumentar la variabilidad en el ensayo, plantas silvestres y plantas iPCC1 se mezclaron en las bandejas de forma aleatoria.

\subsubsection{Infección con Phytophtora brassicae}

Se prepararon suspensiones de esporas de Phytophtora brassicae como se indicó en el apartado 1.2.6. En este caso no se procedió al conteo exhaustivo de zooesporas porque la movilidad de éstas lo hace complicado e inexacto. Se depositaron $30 \mu 1$ de la suspensión de esporas de $P$. brassicae sobre 4-6 hojas de plantas de 3 a 4 semanas de edad, y se incubaron en condiciones de elevada humedad durante 7 días. La intensidad de los síntomas se estimaron con una escala del 1 al 4, según se la superficie necrosada en la planta menor (1), igual (2), o superior (3) al área de la gota de $30 \mu l$ de suspensión de esporas (Figura 54). En el caso de que toda la superficie foliar esté necrosada se le atribuye un valor de 4 (Schlaeppi et al., 2010). 


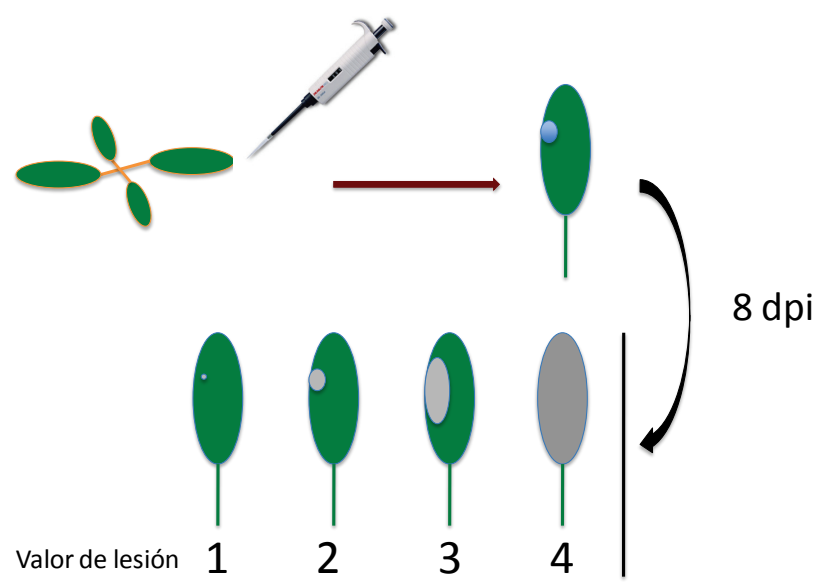

Figura 54. Representación esquemática de la medida de la intensidad de los síntomas en plantas infectadas con Phytophtora brassicae.

\subsection{Tratamiento de vernalización}

Se sembraron semillas de los distintos genotipos ensayados en sustrato humedecido, según lo indicado en el apartado 1.2. Las bandejas de cultivo se cubrieron con un material plástico para favorecer condiciones de alta humedad. Las bandejas cubiertas se incubaron en cámaras de vernalización a $4^{\text {o }} \mathrm{C}$ durante 4-6 semanas. Las plántulas procedentes de semillas así germinadas se pasaron a condiciones de temperatura apropiadas para el crecimiento ( $22^{\circ} \mathrm{C}$ y días largos), y se compararon los fenotipos de floración con el de plantas procedentes de semillas sembradas directamente en condiciones óptimas para la germinación y posterior crecimiento, según lo indicado en el apartado 1.2.

3. Manipulación del material biológico

3.1. Generación de electro-competencia en células de E. coli y transformación genética

E. coli $\mathrm{DH} 5 \alpha$ se sembró por triple estría en placas Petri conteniendo LB sólido. Se picó una colonia y se cultivó a $37^{\circ} \mathrm{C}$ durante 3 horas en $1 \mathrm{ml}$ de LB líquido en agitación. De este precultivo se tomaron $10 \mu \mathrm{l}$ y se añadieron a un segundo precultivo de $5 \mathrm{ml}$, el cual se incubó a $37^{\circ} \mathrm{C}$ en agitación durante 10 horas. Este segundo precultivo se añadió a 500 $\mathrm{ml}$ de LB líquido y se incubó a $37^{\circ}$ en agitación hasta conseguir una $\mathrm{OD}_{600}$ de entre 0.5- 
0.7. El cultivo bacteriano obtenido se enfrió en hielo 30 minutos y se sometió a una serie de centrifugaciones de 15 minutos a $4^{\circ} \mathrm{C}$ y $5250 \mathrm{rpm}$, resuspendiendo el precipitado obtenido en cada caso en 250, 10, y $1,5 \mathrm{ml}$ de solución fría de glicerol al $10 \%$. Se distribuyó el volumen final en alícuotas de $40 \mu \mathrm{l}$, se congelaron en nitrógeno líquido durante 5 minutos, y se almacenaron finalmente a $-80^{\circ} \mathrm{C}$.

Para la transformación genética de células de E. coli DH5 $\alpha$, se descongeló en hielo una alícuota de células electrocompetentes y se añadieron entre 1 y $2 \mu$ del plásmido de interés. Con ayuda de un elecroporador Eppendorf, se sometió la mezcla a un pulso de electricidad de $1800 \mathrm{~V}$ y se le añadieron $600 \mu \mathrm{l}$ de LB. Esta mezcla se incubó durante 3060 minutos a $37^{\circ} \mathrm{C}$ en agitación. La selección de células transformadas se realizó sembrando en placas LB sólidas (1.5\% agar) suplementadas con el antibiótico correspondiente, según el plásmido utilizado para la transformación, y se incubó 10-15 horas a $37^{\circ} \mathrm{C}$.

3.2. Generación de termo-competencia en células de A. tumefaciens y transformación genética

Agrobacterium tumefaciens C58 se sembró por triple estría en placas Petri conteniendo LB sólido suplementadas con rifampicina $(50 \mu \mathrm{g} / \mathrm{ml})$. A partir de una colonia, se preparó un precultivo líquido de $25 \mathrm{ml}$ en LB-rifampicina, y se incubó a $28^{\circ} \mathrm{C}$ durante 48 horas en agitación. Se utilizaron $3 \mathrm{ml}$ del precultivo para inocular $500 \mathrm{ml}$ de LB-rifampicina, y se incubó hasta una $\mathrm{OD}_{600}$ de $0.5-1$. Se centrifugaron $50 \mathrm{ml}$ del cultivo así obtenido a $4^{\circ} \mathrm{C}$ y $6000 \mathrm{rpm}$ durante 10 minutos. El precipitado se resuspendió en $40 \mathrm{ml}$ de $\mathrm{NaCl} 150 \mathrm{mM}$, y se volvió a centrifugar con las mismas condiciones. El precipitado obtenido se resuspendió en $5 \mathrm{ml}$ de $\mathrm{CaCl}_{2}$, y se repartieron en alícuotas de $100 \mu \mathrm{l}$ que se congelaron en nitrógeno líquido. Las alícuotas se almacenaron a $-80^{\circ} \mathrm{C}$ hasta el momento de su uso.

Para la transformación de Agrobacterium se descongeló una alícuota en hielo. Una vez descongelada se añadieron $5 \mu 1$ del plásmido en cuestión, y se incubó 5 minutos a $37^{\circ}$ $\mathrm{C}$ en agitación. Tras esta incubación se congeló la mezcla en nitrógeno líquido y se descongeló en hielo. A continuación se añadieron $250 \mu \mathrm{l}$ de LB y se incubó en agitación a $28^{\circ} \mathrm{C}$ durante 2-3 horas. La selección de células transformadas se realizó sembrando la mezcla en placas Petri conteniendo LB sólido suplementadas con rifampicina y con el 
antibiótico correspondiente según el plásmido utilizado para la transformación, y se incubaron durante $2-3$ días a $28^{\circ} \mathrm{C}$.

3.3. Generación de termo-competencia en células de $S$. cerivisiae y transformación genética

Para la preparación de células de Saccharomyces cerivisiae competentes se siguió el protocolo de alta eficiencia de transformación basado en acetato de litio (Gietz y Schiestl, 2007), con ligeras modificaciones. Saccharomyces cerevisiae AH109 o Mav203, según el caso, se sembraron en placas YPDA para el cultivo rutinario de levaduras. A partir de una colonia se preparó un cultivo líquido de $3 \mathrm{ml}$ en medio YPDA y se cultivó a $28^{\circ} \mathrm{C}$ hasta la saturación (1-2 días). Se preparó una dilución 1:1000 de este precultivo en $200 \mathrm{ml}$ de medio líquido YPDA, y se incubó en agitación a $28^{\circ} \mathrm{C}$ hasta una $\mathrm{OD}_{660}$ de 0.60.8. Este cultivo se centrifugó a temperatura ambiente durante 10 minutos a $2000 \mathrm{rpm}$, y se lavó el precipitado con $4 \mathrm{ml}$ de agua estéril. La suspensión de levaduras obtenida se centrifugó dos veces sucesivas a temperatura ambiente durante 10 minutos a $2000 \mathrm{rpm}$, resuspendiendo el precipitado en 30 y $2 \mathrm{ml}$ de AcLiTE (0.1 M Acetato de Litio, $10 \mathrm{mM}$ Tris-HCl pH 7.6, 1 mM EDTA) preparado en el momento. Los $2 \mathrm{ml}$ finales así obtenidos se incubaron 15 minutos a $28^{\circ} \mathrm{C}$. Finalmente se añadieron $100 \mu \mathrm{l}$ de esperma de salmón (10 mg/ml) previamente hervido, y $25 \mu 1$ de glicerol al 80\% (v/v). Esta suspensión de células competentes de $S$. cerevissiae se repartió en alícuotas de $100 \mu 1$ y se almacenaron a $-80^{\circ} \mathrm{C}$.

Para la co-transformación de levaduras se descongeló una alícuota de levaduras competentes, y se añadieron entre 1 y $3 \mu$ de cada unos de los plásmidos de interés y 700 $\mu l$ de PEG-LiTE (36\% PEG, 1/10 AcLiTE). La mezcla se incubó 30 minutos a $28^{\circ} \mathrm{C}$, se agitó, y se volvió a incubar 20 minutos a $42^{\circ} \mathrm{C}$, agitando ocasionalmente. Finalmente se centrifugó la mezcla durante 5 minutos a temperatura ambiente y $2000 \mathrm{rpm}$, y se resuspendió el precipitado en $100 \mu 1$ de sorbitol 1M. La suspensión resultante se sembró en placas de medio básico SD sin triptófano ni leucina, según se indica en el apartado 1.2.3.

\subsection{Transformación estable de plantas de Arabidopsis thaliana}

La obtención de plantas transgénicas estables de Arabidopsis se realizó por inmersión de yemas florales en un medio de infiltración (5\% sacarosa, $500 \mu 1$ por litro de Silwet L-77) conteniendo células de A. tumefaciens transformadas con las construcciones 
correspondientes, según se ha descrito previamente (Clough y Bent, 1998). Para la selección de transformantes primarios (T1) se sembraron alrededor de 10000 semillas en medio MS suplementado con el antibiótico correspondiente. Las semillas T2 recogidas a partir de los transformantes primarios se sembraron de igual forma, y se seleccionaron aquellas líneas con una segregación 3:1 en el medio de selección correspondiente a cada caso. Finalmente se seleccionaron líneas homocigóticas, a partir de las semillas T3 que exhibieron $100 \%$ de resistencia al antibiótico correspondiente, para la realización de los estudios correspondientes.

\subsection{Transformación transitoria en plantas de Nicotiana benthamiana}

A. tumefaciens C58 transformados con las construcciones correspondientes se cultivaron en placas de LB suplementadas con los antibióticos adecuados, según se indica en el apartado 3.2. A partir de una colonia se obtuvieron $5 \mathrm{ml}$ de cultivo líquido saturado. Los cultivos líquidos se centrifugaron durante 10 minutos a temperatura ambiente a 4000 rpm, y el precipitado se resuspendió en $5 \mathrm{ml}$ de tampón de agroinfiltración (10 $\mathrm{mM} \mathrm{MgCl}_{2}$, 10 mM MES pH 5.6). La concentración de bacterias se midió a partir de diluciones 1:10, y se tomó un volumen para obtener unas suspensiones de $\mathrm{OD}_{600}$ de 0.2 en $5 \mathrm{ml}$. A estas suspensiones se les añadió acetosiringona $200 \mu \mathrm{M}$, y se agitaron suavemente en oscuridad durante al menos 3 horas a temperatura ambiente. Una vez transcurrido este tiempo, se infiltraron las suspensiones bacterianas por el envés de hojas de $N$. benthamiana, y se cultivaron durante 3-4 días hasta su estudio bajo las mismas condiciones de cultivo, según se indica en el apartado 1.1.2.

Para favorecer la expresión del gen recombinante en Nicotiana, se preparó una mezcla 1:1 de unas células de Agrobacterium transformado con el plásmido de interés con células de Agrobacterium transformado con el plásmido inhibidor del silenciamiento p19, preparado de forma idéntica. En el caso del estudio de interacciones por Complementación Bimolecular de Fluorescencia (BiFC), se preparó una mezcla 1:1:1 de las células de Agrobacterium transformadas con ambas construcciones propias de la técnica del BiFC y con el plásmido $\mathrm{p} 19$.

Todas las construcciones para $\mathrm{BiFC}$ fueron generadas en este proyecto a excepción de la construcción pYFN-CO, que fue cedida por el Dr. Francisco Madueño (IBMCP, Valencia). 
4. Aislamiento y manipulación de ácidos nucleicos

4.1. Extracción y purificación de ácidos nucleicos

\subsubsection{Extracción de ADN genómico de Arabidopsis}

Para la extracción de ADN genómico y su posterior amplificación por Reacción en Cadena de la Polimerasa (Polymerase Chain Reaction, PCR; vid apartado 4.2.1.) se siguió el protocolo propuesto por Edwards y colaboradores (1991). Se tomaron 2-3 hojas de roseta y se congelaron en nitrógeno líquido. Se homogenizó la muestra con politrón y se añadieron $400 \mu \mathrm{l}$ de tampón TNES (200 mM Tris- $\mathrm{HCl}$ pH 7.5, $250 \mathrm{mM} \mathrm{NACl}, 25 \mathrm{mM}$ EDTA, 0.5\% SDS). Tras agitar con vórtex la mezcla, se centrifugó durante un minuto a $13000 \mathrm{rpm}$ y se recogieron $300 \mu \mathrm{l}$ del sobrenadante en un tubo nuevo. El ADN genómico se precipitó con un volumen de isopropanol durante 2 minutos a temperatura ambiente. El precipitado obtenido tras centrifugar durante 5 minutos a $13000 \mathrm{rpm}$, se secó durante 10 minutos, y se resuspendió en 100-200 $\mu$ de agua miliQ.

\subsubsection{Extracción de ARN de Arabidopsis}

Para la extracción rutinaria de ARN se siguió el protocolo propuesto por Logemann y colaboradores (Logemann et al., 1987). La extracción de ARN se realizó triturando el material vegetal congelado con nitrógeno líquido con ayuda de un politrón. A continuación, y sin que llegase a descongelarse la muestra, se añadieron $400 \mu 1$ del tampón Z6 (8M Cloruro de Guanidinio, $20 \mathrm{mM}$ MES, $20 \mathrm{mM}$ EDTA, pH 7). Se añadió un volumen de Fenol:Cloroformo:Isoamilalcohol (25:24:1), y tras homogeneizar en vórtex se centrifugó durante 5 minutos. Se recogió el sobrenadante en un tubo nuevo. El ARN se precipitó con ácido acético $(66 \mathrm{mM})$ en etanol absoluto durante 20 minutos a $-20^{\circ} \mathrm{C}$. Tras una centrifugación de 10 minutos, se lavó secuencialmente el precipitado obtenido con 300 $\mu \mathrm{l}$ de acetato de sodio $3 \mathrm{M}$ pH 5.2, y con $300 \mu \mathrm{l}$ de etanol al 70\%. El precipitado resultante se secó en hielo durante 10-20 minutos, y finalmente se resuspendió en agua DEPC. Para favorecer la disolución del ARN se incubó a $60^{\circ} \mathrm{C}$ durante 10 minutos, agitando en vórtex cada 2-3 minutos. Todas las centrifugaciones se realizaron a $4^{\circ} \mathrm{C}$ y velocidad máxima (13000-14000 rpm). 


\subsubsection{Extracción de ARN para el análisis transcriptómico}

Para el análisis transcriptómico realizado en el presente proyecto, se congelaron en nitrógeno líquido muestras de plántulas de 12 días tras la germinación (dtg) de los genotipos de interés. Dado que la expresión de $\mathrm{PCCl}$ cicla a lo largo de un fotoperiodo (Schlaich y Sauernburn, 2004; Segarra et al., 2010), se tomaron las muestras a las 12 horas de luz, que es el momento en el que PCC1 muestra un pico de expresión (Segarra et al., 2010). Para evitar posibles efectos de posición del transgén portador de la construcción de interferencia de $P C C 1$, cada una de las tres réplicas biológicas de la muestra relativa a plantas iPCC1 constaba de una mezcla de réplicas biológicas de cada una de las líneas por separado.

La extracción de RNA para su análisis transcriptómico global se realizó con TriZol (Sigma), y posteriormente se purificó mediante columnas de QUIAGEN para ARN. El análisis transcriptómico se realizó con matrices de Affimetrix en el Servicio de Genómica del Centro Nacional de Biotecnología, (http://www.cnb.uam.es/content/services/genomics/?l=1). Para el análisis comparativo del transcriptoma de plantas iPCC1 frente a plantas Col-0 se analizaron los datos crudos con la herramienta bioinformatica FIESTA (Oliveros, 2007; http://bioinfogp.cnb.csic.es/tools/FIESTA). Los transcritos diferencialmente expresados fueron filtrados considerando un valor de p corregido para FDR (False Discovery Rate) inferior a 0.05 . Con este criterio se obtuvieron los genes cuya expresión estaba alterada significativamente en plantas iPCC1 frente a plantas silvestres.

Para la obtención de categorías funcionales alteradas en las plantas iPCC1 frente a las plantas silvestres se utilizaron diferentes herramientas bioinformáticas (apartado 13.5), y se contrastaron los resultados obtenidos con éstas.

\subsubsection{Extracción de ADN de bacteria}

Para la purificación de ADN plasmídico a partir de células de E. coli transformadas, éstas se cultivaron en medios líquidos selectivos durante 12 horas aproximadamente en las condiciones indicadas en el apartado 1.2.1. Se centrifugaron entre 2 y $5 \mathrm{ml}$ de cultivo bacteriano, y del precipitado resultante se extrajo el ADN plasmídico con el kit de Invitrogen, siguiendo las instrucciones del fabricante. Esencialmente, la extracción consta de una lisis inicial basada en incubación a pH básico, unión del ADN plasmídico a 
columnas de níquel incluidas en el kit, y elución del ADN con agua miliQ o tampón TE (Tris-EDTA).

Para comprobar la presencia del transgén de interés en una colonia de bacterias $E$. coli, se tocó con la punta de un palillo de madera la colonia en cuestión, y se agitó en $50 \mu 1$ de agua miliQ. Para favorecer la ruptura de las células se sometió la suspensión de bacterias a 3 ciclos de congelación en nitrógeno líquido y descongelación a temperatura ambiente. Por último se centrifugó el lisado 1 minuto a 13000 r.p.m., y se tomaron $2 \mu 1$ como molde para una reacción en cadena de la polimerasa, utilizando oligonucleótidos específicos para el gen de interés, según se indica en el apartado 4.2.1.

\subsection{Manipulación de ácidos nucleicos}

\subsubsection{Amplificación de fragmentos específicos de ADN por PCR}

La amplificación de fragmentos de ADN específico se realizó a partir de $2 \mu l$ de preparación de $\mathrm{ADN}$, según se indicó en el apartado 4.1.1, en un volumen final de $25 \mu 1$ con 1 unidad de Tac polimerasa (Netzyme, EPICA) siguiendo las instrucciones del fabricante. Se usó una mezcla de dNTPs (stock a $10 \mathrm{mM}$ ) a una concentración final de 200 $\mu \mathrm{M}$ por reacción. Los oligonucleótidos específicos (Tabla 11) para cada fragmento de ADN se añadieron a la mezcla de reacción a una concentración de $400 \mathrm{nM}$. Para cada reacción de PCR se usó el programa más adecuado atendiendo a la temperatura de anillamiento de los oligonucleótidos específicos y el tamaño de amplicón. Las reacciones se realizaron en un termociclador "Mastercycler Personal" de Eppendorf. 


\begin{tabular}{|c|c|c|}
\hline Nombre & Secuencia (5'-3') & Uso \\
\hline attB1-1180-pPCC1-D & $\begin{array}{l}\text { aca agt ttg tac aaa aaa gea gge } t \text { ca tca } \\
\text { gga ccg gac aca agtc }\end{array}$ & Clonaje del promotor de $\mathrm{PCC} 1$ \\
\hline attB2-8-pPCC1-R & $\begin{array}{l}\text { acc act ttg tac aag aaa get ggg } \mathbf{t} \text { tg agg } \\
\text { agc tga gga gtg agga }\end{array}$ & Clonaje del promotor de PCC1 \\
\hline attB1-PCC1-2-D & $\begin{array}{c}\text { aca agt ttg tac aaa aaa gca ggc } t \text { ta atg } \\
\text { aat caa tcc geg caa aat }\end{array}$ & Expresión de PCC1 en planta \\
\hline attB1-PCC1-STOP-D & $\begin{array}{c}\text { aca agt ttg tac aaa aaa gca gge } t \text { ga atg } \\
\text { aat caa tcc geg caa aat }\end{array}$ & Expresión de GFP libre en planta \\
\hline attB2-PCC1-nostop-R & $\begin{array}{l}\text { acc act ttg tac aag aaa get ggg } \mathbf{t} \text { ac tct } \\
\text { gat gta cag agg ctg ga }\end{array}$ & Expresión de PCC1 en planta \\
\hline attB2-PCC1N59-R & $\begin{array}{c}\text { acc act ttg tac aag aaa get ggg } t \text { ga ctc } \\
\text { att atg get tcg ggg ttg }\end{array}$ & Expresión de N'tPCC1 en planta \\
\hline attB1-FD-2-D & $\begin{array}{c}\text { aca agt ttg tac aaa aaa gca ggc } t \text { ta atg } \\
\text { ttg tca tca gct aagc }\end{array}$ & Expresión de FD en planta \\
\hline attB2-FD-R & $\begin{array}{l}\text { acc act ttg tac aag aaa get ggg } t \text { at caa } \\
\text { gtt cta act cgt ttg }\end{array}$ & Expresión de FD en planta \\
\hline attB1-FT-2-D & $\begin{array}{c}\text { aca agt ttg tac aaa aaa gca gge } t \text { ta atg } \\
\text { tct ata aat ata agag }\end{array}$ & Expresión de FT en planta \\
\hline attB2-FT-R & $\begin{array}{l}\text { acc act ttg tac aag aaa get ggg } t \text { act aaa } \\
\text { gtc ttc ttc ctc } \operatorname{cgc}\end{array}$ & Expresión de FT en planta \\
\hline attB2-CSN5a-D & $\begin{array}{l}\text { aca agt ttg tac aaa aaa gca gge } t \text { cc atg } \\
\text { gaa ggt tcc tcg tca gcc }\end{array}$ & Expresión de CSN5a en planta \\
\hline attB1-CSN5a-R & $\begin{array}{l}\text { acc act ttg tac aag aaa get ggg } t \text { ct cac } \\
\text { gat gta atc atg ggc tc }\end{array}$ & Expresión de CSN5a en planta \\
\hline attB1-CSN5b-D & $\begin{array}{c}\text { aca agt ttg tac aaa aaa gca gge } t \text { cc atg } \\
\text { gag ggt tcg tcg tcg acg }\end{array}$ & Expresión de CSN5b en planta \\
\hline attB2-CSN5b-R & $\begin{array}{l}\text { acc act ttg tac aag aaa get ggg } t \text { ct caa } \\
\text { tat gta atc ata ggg tc }\end{array}$ & Expresión de CSN5b en planta \\
\hline SalI PCC1-D & cgg tcg acc atg aat caa tcc gcg & Expresión de PCC1 en levadura \\
\hline PCC1 Not1-R & $\operatorname{tgc} g g c$ cgc tha ctc tga tgt aca ga & Expresión de PCC1 en levadura \\
\hline $\mathrm{CO}-\mathrm{R}$ & gca gaa tct gca tgg caa taca & Genotipado 35S::CO-GR \\
\hline 35SCaMV-D & get cet aca aat gec atc a & Genotipado 35S::CO-GR \\
\hline pDBleu5' & ga ata agt gcg aca tca tca tc & $\begin{array}{c}\text { Secuenciación en el plásmido } \\
\text { pBDleu }\end{array}$ \\
\hline pDBleu3' & g taa att tct ggc aag gta gac & $\begin{array}{l}\text { Secuenciación en el plásmido } \\
\text { pBDleu }\end{array}$ \\
\hline pPC86 5' & tat aac gcg ttt gga atc act & $\begin{array}{l}\text { Secuenciación en el plásmido } \\
\text { pPC86 }\end{array}$ \\
\hline pPC86 3' & gt aaa ttt ctg gca agg tag ac & $\begin{array}{l}\text { Secuenciación en el plásmido } \\
\text { pPC86 }\end{array}$ \\
\hline attL1-D & tcg cgt taa cgc tag cat gga tct $\mathrm{c}$ & $\begin{array}{l}\text { Secuenciación en el plásmido } \\
\text { pDONR201 }\end{array}$ \\
\hline attL2-R & gta aca tca gag att ttg aga cac & $\begin{array}{l}\text { Secuenciación en el plásmido } \\
\text { pDONR201 }\end{array}$ \\
\hline qACT2-D & ttg ttc cag cec tcg ttt gt & $\begin{array}{c}\text { Normalización de la } \\
\text { cuantificación por RT-qPCR }\end{array}$ \\
\hline $\mathrm{qACT} 2-\mathrm{R}$ & tgt ctc gtg gat tcc agc ag & $\begin{array}{c}\text { Normalización de la } \\
\text { cuantificación por RT-qPCR }\end{array}$ \\
\hline qPCC1-2D & tgc tcc agc ctc tgt aca tca & Cuantificación por RT-qPCR \\
\hline qPCC1-2R & cga ctt ctg tct cat cat gct ga & Cuantificación por RT-qPCR \\
\hline qFT-D & caa ccc tca cet ccg aga ata $t$ & Cuantificación por RT-qPCR \\
\hline qFT-R & $\operatorname{tgc}$ caa agg ttg ttc cag ttg $\mathrm{t}$ & Cuantificación por RT-qPCR \\
\hline qCO-D & aac gac ata ggt agt gga gag aac aac & Cuantificación por RT-qPCR \\
\hline qCO-R & gca gaa tct gca tgg caa tac a & Cuantificación por RT-qPCR \\
\hline qMYB28-D & tcc ctg aca aat act ctt get gaa $\mathrm{t}$ & Cuantificación por RT-qPCR \\
\hline qMYB28-R & cat tgt ggt tat ctc ctc cga att & Cuantificación por RT-qPCR \\
\hline qHRS1-D & tcc gag gac aag aac acg aaa tc & Cuantificación por RT-qPCR \\
\hline
\end{tabular}




\begin{tabular}{|c|c|c|}
\hline qHRS1-R & tgt cat cgt ctc ctg ctg caa & Cuantificación por RT-qPCR \\
\hline qADH1-D & tac cac cgg aca gat tat tcg atg c & Cuantificación por RT-qPCR \\
\hline qADH1-R & tgg ccg aag ata cgt gga aac aa & Cuantificación por RT-qPCR \\
\hline qRGL2-D & gac ggc gcg tag agt tca $\mathrm{c}$ & Cuantificación por RT-qPCR \\
\hline qRGL2-R & tgc atc cet tga tta agc cc & Cuantificación por RT-qPCR \\
\hline qIRT3-D & gcc ctc aca acc ccg ata $g$ & Cuantificación por RT-qPCR \\
\hline qIRT3-R & gct ccg aca ctg tga gaa ttg a & Cuantificación por RT-qPCR \\
\hline qEDS1-D & cga aga cac agg gec gta & Cuantificación por RT-qPCR \\
\hline qEDS1-R & aag cat gat ccg cac tcg & Cuantificación por RT-qPCR \\
\hline qNPR1-D & gat tcg gtt gtg act gtt ttg g & Cuantificación por RT-qPCR \\
\hline qNPR1-R & tct cgt ttg tct tct tgc tct a & Cuantificación por RT-qPCR \\
\hline qRPP4-D & gaa ggc act caa ggc ctc att tac & Cuantificación por RT-qPCR \\
\hline qRPP4-R & gac aat aat ccc acc ata gec ttt & Cuantificación por RT-qPCR \\
\hline qGSTU24-D & cta ctt tgt tat gtt gat ctg ttg ttg c & Cuantificación por RT-qPCR \\
\hline qGSTU24-R & cat aga cct caa aga aaa tag aac aaa gc & Cuantificación por RT-qPCR \\
\hline qPIF1-D & gtt get ttc gaa ggc ggt t & Cuantificación por RT-qPCR \\
\hline qPIF1-R & gcg cta gga ctt acc tgc gt & Cuantificación por RT-qPCR \\
\hline qRAP2.1-D & tcg ggt ttt att acc ggc gga gtg & Cuantificación por RT-qPCR \\
\hline qRAP2.1-R & taa ggg aaa aag cgg cgg agg $\mathrm{t}$ & Cuantificación por RT-qPCR \\
\hline qAOP1-D & tcg agt tge cta ttc cga cca aac & Cuantificación por RT-qPCR \\
\hline qAOP1-2R & tgc tcc gaa aac agg tgt atc gtc t & Cuantificación por RT-qPCR \\
\hline qAt1g44740-D & tcg get ggc caa aag aaa ta & Cuantificación por RT-qPCR \\
\hline qAt1g44740-R & tcg acc tet cet tgg cet ag & Cuantificación por RT-qPCR \\
\hline qPR1-D & tac gca gaa caa cta aga ggc a & Cuantificación por RT-qPCR \\
\hline qPR1-R & ggc ttc tcg ttc aca taa ttc c & Cuantificación por RT-qPCR \\
\hline qRD29-D & ctt ggc acc acc gtt ggg act a & Cuantificación por RT-qPCR \\
\hline qRD29-R & tca gtt ccc aga atc ttg aac $t$ & Cuantificación por RT-qPCR \\
\hline qGSTU24-D & cta ctt tgt tat gtt gat ctg ttg ttg c & Cuantificación por RT-qPCR \\
\hline qGSTU24-R & cat aga cct caa aga aaa tag aac aaa gc & Cuantificación por RT-qPCR \\
\hline
\end{tabular}

Tabla 11. Oligonucleótidos utilizados para la amplificación de productos por PCR, para la secuenciación de secuendias de ADN, o para la cuantificación de transcritos por RT-qPCR, según se indica en cada caso. Las secuencias marcadas en negrita corresponden a las secuencias de recombinación attB1 o attB2, según el caso. Las secuencias subrayadas corresponden a sitios de corte de la enzima de restricción correspondiente en cada caso. Las secuencias contenidas en cajas grises indican la presencia o ausencia de codón de parada en la secuencia del oligonucleótido.

La detección de los productos de PCR obtenidos se efectuó mediante electroforesis en geles de agarosa al 1\% en tampón 1 x TBE (Tris $88 \mathrm{mM}$, ácido bórico $88 \mathrm{mM}$, y EDTA $2 \mathrm{mM}$ pH8), y suplementados con bromuro de etidio para su visualización con irradiación con luz UV.

\subsubsection{Purificación de bandas de ADN}

La banda correspondiente al producto de amplificación deseado se cortó del gel de agarosa con un bisturí. La eliminación de la agarosa y purificación del ADN se hizo con el uso del "QuiaQUICK gel extraction Kit" (QUIAGEN). 


\subsubsection{Retrotranscripción (RT) de ARN}

Antes de la retrotranscripción del ARN de Arabidopsis, se utilizaron $5 \mu \mathrm{g}$ de ARN y se sometieron a una digestión con el kit DNA-free ${ }^{\mathrm{TM}}$ (Ambion), según las instrucciones del fabricante. $1 \mu \mathrm{g}$ del ARN libre de ADN se sometió a una reacción de retrotranscripción para obtener cadenas de ADN complementario. Para ello, con el fin de desnaturalizar el material genético, se sometió a $70^{\circ} \mathrm{C}$ durante 5 minutos una mezcla del ARN y de 100 pmoles de oligo(dT) $)_{15}$, en un volumen final de $11 \mu$. Tras enfriar la mezcla, se añadió a cada reacción una mezcla que contenía $1 \mathrm{mM}$ de una mezcla comercial de nucleótidos (MBI Fermentas), $20 \mathrm{u}$ de inhibidor de RNasa (MBI Fermentas), tampón de reacción (50 mM de Tris- $\mathrm{HCl} \mathrm{pH}$ 8.3, $50 \mathrm{mM} \mathrm{KCl,} 4 \mathrm{mM}$ de $\mathrm{MgCl}_{2}$ y $10 \mathrm{mM}$ de DTT), y $200 \mathrm{U}$ de la enzima RevertAid ${ }^{T M}$ H Minus M-MuLV Reverse Transcriptase (MBI Fermentas), en un volumen final de $20 \mu 1$ de reacción. Esta mezcla se incubó a $42^{\circ} \mathrm{C}$ durante 1 hora, y se inactivó durante 10 minutos a $70^{\circ} \mathrm{C}$.

\subsubsection{Cuantificación de transcritos por RT-qPCR}

Para la cuantificación en tiempo real por PCR cuantitativa (RT-qPCR) se diseñaron oligonucleótidos específicos (Tabla 11) para cada gen con el programa informático Primer Express 2.0. La mezcla de reacción contenía además $10 \mu \mathrm{l}$ del reactivo SYBR Green PCR Master Mix (Applied Biosystems), y $1 \mu 1$ de cDNA.

Las reacciones se llevaron a cabo en placas MicroAMPTM Optical 96-well reaction plate (Applied Biosystems), en un termociclador 7500 Real Time PCR System (Applied Biosystems). El programa usado fue el recomendado por el fabricante ( $2 \mathrm{~min}$ $50^{\circ} \mathrm{C}, 10 \min 95^{\circ} \mathrm{C}, 40$ ciclos de $15 \mathrm{~s} 95^{\circ} \mathrm{C}$ y $1 \min 60^{\circ} \mathrm{C}$ ). Al final de cada ciclo de amplificación se realizó una cinética de temperatura de anillamiento (curva de disociación) para descartar la amplificación inespecífica o la dimerización de cebadores. A partir de los valores de $\mathrm{Ct}$ obtenidos se calcularon los valores de expresión relativa normalizados con el gen constitutivo de la actina (ACT2, tabla 11). Cada reacción se repitió tres veces (réplicas técnicas), descartando alguna en el caso de que la desviación estándar del Ct correspondiente fuera mayor de 0.3. Cada experimento de cuantificación por RT-qPCR consta de al menos de 3 replicas biológicas. 


\subsubsection{Digestión de ADN con enzimas de restricción}

Las digestiones con enzimas de restricción de $\mathrm{ADN}$ o de vectores recombinantes se llevaron a cabo en un volumen de reacción de $20 \mu$, que contenía una concentración final 1x del tampón más apropiado para cada enzima, según el fabricante, y $2 \mathrm{U}$ de dicha enzima de restricción. La cantidad de ADN fue variable según la digestión, siendo entre 500 ng y $2 \mu \mathrm{g}$ generalmente. La mezcla se incubó a la temperatura óptima para cada enzima en un bloque Termomixer compact (Eppendorf) durante 2-6 horas. Las reacciones de digestión se detuvieron calentando la mezcla a $70^{\circ} \mathrm{C}$ durante 10 minutos. En el caso de digestiones dobles, la reacción se llevó a cabo en el tampón más apropiado para las enzimas, siempre y cuando la actividad de éstas fuera igual o superior al 50\%, según las indicaciones del fabricante.

4.2.6. Reacciones de fosforilación y defosforilación de fragmentos de ADN y vectores

La fosforilación de fragmentos de ADN se llevó a cabo en una solución acuosa que contenía una concentración 1x del tampón facilitado por el fabricante, a la que se le añadió $0,75 \mathrm{mM}$ de ATP y 7,5 U de la enzima T4 polinucleótido quinasa (MBI Fermentas). La cantidad de $\mathrm{ADN}$ era variable, según el caso, siempre que no se excediera de la cantidad recomendada por el fabricante. La mezcla de reacción de fosforilación se incubó a $37^{\circ} \mathrm{C}$ durante 30 minutos, y se calentó a $70^{\circ} \mathrm{C}$ durante 10 minutos para la inactivación de la enzima.

Para evitar la religación de los vectores digeridos con enzimas de restricción, se sometieron a una reacción de defosforilación. Para este tipo de reacciones se añadieron $2 \mathrm{U}$ de fosfatasa alcalina (MBI Fermentas) a una solución acuosa que contenía el vector a defosforilar y una concentración 1x del tampón apropiado, según el fabricante. El volumen final de la reacción fue de 50-100 $\mu$ l, según casos. La mezcla de reacción se incubó 1 hora a $37^{\circ} \mathrm{C}$, y se inactivó mediante la adición de 4\% (v/v) de EDTA 0,5 M.

En ambos casos, la precipitación de los ácidos nucleicos se realizó añadiendo a la mezcla de reacción 2 volúmenes de etanol absoluto y 0.1 volúmenes de acetato sódico pH 5.2. El precipitado se secó y se resuspendió en 20-50 $\mu 1$ de agua miliQ o TE, según el caso. 


\subsubsection{Ligación de fragmentos de PCR y plásmidos}

Para la obtención de vectores recombinados con un inserto de interés, se procedió al uso de dos sistemas de ligación distintos. Un método convencional de ligación de fragmentos de $\mathrm{ADN}$ basado en el uso de enzimas de restricción, y un método basado en la recombinación específica de dianas de recombinación e intercambio de material genético (Tecnología Gateway, Invitrogen). En ambos casos, entre 1-3 $\mu$ l de la mezcla de reacción de ligación fue utilizada para la transformación de células electrocompetentes de E. coli DH5.

\subsubsection{Ligaciones convencionales}

La generación de plásmidos recombinantes para la expresión de proteínas fusionadas a los dominios de activación (AD; activation domain) o de unión al ADN (DB; DNA binding domain), según el caso, para la detección de interacciones por ensayos de doble híbrido (ver apartado 6), fueron obtenidos por ligaciones convencionales mediante la acción de una T4 ligasa. Para incorporar un fragmento de ADN específico en un vector de clonación por este sistema, se amplificó por PCR (apartado 4.2.1) el $\mathrm{ADN}$ con oligonucleótidos específicos, los cuales se diseñaron añadiendo en sus extremos 5' sitios de corte por enzimas de restricción compatibles con el vector de destino, es decir, presentes en la zona de clonaje de éste. El producto de PCR se purificó a partir de agarosa (apartado 4.2.2). El ADN purificado se sometió a una reacción de digestión con las enzimas correspondientes a los sitios de corte generados (apartado 4.2.5), y a una posterior reacción de fosforilación (apartado 4.2.6). El vector de clonación se preparó por digestión con las enzimas correspondientes utilizadas para cada inserto (apartado 4.2.5), y su posterior defosforilación (apartado 4.2.6).

Una vez tenemos el inserto y el vector preparados para la reacción de ligación, se incorporaron en una mezcla de reacción con unas relaciones estequiométricas vector:inserto de entre 1:1 y 1:5, según el caso. La reacción de ligación se realizó en 20 $\mu \mathrm{l}$ de volumen final, conteniendo el tampón recomendado por el fabricante a concentración 1x, PEG 4000 5\% (v/v), 5 U de T4 ligasa (MBI Fermentas), además de las cantidades correspondientes de ADN, según la relación estequiométrica utilizada. La mezcla de reacción se incubó a $22^{\circ} \mathrm{C}$ durante 12-24 horas, y se inactivó posteriormente incubándolas a $65^{\circ} \mathrm{C}$ durante $10 \mathrm{~min}$. 


\subsubsection{Ligaciones mediante el uso de tecnología Gateway®}

El resto de construcciones genéticas generadas en el presente proyecto, se obtuvieron mediante el uso de tecnología Gateway ${ }^{\circledR}$ (Invitrogen), basada en la recombinación específica de dianas de recombinación. Los productos de PCR se obtuvieron y purificaron según los apartados 4.2.1 y 4.2.2, respectivamente. Para el diseño de oligonucleótidos específicos para cada gen de interés, se incorporó en el extremo 5' las secuencias attB1 y attB2 (Tabla 11). La ligación de los fragmentos attB1gen-attB2 con el plásmido pDONR201® (Invitrogen) se realizó con la enzima BP clonasa (Invitrogen), según instrucciones del fabricante. El plásmido recombinante obtenido se utilizó para incorporar el gen de interés a los distintos vectores de destino (Tabla 12, Apartado 5) mediante el uso de la clonasa LR (Invitrogen), según instrucciones del fabricante.

5. Obtención de plásmidos recombinantes

\subsection{Generación de fusiones $p P C C 1:: G U S$}

Para el estudio de la expresión espacio-temporal de $P C C 1$, se obtuvieron líneas transgénicas estables que expresan la proteína $\beta$-glucuronidasa GUS bajo el control transcripcional de la región promotora de PCC1. Para ello se amplificaron por PCR fragmentos de la región promotora 5' del gen PCC1 (At3g22231) de 1173 pares de bases con los oligonucleótidos attB1-1180-pPCC1-D/attB2-8-pPCC1-R, y se clonaron inicialmente en el vector pDONR201 (Life Technologies), y finalmente en el vector de destino pMDC162a (Curtis y Grossniklaus, 2003; Tabla 12) según el apartado 4.2.7.2. 


\begin{tabular}{|c|c|}
\hline Nombre & Uso \\
\hline pDONR201 & Donador de insertos a vectores de destino \\
\hline pGWB5 & Fusión de GFP en extremo carboxi-terminal \\
\hline pGWB6 & Fusión de GFP en extremo amino-terminal \\
\hline pGWB14 & Fusión de HA en extremo carboxi-terminal \\
\hline pGWB17 & Fusión de Myc en extremo carboxi-terminal \\
\hline pYFN43 & BiFC. Fusión de N'YFC en amino-terminal \\
\hline pYFC43 & BiFC. Fusión de C'YFC en amino-terminal \\
\hline pPC86 & Doble híbrido en levadura. Fusión de AD-GAL4 \\
\hline pDBleu & Doble híbrido en levadura. Fusión de DB-GAL4 \\
\hline pMCD162a & Fusión de promotor a GUS \\
\hline
\end{tabular}

Tabla 12. Plásmidos utilizados y usos

5.2. Generación de fusiones traduccionales de proteínas con distintas etiquetas para su análisis en plantas

Para la obtención de construcciones destinadas a la expresión de proteínas de fusión a las distintas etiquetas se utilizó la colección pGWB (Nakagawa et al., 2007; Tabla 12) En el caso de la fusión de proteínas a versiones truncadas de YFP para BiFC se usaron los plásmidos pYFN43 y pYFC43 descritos anteriormente (Belda-Palazón et al., 2011). Con el fin de preservar la fase de lectura de la proteína de interés con la etiqueta en cuestión, se incorporaron dos núcleotidos adicionales en el oligonucleótido directo y uno en el reverso según las instrucciones de los autores (Nakagawa et al., 2007). Además, se eliminó de la secuencia el codón de parada de los genes clonados para evitar romper la fusión traduccional entre la proteína de interés y la etiqueta en su extremo carboxi-terminal. En el caso concreto de las distintas construcciones generadas de $P C C 1$, la pareja de oligonucleótidos utilizados para el clonaje de $P C C 1$ fueron attB1PCC1-2-D / attB2-PCC1-nostop R, que amplifican la secuencia codificante de PCC1 desde su codón de iniciación hasta su codón de parada (secuencia codificante completa). El diseño de la construcción que expresa la proteína GFP (Green Fluorescent Protein) libre se realizó incorporando un codón de parada $(\mathrm{S} \equiv \mathrm{STOP})$ entre la secuencia codificante de GFP y el inicio de la de PCC1 (GFP-S-PCC1). Para ello se diseñó un oligonucleótido que incluye un condón TGA justo antes del codón ATG del inicio de 
traducción de PCC1 (attB1-PCC1-STOP-D) (Tabla 11, Figura 55). Para la expresión de la versión de PCC1 truncada en su extremo carboxi-terminal ( $\left.{ }^{\prime}{ }_{\mathrm{t}}-\mathrm{PCC} 1-\mathrm{GFP}\right)$ se diseñó un oligonucleótido que hibrida específicamente en la región del CDS entre los nucleótidos 155 y 176 (attB2-PCC1-N59 R) (Tabla 11, Figura 55). Los oligonucleótidos attB1-PCC1-2-D / attB2-PCC1-N59-R generan un amplicón específico de PCC1 de 176 pares de bases ( +40 pares de bases aportadas por ambas regiones attB), que codifican una versión de PCC1 de 59 aminoácidos correspondientes a su región amino-terminal carente, por tanto, de los 22 últimos amino ácidos de su secuencia. El clonaje del resto de proteínas de fusión generadas en este proyecto se realizó con el uso de los oligonucleótidos correspondientes indicados en la tabla 11. En todos los casos el molde de partida fue un producto de retrotranscripción (apartado 4.2.3), por lo que se obtuvieron fragmentos de ADN correspondientes a la secuencia codificante (CDS, Coding Sequence) de cada gen. Los productos de PCR obtenidos se recombinaron en el vector de entrada pDONR201 (Life Techologies) según se indica en el apartado 4.2.7.2, y posteriormente, se recombinaron con los vectores de destino correspondientes en cada caso (Tabla 12).

En todos los casos, se procedió a la secuenciación de los insertos clonados y secuenciados en el plásmido pDONR201 con los oligonucleótidos adecuados (Tabla 11). Los vectores de destino utilizados se indican en la tabla 12.

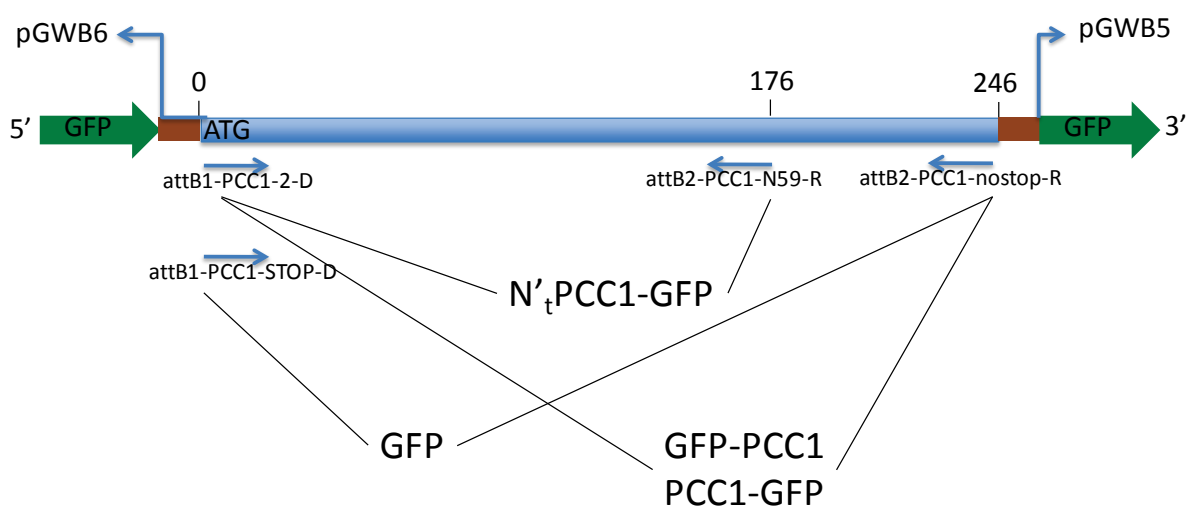

Figura 55. Representación esquemática del sitio de anillamiento de los oligonucleótidos para la expresión de PCC1 fusionada a GFP en su extremo amino- y carboxi-terminal (GFP-PCC1, PCC1-GFP), la versión truncada de PCC1 por su extremo carboxi-terminal ( ${ }^{\prime}{ }_{t}$ PCC1-GFP), y GFP libre (GFP). En el diagrama se representa el plásmido pGWB6 que incorpora GFP en la región amino-terminal de PCC1 (5' de la secuencia de $P C C 1)$, y el plásmido pGWB5 que incorpora GFP en la región carboxi-trminal de PCC1 ( $3^{\text {' }}$ de la secuencia de $P C C 1$ ). 
5.3. Generación de fusiones traduccionales de proteínas con distintas etiquetas para su análisis en levaduras

Para la generación de proteínas fusionadas a los dominios de activación de la transcripción (AD) y de unión a ADN (DB) del gen GAL4 se utilizaron los vectores pPC86 y pDBleu, respectivamente (ProQuest ${ }^{T M}$ Two-Hybrid System, GibcoBRL Life Technologies, Tabla 12). Para el clonaje de los insertos correspondientes en estos vectores se diseñaron oligonucleótidos directo y reverso que incluían respectivamente sitios de corte para las encimas SalI y NotI presentes en el sitio de clonaje múltiple de los vectores pPC86 y pDBleu. Para conservar la fase de lectura se añadió un núcleotido adicional en la región 5' de los sitios de corte. La secuenciación de los insertos se realizó utilizando los oligonucleótidos apropiados para cada plásmido (Tabla 12).

\section{Análisis cuantitativo de ácidos grasos y lípidos polares}

La cuantificación del contenido lipídico fue realizada en colaboración con el grupo del Dr. José Manuel Martínez-Rivas, del Instituto de la Grasa (CSIC; http://www.ig.csic.es/). La cuantificación de los lípidos en Arabidopsis se realizó a partir de plantas de 4 semanas crecidas en condiciones de días cortos. Se tomaron 3 réplicas biológicas de 0,5 g. En el caso de las líneas transgénicas iPCC1, con el fin de evitar un posible efecto de la inserción del transgén, se trató cada una de las líneas como una réplica biológica independiente. El contenido lipídico se extrajo con cloroformo:metanol (1:2) y la separación de los distintos tipos de lípidos se realizó por cromatografía en capa fina, según se ha descrito en Hernández et al., (2008). La detección y cuantificación de los ácidos grasos que componen los distintos tipos de lípidos se realizó por transmetilación ácida (Garcés y Mancha, 1993), y se cuantificaron por cromatografía gaseosa usando un equipo 7890A de Agilent technologies (Santa Clara, CA, USA) con columnas capilares (30 m de longitud, $0.25 \mathrm{~mm}$ i.d., $0.2 \mu \mathrm{m}$ de grosor) sobre una matriz de sílice (Supelco, Bellafonte, PA, USA) y un detector de ionización. Como gas portador se utilizó hidrógeno gaseoso con un flujo lineal de 1.34 $\mathrm{ml} / \mathrm{min}$ y un ratio de separación de 1/50. La temperatura del inyector y del separador fue de $220^{\circ} \mathrm{C}$ y la temperatura del horno de $170^{\circ} \mathrm{C}$. 


\section{Obtención de plantas transgénicas iPCC1 $35 S: \because C O-G R$}

Para la obtención de plantas iPCC1 35S::CO-GR (co-2) se emascularon flores de plantas iPCC1 y se fecundaron con polen procedente de plantas $35 S:: C O-G R$ (co-2). Las construcciones de interferencia de ARN específica para PCC1 (iPCC1) y la sobreexpresión de $C O-G R$ confieren ambas resistencia de las plantas a kanamicina. Por esta razón se procedió a un genotipado basado en la amplificación por PCR con oligonucleótidos directos específicos para el promotor $35 S:: C a M V$, presente en ambas construcciones, y oligonucleótidos reversos específicos para cada una de las construcciones (Tabla 11).

Las plantas procedentes del cruce (plantas F1) se sembraron y se recogieron semillas F2 de forma individual, $1 / 16$ de las cuales deben presentar ambas construcciones en homocigosis. Las semillas F2 se sembraron en MS suplementado con Kanamicina, para eliminar plantas que no tuvieran ninguno de los dos alelos (1/16). Para comprobar la homocigosis de las plantas F2 para ambas construcciones, se obtuvieron semillas de su descendencia (F3), y se evaluaron entre 20 y 30 plantas por PCR. Se seleccionaron las plantas F2 que presentaron una descendencia $100 \%$ homocigota para ambas construcciones.

\section{Ensayos de doble híbrido en levadura}

\subsection{Comprobación directa de interacciones por doble híbrido en levadura}

Se generaron fusiones traduccionales de las proteínas de interés con los dominios de unión a ADN y de activación de la trasncripción del factor de transcripción GAL4, según se indica en el apartado 5.3. A continuación se transformaron levaduras competentes con cantidades similares de cada uno de los vectores recombinantes según se indica en el apartado 3.3. Las levaduras cotransformadas se sembraron en medios líquidos sin triptófano ni leucina hasta la saturación (1-2 días). Se prepararon diluciones seriadas en placas multipocillo de $200 \mu$ de volumen (COSTAR) en condiciones estériles. Las diluciones se hicieron añadiendo $10 \mu \mathrm{l}$ del cultivo saturado (200 $\mu \mathrm{l}$ de dilución 1:1) a un total de $180 \mu$ de medio de cultivo líquido (dilución 1:10). A partir de ésta dilución se repitió el proceso consiguiendo una dilución 1:100. Sucesivamente se consiguieron diluciones hasta 1:100.000. Con la ayuda de un replicador de levaduras, 
se depositó el mismo volumen (4-6 $\mu \mathrm{l})$ sobre placas de medio básico (-histidina, triptófano, -leucina). Se incubaron las placas 2-3 días a $28^{\circ} \mathrm{C}$, y se procedió a su registro fotográfico. Como control de transactivación se utilizó una levadura cotransformada con la proteína de interés fusionada al dominio de activación y el dominio de unión al ADN libre. Con este control evitamos obtener falsos positivos por la posible afinidad de la proteína por el ADN.

8.2. Escrutinio por doble híbrido en levadura para la búsqueda de proteínas interactoras

El escrutinio por doble híbrido ha sido realizado por la empresa Hybrigenics (http://www.hybrigenics-services.com/). Por motivos técnicos que están detallados en la sección de resultados, hemos utilizado los primeros 59 aminoácidos de la región aminoterminal de PCC1 para la búsqueda de potenciales proteínas interactoras. A partir de un vector recombinante que contiene la secuencia codificante de PCCl completa (pDONR201-PCC1) se obtuvo una proteína de fusión $\mathrm{N}_{\mathrm{t}} \mathrm{PCC} 1-\mathrm{DB}$, siendo DB el dominio de unión al ADN de la región promotora de GAL4. El escrutinio se realizó sobre una genoteca de 98.8 millones de clones de cDNAs fusionados al dominio de activación $\mathrm{AD}$ generada a partir de plantas de Arabidopsis de 7 días crecidas en condiciones de días largos. Los plásmidos utilizados por este servicio son $p 6$ (Dominio de Activación) y p66 (Dominio de unión al ADN), obtenidos a partir de $p G A D G H \mathrm{y}$ pAS2 $\triangle$ respectivamente, y las cepas de levadura utilizadas fueron Y187 (mata) y CG1945 (mata) (Fromont-Racine et al., 1997). El escrutinio se basa en el apareamiento de levaduras transformadas con la proteína de interés fusionada al dominio de unión al ADN (N' $\left.{ }_{t} \mathrm{PCC} 1-\mathrm{DB}\right)$ con levaduras transformadas con las proteínas de la genoteca utilizada fusionadas al dominio de activación de la trasncripción (AD). La interacción entre la proteína problema, ${ }^{\prime}{ }_{t} \mathrm{PCC} 1$ en nuestro caso, y la/las posibles proteínas interactoras, se detecta por la activación de genes de biosíntesis de histidina y consecuente el crecimiento de las levaduras en medios carentes de este aminoácido. La identificación de las proteínas interactoras se realiza por la secuenciación de los plásmidos recombinantes de las levaduras de crecimiento en medio básico sin histidina, y la búsqueda de la proteína correspondiente en la base de datos del GenBank (NCBI). 
9. Manipulación de proteínas

\subsection{Análisis Western}

Los extractos crudos (EC) de proteínas se prepararon a partir de discos de hojas de plantas Nicotiana benthamiana trasformadas transitoriamente o a partir de hojas de plantas de Arabidopsis transgénicas, según el caso. Al material vegetal congelado en nitrógeno líquido y pulverizado con la ayuda de un politrón se le añadieron 50-100 $\mu$ l de tampón TBS (10 mM Tris $\mathrm{pH} 4,150 \mathrm{mM} \mathrm{NaCl}$ ) suplementado con 1\% de mezcla comercial de inhibidores de proteasas (Sigma-Aldrich). Según se indique en cada caso, el tampón de extracción TBS se suplementó con SDS 2\%, Nonidet 1\% o CHAPS 5\%. Para eliminar restos de material vegetal y celular se centrifugaron las muestras durante 10 minutos a $4^{\circ} \mathrm{C}$ a $13000 \mathrm{rpm}$, y se recuperó el sobrenadante. Las muestras se cuantificaron según el método descrito por Bradford (1976). En el caso de las muestras extraídas con detergentes, para evitar efectos de interferencia con el reactivo Bradford usado para la cuantificación, se llevó la muestra a $1 \mathrm{ml}$ con TBS, y se concentró por centrifugación con filtros de tubos Microcon de $10 \mu \mathrm{m}$ de diámetro de poro (Millipore).

Para la detección de proteínas etiquetadas por análisis Western se utilizaron entre 10 y $40 \mu \mathrm{g}$ de extracto crudo proteico. A estas muestras se les añadió tampón de carga Laemmli 6x (60 mM Tris-Cl pH 6.8, 2\% SDS, 10\% glicerol, 5\% $\beta$ mercaptoetanol, $0.01 \%$ azul de bromofenol) hasta una concentración final 1x, y se calentaron a $95^{\circ} \mathrm{C}$ durante 5 minutos. Los extractos crudos proteicos se separaron por tamaño en geles desnaturalizantes de poliacrilamida (SDS-PAGE) (Dunn y Bradd, 1993), y se transfirieron a una membrana de nitrocelulosa. Para evitar la unión inespecífica de los anticuerpo a las membranas, éstas fueron incubadas con una solución de leche desnatada en polvo comercial al 5\% en T-TBS $(10 \mathrm{mM}$ Tris pH $4,150 \mathrm{mM}$ $\mathrm{NaCl}, 1 \%$ Tween 20) durante 1-2 horas a temperatura ambiente o 12 horas a $4^{\circ} \mathrm{C}$ en agitación. Posteriormente se incubaron con un anticuerpo primario específico 1-2 horas a temperatura ambiente o 12 horas a $4^{\circ} \mathrm{C}$. A continuación se lavaron las membranas con T-TBS tres veces durante 10 minutos y se incubaron 1-2 horas a temperatura ambiente con un anticuerpo comercial secundario acoplado a peroxidas de rábano (HRP) específico para el reconocimiento de anticuerpos monoclonales (anti-ratón) o policlonales (anti-conejo) (GE Healthcare), según el anticuerpo primario utilizado en cada caso. Las membranas se lavaron con T-TBS tres veces durante 10 minutos en 
agitación. El revelado se realizó con el kit comercial de quimioluminiscencia ECL (GE Healthcare). Los anticuerpos primarios se diluyeron en una solución de leche al 5\% en T-TBS a las concentraciones indicadas en la tabla 13, y los secundarios se prepararon en leche al 5\% en T-TBS a diluciones 1:10.000.

\begin{tabular}{|c|c|c|c|}
\hline Anticuerpo & Tipo & Dilución & Origen \\
\hline anti-GFPm & Monoclonal & $1: 8000$ & Clontech \\
\hline anti-GFPp & Policlonal & $1: 8000$ & AbCam \\
\hline anti-HA & Monoclonal & $1: 5000$ & Sigma-Aldrich \\
\hline anti-MYC-c & Policlonal & $1: 10000$ & Sigma-Aldrich \\
\hline anti-PHYB & Monoclonal & $1: 2500$ & $\begin{array}{c}\text { Cedido por Akira Nagatani } \\
\text { (Univ. Kyoto, Japón) }\end{array}$ \\
\hline anti-TUB & Monoclonal & $1: 10000$ & $\begin{array}{c}\text { Cedido por Pablo Tornero } \\
\text { (IBMCP, Valencia) }\end{array}$ \\
\hline anti-PR1 & Policlonal & $1: 500$ & AbCam \\
\hline anti-Mouse & Secundario & $1: 10000$ & AbCam \\
\hline anti-Rabit & Secundario & $1: 10000$ & . \\
\hline
\end{tabular}

Tabla 13. Anticuerpos utilizados. Tipos, dilución de uso y origen de los anticuerpos. Para la detección de señal de anticuerpos monoclonales se utilizó un anticuerpo secundario anti-ratón conjugado a HRP, y para los policlonales se utilizó un secundario anti-conejo acoplado a HRP. El anticuerpo anti-Myc-c está conjugado a HRP y no requiere de secundario.

\subsection{Inmunoprecipitación de proteínas con anticuerpos específicos}

Para la purificación de proteínas etiquetadas con un anticuerpo específico para cada etiqueta se utilizó un sistema basado en bolas magnéticas de $50 \mathrm{~nm}$ de diámetro tapizadas con el anticuerpo en cuestión $\left(\mu \mathrm{MACS}^{\mathrm{TM}}\right.$ Epitope Tag Protein Isolation Kits, Miltenyi Biotec $\mathrm{GmbH})$. Se prepararon extractos crudos de proteínas a $1 \mathrm{mg} / \mathrm{ml} \mathrm{de}$ concentración y se añadieron $50 \mu \mathrm{d}$ de $\mu \mathrm{MACS}^{\mathrm{TM}}$ por cada mililitro de muestra. La mezcla se incubó durante 1-3 horas en agitación a $4^{\circ} \mathrm{C}$. A continuación se pasó la muestra por columnas $\mu$ Columns (Miltenyi Biotec $\mathrm{GmbH}$ ) previamente equilibradas con el tampón de extracción de proteínas utilizado en cada caso. Las columnas Columns se dispusieron sobre soportes metálicos ofreciendo así un fuerte campo 
magnético que retiene a las bolas $\mu$ MACS tapizadas con el anticuerpo y la proteína a purificar. Finalmente se eluyeron las proteínas con $50 \mu$ de tampón de elución $(50 \mathrm{mM}$ Tris $\mathrm{HCl} \mathrm{pH}$ 6.8, $50 \mathrm{mM}$ DTT, 1\% SDS, 1 mM EDTA, 0.005\% azul de bromofenol, $10 \%$ glicerol) calentado previamente a $95^{\circ} \mathrm{C}$. Las fracciones eluídas se cargaron en geles de poliacrilamida SDS-PAGE y se procedió a la detección por análisis Western, según se ha descrito en el apartado 8.1.

\section{Análisis fenotípicos}

\subsection{Medida de la longitud de hipocotilos}

Para los experimentos de crecimiento de hipocotilos bajo distintas condiciones de luz las semillas se sembraron en placas Petri según se detalla en el apartado 1.1.2. Tras estratificarlas durante 3 días a $4^{\circ} \mathrm{C}$ se pasaron a una cabina de crecimiento a $22^{\circ} \mathrm{C}$ y se les dio un pulso de luz blanca $\left(70 \mu \mathrm{mol} \mathrm{m}-{ }^{2} \mathrm{~s}^{-1}\right)$ durante seis horas, tras las cuales se sometieron a condiciones de oscuridad durante 18 horas adicionales. Tras este paso previo para la sincronización de la germinación, se cultivaron bajo diferentes condiciones lumínicas mediante el uso de una cámara Percival SCI., (USA) provista de

iluminación por LEDs. Las condiciones de luz ensayadas fueron $70 \mu \mathrm{mol} \mathrm{m} \mathrm{m}^{-2} \mathrm{~s}^{-1}$ ara luz blanca, $60 \mu \mathrm{mol} \mathrm{m} \mathrm{m}^{-2}$ para luz roja (R), $15 \mu \mathrm{mol} \mathrm{m} \mathrm{m}^{-2} \mathrm{~s}^{-1}$ para luz azul (A), $5 \mu \mathrm{mol}$ $\mathrm{m}^{-2} \mathrm{~s}^{-1}$ para luz roja lejana (RL), o se mantuvieron en oscuridad. Las plántulas se cultivaron bajo las distintas condiciones durante tres días, tras los cuales se depositaron sobre una hoja de acetato transparente, se escanearon, y se midieron los hipocotilos con el programa informático ImageJ.

10.2. Ensayos de germinación y establecimiento de plántula

Las semillas de los distintos genotipos se sembraron en placas MS suplementadas o no con las distintas concentraciones de ácido abscísico, $\mathrm{NaCl}$ y manitol, según se detalla en el apartado 1.1.2. Se contó el número de semillas germinadas tras 24, 48, 72 y 96 horas de someterlas a condiciones óptimas para la germinación y el crecimiento (fotoperiodos de días largos, $22^{\circ} \mathrm{C}$ ). La germinación se consideró por el criterio de emergencia radicular. Las semillas se dejaron en estas condiciones durante 10 y 15 días y se estimó el establecimiento de plántula. Una planta 
se consideraba establecida cuando presentaba los cotiledones verdes y completamente expandidos.

\subsection{Crecimiento de raíces}

Las semillas estratificadas de cada genotipo se sembraron en medios MS y se pasaron a condiciones de crecimiento en disposición vertical. Tras 6 días de crecimiento en estas condiciones, las plántulas se traspasaron a medios suplementados con las distintas hormonas ensayadas con ayuda de unas pinzas en condiciones estériles. Las plantas se dejaron crecer durante 9 días en disposición vertical. Para la medida de las raíces se consideró como valor cero la longitud de las raíces de plantas de 6 días crecidas en MS, evitando así el efecto sobre la germinación de las distintas hormonas ensayadas. Las plantas de 15 días se escanearon y se procedió a la medida con ayuda del programa informático ImageJ.

\subsection{Medida del cierre estomático}

Plántulas de 6 días crecidas en condiciones de días largos según se indica en el apartado 1.1.2. se aclimataron durante 2 días en medio MS líquido. Tras el tiempo de aclimatación, el medio MS se reemplazó por un tampón de apertura estomática $(10 \mathrm{mM}$ MES-KOH, pH 6.1, suplementado con $30 \mathrm{mM} \mathrm{KCl)} \mathrm{y} \mathrm{se} \mathrm{incubaron} \mathrm{durante} \mathrm{2-3} \mathrm{horas}$ en luz blanca $\left(150 \mu \mathrm{E} \mathrm{m}^{-2} \mathrm{~s}^{-1}\right)$. Tras este tiempo se reemplazó el tampón de apertura estomática por el mismo tampón suplementado o no con $50 \mu \mathrm{M}$ de ABA. Las plántulas se tiñeron con yoduro de propidio para favorecer la visualización de los estomas según se indicará en el apartado 10.2. Se recogieron por microscopio confocal imágenes individuales de 20-25 estomas de cada genotipo pertenecientes a distintas plántulas. La medida de la apertura estomática se estimó como el ratio entre el radio (r) y la longitud (l) de los ostiolos. Mayores valores del ratio r/l indican una mayor apertura del estoma.

\subsection{Estimación de la pérdida de agua}

El cálculo de la pérdida de agua por transpiración se realizó en plántulas de 15 días crecidas in vitro en condiciones de días largos según se indica en el apartado 1.1.2. Las plántulas de 15 días fueron depositadas sobre una superficie plástica y se dejaron en poyata durante el tiempo que duró el experimento. Se utilizaron 4-6 plántulas por medida, y 3 réplicas por genotipo, procedentes de diferentes placas de cultivo in vitro. 
La pérdida de peso se calculó relativizando las mediciones de peso cada 3 minutos durante 30 minutos totales del experimento, al peso fresco inicial (tiempo 0).

\subsection{Tiempo de floración}

El tiempo de floración de las plantas de Arabidopsis se estimó como el número total de hojas de roseta primaria y del tallo principal (Koornneef et al., 1991). Para ello, las plantas se sembraron bajo las condiciones de fotoperiodo indicadas en cada caso y se contaron entre 2 y 3 veces por semanas las hojas expandidas que se iban formando. Para discriminar las hojas que ya habían sido contadas, éstas se marcaron con ayuda de un rotulador permanente resistente al agua. El conteo finalizó cuando el botón floral era visible, momento a partir del cual las hojas se empezaban a formar a partir de yemas laterales.

\section{Obtención de protoplastos a partir de hojas de Nicotiana benthamiana}

Las células vegetales sin pared celular o protoplastos se obtuvieron siguiendo el protocolo propuesto por Martínez y colaboradores (2011). Hojas de Nicotiana transformadas transitoriamente con la correspondiente construcción se cortaron cuidadosamente en tiras de 0,5-1 $\mathrm{mm}$ de ancho con un bisturí y se desecharon las nervaduras. Los limbos resultantes se incubaron un mínimo de 3 horas a $22-25^{\circ} \mathrm{C}$ en oscuridad en una solución de digestión de paredes celulares (1-1,5\% de celulasa RS, 0,2-0,4\% de macerozima R10, 0,4 M de manitol). Tras el tiempo de incubación, la solución se agitó suavemente para favorecer la liberación de los protoplastos y se filtró cuidadosamente con un filtro de nylon de 35-75 $\mu \mathrm{m}$ de diámetro. La suspensión de protoplastos se centrifugó a $100 \mathrm{~g}$ durante 1 minuto. El precipitado resultante se lavó con tampón W5 (2 mM MES, pH 5.7, suplementado con $154 \mathrm{mM} \mathrm{NaCl}, 125 \mathrm{mM} \mathrm{CaCl}_{2}$ y 5 $\mathrm{mM} \mathrm{KCl}$,), y tras una segunda centrifugación en las mismas condiciones se resuspendió en $500 \mu 1$ de tampón W5. Se incubó la solución resultante en hielo durante 30 minutos. Finalmente se centrifugó la suspensión de protoplastos a $100 \mathrm{~g}$ durante 1 minuto, y se resuspendió el precipitado en un tampón MMg (4 mM MES, pH 5.7, suplementado con 0,4 M manitol y $15 \mathrm{mM} \mathrm{MgCl}_{2}$ ). Los protoplastos obtenidos fueron analizados mediante microscopía confocal. 
12. Tinciones histoquímicas

\subsection{Tinción de actividad $\beta$-glucuronidasa (GUS)}

Para la detección in situ de la actividad $\beta$-glucuronidasa (GUS) se siguió el protocolo descrito por Castillo y León (2008) con ligeras modificaciones. Las muestras se recogieron en una solución de acetona fría al 90\% y se incubaron durante 30 minutos. Tras este período de fijación de tejidos se reemplazó la acetona por $1 \mathrm{ml}$ de tampón de tinción histoquímica GUS (tampón fosfato $80 \mathrm{mM}, \mathrm{pH} 7.2,0.2 \%$ Tritón X-100, ferricianuro potásico $5 \mathrm{mM}$ y ferrocianuro potásico $5 \mathrm{mM}$ ). A continuación se reemplazó el tampón descrito por un volumen adecuado para cada muestra consistente en el mismo tampón suplementado con $2 \mathrm{mM}$ del sustrato 5-bromo-4-chloro-3-indolil$\beta$-D-glucurónido (X-Gluc) que, por la acción de la $\beta$-glucuronidasa, se transformará en un compuesto azulado. A continuación se infiltraron al vacío las muestras con ayuda de una bomba de vació durante un período de 20 minutos, rompiendo una vez el vacío a los 10 minutos. Tras la infiltración se incubaron las muestras durante 12 horas aproximadamente a $37^{\circ} \mathrm{C}$ para favorecer la reacción de la enzima GUS. Por último se procedió al lavado y decoloración de las muestras mediante lavados de 30 minutos con soluciones de concentración creciente de etanol $(20,35,50)$, y se fijó la tinción con una solución de fijación (50\% de etanol, 10\% de ácido acético, 5\% de formaldehído). Finalmente se lavó la solución de fijación con una solución de etanol al 70\% durante 10-16 horas, y se incubaron con una solución de hidrato de cloral (8 g de hidrato de cloral en $3 \mathrm{ml}$ de glicerol al 30\%) durante 2-4 días, que fue reemplazada por una solución de glicerol al 30\% y almacenada en frío hasta su evaluación.

En el caso de la tinción histoquímica GUS en condiciones más restrictivas, se utilizaron concnetraciones de $10 \mathrm{mM}$ de ferricianuro potásico y ferrocianuro potásico, manteniendo el resto de las condiciones de tinción idénticas a las descritas anteriormente.

\subsection{Tinción con yoduro de propidio}

El yoduro de propidio (Sigma-Aldrich) es un agente fluoróforo utilizado por su capacidad de unión a ácidos nucleicos. Las membranas celulares son impermeables a este compuesto, por lo que se ha utilizado además para la tinción de paredes celulares en células vivas intactas (Link et al., 2011). El protocolo de tinción con yoduro de 
propidio ha sido descrito previamente (Vogel et al., 2007). Para la tinción de estomas en plántulas de Arabidopsis se incubaron plántulas enteras durante 5 minutos en una solución acuosa de yoduro de propidio $1 \mu \mathrm{g} / \mathrm{ml}$ preparada a partir de una solución stock a $0.1 \mathrm{mg} / \mathrm{ml}$ diluída 1:100. Tras el tiempo de incubación se lavaron las plantas con $1 \mathrm{ml}$ de agua, y se observaron en el microscopio confocal. En el caso de plantas de Nicotiana se procedió de idéntica manera a partir de discos de hoja de $1 \mathrm{~mm}$ de diámetro.

\subsection{Tinción con $\mathrm{FM}^{\mathrm{TM}} 4-64 \mathrm{FX}$}

El FM ${ }^{\mathrm{TM}}$ 4-64FX (Life Technologies) es un compuesto lipofílico capaz de emitir fluorescencia cuando está ubicado en un ambiente hidrofóbico, como es el caso de las membranas plasmáticas de las células (Bolte et al., 2004; Ivanov et al., 2012). Se preparó una solución acuosa $20 \mathrm{mM}$ de FM4-64 que se almacenó en alícuotas de 1ml a $20^{\circ}$ C. A partir de esta solución stock se prepararon diluciones en agua a concentraciones finales de entre 18-22 $\mu \mathrm{M}$. Para la tinción de membranas de Nicotiana se infiltraron zonas de $1-2 \mathrm{~cm}$ de diámetro con esta solución con la ayuda de jeringuillas. Tras una hora de incubación a temperatura ambiente las regiones infiltradas con $\mathrm{FM}^{\mathrm{TM}} 4-64 \mathrm{FX}$ se observaron por microscopía confocal.

\section{Técnicas microscópicas}

\subsection{Toma de imágenes de plantas pPCC1 $1180 \because: G U S$}

La toma de imágenes de plantas transgénicas pPCC1 1180::GUS teñidas según se ha descrito en el apartado 11.1 se realizó con un microscopio binocular Macro Fluo MZZ16F (Leica) con una cámara digital DFC300 FX (Leica) acoplada. Para la toma de fotos con mayor aumento se utilizó un microscopio óptico vertical Eclipse 600 (Nikon) al cual tiene acoplada una cámara fotográfica digital DS-Fil (Nikon).

\subsection{Microscopía confocal}

Para la visualización de imágenes por microscopía confocal se utilizó un microscopio Leica TCS SL (Leica Microsystems Heidelberg GMBH, Heidelberg, Alemania). Para el análisis de plantas que expresan las proteínas GFP e YFP se excitaron las muestras con un láser de argón a $488 \mathrm{~nm}$ y se recogió la emisión entre 500 
y $520 \mathrm{~nm}$. La señal de fluorescencia relativa a la clorofila se recogió entre 660 y 690 $\mathrm{nm}$.

En el estudio de interacciones por BiFC se evaluó la intensidad del láser del microscopio a partir de la cual se detectaba fluorescencia inespecífica emitida en los controles negativos utilizados en cada caso. Esta intensidad se detectaba a intensidades de láser muy elevadas ( $\operatorname{circa} 900 \mathrm{~V}$ ), y era irregular en la superficie celular analizada. Para la detección de interacciones se trabajó con intensidades de láser al menos $300 \mathrm{~V}$ por debajo de aquéllas para las que se observaba emisión en los controles negativos.

La detección de la fluorescencia emitida por el yoduro de propidio se realizó excitando la muestra a $488 \mathrm{~nm}$ y se recogió la fluorescencia en un rango entre 598 y 650 nm no solapante con el rango de la GFP (500-520nm). El en caso de la tinción con FM4-64 se recogió la emisión a 605-625. En ambos casos se realizó un barrido de longitudes de onda ( $\lambda$-scan) para discriminar en los distintos canales si la emisión recogida se debía a la GFP o a los reactivos fluorescentes utilizados en cada caso.

14. Aplicaciones bioinformáticas y bases de datos

14.1. Herramientas básicas para el manejo de secuencias

- ClustalW (www.ebi.ac.uk/Tools/msa/clustalw2/). Alineamiento de secuencias de núcleotidos y de aminoácidos.

- DNA translator (web.expasy.org/translate/). Traduce secuencias nucleotídicas en secuencias de aminoácidos y viceversa.

- Reverse Complement (http://www.bioinformatics.org/sms/rev_comp.html). Lanza la secuencia reversa, complementaria o reversa-complementaria de una secuencia de núcleotidos dada.

- Protein molecular weigth (http://www.bioinformatics.org/sms/prot_mw.html). Calcula el peso molecular de una proteína a partir de su secuencia primaria.

- SerialCloner 2-1. Programa de libre distribución para el manejo de secuencias de genes y de vectores, y la recombinación basada en el sistema Gateway in silico.

- ProtScale (ExPASy; Gasteiger et al., 2005). Predice la hidrofobicidad a lo largo de una secuencia aminoacídica según la escala de Kyte-Doolittle. 
14.2. Predicción de modificaciones secundarias de proteínas

La predicción de sitios de palmitoilación, nitración de tirosinas (Y-NO) y nitrosilación de cisteínas (S-NO) a partir de la secuencia de PCC1 se ha realizado con el paquete de herramientas CCS. En todos los casos se ha utilizado un umbral alto para la minimización de la identificación de falsos positivos. Los sitios web de cada herramienta son:

- CCS Palm3.0: http://csspalm.biocuckoo.org/online.php (Ren et al., 2008).

- GPS-SNO: http://sno.biocuckoo.org/ (Xue et al., 2010).

- GPS-YNO2: http://yno2.biocuckoo.org/ (Liu et al., 2011b).

La predicción de sitios de fosforilación en la secuencia de PCC1 se ha realizado con la herramienta NetPhos 2.0 (Blom et al., 1999) de la base de datos del ExPASy.

14.3. Predicción de localización subcelular

$\begin{array}{lllll}\text { TMPred } & \text { (Koffmann } & \text { y } & \text { Stroffel, }\end{array}$ http://www.ch.embnet.org/software/TMPRED_form.html).

Phobious (Käll et al., 2004; http://phobius.sbc.su.se/).

CELOO v2.5 (Yu et al., 2006; http://cello.life.nctu.edu.tw/).

iPSORT (Bannai et al., 2002; http://ipsort.hgc.jp/).

LOCtree (Petersen et al., 2011).

SubLoc v1.0 (Hua y Sun, 2001).

MultiLoc2 (Blum et al., 2009; http://abi.inf.unituebingen.de/Services/MultiLoc2).

AtSUB P (Kaundal et al., 2010).

14.4. Bases de datos consultadas

BAR (The Bio-Array Resource for Plant Biology; http://bar.utoronto.ca/welcome.htm).

EMBL (European Molecular Biology Laboratory; http://www.embl.org/).

ExPASy (SIB Bioinformatics Resource Portal; http://expasy.org/tools/).

NCBI (National Center for Biotechnology Information; http://www.ncbi.nlm.nih.gov/).

PhosPhAt 4.0 (Durek et al., 2010; Heazlewood et al., 2008; http://phosphat.mpimp-golm.mpg.de/).

TAIR (The Arabidopsis Information Resource; http://www.arabidopsis.org/) 
14.5. Herramientas utilizadas para el análisis de datos transcriptómicos AgriGO (Du et al., 2010; http://bioinfo.cau.edu.cn/agriGO/)

ProfCom (Antonov et al., 2008; http://webclu.bio.wzw.tum.de/profcom/)

GOEAST (Zheng y Wang, 2008; http://omicslab.genetics.ac.cn/GOEAST/) 
Bibliografía 

Abe M, Kobayashi Y, Yamamoto S, Daimon Y, Yamaguchi A, Ikeda Y, Ichinoki H, Notaguchi M, Goto K, Araki T. (2005). FD, a bZIP protein mediating signals from the floral pathway integrator FT at the shoot apex. Science. 309:1052-6.

Ahmad M, Cashmore AR. (1993). HY4 gene of A. thaliana encodes a protein with characteristics of a blue-light photoreceptor. Nature. 366:162-6.

Ajjawi I, Coku A, Froehlich JE, Yang Y, Osteryoung KW, Benning C, Last RL. (2011). A j-like protein influences Fatty Acid composition of chloroplast lipids in Arabidopsis. PLoS One. 6: e25368.

Alabadí D, Oyama T, Yanovsky MJ, Harmon FG, Más P, Kay SA. (2001). Reciprocal regulation between TOC1 and LHY/CCA1 within the Arabidopsis circadian clock. Science. 293:880-3.

Alabadí D, Gil J, Blázquez MA, García-Martínez JL. (2004). Gibberellins repress photomorphogenesis in darkness. Plant Physiol. 134:1050-7.

Amasino RM, Michaels SD. (2010). The timing of flowering. Plant Physiol. 154: $516-20$.

An C, Mou Z. (2011). Salicylic acid and its function in plant immunity. J Integr Plant Biol. 53:412-28.

Andreou A, Brodhun F, Feussner I. (2009). Biosynthesis of oxylipins in nonmammals. Prog Lipid Res. 2009 48:148-70.

Antonov AV, Schmidt T, Wang Y, Mewes HW. (2008). ProfCom: a web tool for profiling the complex functionality of gene groups identified from high-throughput data. Nucleic Acids Res. 1:36.

Aravind L, Ponting CP. (1998). Homologues of 26S proteasome subunits are regulators of transcription and translation. Protein Sci. 7:1250-4.

Ascencio-Ibáñez JT, Sozzani R, Lee TJ, Chu TM, Wolfinger RD, Cella R, Hanley-Bowdoin L. (2008). Global analysis of Arabidopsis gene expression uncovers a complex array of changes impacting pathogen response and cell cycle during geminivirus infection. Plant Physiology. 148:436-454

Bannai H, Tamada Y, Maruyama O, Nakai K, Miyano S. (2002). Extensive feature detection of $\mathrm{N}$-terminal protein sorting signals. Bioinformatics. 18 298-305.

Bäurle I, Dean C. (2006). The timing of developmental transitions in plants. Cell. 125:655-64. 
Bech-Otschir D, Kraft R, Huang X, Henklein P, Kapelari B, Pollmann C, Dubiel W. (2001). COP9 signalosome-specific phosphorylation targets p53 to degradation by the ubiquitin system. EMBO J. 20:1630-9.

Beilharz T, Egan B, Silver PA, Hofmann K, Lithgow T. (2003). Bipartite signals mediate subcellular targeting of tail-anchored membrane proteins in Saccharomyces cerevisiae. J Biol Chem. 278:8219-23.

Belda-Palazón B, Ruiz L, Martí E, Tárraga S, Tiburcio AF, Culiáñez F, Farràs R, Carrasco P, Ferrando A. (2012). Aminopropyltransferases involved in polyamine biosynthesis localize preferentially in the nucleus of plant cells. PLoS One. 7: e46907.

Bent AF, Kunkel BN, Dahlbeck D, Brown KL, Schmidt R, Giraudat J, Leung J, Staskawicz BJ. (1994). RPS2 of Arabidopsis thaliana: a leucine-rich repeat class of plant disease resistance genes. Science. 265:1856-60.

Bessire M, Chassot C, Jacquat AC, Humphry M, Borel S, Petétot JM, Métraux JP, Nawrath C. (2007). A permeable cuticle in Arabidopsis leads to a strong resistance to Botrytis cinerea. EMBO J. 26:2158-68.

Blázquez MA, Green R, Nilsson O, Sussman MR, Weigel D. (1998). Gibberellins promote flowering of arabidopsis by activating the LEAFY promoter. Plant Cell. 10:791-800.

Blázquez MA, Ahn JH, Weigel D. (2003). A thermosensory pathway controlling flowering time in Arabidopsis thaliana. Nat Genet. 33:168-71.

Blom N, Gammeltoft S, Brunak S. (1999). Sequence- and structure-based prediction of eukaryotic protein phosphorylation sites. Journal of Molecular Biology: 294: $1351-1362$.

Blum T, Briesemeister S, Kohlbacher O. (2009). MultiLoc2: integrating phylogeny and Gene Ontology terms improves subcellular protein localization prediction. BMC Bioinformatics. 10:274.

Boller T, Felix G. (2009). A renaissance of elicitors: perception of microbeassociated molecular patterns and danger signals by pattern-recognition receptors. Annu Rev Plant Biol. 60:379-406.

Bolte S, Talbot C, Boutte Y, Catrice O, Read ND, Satiat-Jeunemaitre B. (2004). FM-dyes as experimental probes for dissecting vesicle trafficking in living plant cells. J Microsc. 214:159-73. 
Bonhomme F, Kurz B, Melzer S, Bernier G, Jacqmard A. (2000). Cytokinin and gibberellin activate SaMADS A, a gene apparently involved in regulation of the floral transition in Sinapis alba. Plant J. 24:103-11.

Borner R, Kampmann G, Chandler J, Gleissner R, Wisman E, Apel K, Melzer S. (2000). A MADS domain gene involved in the transition to flowering in Arabidopsis. Plant J. 24:591-9.

Bounpheng MA, Melnikova IN, Dodds SG, Chen H, Copeland NG, et al. (2000). Characterization of the mouse JAB1 cDNA and protein. Gene 242:41-50.

Bouwmeester K, de Sain M, Weide R, Gouget A, Klamer S, Canut H, Govers F. (2011). The lectin receptor kinase LecRK-I.9 is a novel Phytophthora resistance component and a potential host target for a RXLR effector. PLoS Pathog. 7: e1001327.

Boyes DC, Nam J, Dangl JL. (1998). The Arabidopsis thaliana RPM1 disease resistance gene product is a peripheral plasma membrane protein that is degraded coincident with the hypersensitive response. Proc Natl Acad Sci U S A. 95:15849-54

Briggs WR, Christie JM, Salomon M. (2001). Phototropins: a new family of flavin-binding blue light receptors in plants. Antioxid Redox Signal. 3:775-88.

Browse J. (2009). The power of mutants for investigating jasmonate biosynthesis and signaling. Phytochemistry. 70:1539-46.

Cai X, Ballif J, Endo S, Davis E, Liang M, Chen D, DeWald D, Kreps J, Zhu T, Wu Y. (2007). A putative CCAAT-binding transcription factor is a regulator of flowering timing in Arabidopsis. Plant Physiol. 145:98-105.

Canonne J, Froidure-Nicolas S, Rivas S. (2011). Phospholipases in action during plant defense signaling. Plant Signal Behav. 6:13-8.

Cao FY, Yoshioka K, Desveaux D. (2011). The roles of ABA in plantpathogen interactions. J Plant Res. 124:489-99.

Carroll AJ, Heazlewood JL, Ito J, Millar AH. (2008). Analysis of the Arabidopsis cytosolic ribosome proteome provides detailed insights into its components and their post-translational modification. Mol Cell Proteomics. 7:347-69.

Cashmore AR, Jarillo JA, Wu YJ, Liu D. (1999). Cryptochromes: blue light receptors for plants and animals. Science. 284:760-5.

Castillejo C, Pelaz S. (2008). The balance between CONSTANS and TEMPRANILLO activities determines FT expression to trigger flowering. Curr Biol. $18: 1338-43$. 
Castillo MC, León J. (2008). Expression of the beta-oxidation gene 3-ketoacylCoA thiolase 2 (KAT2) is required for the timely onset of natural and dark-induced leaf senescence in Arabidopsis. J Exp Bot. 59:2171-9.

Chamovitz DA, Wei N, Osterlund MT, von Arnim AG, Staub JM, Matsui M, Deng XW. (1996). The COP9 complex, a novel multisubunit nuclear regulator involved in light control of a plant developmental switch. Cell. 86:115-21.

Chamovitz DA. (2009). Revisiting the COP9 signalosome as a transcriptional regulator. EMBO Rep.10:352-8.

Champigny MJ, Shearer H, Mohammad A, Haines K, Neumann M, Thilmony R, He SY, Fobert P, Dengler N, Cameron RK. (2011). Resistance in Arabidopsis using DIR1:GUS and DIR1:EGFP reporters. BMC Plant Biol. 11:125.

Chandra-Shekara AC, Venugopal SC, Barman SR, Kachroo A, Kachroo P. (2007). Plastidial fatty acid levels regulate resistance gene-dependent defense signaling in Arabidopsis. Proc Natl Acad Sci U S A. 104:7277-82.

Chassot C, Nawrath C, Métraux JP. (2007). Cuticular defects lead to full immunity to a major plant pathogen. Plant J. 49:972-80.

Chassot C, Nawrath C, Métraux JP. (2008). The cuticle: Not only a barrier for plant defence: A novel defence syndrome in plants with cuticular defects. Plant Signal Behav. 3:142-4.

Chen H, Shen Y, Tang X, Yu L, Wang J, Guo L, Zhang Y, Zhang H, Feng S, Strickland E, Zheng N, Deng XW. (2006). Arabidopsis CULLIN4 Forms an E3 Ubiquitin Ligase with RBX1 and the CDD Complex in Mediating Light Control of Development. Plant Cell. 18:1991-2004.

Chen NZ, Zhang XQ, Wei PC, Chen QJ, Ren F, Chen J, Wang XC. (2007). AtHAP3b plays a crucial role in the regulation of flowering time in Arabidopsis during osmotic stress. J Biochem Mol Biol. 40:1083-9.

Chen H, Huang X, Gusmaroli G, Terzaghi W, Lau OS, Yanagawa Y, Zhang Y, Li J, Lee JH, Zhu D, Deng XW. (2010). Arabidopsis CULLIN4-damaged DNA binding protein 1 interacts with CONSTITUTIVELY PHOTOMORPHOGENIC1SUPPRESSOR OF PHYA complexes to regulate photomorphogenesis and flowering time. Plant Cell. 22:108-23.

Cleland CF, Tanaka O. (1979). Effect of Daylength on the Ability of Salicylic Acid to Induce Flowering in the Long-day Plant Lemna gibba G3 and the Short-day Plant Lemna paucicostata 6746. Plant Physiol. 64:421-4. 
Cleland CF, Ben-Tal Y. (1982). Influence of Giving Salicylic Acid for Different Time Periods on Flowering and Growth in the Long-Day Plant Lemna gibba G3. Plant Physiol. 70:287-90.

Clough SJ, Bent AF. (1998). Floral dip: a simplified method for Agrobacterium-mediated transformation of Arabidopsis thaliana. Plant J. 16:735-43.

Cope GA, Suh GS, Aravind L, Schwarz SE, Zipursky SL, Koonin EV, Deshaies RJ. (2002). Role of predicted metalloprotease motif of Jab1/Csn5 in cleavage of Nedd8 from Cul1. Science. 298:608-11.

Corbesier L, Vincent C, Jang S, Fornara F, Fan Q, Searle I, Giakountis A, Farrona S, Gissot L, Turnbull C, Coupland G. (2007). FT protein movement contributes to long-distance signaling in floral induction of Arabidopsis. Science. 316:1030-3.

Curtis MD, Grossniklaus U. (2003). A gateway cloning vector set for highthroughput functional analysis of genes in planta. Plant Physiol. 133:462-9.

Cutler SR, Rodriguez PL, Finkelstein RR, Abrams SR. (2010). Abscisic acid: emergence of a core signaling network. Annu Rev Plant Biol. 61:651-79.

D'Angelo G, Vicinanza M, De Matteis MA. (2008). Lipid-transfer proteins in biosynthetic pathways. Curr Opin Cell Biol. 20:360-70.

Daszkowska-Golec A. (2011). Arabidopsis seed germination under abiotic stress as a concert of action of phytohormones. OMICS. 15:763-74.

de Lucas M, Davière JM, Rodríguez-Falcón M, Pontin M, Iglesias-Pedraz JM, Lorrain S, Fankhauser C, Blázquez MA, Titarenko E, Prat S. (2008). A molecular framework for light and gibberellin control of cell elongation. Nature. 451:480-4.

de Torres M, Sanchez P, Fernandez-Delmond I, Grant M. (2003). Expression profiling of the host response to bacterial infection: the transition from basal to induced defence responses in RPM1-mediated resistance. Plant J. 33:665-76.

Deblaere R, Bytebier B, De Greve H, Deboeck F, Schell J, Van Montagu M, Leemans J. (1985). Efficient octopine Ti plasmid-derived vectors for Agrobacteriummediated gene transfer to plants. Nucleic Acids Res. 13:4777-88.

Delaney TP, Uknes S, Vernooij B, Friedrich L, Weymann K, Negrotto D, Gaffney T, Gut-Rella M, Kessmann H, Ward E, Ryals J. (1994). A central role of salicylic Acid in plant disease resistance. Science. 266:1247-1250. 
Dempsey DA, Klessig DF. (2012). SOS - too many signals for systemic acquired resistance? Trends Plant Sci. 17:538-45.

Deng W, Ying H, Helliwell CA, Taylor JM, Peacock WJ, Dennis ES. (2011). FLOWERING LOCUS C (FLC) regulates development pathways throughout the life cycle of Arabidopsis. Proc Natl Acad Sci U S A. 108: 6680-6685.

Deng XW, Dubiel W, Wei N, Hofmann K, Mundt K, Colicelli J, Kato J, Naumann M, Segal D, Seeger M, Carr A, Glickman M, Chamovitz DA. (2000). Unified nomenclature for the COP9 signalosome and its subunits: an essential regulator of development. Trends Genet. 16:202-3.

Després C, DeLong C, Glaze S, Liu E, Fobert PR. (2000). The Arabidopsis NPR1/NIM1 protein enhances the DNA binding activity of a subgroup of the TGA family of bZIP transcription factors. Plant Cell. 12:279-90.

Dohmann EM, Levesque MP, Isono E, Schmid M, Schwechheimer C. (2008). Auxin responses in mutants of the Arabidopsis CONSTITUTIVE PHOTOMORPHOGENIC9 signalosome. Plant Physiol. 147:1369-79.

Dohmann EM, Nill C, Schwechheimer C. (2010). DELLA proteins restrain germination and elongation growth in Arabidopsis thaliana COP9 signalosome mutants. Eur J Cell Biol. 89:163-8.

Du Z, Zhou X, Ling Y, Zhang Z, Su Z. (2010). agriGO: a GO analysis toolkit for the agricultural community. Nucleic Acids Res. 38:W64-70.

Duda DM, Borg LA, Scott DC, Hunt HW, Hammel M, Schulman BA. (2008). Structural insights into NEDD8 activation of cullin-RING ligases: conformational control of conjugation. Cell. 134:995-1006.

Dunlap JC. (1999). Molecular bases for circadian clocks. Cell. 96:271-90.

Dunn MJ, Bradd SJ. (1993). Separation and analysis of membrane proteins by SDS-polyacrylamide gel electrophoresis. Methods Mol Biol.19:203-10.

Durek P, Schmidt R, Heazlewood JL, Jones A, MacLean D, Nagel A, Kersten B, Schulze WX. (2010). PhosPhAt: the Arabidopsis thaliana phosphorylation site database. An update. Nucleic Acids Res. 38:D828-34.

Durrant WE, Dong X. (2004). Systemic acquired resistance. Annu Rev Phytopathol. 42:185-209.

Edwards K, Johnstone C, Thompson C (1991). A simple a rapid method for the preparation of plant genomic DNA for PCR analysis. Nucleic Acids Res. 19:1349. 
Eulgem T, Tsuchiya T, Wang XJ, Beasley B, Cuzick A, Tör M, Zhu T, McDowell JM, Holub E, Dangl JL. (2007). EDM2 is required for RPP7-dependent disease resistance in Arabidopsis and affects RPP7 transcript levels. Plant J. 49:829-39.

Fahy E, Cotter D, Sud M, Subramaniam S. (2011). Lipid classification, structures and tools. Biochim Biophys Acta. 1811:637-47.

Falk A, Feys BJ, Frost LN, Jones JD, Daniels MJ, Parker JE. (1999). EDS1, an essential component of $\mathrm{R}$ gene-mediated disease resistance in Arabidopsis has homology to eukaryotic lipases. Proc Natl Acad Sci U S A. 96:3292-7.

Farré EM, Harmer SL, Harmon FG, Yanovsky MJ, Kay SA. (2005). Overlapping and distinct roles of PRR7 and PRR9 in the Arabidopsis circadian clock. Curr Biol. 15:47-54.

Feng S, Ma L, Wang X, Xie D, Dinesh-Kumar SP, Wei N, Deng XW. (2003). The COP9 signalosome interacts physically with SCF COI1 and modulates jasmonate responses. Plant Cell. 15:1083-94.

Fernández-Calvo P, Chini A, Fernández-Barbero G, Chico JM, GimenezIbanez S, Geerinck J, Eeckhout D, Schweizer F, Godoy M, Franco-Zorrilla JM, Pauwels L, Witters E, Puga MI, Paz-Ares J, Goossens A, Reymond P, De Jaeger G, Solano R. (2011). The Arabidopsis bHLH transcription factors MYC3 and MYC4 are targets of JAZ repressors and act additively with MYC2 in the activation of jasmonate responses. Plant Cell. 23:701-15.

Feys BJ, Moisan LJ, Newman MA, Parker JE. (2001). Direct interaction between the Arabidopsis disease resistance signaling proteins, EDS1 and PAD4. EMBO J. 20:5400-11.

Feys BJ, Wiermer M, Bhat RA, Moisan LJ, Medina-Escobar N, Neu C, Cabral A, Parker JE. (2005). Arabidopsis SENESCENCE-ASSOCIATED GENE101 stabilizes and signals within an ENHANCED DISEASE SUSCEPTIBILITY1 complex in plant innate immunity. Plant Cell. 17:2601-13.

Flor H. H. (1971). Current Status of the Gene-For-Gene Concept. Annual Review of Phytopathology. 9:275-296

Fonseca S, Chico JM, Solano R. (2009). The jasmonate pathway: the ligand, the receptor and the core signalling module. Curr Opin Plant Biol. 12:539-47.

Fornara F, Panigrahi KC, Gissot L, Sauerbrunn N, Rühl M, Jarillo JA, Coupland G. (2009). Arabidopsis DOF transcription factors act redundantly to reduce 
CONSTANS expression and are essential for a photoperiodic flowering response. Dev Cell. 17:75-86.

Fowler S, Lee K, Onouchi H, Samach A, Richardson K, Morris B, Coupland G, Putterill J. (1999). GIGANTEA: a circadian clock-controlled gene that regulates photoperiodic flowering in Arabidopsis and encodes a protein with several possible membrane-spanning domains. EMBO J. 18:4679-88.

Fragnière C, Serrano M, Abou-Mansour E, Métraux JP, L'Haridon F. (2011). Salicylic acid and its location in response to biotic and abiotic stress. FEBS Lett. 585:1847-52.

Frankhauser C, Staiger D. (2002). Photoreceptors in Arabidopsis thaliana: light perception, signal transduction and entrainment of the endogenous clock. Planta. 216:1-16.

Franklin KA, Larner VS, Whitelam GC. (2005). The signal transducing photoreceptors of plants. Int J Dev Biol. 49:653-64.

Fromont-Racine M, Rain JC, Legrain P. (1997) Toward a functional analysis of the yeast genome through exhaustive two-hybrid screens. Nat. Genet. 16, 277-282.

Fu H, Reis N, Lee Y, Glickman MH, Vierstra RD. (2001). Subunit interaction maps for the regulatory particle of the $26 \mathrm{~S}$ proteasome and the COP9 signalosome. EMBO J. 20:7096-107.

Furlan G, Klinkenberg J, Trujillo M. (2012). Regulation of plant immune receptors by ubiquitination. Front Plant Sci. 3:238.

García AV, Blanvillain-Baufumé S, Huibers RP, Wiermer M, Li G, Gobbato E, Rietz S, Parker JE. (2010). Balanced nuclear and cytoplasmic activities of EDS1 are required for a complete plant innate immune response. PLoS Pathog. 6: e1000970.

Garner WW, Allard HA. (1922). Photoperiodism, the response of the plant to relative lenght of day and night. Science. 55:582-3.

Gasteiger E, Hoogland C, Gattiker A, Duvaud S, Wilkins MR, Appel RD, Bairoch A. (2005). Protein Identification and Analysis Tools on the ExPASy Server; (In) John M. Walker (ed): The Proteomics Protocols Handbook, Humana Press. pp. 571-607.

Gietz RD, Schiestl RH. (2007). Quick and easy yeast transformation using the LiAc/SS carrier DNA/PEG method. Nat Protoc. 2:35-7. 
Glauser G, Grata E, Dubugnon L, Rudaz S, Farmer EE, Wolfender JL. (2008). Spatial and temporal dynamics of jasmonate synthesis and accumulation in Arabidopsis in response to wounding. J Biol Chem. 283:16400-7.

Glazebrook J. (2005). Contrasting mechanisms of defense against biotrophic and necrotrophic pathogens. Annu Rev Phytopathol. 43:205-27.

Griffiths J, Murase K, Rieu I, Zentella R, Zhang ZL, Powers SJ, Gong F, Phillips AL, Hedden P, Sun TP, Thomas SG. (2006). Genetic characterization and functional analysis of the GID1 gibberellin receptors in Arabidopsis. Plant Cell. 18:3399-414.

Groisman R, Polanowska J, Kuraoka I, Sawada J, Saijo M, Drapkin R, Kisselev AF, Tanaka K, Nakatani Y. (2003). The ubiquitin ligase activity in the DDB2 and CSA complexes is differentially regulated by the COP9 signalosome in response to DNA damage. Cell. 113:357-67.

Gubler F, Millar AA, Jacobsen JV. (2005). Dormancy release, ABA and preharvest sprouting. Current Opinion in Plant Biology. 8:183-187

Guo H, Yang H, Mockler TC, Lin C. (1998). Regulation of flowering time by Arabidopsis photoreceptors. Science. 279:1360-3.

Harmer SL, Hogenesch JB, Straume M, Chang HS, Han B, Zhu T, Wang X, Kreps JA, Kay SA. (2000). Orchestrated transcription of key pathways in Arabidopsis by the circadian clock. Science. 290:2110-3.

Hayama R, Coupland G. (2004). The molecular basis of diversity in the photoperiodic flowering responses of Arabidopsis and rice. Plant Physiol. 135:677-84.

Heazlewood JL, Durek P, Hummel J, Selbig J, Weckwerth W, Walther D, Schulze WX. (2008). PhosPhAt: a database of phosphorylation sites in Arabidopsis thaliana and a plant-specific phosphorylation site predictor. Nucleic Acids Res. 36:D1015-21.

Hernández ML, Guschina IA, Martínez-Rivas JM, Mancha M, Harwood JL. (2008). The utilization and desaturation of oleate and linoleate during glycerolipid biosynthesis in olive (Olea europea L.) callus cultures. Journal of Experimental Botany. 59: $2425-2435$.

Hershko A, Ciechanover A. (1998). The ubiquitin system. Annu Rev Biochem. $67: 425-79$. 
Hind SR, Pulliam SE, Veronese P, Shantharaj D, Nazir A, Jacobs NS, Stratmann JW. (2011). The COP9 signalosome controls jasmonic acid synthesis and plant responses to herbivory and pathogens. Plant J. 65:480-91.

Hisamatsu T, King RW. (2008). The nature of floral signals in Arabidopsis. II. Roles for FLOWERING LOCUS T (FT) and gibberellin. J Exp Bot. 59:3821-9.

Holm M, Ma LG, Qu LJ, Deng XW. (2002). Two interacting bZIP proteins are direct targets of COP1-mediated control of light-dependent gene expression in Arabidopsis. Genes Dev. 16:1247-59.

Hua S, Sun Z. (2001). Support vector machine approach for protein subcellular localization prediction. Bioinformatics. 17:721-8.

Hua Z, Vierstra RD. (2011). The cullin-RING ubiquitin-protein ligases. Annu Rev Plant Biol. 62:299-334.

Huijser P, Schmid M. (2011). The control of developmental phase transitions in plants. Development. 138:4117-29.

Huq E, Tepperman JM, Quail PH. (2000). GIGANTEA is a nuclear protein involved in phytochrome signaling in Arabidopsis. Proc Natl Acad Sci USA. 97:978994.

Imaizumi T, Schultz TF, Harmon FG, Ho LA, Kay SA. (2005). FKF1 F-box protein mediates cyclic degradation of a repressor of CONSTANS in Arabidopsis. Science. 309:293-7.

Imaizumi T. (2010). Arabidopsis circadian clock and photoperiodism: time to think about location. Curr Opin Plant Biol. 13:83-9.

Ivanov IE, Boyd CD, Newell PD, Schwartz ME, Turnbull L, Johnson MS, Whitchurch CB, O'Toole GA, Camesano TA. (2012). Atomic force and superresolution microscopy support a role for LapA as a cell-surface biofilm adhesin of Pseudomonas fluorescens. Res Microbiol. 163:685-91.

Jaeger KE, Wigge PA. (2007). FT protein acts as a long-range signal in Arabidopsis. Curr Biol. 17:1050-4.

Jang S, Marchal V, Panigrahi KC, Wenkel S, Soppe W, Deng XW, Valverde F, Coupland G. (2008). Arabidopsis COP1 shapes the temporal pattern of CO accumulation conferring a photoperiodic flowering response. EMBO J. 27:1277-88.

Jetter R, Kunst L, Samuels AL. (2007). Composition of Plant Cuticular Waxes, in Annual Plant Reviews Volume 23: Biology of the Plant Cuticle (eds M. Riederer and C. Müller), Blackwell Publishing Ltd, Oxford, UK. 
Johnson E, Bradley M, Harberd NP, Whitelam GC. (1994). Photoresponses of Light-Grown phyA Mutants of Arabidopsis (Phytochrome A Is Required for the Perception of Daylength Extensions). Plant Physiol. 105:141-149.

Jones JD, Dangl JL. (2006). The plant immune system. Nature. 444:323-9.

Jung JH, Seo YH, Seo PJ, Reyes JL, Yun J, Chua NH, Park CM. (2007). The GIGANTEA-regulated microRNA172 mediates photoperiodic flowering independent of CONSTANS in Arabidopsis. Plant Cell. 19:2736-48.

Kachroo P, Shanklin J, Shah J, Whittle EJ, Klessig DF. (2001). A fatty acid desaturase modulates the activation of defense signaling pathways inplants. Proc Natl Acad Sci USA 98: 9448-9453.

Kachroo P, Venugopal SC, Navarre DA, Lapchyk L, Kachroo A. (2005). Role of salicylic acid and fatty acid desaturation pathways in ssi2-mediated signaling. Plant Physiol.139:1717-35.

Kachroo A, Kachroo P. (2009). Fatty Acid-derived signals in plant defense. Annu Rev Phytopathol. 47:153-76.

Kagaya Y, Ohmiya K, Hattori T. (1999). Regulation by external and developmental signals of the RAV2 gene encoding a DNA binding proteína containing AP2 and B3-like domains. Plant Biotechnology 16:135-140.

Käll L, Krogh A, Sonnhammer EL. (2004). A Combined Transmembrane Topology and Signal Peptide Prediction Method. Journal of Molecular Biology, 338:1027-1036.

Kannangara R, Branigan C, Liu Y, Penfield T, Rao V, Mouille G, Höfte H, Pauly M, Riechmann JL, Broun P. (2007). The transcription factor WIN1/SHN1 regulates cutin biosynthesis in Arabidopsis thaliana. The Plant Cell. 19:1278-1294.

Karniol B, Malec P, Chamovitz DA. (1999). Arabidopsis FUSCA5 encodes a novel phosphoprotein that is a component of the COP9 complex. Plant Cell. 11:839-48.

Kaundal R, Saini R, Zhao PX. (2010). Combining machine learning and homology-based approaches to accurately predict subcellular localization in Arabidopsis. Plant Physiol. 154:36-54.

Khanna R, Kikis EA, Quail PH (2003). EARLY FLOWERING 4 Functions in Phytochrome B-Regulated Seedling De-Etiolation. Plant Physiol. 133:1530-1538.

Kim SY, He Y, Jacob Y, Noh YS, Michaels S, Amasino R. (2005). Establishment of the vernalization-responsive, winter-annual habit in Arabidopsis requires a putative histone H3 methyl transferase. Plant Cell. 17:3301-10. 
Kim SG, Kim SY, Park CM. (2007). A membrane-associated NAC transcription factor regulates salt-responsive flowering via FLOWERING LOCUS $\mathrm{T}$ in Arabidopsis. Planta. 226:647-54.

Kim TH, Hauser F, Ha T, Xue S, Böhmer M, Nishimura N, Munemasa S, Hubbard K, Peine N, Lee BH, Lee S, Robert N, Parker JE, Schroeder JI. (2011). Chemical genetics reveals negative regulation of abscisic acid signaling by a plant immune response pathway. Curr Biol. 21:990-7.

Kinkema M, Fan W, Dong X. (2000). Nuclear localization of NPR1 is required for activation of PR gene expression. Plant Cell. 12:2339-2350.

Kinoshita T, Ono N, Hayashi Y, Morimoto S, Nakamura S, Soda M, Kato Y, Ohnishi M, Nakano T, Inoue S, Shimazaki K. (2011). FLOWERING LOCUS T regulates stomatal opening. Curr Biol. 21:1232-8.

Kobayashi Y, Kaya H, Goto K, Iwabuchi M, Araki T. (1999). A pair of related genes with antagonistic roles in mediating flowering signals. Science. 286:19602.

Komeda Y. (2004). Genetic regulation of time to flower in Arabidopsis thaliana. Annu Rev Plant Biol. 55:521-35.

Koornneef M, Hanhart CJ, van der Veen JH. (1991). A genetic and physiological analysis of late flowering mutants in Arabidopsis thaliana. Mol Gen Genet. 229:57-66.

Koornneef M, Alonso-Blanco C, Peeters AJ, Soppe W. (1998). GENETIC CONTROL OF FLOWERING TIME IN ARABIDOPSIS. Annu Rev Plant Physiol Plant Mol Biol. 49:345-370.

Korves TM, Bergelson J. (2003). A developmental response to pathogen infection in Arabidopsis. Plant Physiol. 133:339-47.

Krinke O, Ruelland E, Valentová O, Vergnolle C, Renou JP, Taconnat L, Flemr M, Burketová L, Zachowski A. (2007). Phosphatidylinositol 4-kinase activation is an early response to salicylic acid in Arabidopsis suspension cells. Plant Physiol. 144:1347-59.

Kumimoto RW, Adam L, Hymus GJ, Repetti PP, Reuber TL, Marion CM, Hempel FD, Ratcliffe OJ. (2008). The Nuclear Factor Y subunits NF-YB2 and NFYB3 play additive roles in the promotion of flowering by inductive long-day photoperiods in Arabidopsis. Planta. 228:709-23. 
Kumimoto RW, Zhang Y, Siefers N, Holt BF (2010). NF-YC3, NF-YC4 and NF-YC9 are required for CONSTANS-mediated, photoperiod-dependent flowering in Arabidopsis thaliana. Plant J. 63:379-91.

Kuramata M, Masuya S, Takahashi Y, Kitagawa E, Inoue C, Ishikawa S, Youssefian S, Kusano T. (2009). Novel cysteine-rich peptides from Digitaria ciliaris and Oryza sativa enhance tolerance to cadmium by limiting its cellular accumulation. Plant Cell Physiol. 50:106-17.

Kurdyukov S, Faust A, Nawrath C, Bär S, Voisin D, Efremova N, Franke R, Schreiber L, Saedler H, Métraux JP, Yephremov A. (2006). The epidermisspecific extracellular BODYGUARD controls cuticle development and morphogenesis in Arabidopsis. Plant Cell. 18:321-39.

Kwok SF, Solano R, Tsuge T, Chamovitz DA, Ecker JR, Matsui M, Deng XW. (1998). Arabidopsis homologs of a c-Jun coactivator are present both in monomeric form and in the COP9 complex, and their abundance is differentially affected by the pleiotropic cop/det/fus mutations. Plant Cell. 10:1779-90.

Kyte J, Doolittle RF. (1982). A simple method for displaying the hydropathic character of a protein. J Mol Biol. 157:105-32.

Lázaro A, Valverde F, Piñeiro M, Jarillo JA. (2012). The Arabidopsis E3 ubiquitin ligase HOS1 negatively regulates CONSTANS abundance in the photoperiodic control of flowering. Plant Cell. 24:982-99.

Laxalt AM, Munnik T. (2002). Phospholipid signalling in plant defence. Curr Opin Plant Biol. 5:332-8.

L'Haridon F, Besson-Bard A, Binda M, Serrano M, Abou-Mansour E, Balet F, Schoonbeek HJ, Hess S, Mir R, Léon J, Lamotte O, Métraux JP. (2011). A permeable cuticle is associated with the release of reactive oxygen species and induction of innate immunity. PLoS Pathog. 7:e1002148.

Lee J, Oh M, Park H, Lee I. (2008). SOC1 translocated to the nucleus by interaction with AGL24 directly regulates leafy. Plant J. 55: 832-43.

Lee BH, Zhu JK. (2010). Phenotypic analysis of Arabidopsis mutants: germination rate under salt/hormone-induced stress. Cold Spring Harb Protoc. prot4969

León-Reyes A, Spoel SH, De Lange ES, Abe H, Kobayashi M, Tsuda S, Millenaar FF, Welschen RA, Ritsema T, Pieterse CM. (2009). Ethylene modulates the role of NONEXPRESSOR OF PATHOGENESIS-RELATED GENES1 in cross talk between salicylate and jasmonate signaling. Plant Physiol. 149:1797-809. 
Li J, Zhang J, Wang X, Chen J. (2010). A membrane-tethered transcription factor ANAC089 negatively regulates floral initiation in Arabidopsis thaliana. Sci China Life Sci. 53:1299-306.

Li W, Ahn IP, Ning Y, Park CH, Zeng L, Whitehill JG, Lu H, Zhao Q, Ding B, Xie Q, Zhou JM, Dai L, Wang GL. (2012). The U-Box/ARM E3 ligase PUB13 regulates cell death, defense, and flowering time in Arabidopsis. Plant Physiol. 159:239-50.

Lifschitz E, Eviatar T, Rozman A, Shalit A, Goldshmidt A, Amsellem Z, Alvarez JP, Eshed Y. (2006). The tomato FT ortholog triggers systemic signals that regulate growth and flowering and substitute for diverse environmental stimuli. Proc Natl Acad Sci U S A. 103:6398-403.

Lin C, Yang H, Guo H, Mockler T, Chen J, Cashmore AR. (1998). Enhancement of blue-light sensitivity of Arabidopsis seedlings by a blue light receptor cryptochrome 2. Proc Natl Acad Sci U S A. 95:2686-90.

Lin C. (2000). Photoreceptors and regulation of flowering time. Plant Physiol. 123:39-50.

Lin YF, Liang HM, Yang SY, Boch A, Clemens S, Chen CC, Wu JF, Huang JL, Yeh KC. (2009). Arabidopsis IRT3 is a zinc-regulated and plasma membrane localized zinc/iron transporter. New Phytol. 182:392-404.

Link K, Vogel F, Sonnewald U. (2011). PD Trafficking of Potato Leaf Roll Virus Movement Protein in Arabidopsis Depends on Site-specific Protein Phosphorylation. Front Plant Sci. 2:18.

Liu Y, Schiff M, Serino G, Deng XW, Dinesh-Kumar SP. (2002). Role of SCF ubiquitin-ligase and the COP9 signalosome in the $\mathrm{N}$ gene-mediated resistance response to Tobacco mosaic virus. Plant Cell. 14:1483-96.

Liu H, Yu X, Li K, Klejnot J, Yang H, Lisiero D, Lin C. (2008a). Photoexcited CRY2 interacts with CIB1 to regulate transcription and floral initiation in Arabidopsis. Science. 322:1535-9.

Liu LY, Zhang YC, Li QH, Sang Y, Mao J, Lian HL, Wang L, Yang HQ (2008b). COP1-Mediated Ubiquitination of CONSTANS Is Implicated in Cryptochrome Regulation of Flowering in Arabidopsis. Plant Cell. 20: 292-306.

Liu B, Zuo Z, Liu H, Liu X, Lin C. (2011a). Arabidopsis cryptochrome 1 interacts with SPA1 to suppress COP1 activity in response to blue light. Genes Dev. 25:1029-34. 
Liu Z, Cao J, Ma Q, Gao X, Ren J, Xue Y. (2011b). GPS-YNO2: Computational prediction of tyrosine nitration sites in proteins Molecular BioSystems. 7: 1197-1204.

Liu J, Li W, Ning Y, Shirsekar G, Cai Y, Wang X, Dai L, Wang Z, Liu W, Wang GL. (2012). The U-Box E3 ligase SPL11/PUB13 is a convergence point of defense and flowering signaling in plants. Plant Physiol. 160:28-37.

Logemann J, Schell J, Willmitzer L. (1987). Improved method for the isolation of RNA from plant tissues. Anal Biochem. 163:16-20.

Lorenzo O, Chico JM, Sánchez-Serrano JJ, Solano R. (2004). JASMONATE-INSENSITIVE1 encodes a MYC transcription factor essential to discriminate between different jasmonate-regulated defense responses in Arabidopsis. Plant Cell. 16:1938-50.

Lu D, Lin W, Gao X, Wu S, Cheng C, Avila J, Heese A, Devarenne TP, He P, Shan L. (2011). Direct ubiquitination of pattern recognition receptor FLS2 attenuates plant innate immunity. Science. 332:1439-42.

Luan S. (2003). Protein phosphatases in plants. Annu Rev Plant Biol.;54:63-92.

Lyapina S, Cope G, Shevchenko A, Serino G, Tsuge T, Zhou C, Wolf DA, Wei N, Shevchenko A, Deshaies RJ. (2001). Promotion of NEDD-CUL1 conjugate cleavage by COP9 signalosome. Science. 292:1382-5.

Maldonado AM, Doerner P, Dixon RA, Lamb CJ, Cameron RK. (2002). A putative lipid transfer protein involved in systemic resistance signalling in Arabidopsis. Nature. 419:399-403.

Marathe R, Anandalakshmi R, Liu Y, Dinesh-Kumar SP. (2002). The tobacco mosaic virus resistance gene, N. Mol Plant Pathol. 3:167-72.

Marmagne A, Rouet MA, Ferro M, Rolland N, Alcon C, Joyard J, Garin J, Barbier-Brygoo H, Ephritikhine G. (2004). Identification of new intrinsic proteins in Arabidopsis plasma membrane proteome. Mol Cell Proteomics. 3:675-91.

Martínez C, Pons E, Prats G, León J. (2004). Salicylic acid regulates flowering time and links defence responses and reproductive development. Plant J. 37:209-17.

Martínez F, Sardanyés J, Elena SF, Darós JA. (2011). Dynamics of a plant RNA virus intracellular accumulation: stamping machine vs. geometric replication. Genetics. 188:637-46. 
Más P. (2008). Circadian clock function in Arabidopsis thaliana: time beyond transcription. Trends Cell Biol. 18:273-81.

Mathieu J, Warthmann N, Küttner F, Schmid M. (2007). Export of FT protein from phloem companion cells is sufficient for floral induction in Arabidopsis. Curr Biol. 17: 1055-60.

Mathieu J, Yant LJ, Mürdter F, Küttner F, Schmid M. (2009). Repression of flowering by the miR172 target SMZ. PLoS Biol. 7:e1000148.

Maytal-Kivity V, Piran R, Pick E, Hofmann K, Glickman MH. (2002). COP9 signalosome components play a role in the mating pheromone response of $\mathrm{S}$. cerevisiae. EMBO Rep. 3:1215-21.

McGinnis KM, Thomas SG, Soule JD, Strader LC, Zale JM, Sun TP, Steber CM. (2003). The Arabidopsis SLEEPY1 gene encodes a putative F-box subunit of an SCF E3 ubiquitin ligase. Plant Cell. 15:1120-30.

Mellersh DG, Heath MC. (2001). Plasma membrane-cell wall adhesion is required for expression of plant defense responses during fungal penetration. Plant Cell. $13: 413-24$

Melotto M, Underwood W, Koczan J, Nomura K, He SY. (2006). Plant stomata function in innate immunity against bacterial invasion. Cell. 126:969-80.

Melzer S, Lens F, Gennen J, Vanneste S, Rohde A, Beeckman T. (2008). Flowering-time genes modulate meristem determinacy and growth form in Arabidopsis thaliana. Nat Genet. 40:1489-92.

Menon S, Rubio V, Wang X, Deng XW, Wei N. (2005). Purification of the COP9 signalosome from porcine spleen, human cell lines, and Arabidopsis thaliana plants. Methods Enzymol. 398:468-81.

Menon S, Chi H, Zhang H, Deng XW, Flavell RA, Wei N. (2007). COP9 signalosome subunit 8 is essential for peripheral $\mathrm{T}$ cell homeostasis and antigen receptor-induced entry into the cell cycle from quiescence. Nat Immunol. 8:1236-45.

Merlet J, Burger J, Gomes JE, Pintard L. (2009). Regulation of cullin-RING E3 ubiquitin-ligases by neddylation and dimerization. Cell Mol Life Sci. 66:1924-38.

Milner MJ, Seamon J, Craft E, Kochian LV. (2013). Transport properties of members of the ZIP family in plants and their role in $\mathrm{Zn}$ and Mn homeostasis. J Exp Bot. 64:369-81. 
Mishina TE, Zeier J. (2007). Pathogen-associated molecular pattern recognition rather than development of tissue necrosis contributes to bacterial induction of systemic acquired resistance in Arabidopsis. Plant J. 50:500-13.

Mosher S, Moeder W, Nishimura N, Jikumaru Y, Joo SH, Urquhart W, Klessig DF, Kim SK, Nambara E, Yoshioka K. (2010). The lesion-mimic mutant cpr22 shows alterations in abscisic acid signaling and abscisic acid insensitivity in a salicylic acid-dependent manner. Plant Physiol. 152:1901-13.

Mou Z, Fan W, Dong X. (2003). Inducers of plant systemic acquired resistance regulate NPR1 function through redox changes. Cell. 113:935-44.

Mouradov A, Cremer F, Coupland G. (2002). Control of flowering time: interacting pathways as a basis for diversity. Plant Cell. 14:111-30.

Munnik T, Irvine RF, Musgrave A. (1998). Phospholipid signalling in plants. Biochim Biophys Acta. 1389:222-72.

Munnik T. (2001). Phosphatidic acid: an emerging plant lipid second messenger. Trends Plant Sci. 6:227-33.

Murase K, Hirano Y, Sun TP, Hakoshima T. (2008). Gibberellin-induced DELLA recognition by the gibberellin receptor GID1. Nature. 456:459-63.

Murashige T, Skoog F (1962). A revised medium for rapid growth and bioassays with tobacco tissue cultures. Physiol Plant 15: 473-497.

Mutasa-Göttgens E, Hedden P. (2009). Gibberellin as a factor in floral regulatory networks. J Exp Bot. 60:1979-89.

Nakagawa T, Kurose T, Hino T, Tanaka K, Kawamukai M, Niwa Y, Toyooka K, Matsuoka K, Jinbo T, Kimura T. (2007). Development of series of gateway binary vectors, pGWBs, for realizing efficient construction of fusion genes for plant transformation. J Biosci Bioeng. 104:34-41.

Nakamichi N, Kita M, Ito S, Sato E, Yamashino T, Mizuno T. (2005). The Arabidopsis pseudo-response regulators, PRR5 and PRR7, coordinately play essential roles for circadian clock function. Plant Cell Physiol. 46:609-19.

Nakamichi N, Kita M, Niinuma K, Ito S, Yamashino T, Mizoguchi T, Mizuno T. (2007). Arabidopsis clock-associated pseudo-response regulators PRR9, PRR7 and PRR5 coordinately and positively regulate flowering time through the canonical CONSTANS-dependent photoperiodic pathway. Plant Cell Physiol. 48:82232. 
Nambara E, Marion-Poll A. (2003). ABA action and interactions in seeds. Trends Plant Sci. 8:213-7.

Nandi A, Moeder W, Kachroo P, Klessig DF, Shah J. (2005). Arabidopsis ssi2-conferred susceptibility to Botrytis cinerea is dependent on EDS5 and PAD4. Mol Plant Microbe Interact. 18:363-70.

Nawrath C, Heck S, Parinthawong N, Métraux JP. (2002). EDS5, an essential component of salicylic acid-dependent signaling for disease resistance in Arabidopsis, is a member of the MATE transporter family. Plant Cell. 14:275-86.

Nawrath C, Métraux JP. (1999). Salicylic acid induction-deficient mutants of Arabidopsis express PR-2 and PR-5 and accumulate high levels of camalexin after pathogen inoculation. Plant Cell. 11:1393-404.

Nelson DC, Lasswell J, Rogg LE, Cohen MA, Bartel B. (2000). FKF1, a clock-controlled gene that regulates the transition to flowering in Arabidopsis. Cell. 101:331-40.

Nordgård O, Dahle Ø, Andersen TØ, Gabrielsen OS. (2001). JAB1/CSN5 interacts with the GAL4 DNA binding domain: a note of caution about two-hybrid interactions. Biochimie. 83:969-71.

Novoplanrky A. (2002). Developmental plasticity in plants: implications of noncognitive behavior. Evolutionary Ecology. 16: 177-188.

Nozawa Y. (2011). Adaptive regulation of membrane lipids and fluidity during thermal acclimation in Tetrahymena. Proc Jpn Acad Ser B Phys Biol Sci. 87:450-62.

Nühse TS, Stensballe A, Jensen ON, Peck SC. (2004). Phosphoproteomics of the Arabidopsis plasma membrane and a new phosphorylation site database. Plant Cell. 16:2394-405.

Ohlrogge JB, Kuhn DN, Stumpf PK. (1979). Subcellular localization of acyl carrier protein in leaf protoplasts of Spinacia oleracea. Proc Natl Acad Sci U S A. 76: 1194-1198.

Ohlrogge JB, Jaworski JG. (1997). REGULATION OF FATTY ACID SYNTHESIS. Annu Rev Plant Physiol Plant Mol Biol. 48:109-136.

Oliveros JC. (2007). FIESTA@BioinfoGP. An interactive server for analyzing DNA microarray experiments with replicates. http://bioinfogp.cnb.csic.es/tools/FIESTA. 
Osnato M, Castillejo C, Matías-Hernández L, Pelaz S. (2012). TEMPRANILLO genes link photoperiod and gibberellin pathways to control flowering in Arabidopsis. Nat Commun. 3:808.

Osterlund MT, Hardtke CS, Wei N, Deng XW. (2000). Targeted destabilization of HY5 during light-regulated development of Arabidopsis. Nature. 405:462-6.

Palmer CM, Bush SM, Maloof JN. (2012). Phenotypic and Developmental Plasticity in Plants. En: eLS. John Wiley \& Sons Ltd, Chichester.

Panikashvili D, Shi JX, Bocobza S, Franke RB, Schreiber L, Aharoni A. (2010). The Arabidopsis DSO/ABCG11 transporter affects cutin metabolism in reproductive organs and suberin in roots. Molecular Plant. 3:563-575.

Peng Z, Serino G, Deng XW. (2001). A role of Arabidopsis COP9 signalosome in multifaceted developmental processes revealed by the characterization of its subunit 3. Development. 128:4277-88.

Petersen TN, Brunak S, von Heijne G, Nielsen H. (2011). SignalP 4.0: discriminating signal peptides from transmembrane regions. Nat Methods. 8:785-6.

Petroski MD, Deshaies RJ. (2005). Function and regulation of cullin-RING ubiquitin ligases. Nat Rev Mol Cell Biol. 6:9-20.

Piñeiro M, Jarillo JA. (2013). Ubiquitination in the control of photoperiodic flowering. Plant Sci. 198:98-109.

Ponting CP, Aravind L, Schultz J, Bork P, Koonin EV. (1999). Eukaryotic signalling domain homologues in archaea and bacteria. Ancient ancestry and horizontal gene transfer. J Mol Biol. 289:729-45.

Pruneda-Paz JL, Breton G, Para A, Kay SA. (2009). A functional genomics approach reveals $\mathrm{CHE}$ as a component of the Arabidopsis circadian clock. Science. 323:1481-5.

Qi Q, Gibson A, Fu X, Zheng M, Kuehn R, Wang Y, Wang Y, Navarro S, Morrell JA, Jiang D, Simmons G, Bell E, Ivleva N, McClerren AL, Loida P, Ruff TG, Petracek ME, Preuss SB. (2012). Involvement of the N-terminal B-box domain of Arabidopsis BBX32 protein in interaction with soybean BBX62 protein. J Biol Chem. 287(37):31482-93.

Quail PH. (2002). Photosensory perception and signalling in plant cells: new paradigms? Curr Opin Cell Biol. 14:180-8. 
Rajjou L, Duval M, Gallardo K, Catusse J, Bally J, Job C, Job D. (2012). Seed germination and vigor. Annu Rev Plant Biol. 63:507-33.

Reed JW, Nagpal P, Poole DS, Furuya M, Chory J. (1993). Mutations in the gene for the red/far-red light receptor phytochrome B alter cell elongation and physiological responses throughout Arabidopsis development. Plant Cell. 5:147-57.

Reeves PH, Coupland G. (2001). Analysis of flowering time control in Arabidopsis by comparison of double and triple mutants. Plant Physiol. 126:1085-91.

Reiland S, Messerli G, Baerenfaller K, Gerrits B, Endler A, Grossmann J, Gruissem W, Baginsky S. (2009). Large-scale Arabidopsis phosphoproteome profiling reveals novel chloroplast kinase substrates and phosphorylation networks. Plant Physiol. 150:889-903.

Ren C, Pan J, Peng W, Genschik P, Hobbie L, Hellmann H, Estelle M, Gao B, Peng J, Sun C, Xie D. (2005). Point mutations in Arabidopsis Cullin1 reveal its essential role in jasmonate response. Plant J. 42:514-24.

Ren J, Wen L, Gao X, Jin C, Xue Y, Yao X. (2008). CSS-Palm 2.0: an updated software for palmitoylation sites prediction. Protein Engineering, Design and Selection. 21:639-644.

Rizzini L, Favory JJ, Cloix C, Faggionato D, O'Hara A, Kaiserli E, Baumeister R, Schäfer E, Nagy F, Jenkins GI, Ulm R. (2011). Perception of UV-B by the Arabidopsis UVR8 protein. Science. 332:103-6.

Robert-Seilaniantz A, Grant M, Jones JD. (2011). Hormone crosstalk in plant disease and defense: more than just jasmonate-salicylate antagonism. Annu Rev Phytopathol. 49:317-43.

Roetschi A, Si-Ammour A, Belbahri L, Mauch F, Mauch-Mani B. (2001). Characterization of an Arabidopsis-Phytophthora pathosystem: resistance requires a functional PAD2 gene and is independent of salicylic acid, ethylene and jasmonic acid signalling. Plant J. 28:293-305.

Sadanandom A, Bailey M, Ewan R, Lee J, Nelis S. (2012). The ubiquitinproteasome system: central modifier of plant signalling. New Phytol. 196:13-28.

Samarakoon T, Shiva S, Lowe K, Tamura P, Roth MR, Welti R. (2012). Arabidopsis thaliana membrane lipid molecular species and their mass spectral analysis. Methods Mol Biol. 918:179-268.

Sauerbrunn N, Schlaich NL. (2004). PCC1: a merging point for pathogen defence and circadian signalling in Arabidopsis. Planta. 218:552-61. 
Sawa M, Kay SA. (2011). GIGANTEA directly activates Flowering Locus T in Arabidopsis thaliana. Proc Natl Acad Sci U S A. 108:11698-703.

Schlaeppi K, Abou-Mansour E, Buchala A, Mauch F. (2010). Disease resistance of Arabidopsis to Phytophthora brassicae is established by the sequential action of indole glucosinolates and camalexin. Plant J. 62:840-51.

Schultz TF, Kiyosue T, Yanovsky M, Wada M, Kay SA. (2001). A role for LKP2 in the circadian clock of Arabidopsis. Plant Cell. 13:2659-70.

Schwechheimer C, Serino G, Callis J, Crosby WL, Lyapina S, Deshaies RJ, Gray WM, Estelle M, Deng XW. (2001). Interactions of the COP9 signalosome with the E3 ubiquitin ligase SCFTIRI in mediating auxin response. Science. 292:1379-82.

Schwechheimer C, Isono E. (2010). The COP9 signalosome and its role in plant development. Eur J Cell Biol. 89:157-62.

Seeger M, Kraft R, Ferrell K, Bech-Otschir D, Dumdey R, Schade R, Gordon C, Naumann M, Dubiel W. (1998). A novel protein complex involved in signal transduction possessing similarities to $26 \mathrm{~S}$ proteasome subunits. FASEB J. $12: 469-78$.

Segarra S. (2009). Función del ácido salicílico en la floración acelerada por estrés en Arabidopsis thaliana. Tesis Doctoral. Departamento de Biotecnología de la Universidad Politécnica de València.

Segarra S, Mir R, Martínez C, León J. (2010). Genome-wide analyses of the transcriptomes of salicylic acid-deficient versus wild-type plants uncover Pathogen and Circadian Controlled 1 (PCC1) as a regulator of flowering time in Arabidopsis. Plant Cell Environ. 33:11-22.

Serino G, Tsuge T, Kwok S, Matsui M, Wei N, Deng XW. (1999). Arabidopsis cop8 and fus 4 mutations define the same gene that encodes subunit 4 of the COP9 signalosome. Plant Cell. 11:1967-80.

Serino G, Deng XW. (2003). The COP9 signalosome: regulating plant development through the control of proteolysis. Annu Rev Plant Biol. 54:165-82.

Serino G, Su H, Peng Z, Tsuge T, Wei N, Gu H, Deng XW. (2003). Characterization of the last subunit of the Arabidopsis COP9 signalosome: implications for the overall structure and origin of the complex. Plant Cell. 15:719-31.

Shah J, Kachroo P, Nandi A, Klessig DF. (2001). A recessive mutation in the Arabidopsis SSI2 gene confers SA- and NPR1-independent expression of PR genes and resistance against bacterial and oomycete pathogens. Plant J. 25:563-74. 
Shah J. (2003). The salicylic acid loop in plant defense. Curr Opin Plant Biol. 6:365-71.

Shah J. (2005). Lipids, lipases, and lipid-modifying enzymes in plant disease resistance. Annu Rev Phytopathol. 43:229-60.

Shimojima M. (2011). Biosynthesis and functions of the plant sulfolipid. Prog Lipid Res. 50:234-9.

Simon R, Igeño MI, Coupland G. (1996). Activation of floral meristem identity genes in Arabidopsis. Nature. 384:59-62.

Simpson GG, Gendall AR, Dean C. (1999). When to switch to flowering. Annu Rev Cell Dev Biol. 15:519-50.

Slabaugh E, Brandizzi F. (2011). Membrane-tethered transcription factors provide a connection between stress response and developmental pathways. Plant Signal Behav. 6:1210-1.

Somers DE, Devlin PF, Kay SA. (1998). Phytochromes and cryptochromes in the entrainment of the Arabidopsis circadian clock. Science. 282:1488-90.

Somers DE, Schultz TF, Milnamow M, Kay SA. (2000). ZEITLUPE encodes a novel clock-associated PAS protein from Arabidopsis. Cell. 101:319-29.

Song WY, Martinoia E, Lee J, Kim D, Kim DY, Vogt E, Shim D, Choi KS, Hwang I, Lee Y. (2004). A novel family of cys-rich membrane proteins mediates cadmium resistance in Arabidopsis. Plant Physiol. 135:1027-39.

Song YH, Song NY, Shin SY, Kim HJ, Yun DJ, Lim CO, Lee SY, Kang KY, Hong JC. (2008). Isolation of CONSTANS as a TGA4/OBF4 interacting protein. Mol Cells. 25:559-65.

Song YH, Lee I, Lee SY, Imaizumi T, Hong JC. (2012). CONSTANS and ASYMMETRIC LEAVES 1 complex is involved in the induction of FLOWERING LOCUS T in photoperiodic flowering in Arabidopsis. Plant J. 69:332-42.

Speers AE, Wu CC. (2007). Proteomics of integral membrane proteins--theory and application. Chem Rev. 107:3687-714.

Spoel SH, Mou Z, Tada Y, Spivey NW, Genschik P, Dong X. (2009). Proteasome-mediated turnover of the transcription coactivator NPR1 plays dual roles in regulating plant immunity. Cell. 137:860-72.

Staub JM, Wei N, Deng XW. (1996). Evidence for FUS6 as a component of the nuclear-localized COP9 complex in Arabidopsis. Plant Cell. 8:2047-56. 
Stratmann JW, Gusmaroli G. (2012). Many jobs for one good cop - the COP9 signalosome guards development and defense. Plant Sci. 185-186:50-64.

Suárez-López P, Wheatley K, Robson F, Onouchi H, Valverde F, Coupland G. (2001). CONSTANS mediates between the circadian clock and the control of flowering in Arabidopsis. Nature. 2001 Apr 26;410(6832):1116-20.

Sultan SE. (2000). Phenotypic plasticity for plant development, function and life history. Trends Plant Sci. 5:537-42.

Takada S, Goto K. (2003). Terminal flower2, an Arabidopsis homolog of heterochromatin protein1, counteracts the activation of flowering locus $\mathrm{T}$ by constans in the vascular tissues of leaves to regulate flowering time. Plant Cell. 15:2856-65.

Tepperman JM, Hwang YS, Quail PH. (2006). phyA dominates in transduction of red-light signals to rapidly responding genes at the initiation of Arabidopsis seedling de-etiolation. Plant J. 48:728-42.

Thaler JS, Humphrey PT, Whiteman NK. (2012). Evolution of jasmonate and salicylate signal crosstalk. Trends Plant Sci. 17:260-70.

Thilmony R, Underwood W, He SY. (2006). Genome-wide transcriptional analysis of the Arabidopsis thaliana interaction with the plant pathogen Pseudomonas syringae pv. tomato DC3000 and the human pathogen Escherichia coli O157:H7. Plant J. 46:34-53.

Thomma BP, Eggermont K, Penninckx I, Mauch-Mani B, Vogelsang R, Cammue B, Broekaert WF (1998). Separate jasmonate-dependent and salicylatedependent defense-response pathways in Arabidopsis are essential for resistance to distinct microbial pathogens. Proc Natl Acad Sci U S A. 95:15107-15111.

Tiwari SB, Shen Y, Chang HC, Hou Y, Harris A, Ma SF, McPartland M, Hymus GJ, Adam L, Marion C, Belachew A, Repetti PP, Reuber TL, Ratcliffe OJ. (2010). The flowering time regulator CONSTANS is recruited to the FLOWERING LOCUS T promoter via a unique cis-element. New Phytol. 187:57-66.

Tsuge T, Matsui M, Wei N. (2001). The subunit 1 of the COP9 signalosome suppresses gene expression through its $\mathrm{N}$-terminal domain and incorporates into the complex through the PCI domain. J Mol Biol. 305:1-9.

Ueguchi-Tanaka M, Nakajima M, Motoyuki A, Matsuoka M. (2007). Gibberellin receptor and its role in gibberellin signaling in plants. Annu Rev Plant Biol. 58:183-98. 
Ullah Z, Buckley MS, Arnosti DN, Henry RW. (2007). Retinoblastoma protein regulation by the COP9 signalosome. Mol Biol Cell. 18:1179-86.

Valverde F, Mouradov A, Soppe W, Ravenscroft D, Samach A, Coupland G. (2004). Photoreceptor regulation of CONSTANS protein in photoperiodic flowering. Science. 303:1003-6.

van der Biezen EA, Jones JD. (1998). Plant disease-resistance proteins and the gene-for-gene concept. Trends Biochem Sci. 23:454-6.

van Kasteren S. (2012). Synthesis of post-translationally modified proteins. Biochem Soc Trans. 40:929-44.

Vance DE, Vance, JE. (2008) Biochemistry of Lipids, Lipoproteins, and Membranes. Elsevier, Amsterdam, Boston.

Venancio TM, Aravind L. (2010). CYSTM, a novel cysteine-rich transmembrane module with a role in stress tolerance across eukaryotes. Bioinformatics. 26:149-52.

Vijayan P, Shockey J, Lévesque CA, Cook RJ, Browse J. (1998). A role for jasmonate in pathogen defense of Arabidopsis. Proc Natl Acad Sci U S A. 95:7209-14.

Vlot AC, Dempsey DA, Klessig DF. (2009). Salicylic Acid, a multifaceted hormone to combat disease. Annu Rev Phytopathol. 47:177-206.

Vogel F, Hofius D, Sonnewald U. (2007). Intracellular trafficking of Potato leafroll virus movement protein in transgenic Arabidopsis. Traffic. 8:1205-14.

von Arnim AG, Deng XW. (1994). Light inactivation of Arabidopsis photomorphogenic repressor COP1 involves a cell-specific regulation of its nucleocytoplasmic partitioning. Cell. 79:1035-45.

von Arnim AG. (2003). On again-off again: COP9 signalosome turns the key on protein degradation. Curr Opin Plant Biol. 6:520-9.

von Heijne G. (2007) The membrane protein universe: what's out there and why bother? J. Intern. Med. 261:543-557.

Wada KC, Takeno K. (2010). Stress-induced flowering. Plant Signal Behav. 5:944-7.

Wang X, Feng S, Nakayama N, Crosby WL, Irish V, Deng XW, Wei N. (2003). The COP9 signalosome interacts with SCF UFO and participates in Arabidopsis flower development. Plant Cell. 15:1071-82.

Wang X. (2004). Lipid signaling. Curr Opin Plant Biol. 7:329-36. 
Wang X, Li W, Piqueras R, Cao K, Deng XW, Wei N. (2009). Regulation of COP1 nuclear localization by the COP9 signalosome via direct interaction with CSN1. Plant J. 58:655-67.

Wasternack C, Kombrink E. (2010). Jasmonates: structural requirements for lipid-derived signals active in plant stress responses and development. ACS Chem Biol. 5:63-77.

Wee S, Geyer RK, Toda T, Wolf DA. (2005). CSN facilitates Cullin-RING ubiquitin ligase function by counteracting autocatalytic adapter instability. Nat Cell Biol. 7:387-91.

Weidler G, Zur Oven-Krockhaus S, Heunemann M, Orth C, Schleifenbaum F, Harter K, Hoecker U, Batschauer A. (2012). Degradation of Arabidopsis CRY2 is regulated by SPA proteins and phytochrome A. Plant Cell. 24:2610-23.

Wei N, Deng XW. (1992). COP9: a new genetic locus involved in lightregulated development and gene expression in arabidopsis. Plant Cell. 4:1507-18.

Wei N, Tsuge T, Serino G, Dohmae N, Takio K, Matsui M, Deng XW. (1998). The COP9 complex is conserved between plants and mammals and is related to the 26S proteasome regulatory complex. Curr Biol. 8:919-22.

Wei N, Deng XW. (1996). The role of the COP/DET/FUS genes in light control of arabidopsis seedling development. Plant Physiol. 112:871-8.

Wei N, Deng XW. (1999). Making sense of the COP9 signalosome. A regulatory protein complex conserved from Arabidopsis to human. Trends Genet. 15:98-103.

Wei N, Deng XW. (2003). The COP9 signalosome. Annu Rev Cell Dev Biol. 19:261-86.

Wei N, Serino G, Deng XW. (2008). The COP9 signalosome: more than a protease. Trends Biochem Sci. 33:592-600.

Wenkel S, Turck F, Singer K, Gissot L, Le Gourrierec J, Samach A, Coupland G. (2006). CONSTANS and the CCAAT box binding complex share a functionally important domain and interact to regulate flowering of Arabidopsis. Plant Cell. 18:2971-84.

Wiermer M, Feys BJ, Parker JE. (2005). Plant immunity: the EDS1 regulatory node. Curr Opin Plant Biol. 8:383-9. 
Wigge PA, Kim MC, Jaeger KE, Busch W, Schmid M, Lohmann JU, Weigel D. (2005). Integration of spatial and temporal information during floral induction in Arabidopsis. Science. 309:1056-9.

Wildermuth MC, Dewdney J, Wu G, Ausubel FM. (2001). Isochorismate synthase is required to synthesize salicylic acid for plant defence. Nature. 414:562-5.

Wilson RN, Heckman JW, Somerville CR. (1992). Gibberellin Is Required for Flowering in Arabidopsis thaliana under Short Days. Plant Physiol. 100:403-408.

Wu J, Lightner J, Waewick N, Browse J. (1997). Low-temperature damage and subsequent recovery of fab1 mutant Arabidopsis exposed to $28^{\circ} \mathrm{C}$. Plant Physiol. 113:347-356.

Wu JT, Chan YR, Chien CT. (2006). Protection of cullin-RING E3 ligases by CSN-UBP12. Trends Cell Bio. 116:362-9.

Xing J, Chin CK. (2000). Modification of fatty acids in eggplant afects its resistance to Verticillium dahliae. Physiological and Molecular Plant Pathology. $56: 217-225$.

Xiong L, Gong Z, Rock CD, Subramanian S, Guo Y, Xu W, Galbraith D, Zhu JK. (2001). Modulation of abscisic acid signal transduction and biosynthesis by an Sm-like protein in Arabidopsis. Dev Cell. 1:771-81.

Xirodimas DP. (2008). Novel substrates and functions for the ubiquitin-like molecule NEDD8. Biochem Soc Trans. 36:802-6.

Xu L, Liu F, Lechner E, Genschik P, Crosby WL, Ma H, Peng W, Huang D, Xie D. (2002). The SCF(COI1) ubiquitin-ligase complexes are required for jasmonate response in Arabidopsis. Plant Cell. 14:1919-35.

Xue Y, Liu Z, Gao X, Jin C, Wen L, Yao X, Ren J. (2010). GPS-SNO: Computational prediction of protein $\boldsymbol{S}$-nitrosylation sites with a modified GPS algorithm. Plos One. 5:e11290.

Yalpani N, Enyedi AJ, León J, Raskin I. (1994). Ultraviolet light and ozone stimulate accumulation of salicylic acid, pathogenesis-related proteins and virus resistance in tobacco. Planta. 193:372-376.

Yeats TH, Rose JK. (2008). The biochemistry and biology of extracellular plant lipid-transfer proteins (LTPs). Protein Sci. 17:191-8.

Yu D, Chen C, Chen Z. (2001). Evidence for an important role of WRKY DNA binding proteins in the regulation of NPR1 gene expresión. Plant Cell. 13:1527-40. 
Yu CS, Chen YC, Lu CH, Hwang JK. (2006). Prediction of protein subcellular localization. Proteins: Structure, Function and Bioinformatics. 64:643-651.

Yu X, Liu H, Klejnot J, Lin C. (2010). The Cryptochrome Blue Light Receptors. Arabidopsis Book. 8:e0135.

Zander M, La Camera S, Lamotte O, Métraux JP, Gatz C. (2010). Arabidopsis thaliana class-II TGA transcription factors are essential activators of jasmonic acid/ethylene-induced defense responses. Plant J. 61:200-10.

Zeng W, Melotto M, He SY. (2010). Plant stomata: a checkpoint of host immunity and pathogen virulence. Curr Opin Biotechnol. 21:599-603.

Zhang Y, Goritschnig S, Dong X, Li X. (2003). A gain-of-function mutation in a plant disease resistance gene leads to constitutive activation of downstream signal transduction pathways in suppressor of npr1-1, constitutive 1. Plant Cell. 15:2636-46.

Zhao D, Yu Q, Chen M, Ma H. (2001). The ASK1 gene regulates B function gene expression in cooperation with UFO and LEAFY in Arabidopsis. Development. 128:2735-46.

Zhao J, Wang J, An L, Doerge RW, Chen ZJ, Grau CR, Meng J, Osborn TC. (2007). Analysis of gene expression profiles in response to Sclerotinia sclerotiorum in Brassica napus. Planta. 227:13-24.

Zhao Y. (2010). Auxin biosynthesis and its role in plant development. Annu Rev Plant Biol. 61:49-64.

Zheng Q, Wang XJ. (2008). GOEAST: a web-based software toolkit for Gene Ontology enrichment analysis. Nucleic Acids Res. 36: W358-63.

Zhou JM, Trifa Y, Silva H, Pontier D, Lam E, Shah J, Klessig DF. (2000). NPR1 differentially interacts with members of the TGA/OBF family of transcription factors that bind an element of the PR-1 gene required for induction by salicylic acid. Mol Plant Microbe Interact. 13:191-202.

Zhou D, Zhou X, Ling Y, Zhang Z, Su Z. (2010). agriGO: a GO analysis toolkit for the agricultural community Nucleic Acids Research Advance. Nucl. Acids Res. 38: W64-W70. 

Agradecimientos 

Son muchas las personas a las que les debo agradecer todo lo aprendido y lo vivido durante estos últimos años, así que de antemano pido disculpas a todos aquellos a los que por motivos de espacio no menciono en las siguientes líneas. En primer lugar me gustaría dar las gracias a mi director de tesis, el Dr. José León, por haberme dado la oportunidad de realizar mi tesis doctoral en su laboratorio. Durante estos años he aprendido a manejarme de una forma autónoma entre moléculas de ADN y de proteínas, siempre bajo su tutela, sus consejos, sus críticas y sus advertencias. También debo agradecer al Dr. Jean-Pierre Metraux y a su equipo la calurosa acogida que recibí en su laboratorio, sus recomendaciones, y la motivación por la ciencia que me fue transmitida durante los meses de mi estancia.

Un laboratorio no es tal sin la gente que en éste trabaja día a día. Por esta razón quiero expresar mi agradecimiento a los compañeros con los que he trabajado estos años, y con los que he tenido la suerte de establecer una relación que va más allá de lo meramente profesional. Rosa y Jorge, gracias por enseñarme a trastear en el laboratorio, y por las discusiones y pláticas acerca de nuestros trabajos que, por alguna razón, solían tener lugar los viernes a última hora. Gracias a ti también, Laura, por todos los ánimos que me has dado durante estos años y porque los Westerns en buena compañía siempre salen mejor. Mari Cruz, algún día me gustaría saber cómo haces para inundar de alegría los sitios por donde pasas. Hasta que lo descubra, me conformo con cruzarme con gente como tú en el futuro. Silbi, nunca llegamos a saber ese nexo de unión que existía entre nosotros antes de mi llegada al laboratorio. Sin embargo, estoy seguro de que estos años hemos establecido un nexo que nunca podremos olvidar. Obviamente hablo de PCC1. Alberto y Esther, gracias por el buen ambiente generado en el laboratorio y por vuestros consejos. Finalmente mi reconocimiento a los estudiantes Álvaro, Juan Luís y Aída que me han enseñado que la mejor forma de aprender es enseñar.

Son muchas las personas que me han apoyado en lo personal y en lo profesional a lo largo de estos años. Me gustaría agradecer a Cristina y Aurora por aguantar todos mis rollos, y por vuestra disposición incondicional y desinteresada para afrontar los problemas que me han ido surgiendo durante las etapas más difíciles de mi tesis. No voy a olvidar los buenos momentos que hemos pasado durante la hora de la comida, o en ambientes más distendidos y "alternativos" con nuestro dream team de paqueros. Mapi, Sole, Teresa, Dave, Forment y Lorenzo, gracias por los buenos momentos vividos, y por ayudarme a desconectar del trabajo de vez en cuando, que tampoco viene mal. 
Escribir la tesis es sin duda una labor ardua. Sin embargo, hacerlo con la compañía y con el apoyo moral de gente como Jasna, Alfredo (perdón, Dr. Zambrano) y Regi ha sido un verdadero placer. Ese café a las 5, junto con Vicent, ha sido la rutina que me ha ayudado a no volverme demasiado loco durante la escritura de la tesis. Jasna, debo agradecerte la ayuda prestada en el análisis estadístico y en la interpretación de algunos de mis datos, y por haber escuchado y criticado mis hipótesis y mis resultados.

Me gustaría agradecer a Vicente y a Ana la ayuda ofrecida en los experimentos con Pseudomonas, y a Javi el tiempo que me ha dedicado para la preparación de protoplastos. Escribiendo de vosotros no puedo dejar de mostrar mi reconocimiento a David, simplemente por lo krak que eres!. Además me gustaría agradecer a la gente de los laboratorios de los doctores Carbonell, Blázquez, Alabadí, Orzáez, Pérez, Rodríguez y Tornero su generosidad y compañerismo a la hora de ceder o prestar material de laboratorio. También a Teresa, Peter, Carito, Ana Cristina y Daniela por vuestra amistad y vuestro apoyo, y a otros muchos que ya pasaron y que de alguna forma también han formado parte de mi experiencia en el IBMCP.

Por último, pero no por ello menos importante, quiero expresar mi agradecimiento a mi familia, especialmente a mis padres y a mi tía Amparo, por su contribución en la parte menos científica pero esencial del presente trabajo. A vosotros mil gracias. 